José Rodrigo Valim Pimentel

Liberação sustentada de progesterona em micro partículas de PHB-V e PHB-V/PCL produzidas em meio super-critico 
José Rodrigo Valim Pimentel

\title{
Liberação sustentada de progesterona em micro partículas de PHB-V e PHB-V/PCL produzidas em meio supercritico
}

\author{
Tese apresentada ao programa de Pós- \\ Graduação em Reprodução Animal da \\ Faculdade de Medicina Veterinária e \\ Zootecnia da Universidade de São Paulo \\ para obtenção do título de Doutor \\ em Ciências.
}

\author{
Departamento: \\ Reprodução Animal \\ Área de concentração: \\ Reprodução animal \\ Orientador: \\ Prof. Dr. Ed Hoffmann Madureira
}

São Paulo

2010 
Autorizo a reprodução parcial ou total desta obra, para fins acadêmicos, desde que citada a fonte.

DADOS INTERNACIONAIS DE CATALOGAÇÃO-NA-PUBLICAÇÃO

(Biblioteca Virginie Buff D’Ápice da Faculdade de Medicina Veterinária e Zootecnia da Universidade de São Paulo)

Pimentel, José Rodrigo Valim

Liberação sustentada de progesterona em micro partículas de PHB-V e PHB-

V/PCL produzidas em meio supercritico / José Rodrigo Valim Pimentel. -- 2010.

$140 \mathrm{f}$. : il.

Tese (Doutorado) - Universidade de São Paulo. Faculdade de Medicina Veterinária e Zootecnia. Departamento de Reprodução Animal, São Paulo, 2010.

Programa de Pós-Graduação: Reprodução Animal.

Área de concentração: Reprodução Animal.

Orientador: Prof. Dr. Ed Hoffmann Madureira.

1. Progesterona. 2. Biopolimeros. 3. Microparticulas. 4. Supercritico. 5. Liberação in vitro. I. Título. 


\section{FOLHA DE AVALIAÇÃO}

\section{Nome: Pimentel, José Rodrigo Valim}

Título: Liberação sustentada de progesterona em micro partículas de PHB-V e PHB-V/PCL produzidas em meio super-critico

Tese apresentada ao Programa de Pós-Graduação em Reprodução Animal da Faculdade de Medicina Veterinária e Zootecnia da Universidade de São Paulo para a obtenção do título de Doutor em Ciências

Data:

Banca Examinadora

Prof. Dr.

Assinatura:

Prof. Dr.

Assinatura:

Prof. Dr.

Assinatura:

Prof. Dr.

Assinatura:

Prof. Dr.

Assinatura:
Instituição:

Julgamento:

Instituição:

Julgamento:

Instituição:

Julgamento:

Instituição:

Julgamento:

Instituição:

Julgamento: 
Um dia a gente chega, no outro vai embora Cada um de nós compõe a sua história Cada ser em si carrega o dom de ser capaz e ser feliz” 
Agradecimentos

Fica difícil escrever em uma ou mil paginas os agradecimentos de uma tese de doutorado... Talves porque nesta estrada, conhecemos pessoas extremamente importantes e são quase que substituídas no quesito importância por outras que estão chegando...

Como não iniciar uma confissão sem começar por Deus? Se é somente através dele que estou e estamos aqui!! Então...

Pai todo poderoso, a ti lhe agradeço pela dádiva da vida, pela minha família, pelos meus filhos, por meus amigos, por minha profissão, por eu ser uma pessoa privilegiada em escrever estas palavras nesta tese. A ti agradeço meu Deus. A ti eu lhe peço perdão por meus erros, minhas falhas, minhas nescessidades, minha raiva, meu orgulho, mina ambição que as vezes me cega para todos e tudo... a ti pai, peço perdão. Obrigado!

Entre meus amigos, vou tentar lembrar me de todos... Claro que esquecerei vários...

Ao Ed, meu orientador e amigo, que me orienta a sete anos... por me apoiar, me educar, me ensinar e sobre tudo, me respeitar.

Ao professor Rubens, grande pesquisador, cheio de idéias, com um gosto apurado para musica e uma noção meio aumentada de futebol ( eu sou do tempo que quem entrava no VRA, tinha que ouvir a fita do GOl que ele marcou contra sabe deus quem!!)

A minha amiga Kiky, por apoio e ajuda, em momentos que eu acreditava que não ia dar, ela sempre chegava e me mostrava um caminho que implicava sua participação.Kiky, eu acredito que se um dia eu precisar de roupa, você me entrega a que esta vestindo!

Ao Mario binelli, grande amigo, pesquisador excemplar esportista... O Cara!!

Os professores de são Paulo, Marcelo, Claudio, visintin, Maira, Camila, Claudia, Carlinha, Pietro e todos seus pós graduandos

Aos funcionários do VRA De carli, João, Zé Maria, Cleiton

A Harumi pelpo profissionalismo, por ser uma faciloitadora dentro do regulamento

Ao Lucio Cardoso Filho, grande amigo, mentor, co-orientador e antigamente.. companheiro de cerva!!

Aos amigos do LFER, patrícia Miguez, Miltom Maturama, Aline Keire,. Gabriel, Cesar A minha grande amiga e companheira desde o mestrado, Lindsay! Querida pio bella Ao meu companheiro Paulo Fantinato (Pulinho) pela ajuda na formatação e em tantas outras situações onde eu sempre pude contar com a sua ajuda.

A Cristina Ferreira e a Rosy, sem a sua ajuda com certeza este trabalho não seria terminado em tempo.. Cris, que com a sua parceria, validamos um método de quantificar p4 no plasma sanguineo por LC/MS 
Aos amigos de Maringá, Rogério, Marcos hunita e Marquinho pela força neste final e durante o percurso

A Faculdade de Medicina veterinária e Zootecnia da Universidade de São Paulo, que foi minha casa nestes últimos 8 anos No mestrado e agora.

Agradeço a FAPESP pela bolsa concedida e o projeto que sem estes esta tese não existiria

A CAPES pela bolsa no inicio do programa e no meu mestrado

A universidade Estadual de Campinas e ao Laboratório THONSOM na pessoa do Professor Marcos Eberlin, pela disposição em trabalhar nas técnicas de LC/MS/MS

A Universidade Estadual de Maringá, onde a maior parte deste trabalho foi realizado

A universidade federal de São Carlos,

Ao Centro de pesquisa da Embrapa ( CNPDIA) na pessoa de Adriana Thomasi, onde foi realizado os testes para determinação do potencial zeta.

Desculpe os erros e a omissão, foi muito em cima da hora. Mas quem me conhece sabe o tanto que valorizo toda ajuda. Muito obrigado 


\section{RESUMO}

Pimentel, J.R.V. Liberação sustentada de progesterona em micro partículas de PHB-V e PHB-VIPCL produzidas em meio super-critico. [Sustained release of progesterone in micro-particles of PHB-V and PHB-V/PCL produced in super-critical environment.]. 2010. 140f. Tese (Doutorado em Ciências) - Faculdade de Medicina Veterinária e Zootecnia, Universidade de São Paulo, São Paulo, 2010.

A progesterona é um hormônio esteróide comumente utilizado na sincronização do estro em programas de manejo reprodutivo de bovinos. Sua administração por meio de implantes auriculares compostos de nanopartículas é uma estratégia promissora para a indústria farmacêutica veterinária. Este trabalho foi delineado com o intuito de produzir e estudar a cinética de liberação da progesterona $\left(\mathrm{P}_{4}\right)$ encapsulada em nanopartículas de polímeros biodegradáveis produzida por meio supercrítico (SAS). Partículas de Poli-hidroxi-butirato e valerato (PHB-V) de três diferentes tamanhos (grupos PHB-V1, PHB-V2 e PHB-V3) e suas combinações com poli-e-caprolactano (PCL; grupos PHB-V1/PCL, PHB-V2/PCL e PHB-V3/PCL) foram impregnadas com $\mathrm{P}_{4}$, pesadas, suspendidas em $10 \mathrm{~mL}$ de solução de etanol/água 60:40 (v/v) e colocadas em banho-maria com agitação. Nos tempos 2min; 2h, 4h, 8h, 12h, 24h e $48 \mathrm{~h}$ foram coletadas amostras de $1 \mathrm{~mL}$. Após centrifugação $(2.000 \mathrm{~g}$ por $10 \mathrm{~min}$ a $\left.37^{\circ} \mathrm{C}\right)$ as amostras foram filtradas $(0,45 \mu \mathrm{m})$ e submetidas à análise por LC-MS/MS para quantificação de $\mathrm{P}_{4}$. Foi utilizado um espectrômetro de massas tripo-quadrupolo API4000 Q TRAP (Applied Biosystems) equipado com fonte e ESI Turbo-V. As análises foram realizadas em modo MRM em modo positivo visando monitorar as transições 315.5>109.1 e 315.5>297.2. Utilizou-se um HPLC Agilent series 1100 para eluição isocrática do analito em metanol/água $50 \%$, em tempo total de corrida de $2,5 \mathrm{~min}$. A curva de calibração foi construída com triplicatas de $1,5,10,25$ e $50 \mathrm{ng} / \mathrm{mL}$ de $\mathrm{P}_{4}$. A análise estatística incluiu ANOVA e interação (tamanhos de PHB-V e presença/ausência de PCL), considerando o nível de significância de 5\%. Observou-se que a associação do PHB-V1/PCL aumentou a quantidade de progesterona liberada em relação ao PHB-V1 isolado. O mesmo efeito foi observado para o grupo PHB-V3/PCL. No entanto, a associação PHB-V2/PCL levou à diminuição na liberação de progesterona em relação ao PHB-V2 isolado. A cinética de liberação diferiu entre os grupos nos diferentes tempos avaliados. Dessa maneira, os resultados demonstram que diferenças de tamanho de nanopartículas de PHB-V e suas associações ao PCL podem afetar a 
quantidade, bem como a cinética da liberação do fármaco na liberação in vitro usando solvente álcool/água. A utilização do meio super critico para produção da partículas, proporcionou uma carga maior de $\mathrm{P} 4$ e alterou a cinética de liberação.

Palavras Chave: Progesterona, Microparticulas, Supercritico, liberação in vitro. 


\begin{abstract}
Pimentel, J.R.V. Sustained release of progesterone in micro-particles of PHB-V and PHB-VIPCL produced in super-critical environment. [Liberação sustentada de progesterona em micro partículas de PHB-V e PHB-V/PCL produzidas em meio super-critico.]. 2010. 140f. Tese (Doutorado em Ciências) - Faculdade de Medicina Veterinária e Zootecnia, Universidade de São Paulo, São Paulo, 2010.
\end{abstract}

Progesterone is a steroid hormone commonly used in estrus synchronization programs in reproductive management of cattle. His administration through ear implants composed of nanoparticles is a promising strategy for the veterinary pharmaceutical industry. This study was designed with the intent to produce and study the kinetics of release of progesterone (P4) encapsulated in nanoparticles of biodegradable polymers produced using supercritical (SAS). Particles of Poly-hydroxy-butyrate and valerate (PHB-V) of three different sizes (groups V1-PHB, PHB-PHB-V2 and V3) and their combination with poly-e-caprolactano (PCL; groups PHB-V1/PCL , and PHB-V2/PCL PHB-V3/PCL) were impregnated with P4, weighed, suspended in $10 \mathrm{~mL}$ of ethanol / water 60:40 (v/ v) and placed in a water bath with agitation. In times $2 \mathrm{~min}, 2 \mathrm{~h}, 4 \mathrm{~h}, 8 \mathrm{~h}$, $12 \mathrm{~h}, 24 \mathrm{~h}$ and $48 \mathrm{~h}$, samples of $1 \mathrm{~mL}$. After centrifugation $\left(2,000 \mathrm{~g}\right.$ for $10 \mathrm{~min}$ at $\left.37^{\circ} \mathrm{C}\right)$ samples were filtered $(0.45 \mathrm{~mm})$ and subjected to analysis by LC-MS/MS for the quantification of P4. We used a mass spectrometer tripo-quadrupole API-4000 Q TRAP (Applied Biosystems) equipped with ESI source and Turbo-V. Analyses were performed in MRM mode in positive mode in order to monitor the transitions 315.5> 109.1 and 315.5> 297.2. We used a HPLC Agilent 1100 series isocratic conditions for the analyte in methanol / water $50 \%$ in total running time of $2.5 \mathrm{~min}$. The calibration curve was constructed with triplicates of one, five, 10, 25 and $50 \mathrm{ng} / \mathrm{ml}$ of P4. Statistical analysis included ANOVA and interaction (sizes of PHB-V and the presence / absence of PCL), considering the significance level of 5\%. It was observed that the association of PHB-V1/PCL increased the amount of progesterone released in relation to PHB-V1 isolate. The same effect was observed for the group PHB-V3/PCL. However, the association PHB-V2/PCL led to a decrease in the release of progesterone in relation to isolated PHB-V2. The release kinetics differed between groups in different time periods studied. Thus, the results show that differences in size of nanoparticles of 
PHB-V and its associations with the PCL can affect the quantity and the kinetics of drug release in vitro release using solvent alcohol and water. The use of super critical means for producing particles, provided a greater burden of $\mathrm{P} 4$ and alters the release kinetics. Keywords: Progesterone, biopolymers, Microparticles, supercritical release in vitro 


\section{Lista de figuras}

Figura 1 - Diagrama esquemático da liberação de um fármaco a partir de matriz

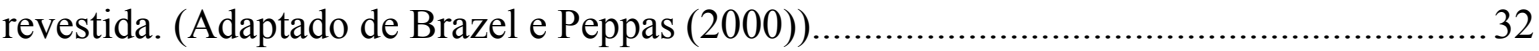

Figura 2 - Uso de revestimentos que controlam a passagem do fármaco............................. 34 Figura 3 - Perfis das concentrações teóricas do solvente (a) e do soluto (b) durante o processo de dilatação por liberação controlada, ao tempo t, em que as frentes plastômera/elastômera ainda coexistem. 34

Figura 4 - Mudanças macroscópicas em sistemas matriciais que intumescem e sofrem erosão 35

Figura 5 - Processo de difusão (A) e erosão (B) em matriz polimérica. 36

Figura 6 - Perfil teórico da concentração do fármaco num sistema matricial em contacto directo com um meio de liberação em condições "sink".(Manadas et all., 2002)................ 42

Figura 7 - Estrutura química do PHBV (Fonte: PICH et al., 2006b).................................58

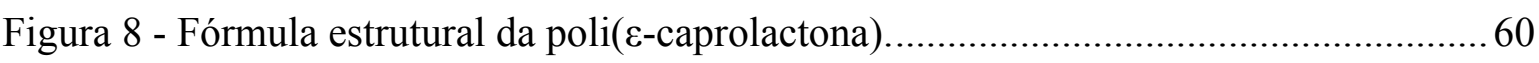

Figura 9 - Diagrama esquemático do aparato experimental de medidas de equilíbrio de fases. 72

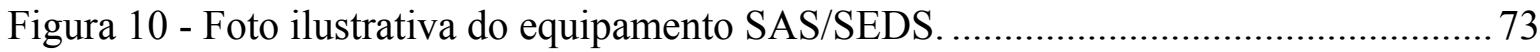

Figura 11 - Varredura de UV-Vis de progesterona em álcool etílico.................................76

Figura 12 - Curva de calibração de progesterona em álcool etílico. .................................... 77

Figura 13 - Diagrama P,x,y para o sistema binário CO2 (1) + clorofórmio (2); $\diamond 30^{\circ} \mathrm{C}$, 。 $40{ }^{\circ} \mathrm{C} \mathrm{K}, \square 50{ }^{\circ} \mathrm{C}, \Delta 60^{\circ} \mathrm{C}$ (FAVARETO et al., 2008b) e ternário CO2 (1) + clorofórmio

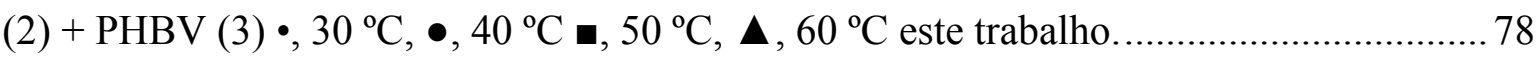

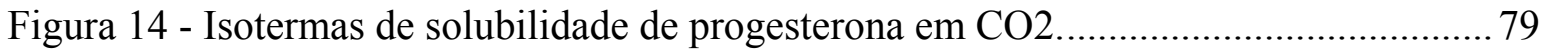

Figura 15 - Microscopia eletrônica de varredura das partículas provenientes dos experimentos $1,23,4,5$ e 6 .

Figura 16 - Microscopia eletrônica de varredura das partículas provenientes dos experimentos 7,8,9,10,11 e 12 .

Figura 17 - Microscopia eletrônica de varredura das partículas provenientes dos experimentos 13,14 83

Figura 18 - Micrografia das partículas precipitadas no experimento 3. Aumento 1000x...84 Figura 19 - Micrografia das partículas precipitadas no experimento 15. Aumento 9000x. .84 Figura 20 - Micrografias das amostras impregnadas. 


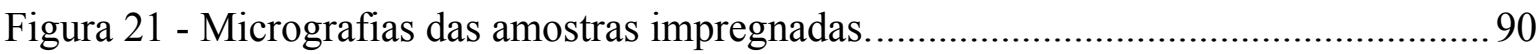

Figura 22 - Cromatograma do padrão de progesterona HPLC........................................... 93

Figura 23 - Equipamento 4000 Qtrap LC/MS/MS - Applied Biosystems ${ }^{\circledR}$;

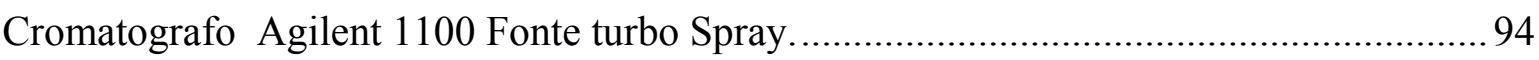

Figura 24 - Curva de calibração do íon de quantificação m/z 109....................................95

Figura 25 - Espectro de íons totais (TIC) do branco. ..................................................... 96

Figura 26 - Espectro de íons totais (TIC) de solução padrão de P4 ................................... 96

Figura 27 - Calorimétrico diferencial SHIMADZU modelo TGA-50., ..............................98

Figura 28 - Microscópio eletronico SHIMADZU, modelo SS-550 Superscan. MaringáPR.

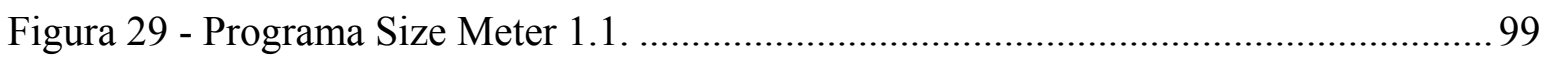

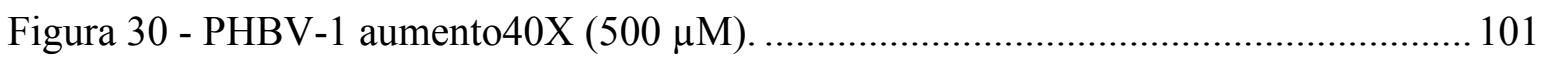

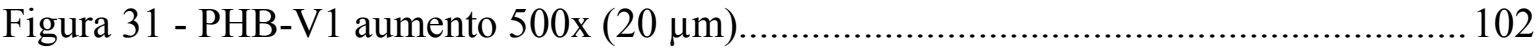

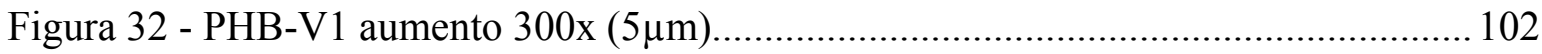

Figura 33 - Distribuição do tamanho das partículas de PHB-V1 amostra não processada.103 Figura 34 - Microscopias eletrônicas de varredura PHB-V2. ............................................ 103

Figura 35 - Distribuição do tamanho das partículas da amostra de PHB-V2 obtida por

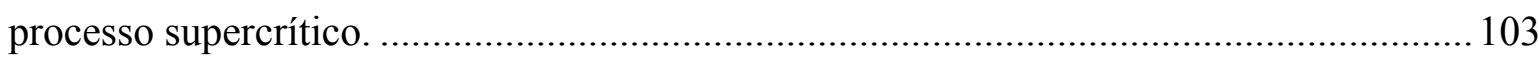

Figura 36 - Microscopias eletrônicas de varredura PHB-V3. .......................................... 104

Figura 37 - Distribuição do tamanho das partículas da amostra de PHB-V3 obtida por

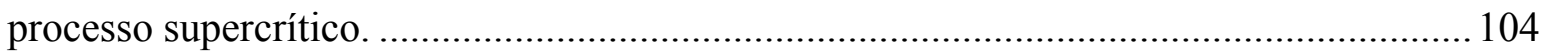

Figura 38 - Tamanho médio de partícula PHB-V/PCL e porcentagem de progesterona impregnada, em relação à massa de NPs na amostra. ........................................................ 105

Figura 39 - Microscopias eletrônicas de varredura PHB-V1/PCL.................................. 106

Figura 40 - Distribuição do tamanho das partículas de PHB-V1/PCL obtidas por

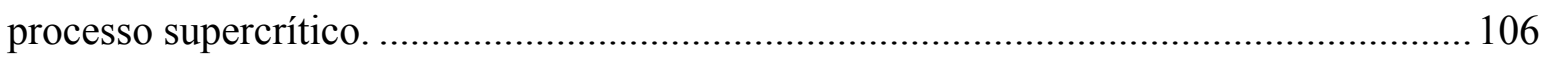

Figura 41 - Microscopias eletrônicas de varredura PHB-V2/PCL.................................. 106

Figura 42 - Distribuição do tamanho das partículas de PHB-V2/PCL obtidas por

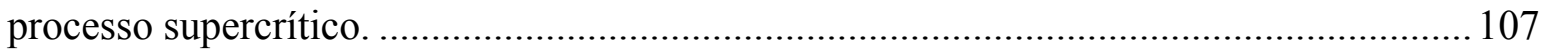

Figura 43 - Microscopias eletrônicas de varredura PHB-V3/PCL...................................... 107

Figura 44 - Distribuição do tamanho das partículas de PHB-V3/PCL obtidas por processo supercrítico.

Figura 45 - Exemplo de partículas em suspensão em solução álcool/água. Pirassununga 2010. 


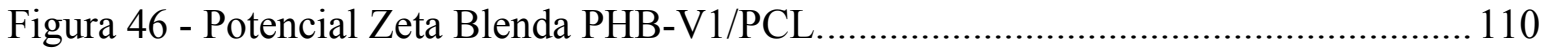

Figura 47 - Potencial Zeta Blenda Potencial Zeta Blenda PHB-V2/PCL. ......................... 110

Figura 48 - Potencial Zeta Blenda Potencial Zeta Blenda PHB-V3/PCL. ......................... 111

Figura 49 - Potencial Zeta Blenda PHB-V1, Ph 7,0, viscosidade 1.1900, potencial Zeta -

$30,6 \mathrm{mV}$ variação $12,7 \mathrm{mV}$

Figura 50 - Potencial Zeta Blenda PHB-V2, Ph 7,6, viscosidade 1.1900, potencial Zeta -

$51,6 \mathrm{mV}$ variação $18,5 \mathrm{mV}$.

Figura 51 - Potencial Zeta Blenda PHB-V3, Ph 7,6, viscosidade 1.1900, potencial Zeta -

$72,6 \mathrm{mV}$ variação $17,3 \mathrm{mV}$.

Figura 52 - Determinação do ponto de fusão dos variados compostos das blendas

poliméricas.

Figura 53 - Termogravimetria diferencial (DSC) PHB-V1/PCL. .................................. 113

Figura 54 - Termogravimetria diferencial (DSC) PHB-V2/PCL. ..................................... 113

Figura 55 - Termogravimetria diferencial (DSC) PHB-V3/PCL. ...................................... 114

Figura 56Quantidade de Progesterona (mg) liberada por $50 \mathrm{mg}$ de NPs de PHB-V em função do tempo.

Figura 57Quantidade de Progesterona (mg) liberada em função do tempo em $50 \mathrm{mg}$ de NPs.

Figura 58 - Modelo do mecanismo de liberação de fármacos em nano ou micro

partículas poliméricas.

Figura 59 - Quantidade de progesterona liberada (mg por $50 \mathrm{mg}$ de NPs) in vitro

conforme tempo.( abcdLetras diferentes indicam diferença estatística $\mathrm{p} \leq 0,05)$.

Figura 60 - Representação gráfica das curvas de liberação das diferentes amostras. 


\section{LISTA DE TABELAS}

Tabela 1 - Solubilidade das substâncias. .37

Tabela 2 - Teorias da dissolução (Farinha et al., 2000). 38

Tabela 3 - Polímeros precipitados pelos processos GAS e SAS. .........................................53

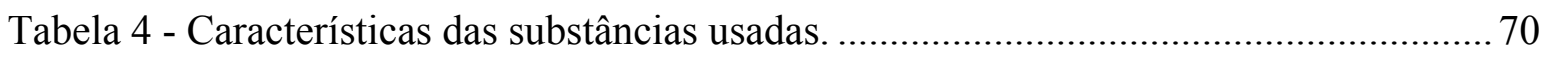

Tabela 5 - Condições operacionais do processo para expansão dos polímeros PHBV........ 74

Tabela 6 - Condições operacionais para expansão da blendas de PHBV/PCL. ….............. 75

Tabela 7 - Dados experimentais de solubilidade de progesterona em solventes

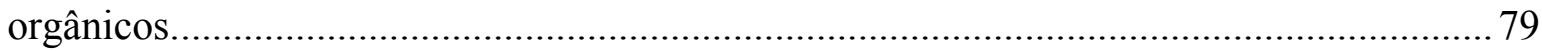

Tabela 8 - Experimentos de Precipitação. ....................................................................... 80

Tabela 9 - Fração mássica de progesterona impregnada na amostra................................... 85

Tabela 10 - Dados experimentais de ELV e ESLV para o sistema CO2 (1) + clorofórmio (2) + PHB FE113, com concentração da solução de $10 \mathrm{mg} / \mathrm{mL}$........................................... 86

Tabela 11 - Condições operacionais do processo para expansão dos polímeros PHBV ...... 87 Tabela 12 -Planejamento experimental de precipitação de PHB-V ....................................... 88

Tabela 13 - Condições operacionais para expansão da blendas de PHBV/PCL................. 89

Tabela 14 - Tamanho médio de partículas e respectivo desvio-padrão do tamanho de partículas experimentais obtidas por precipitação de blendas de PHBV/PCL, segundo

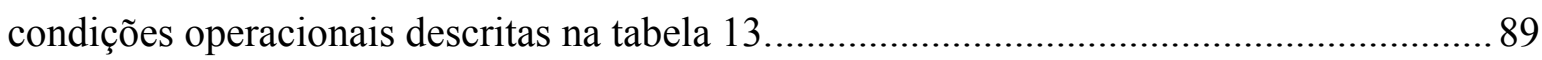

Tabela 15 - Condições operacionais do processo de impregnação de progesterona no polímero PHBV e blendas de PHBV/PCL.

Tabela 16 - Tamanho médio de partícula PHB-V e porcentagem de progesterona impregnada, em relação à massa de NPs na amostra. .................................................... 101

Tabela 17 - Potencial zeta das partículas................................................................... 110

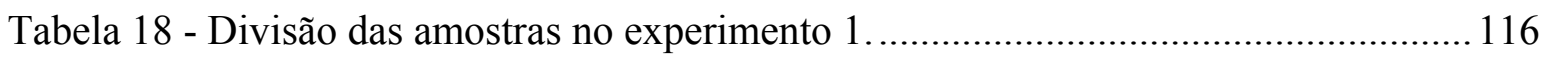

Tabela 19 - Quantidade (mg) de Progesterona liberada por $50 \mathrm{mg}$ de NPs. ..................... 118

Tabela 20 - Quantidade de Progesterona (mg) liberada pelas amostras de PCL por 50 mg de NPs.

Tabela 21 - Quantidade de P4 inicial e final (mg/50mg de NPs) e porcentagem liberada durante o ensaio.

Tabela 22 - Massa de Progesterona liberada (mg) por 50 mg das amostras de MPs PHBV1, PHB-V2, PHB-V3, PHB-V1PCL, PHB-V2PCL, PHB-V3PCL, em função do tempo. 


\section{Sumário}

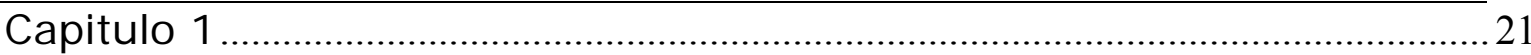

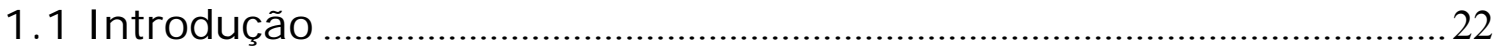

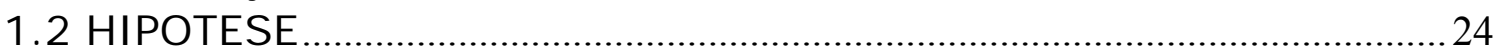

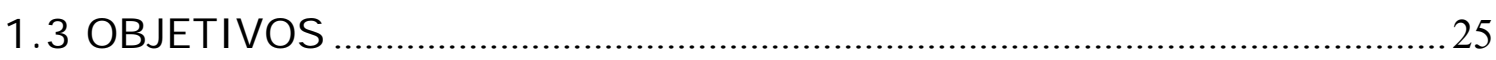

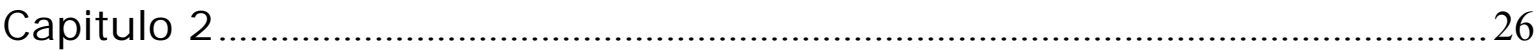

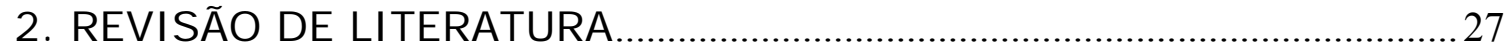

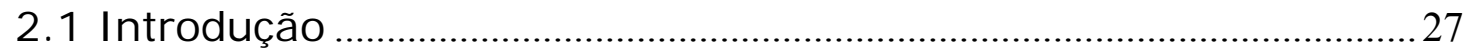

2.2 Inseminação artificial em tempo fixo....................................................2

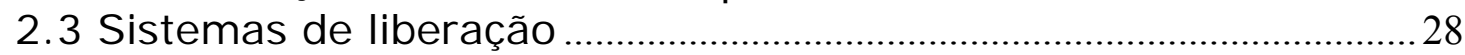

2.4 Modelos de liberação do fármaco …………………………………...........

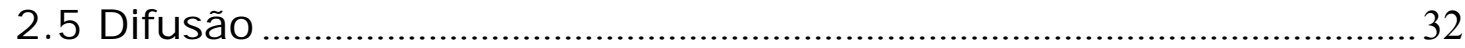

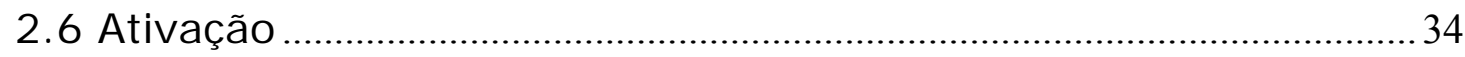

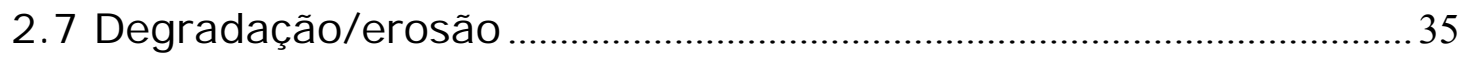

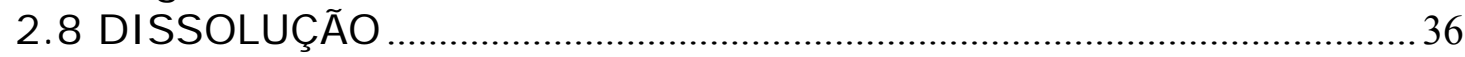

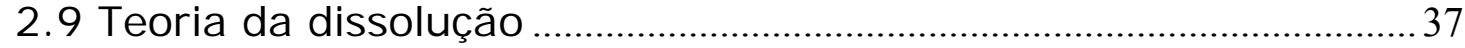

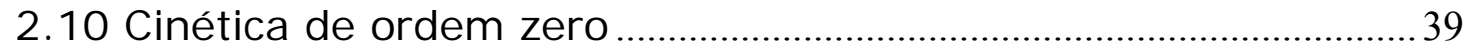

2.11 Cinética de primeira ordem ...................................................................40

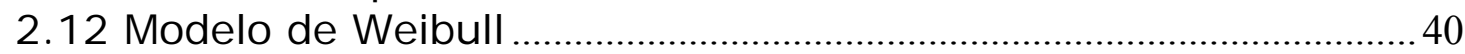

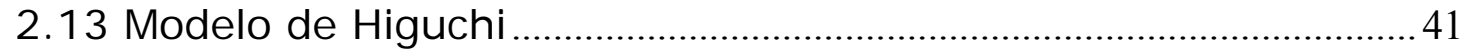

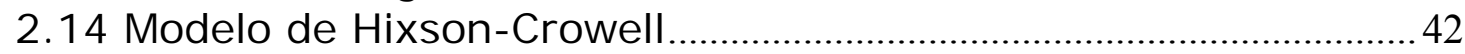

2.15 Modelo de Korsmeyer-Peppas .................................................................. 43

2.16 Produção de nanoparticulas (NPs) e microparticulas (MPs) ........44

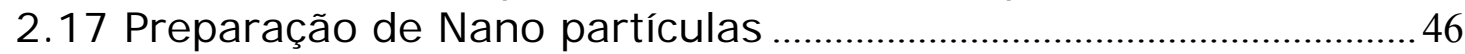

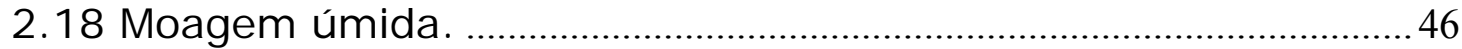

2.19 Homogeneização por alta pressão. …………………………………....4

2.19 Tecnologia da Emulsificação ou nano precipitação..........................48

2.20 Congelamento por atomização em líquido (SFL) . ............................4 48

2.21 Precipitação pro evaporação em solução aquosa (EPAS) . ...........49

2.22 Precipitação com fluido supercrítico (PCA) ........................................49

2.23 Expansão rápida sob uma interface líquido-gás (RESS) .............50

2.24 Produção de partículas utilizando fluido super critico......................50

2.25 Equilíbrio de fases relacionado ao processo de precipitação e/ou encapsulamento de partículas em fluidos pressurizados .............54

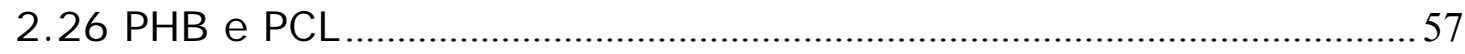

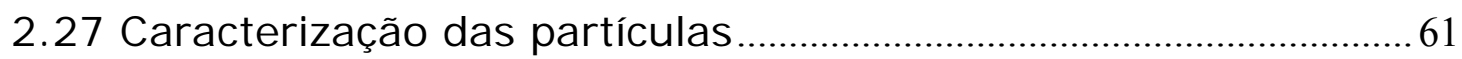

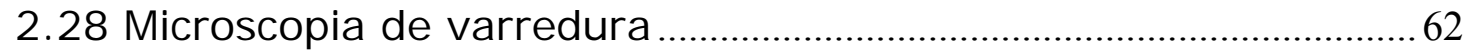

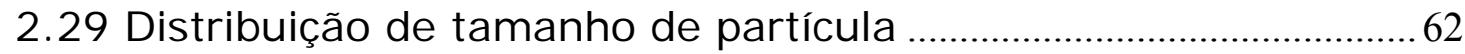

2.30 Calorimetria exploratória diferencial, difração de raios $\mathrm{X} \mathrm{e}$

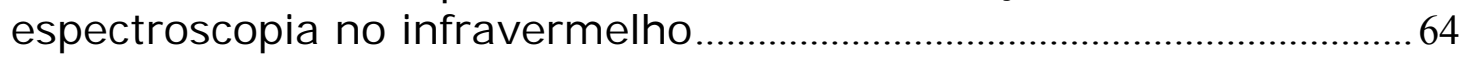

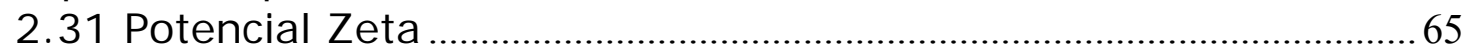

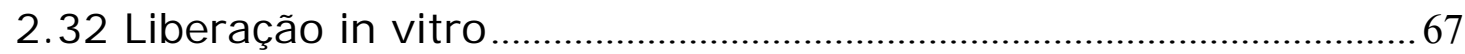

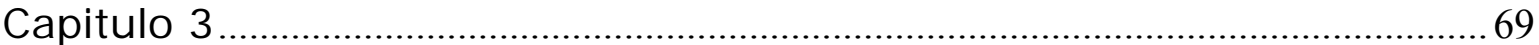

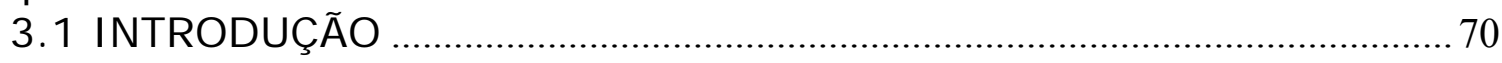

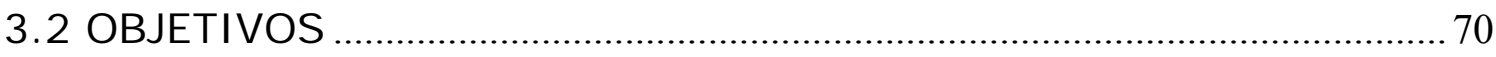

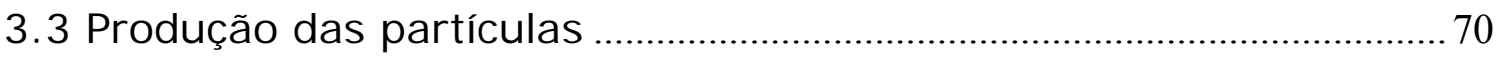

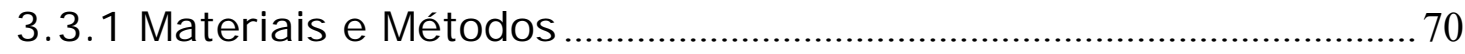




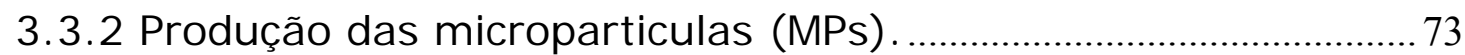

3.3.3 I mpregnação de Progesterona nas MPs............................................75

3.3.4 Determinação da quantidade de progesterona na amostra......76

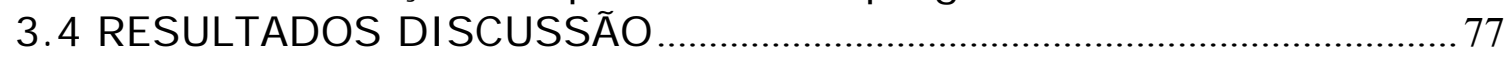

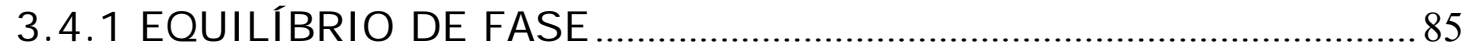

3.4.2 Precipitação de PHBV e blendas PHBV-PCL ....................................... 86

3.4.3 Impregnação de progesterona em partículas de PHBV e

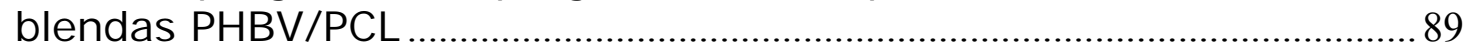

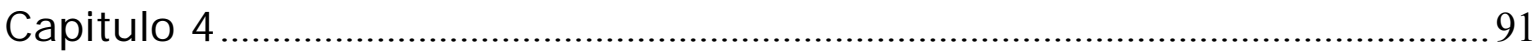

4 CARACTERIZAÇÃO DAS AMOSTRAS E EXPERIMENTOS DE

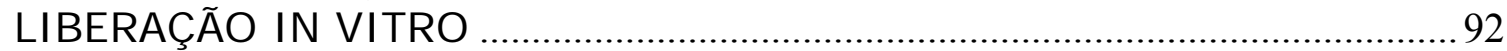

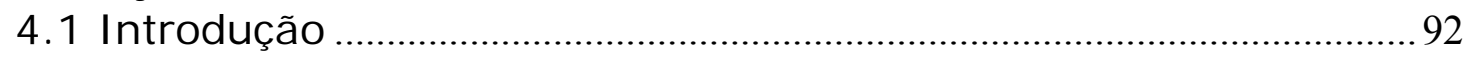

4.4 Caracterização das partículas de PHB-V/PCL....................................... 105

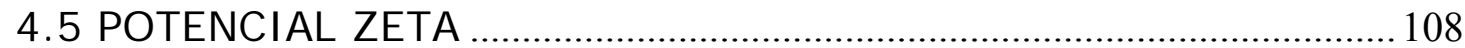

4.6 Calorimetria exploratória diferencial (DSC) …………………........... 112

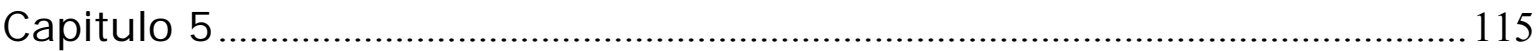

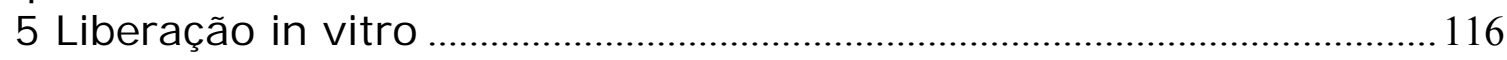

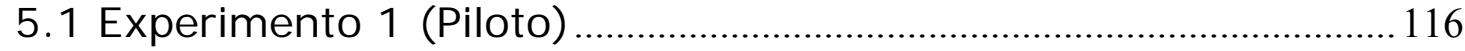

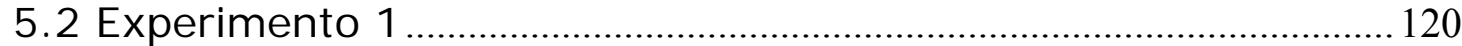

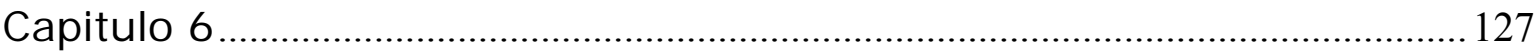

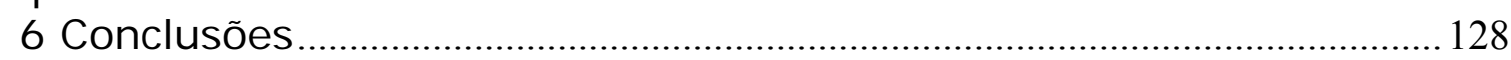


Capitulo 1 


\subsection{INTRODUÇÃO}

A concepção de sistemas que carreiam fármacos ou substancias ativas para sítios de ação específicos no organismo, parte do principio que eles manteriam a estabilidade do fármaco na circulação, permitindo assim uma maior concentração do mesmo no local de ação. Esta visão, vinda desde a antiguidade, incluía os inalantes de polens de plantas medicinais, aplicação de cataplasma na pele e administração de fármacos na corrente sanguínea utilizando espinhos de plantas e bicos de pássaros, como material perfurante. Alem das formas farmacêuticas populares como ingestão de soluções, comprimidos e capsulas (YANG; ROBINSON, 1998).

Os fármacos são raramente administrados como uma substancia química pura, mas sempre em preparações formuladas. Há numerosas formas farmacêuticas não convencionais nas quais uma substancia pode ser incorporada para o tratamento conveniente e eficaz de uma doença, promovendo interesse no desenvolvimento de sistemas de liberação controlada e sustentada de fármacos. Sistemas estes, desenvolvidos através da investigação de novos polímeros ou copolímeros e também de substancias que promovam um melhor reconhecimento pelas células dos tecidos alvos.

Durante as décadas de 80 e 90 vários sistemas de liberação de fármacos foram desenvolvidos com o objetivo de aumentar a eficiência do fármaco e minimizar os efeitos colaterais. Lipossomas, vesículas lipídicas, tem sido usados como potenciais carreadores de fármaco por apresentarem tais vantagens, entretanto suas aplicações são limitadas devido a problemas como baixa eficiência de encapsulação e rápida liberação de fármacos solúveis em água na presença de dos componentes sanguíneos (SOPPIMATH, et al.,2001). Por outro lado, nano partículas poliméricas oferecem algumas vantagens sobre os lipossomas por aumentarem a estabilidade do fármaco e terem a capacidade de gerar uma uma liberação controlada dependendo da matriz polimérica.

Segundo Martin et al. (1993) e Barrat (2000), nano partículas são definidas como um sistema coloidal submicrônico $(<1 \mu \mathrm{m})$ formadas por polímeros biodegradáveis ou não. Conforme a metodologia de preparação utilizada as características do produto final obtido podem ser denominadas nano partículas ou nano capsulas. Na primeira, o fármaco esta 
distribuído por toda extenção da partícula e as nano capsulas, são constituídas de um reservatório no qual uma cavidade oca ou oleosa está circundada por uma fina parede polimérica. As nano partículas, podem ser obtidas por variadas técnicas com diferentes graus de pureza, tamanho, eficiência em capturar o fármaco. Estas técnicas envolvem a conversão do estados sólido para o liquido e solido ou solido, liquido, gasoso, solido, ou gás para solido. As técnicas mais comumente utilizadas são:emulsificação com eliminação de solventes, moagem úmida, homogeneização sob alta-pressão, emulsificação, expansão rápida e congelamento por atomização e mais recentemente processo supercrítico SAS (Fluídos Supercríticos como Anti-Solventes).(KHARB et al., 2006).

Dentre as aplicações veterinárias de micro e/ou nano partículas, destaca-se o interesse do setor de reprodução animal, voltado à produção de nano partículas de biopolímeros tais como, PHB-V (poli(3-hidróxibutirato-co-3-hidroxivalerato e valerato) e PCL (poli- $\in$-caprolactona), para aplicação como carregadores de esteróides (drug delivery devices), em protocolos de inseminação artificial em tempo fixo (IATF), superovulação (SOV), com o intuito de coleta de embriões e indução de puberdade. O PHBV é um copolímero termoplástico semi-cristalino biodegradável e biocompativel produzido por fermentação bacteriana. A biodegradabilidade do polímero oferece a possibilidade de aplicações biomédicas, incluindo a liberação controlada de agentes terapêuticos de drogas (VOLOVA et al., 2003). Embora PHBV apresente maior flexibilidade e reduzida fragilidade em comparação com o material relato, polihidroxibutirato, tentativas têm sido feitas para melhorar ainda mais as propriedades físicas do PHBV por mistura com outros polímeros (JENKINS et al., 2007), e o PCL é um poliéster alifático produzido pela polimerização de $\varepsilon$-caprolactona. PCL também é biodegradável e na área de liberação controlada (SINHA et al., 2003). 


\subsection{HIPOTESE}

A técnica de produção de microparticulas em meio supercrítico, carrega uma quantidade maior de progesterona por impregnação.

A associação de polímeros na produção de micro-particulas, altera a cinética de liberação da progesterona. 


\subsection{OBJETIVOS}

$>$ Empregar o processo SAS (Fluídos Supercríticos como Anti-Solventes) para a produção de nanopartículas de poli hidroxibutirato com Valerato (PHB-V) + Progesterona $\left(\mathrm{P}_{4}\right)$ e Poli- $\in$-caprolactona (PCL) para ser empregado na produção de um sistema de liberação, para o controle do ciclo estral em Fêmeas Bovinas; Super ovulação; indução da puberdade.

Caracterizar por processos físicos, químicos e físico-químicos as nanopartículas, obtidas pelos métodos de Fluídos Supercríticos, utilizando microscopia eletrônica de varredura, Análises Termogravimétricas e potencial Zeta para analisar as nano partículas obtidas.

Estudar a cinética de liberação in vitro da progesterona em biopolimeros na forma de nano partículas (NPs) e micro partículas (MPs), com diferentes tamanhos e mistura de dois polímeros (PHB-V e PCL), empregando-se dosagens de progesterona por HPLC e LC/MS 
Capitulo 2 


\section{REVISÃO DE LITERATURA}

Nesta seção, foi realizada uma revisão de literatura com ênfase na produção das nano partículas, métodos de caracterização, sistemas de liberação in vitro e in vivo.

\subsection{Introdução}

A nanotecnologia é um campo científico multidisciplinar que atualmente está em franco desenvolvimento. Entre os mais diferentes campos está a liberação controlada de fármacos em nano escala. Uma estratégia bem conhecida para possibilitar o desenvolvimento da nanotecnologia é o desenvolvimento de nano partículas para aplicações biomédicas e biotecnológicas (KREUTER, 2007). Nano partículas consistem de diferentes materiais biodegradáveis, sejam polímeros naturais ou sintéticos, lipídios, fosfolipídios e mesmo metais. A droga pode ser integrada na matriz ou ligada na superfície da partícula. Nanopartículas possuem alta relação superfície/volume e, como conseqüência, o índice de dissolução é aumentado. Essas formulações (nano suspensões), por sua alta capacidade de dissolução, são particularmente interessantes para compostos pouco solúveis. Por outro lado, as principais desvantagens das nano partículas são as dificuldades de produção, armazenagem e administração, devido ao fenômeno da instabilidade física, tal como a agregação.

\subsection{Inseminação artificial em tempo fixo}

Dentro de reprodução bovina, a introdução de protocolos de inseminação em tempo fixo (IAFT) nas propriedades, melhorou os índices zootécnicos com o aumento de animais disponíveis para inseminação(BARUSELLI, ET al., 2004). Dispositivos de liberação sustentada de 
progesterona, introduzidos na cavidade vaginal de fêmeas bovinas, administrados pelas vias orais ou subcutâneas, tem como objetivo, uma liberação por vários dias do fármaco.

A progesterona e seus análogos têm sido usados em protocolos de sincronização há vários anos (ODDE,1990). Vários métodos de liberação de progesterona e progestágenos têm sido usados incluindo injeções (ZIMBELMAN; CHRISTIAN; CASIDA,1951, WHISNANT; BURNS, 2002), administração oral, implantes auriculares (GONZÁLES-PADILHA et al.,1975) e intra-vaginais (MACMILLAN et.al.,1991; PIMENTEL, 2006). Entretanto, uma simples injeção de nanopartículas (NPs) ou micro partículas (MPs) de progesterona em polímeros biodegradáveis pode ser capaz de proporcionar níveis adequados deste hormônio, suficientes para sincronizar a ovulação ou indução da puberdade em novilhas (WHISNANT; BURNS, 2002).

\subsection{Sistemas de liberação}

De acordo com Embleton e Tigue (2002), partículas na ordem micrométrica são atraentes veículos para fins de liberação de substâncias ativas de interesse por apresentarem facilidade na liberação de macromoléculas aprisionadas via mecanismo de difusão aquosa. Nesse aspecto, microesferas biodegradáveis têm sido amplamente investigadas como sistemas de liberação de compostos bioativos, tais como agentes terapêuticos de baixa massa molar ou macromoleculares, antígenos e DNA. Indicadas para a administração pulmonar, oral ou nasal, as microesferas são capazes de promover uma liberação sustentada ou controlada de um composto bioativo, enquanto que o material não-liberado permanece protegido da degradação e da metabolização fisiológica (FREITAS et al., 2005).

Gursel et al. (2002) menciona que, em se tratando particularmente de microesferas de PHBV, é difícil conseguir uma rápida liberação devido à estabilidade hidrolítica destes polímeros. Em contrapartida, processos que possibilitem um controle sobre a porosidade deste material seriam particularmente atraentes, permitindo liberar o princípio ativo encapsulado de acordo com no número, o tamanho, a profundidade e a tortuosidade dos poros do polímero. Outra vantagem dos polímeros PHBV em relação a outros polímeros biodegradáveis é a taxa de 
degradação mais lenta, o que ajudaria a evitar problemas como o acúmulo de produtos ácidos e diminuição do $\mathrm{pH}$, característicos da rápida degradação.

$\mathrm{Na}$ literatura, alguns trabalhos são reportados com referência à liberação de princípios ativos de interesse em diversos setores industriais. Em 2005, Soottitantawat et al. verificaram o microencapsulamento de 1-mentol em goma arábica (GA) e amido modificado (HI-CAP 100 e CAPSUL) bem como suas características de liberação (sabor) através do processo de atomização (spray drying). Os autores verificaram que a umidade relativa e a temperatura são os parâmetros do processo que exercem influência significativa, ou seja, a taxa de liberação é aumentada após a elevação da umidade relativa e da temperatura. Em alta atividade de água pode ocorrer uma maior absorção de água pelo polímero resultando em danos à sua estrutura e conseqüentemente maior dissolução e liberação do 1-mentol a partir da matriz polimérica. Com relação aos materiais estudados, verificaram que, em alta atividade de água o amido modificado CAPSUL apresentou uma menor taxa de liberação em comparação ao amido HI-CAP 100 e à goma arábica, devido ao fato deste absorver menor quantidade de água do que os outros citados. Para a análise da liberação, focada principalmente nas características de sabor do 1-mentol, uma determinada amostra do pó obtido na atomização era pesada, espalhada em finas camadas e posteriormente colocada em frascos de vidro de $15 \mathrm{~mL}$. Os recipientes eram então colocados em dessecador contendo solução saturada de sal a fim de manter a umidade relativa constante $(8 \pm 5 \%, 33 \pm 5 \%$, $51 \pm 5 \%, 75 \pm 5 \%$, e $83 \pm 5 \%$ ) e temperatura controlada de $30{ }^{\circ} \mathrm{C}$. Utilizaram também um método para acelerar a liberação de 1-mentol e, em intervalos de $6 \mathrm{~h}$ era realizada uma purga de ar contendo umidade igual à umidade relativa do experimento. Em intervalos pré-determinados, os frascos foram retirados do dessecador e a quantidade residual de 1-mentol no pó era medida pelo método de extração com solvente. A retenção de 1-mentol no experimento de liberação foi expressa em relação ao conteúdo inicial.

Lionzo et al. (2007) ao estudarem a influência das concentrações de poli ( $\varepsilon$-caprolactona - PCL) e poli (hidroxibutirato-co-hidroxivalerato - PHBV) como agentes encapsulantes do acetato de dexametasona preparadas através do processo convencional por emulsão/evaporação de solvente, demonstraram que o perfil de liberação do princípio ativo pode ser modulado pela variação entre as concentrações das micropartículas formadas a partir do PCL e PHBV, ou seja, o aumento da concentração de PCL na mistura aumentou a taxa de liberação do princípio ativo e que seu mecanismo de liberação era dependente da presença do PCL nas micropartículas. Para a 
determinação dos perfis de liberação, uma determinada quantidade de material microencapsulado era adicionada em frascos protegidos da luz e sob agitação contendo uma solução tampão fosfato $(\mathrm{pH} 7,4)$ na temperatura de $37 \pm 0,5^{\circ} \mathrm{C}$. Em tempos pré-determinados, alíquotas eram retiradas, filtradas e analisadas em espectrofotômetro no comprimento de onda de $242 \mathrm{~nm}$. Procedimento semelhante é descrito por Lin et al. (2000) no estudo do comportamento de dissolução in vitro de micropartículas de diclofenaco sódico encapsuladas em poliésteres com diferentes massas moleculares. Os perfis de dissolução foram determinados em shaker a $20 \mathrm{rpm}$, onde uma determinada quantidade das microesferas encapsuladas era suspensa em $50 \mathrm{~mL}$ de uma solução tampão fosfato $\left(\mathrm{pH} \mathrm{7,4)}\right.$ na temperatura de $37 \pm 0,5{ }^{\circ} \mathrm{C}$. O diclofenaco sódico residual e liberado era periodicamente determinado por espectrômetro a $276 \mathrm{~nm}$.

Em 2008, Kang et al., realizaram um estudo concernente à preparação, caracterização e citotoxicidade in vitro das micropartículas de indometacina (IDMC) encapsulada em poli ácido-1láctico/poli ácido-láctico-co-ácido glicólico (PLLA/PLGA) utilizando dióxido de carbono supercrítico como anti-solvente e observaram uma liberação inicial de 11,85\% em 30 minutos seguido pela liberação acumulativa de $83,67 \%$ após 30 dias. Os autores indicaram que a IDMC livre atingiu rapidamente o patamar de saturação $(48,95 \%)$ em $4 \mathrm{~h}$, enquanto que as amostras contendo IDMC encapsulado apresentaram um baixo burst inicial, não excedendo a liberação de IDMC livre após 48 horas. Concluem que os perfis ocorrem em duas etapas, sendo a primeira dada pela liberação da substância através de sua difusão seguida da degradação polimérica posteriormente. Ainda, a proporção entre PLLA e PLGA, cristalinidade e peso molecular do polímero, e tamanho de partícula de micropartículas também têm efeitos sobre a degradação do polímero e taxa de liberação da droga. Os perfis de liberação foram determinados como segue: vinte microgramas de amostra do material encapsulado foi alocado em sacos de diálise prétratados e estes colocados em um recipiente contendo uma solução tampão fosfato ( $\mathrm{pH}$ 6,8) sob agitação e temperatura de $37{ }^{\circ} \mathrm{C}$. Alíquotas da solução eram periodicamente removidas e a concentração de IDMC era analisada por espectrometria a $320 \mathrm{~nm}$. A fim de manter o volume de solução original, a mesma quantidade retirada para análise era imediatamente recolocada.

Em 2009, Chong et al. avaliaram os perfis de liberação de nanopartículas de paracetamol (acetominophen) encapsuladas em um copolímero de acrilato e metacrilato utilizando a técnica que emprega fluido supercrítico como anti-solvente e verificaram que a liberação do princípio ativo encapsulado foi mais lenta em relação ao paracetamol não processado, constatando que o 
polímero empregado, age como uma barreira à liberação da substância. Os perfis de liberação in vitro do paracetamol não processado e encapsulado foram determinados através de cromatografia líquida de alta eficiência (HPLC), onde uma amostra de ambos os materiais era colocada separadamente em $100 \mathrm{~mL}$ de solução tampão (pH 7,4), agitadas a $50 \mathrm{rpm}$ à $37^{\circ} \mathrm{C}$. No mesmo ano, Leimann et al., estudaram o microencapsulamento de óleo essencial de capim-limão utilizando o processo de coacervação simples e encontraram microcápsulas com tamanhos no intervalo de 10 a $250 \mu \mathrm{m}$ constatando que este processo de microencapsulamento não deteriora o óleo essencial encapsulado, com relação à composição e atividade biológica, porém dependendo a condição experimental, microcápsulas de até $1 \mathrm{~mm}$ podem ser formadas. A liberação do óleo essencial foi obtida através da hidrodestilação das microcápsulas em aparelho do tipo Clevenger, onde inicialmente as microcápsulas foram filtradas sob vácuo, lavadas triplamente com água destilada e uma vez com etanol para retirada do óleo essencial que não tenha sido microencapsulado. Em intervalos determinados de tempo o óleo essencial obtido foi retirado do aparelho e pesado em uma balança repetindo-se o procedimento até que não fosse observada mais extração de óleo das microcápsulas.

\subsection{Modelos de liberação do fármaco}

Diversos tipos de liberação controlada ou sustentada têm sido desenvolvidos ao longo dos últimos anos, sendo os mais populares os sistemas revestidos (tais como pellets de difusão), comprimidos matriciais, comprimidos que sofrem degradação/erosão e sistemas osmóticos (ZULEGER; LIPPOLD, 2001). Ao contrário das Formas farmacêuticas de liberação convencional, nas quais todo o sistema é concebido para favorecer o processo de dissolução, nas formas de liberação sustentada, é a cinética de liberação que é modulada, mesmo que ocorra a dissolução, o fármaco fica retido no seu interior. Uma forma farmacêutica (matriz revestida) tem adquirido popularidade em alguns mercados, sendo usada não só para obter uma liberação de ordem zero, mas fármaco. A Figura 1 apresenta um diagrama esquemático da liberação de um fármaco a partir deste tipo de forma farmacêutica, no qual $C$ é a concentração do fármaco, $C d$ é a concentração do fármaco no núcleo da matriz (que é superior a Cs), Cs é a concentração de 
saturação do fármaco no material do núcleo. As concentrações do fármaco nas zonas de liberação do núcleo, do revestimento e do meio de extração são representadas, respectivamente, por $C m, C f$ e Ce (TONGWEN; BINGLIN, 2000).

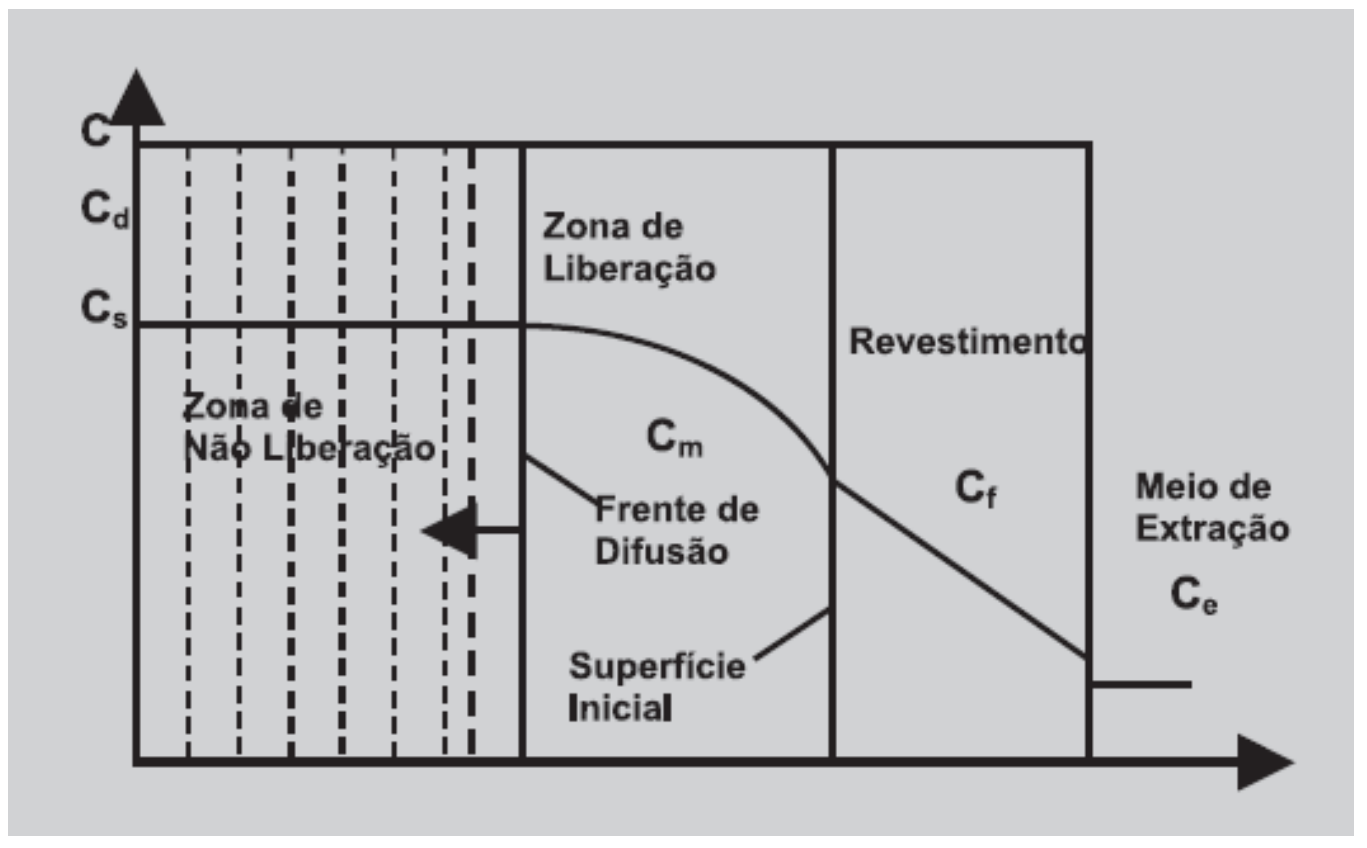

Figura 1 - Diagrama esquemático da liberação de um fármaco a partir de matriz revestida. (Adaptado de Brazel e Peppas (2000))

Os processos que decorrem na maioria dos sistemas de liberação modificada podem englobar-se numa das três categorias que seguem: difusão, liberação por processo deativação e desagregação/erosão polimérica (COSTA; LOBO, 1999; ZULEGER; LIPPOLD, 2001).

\subsection{Difusão}

A difusão é o processo pelo qual a matéria é transportada de um local para outro situado no interior do próprio sistema e resulta de movimentos moleculares aleatórios, que ocorrem em pequenas distâncias (COSTA; LOBO, 1999). Adolf Fick, em 1855, foi o primeiro a procurar quantificar o processo de difusão ao adotar a equação matemática do fenômeno de transferência de calor proposta por Fourier. A expressão matemática que traduz esta velocidade de transferência, por unidade de superfície, da substância a difundir num meio isotrópico através de uma seção do polímero pode representar-se como segue: 


$$
\frac{d Q}{d t}=-D \frac{d C}{d X}
$$

onde $d Q / d t$ representa a velocidade de difusão, $Q$, a massa de fármaco transportada, $t$, o tempo, $C$, a concentração da substância que se difunde, $X$, a coordenada espacial normal à seção e $D$, o coeficiente de difusão. O sinal negativo surge porque a difusão ocorre na direção oposta à do aumento da concentração. Nos sistemas farmacêuticos, $X$ representa a distância do local onde o fármaco se encontra acumulado até a superfície de liberação $S$ (COSTA; LOBO, 1999).

O coeficiente de difusão de um fármaco num polímero pode ser influenciado por vários parâmetros: densidade de reticulação, grau de ramificação, grau de cristalinidade, tamanho das zonas cristalinas (COSTA; LOBO, 1999; PEPPAS, 1983). A difusão em muitos polímeros não é adequadamente descrita pela lei de Fick ou por expressões dela derivadas, expressões essas dependentes da concentração e com condições de fronteira constantes. Isto se verifica principalmente quando a substância penetrante provoca no polímero grande aumento de volume, como é o caso dos plastômeros ("glassy polymers"), que apresentam comportamento nãoFickiano ou anômalo. Pelo contrário, nos elastômeros ("rubbery polymers") a difusão segue geralmente a lei de Fick (COSTA; LOBO, 1999). Num sistema de difusão, o fármaco pode estar revestido por uma membrana polimérica (ou incorporado em matriz polimérica). Tipicamente, o curso dos fenômenos é o seguinte: a água difunde-se para a membrana ou para a matriz, o fármaco dissolve-se e finalmente o fármaco dissolvido difunde-se para fora do polímero. Surgem, então, sistemas farmacêuticos de difusão por matriz ou por membrana. Na Figura 2 apresentamse exemplos do uso de revestimentos que controlam a passagem do fármaco (COSTA,LOBO, 1999).

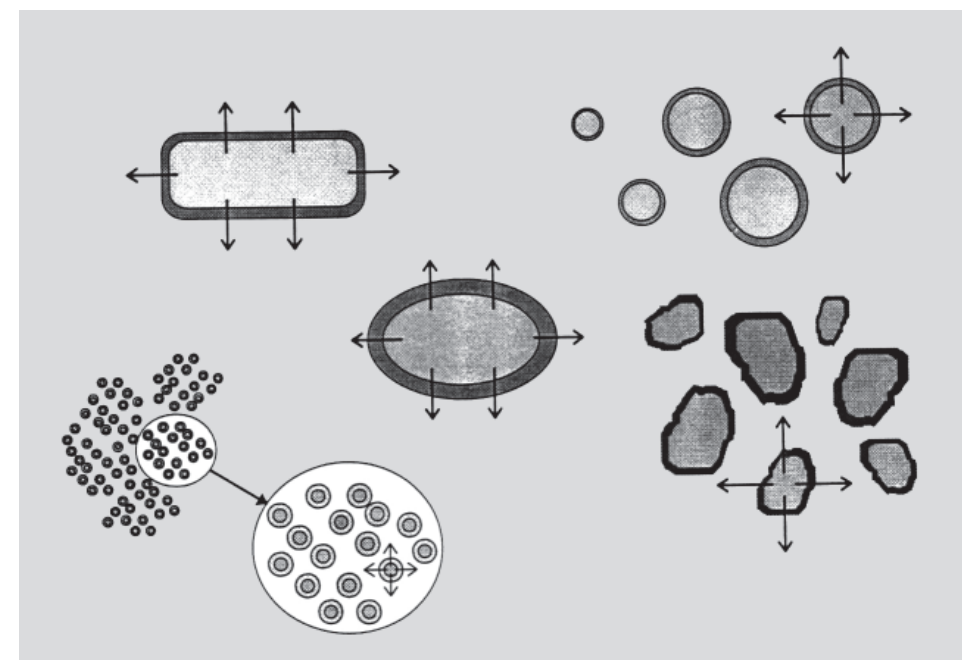


Figura 2 - Uso de revestimentos que controlam a passagem do fármaco.

Brazel e Peppas (2000) desenvolveram um modelo que descreve o processo de liberação de fármacos a partir de matrizes poliméricas, tendo em conta o tipo de resposta viscoelástica do polímero, o qual permite obter uma previsão gráfica da correlação entre e a importância relativa dos fatores moleculares no desenvolvimento de forma de liberação sustentada (Figura 3).

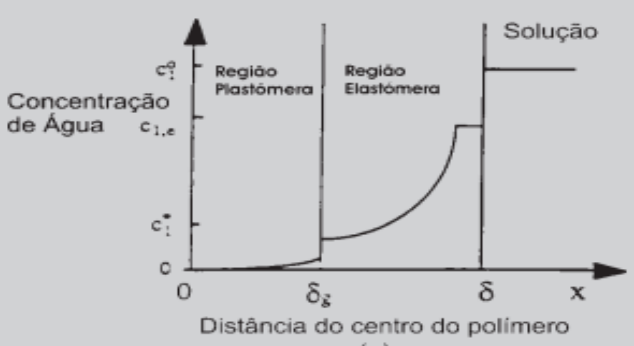

(a)

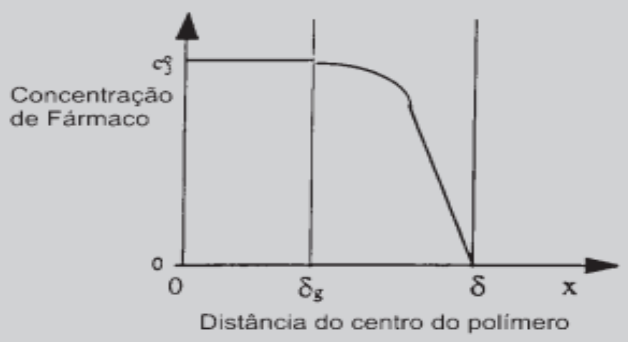

(b)

Figura 3 - Perfis das concentrações teóricas do solvente (a) e do soluto (b) durante o processo de dilatação por liberação controlada, ao tempo t, em que as frentes plastômera/elastômera ainda coexistem.

\subsection{Ativação}

Os sistemas de liberação por processos de ativação recorrem a um de vários mecanismos, sendo o mais comum a utilização de membrana semipermeável contendo um pequeno orifício feito por laser ("bombas osmóticas"). Outros processos de ativação são a pressão hidrodinâmica, a pressão de vapor, as forças elétricas e/ou magnéticas, os ultra-sons, a iontoforese, o pH e a força iônica (PRISTA et al., 1996). 


\subsection{Degradação/erosão}

Os sistemas cuja liberação é controlada por erosão são preparados pela incorporação do fármaco em polímeros hidrossolúveis (hidrocolóides). A liberação do fármaco a partir de formas farmacêuticas sólidas matriciais deste tipo (degradação/erosão) (Figura 4) envolve dois processos seqüenciais, dependentes do tempo, que são a difusão do meio para o interior da matriz com conseqüente dilatação e formação de um gel e a degradação/ erosão, que podem ocorrer de modo mais ou menos simultâneo até a completa desagregação das cadeias poliméricas.

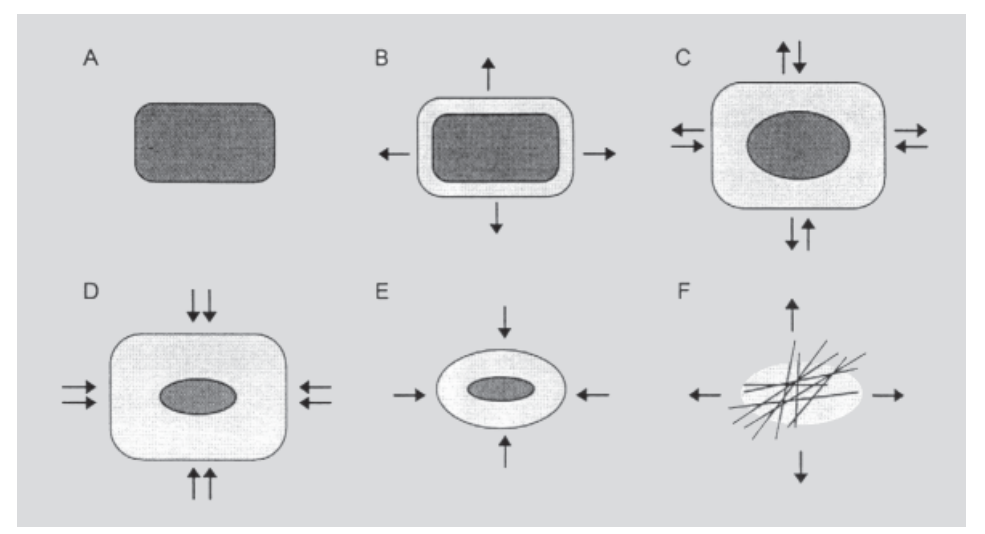

Figura 4 - Mudanças macroscópicas em sistemas matriciais que intumescem e sofrem erosão.

Para fármacos com razoável solubilidade aquosa, a liberação ocorre por dissolução no meio de difusão e por dissolução a partir de partículas da forma farmacêutica que sofreram erosão. A liberação de fármacos solúveis a partir da matriz envolve o processo seqüencial de difusão do meio para a matriz, hidratação e dilatação da matriz, dissolução do fármaco e difusão através dos canais intersticiais da matriz para o meio, o que é em grande parte dependente do grau de viscosidade do gel formado (COLOMBO et al., 1995, COSTA; LOBO, 1999, HARLAND et al., 1988, KATZHENDLER et al., 1997, KIM; FASSIHI, 1997A, 1997B, OFOEFULE et al., 2000, ZULEGER; LIPPOLD, 2001). O diferente modo como a erosão ocorre condiciona fortemente o perfil de liberação do fármaco. Para fármacos muito solúveis, a liberação é determinada principalmente pela difusão do fármaco através da camada gelificada, mas para fármacos pouco ou muito pouco solúveis a liberação será controlada pelo processo de erosão (Figura 5). 


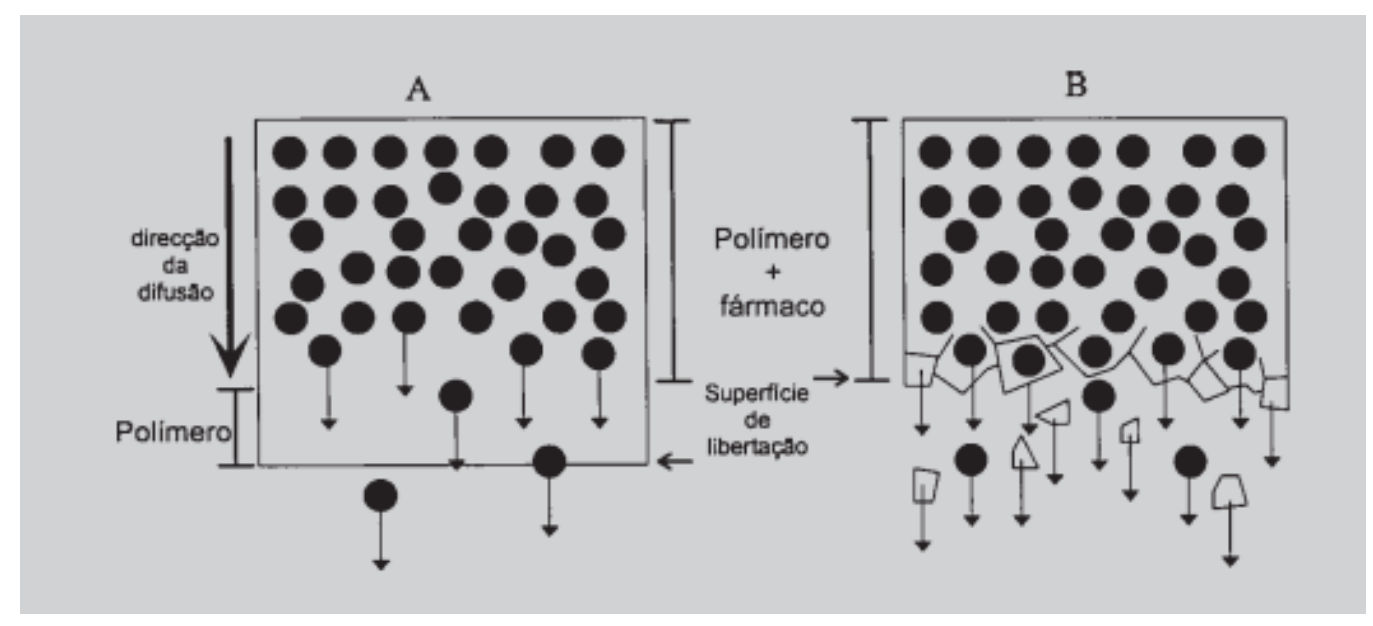

Figura 5 - Processo de difusão (A) e erosão (B) em matriz polimérica.

\subsection{DISSOLUÇÃO}

A dissolução pode ser definida, num sentido restrito, como o processo pelo qual uma substância sólida entra no solvente para formar uma solução. No entanto, no sentido amplo da palavra, é mais do que a simples medida da taxa de solubilidade, podendo ser mais corretamente descrita como um ensaio físico para prever a liberação para uma determinada área numa determinada quantidade e no tempo correto. Esta definição é mais consentânea com a aplicação dos ensaios de dissolução aos estudos biofarmacêuticos e farmacocinéticos. Fundamentalmente, este processo é controlado pela afinidade entre a substância sólida e o solvente e pelo modo como o sistema farmacêutico o libera (COSTA; LOBO, 1999, HANSON-RESEARCHCORPORATION, 1996). No entanto, podem ser incorporadas substâncias no seio da forma farmacêutica, quepermitem alterar a solubilidade do fármaco no meio (PREECHAGOON et al., 2000). A solubilidade de um fármaco é parâmetro chave nos estudos de pré-formulação. Normalmente, a solubilidade (ou concentração de saturação) é determinada através da adição de um excesso de fármaco ao meio, agitação da suspensão durante um determinado período, filtração ou centrifugação da suspensão e medição da quantidade de fármaco dissolvida. No entanto, vêm sendo desenvolvidas técnicas que permitem a determinação deste parâmetro de 
formas mais rápidas e menos dispendiosas (ROY ET AL., 2001). As substâncias podem ser classificadas, quanto à sua solubilidade, de acordo com a Tabela I (INFARMED, 1997).

Tabela 1 - Solubilidade das substâncias.

Termos Descritos

Quantidades aproximadas do solvente, em

Muito solúvel mililitros, para um grama da substância.

Facilmente solúvel Menos de 1

Solúvel

De 1 a 10

Ligeiramente solúvel

De 10 a 30

Pouco solúvel

De 30 a 100

Muito pouco solúvel

De 100 a 1.000

Praticamente insolúvel

De 1000 a 10.000

Mais de 10.000

\subsection{Teoria da dissolução}

Em 1897, Noyes e Whitney estabeleceram, com base na segunda lei de difusão de Fick, a relação entre a velocidade de dissolução, a solubilidade máxima do soluto (ou constante de saturação) e a concentração ao tempo t (DIGHE, 1993; FARINHA et al., 1997):

$$
\frac{d C}{d t}=K(C s-C t)(\text { Tabela } 2)
$$

Em 1904, Nernst e Brunner modificaram a equação de Noyes e Whitney, tendo incluído como parâmetros influentes no processo o coeficiente de difusão (D), a área de superfície (S), a espessura da camada de difusão (h) e o volume do meio de dissolução (V) (FARINHA et al., 2000, FARINHA et al. 1997):

$$
\frac{d C}{d t}=K \frac{D S}{V h}(C s-C t)
$$

Esta é a teoria da velocidade de dissolução com maior aceitação e dela se constata que quando o volume do meio de dissolução é suficientemente grande de modo que $t<<C s$ normalmente $<10 \%$ ), considera-se que a concentração do soluto no solvente não afeta a velocidade de dissolução. As determinações da velocidade de dissolução têm que ser feitas respeitando sempre esta condição (FARINHA et al., 1997). Na Tabela II apresenta-se um resumo das teorias de dissolução mais freqüentemente referenciadas (FARINHA et.al., 2000). Nelson e 
Shah (ANO) propuseram um modelo no qual o processo de dissolução num líquido sob agitação envolve 2 etapas fundamentais: a difusão molecular e a convecção forçada pelo fluxo do meio de dissolução (Teoria da Difusão Convectiva) (BANAKAR, 1992; FARINHA et al., 2000).

Tabela 2 - Teorias da dissolução (Farinha et al., 2000).

\begin{tabular}{|c|c|c|}
\hline Modelo & Equação do modelo & Características relevantes \\
\hline Noyes e Whitney & $\begin{array}{l}\qquad \frac{d c}{d t}=\boldsymbol{k}(\boldsymbol{c s}-\boldsymbol{c t}) \text {, onde, } \frac{d \boldsymbol{d}}{d t} \\
\text { é a velocidade de dissolução, K } \\
\text { representa o coeficiente de dissolução } \\
\text { ou de transferência de massa, Cs é a } \\
\text { solubilidade } \\
\text { máxima no meio de dissolução e } C t \text { a } \\
\text { concentração ao tempo } t \text {. }\end{array}$ & $\begin{array}{l}\text { Relaciona a velocidade } \\
\text { de dissolução com a } \\
\text { solubilidade máxima e a } \\
\text { concentração ao tempo } t \text {. }\end{array}$ \\
\hline $\begin{array}{l}\text { Teoria do filme Nernst } \\
\text { e Brunner }\end{array}$ & $\begin{array}{l}\left.\qquad \frac{d C}{d t}=\boldsymbol{K}\left(\frac{A}{V h}\right) \boldsymbol{C s}-\boldsymbol{C} t\right) \text { onde } A \\
\text { é a área de superfície, } h \text { a espessura da } \\
\text { camada de difusão e } V \text { o volume do } \\
\text { meio de dissolução. }\end{array}$ & $\begin{array}{l}\text { Inclui a área de } \\
\text { superfície, a espessura da } \\
\text { camada de difusão e o } \\
\text { volume do meio como } \\
\text { parâmetros influentes no } \\
\text { processo. }\end{array}$ \\
\hline $\begin{array}{l}\text { Difusão convectiva O } \\
\text { Nelson e Shah/Levich }\end{array}$ & $\frac{d C}{d t}=($ Ddiv. grad. $C)-(V g$ & $\begin{array}{l}\text { O primeiro termo } \\
\text { constitui a componente } \\
\text { de difusão e o segundo a } \\
\text { de convecção, etapas do } \\
\text { processo de dissolução. }\end{array}$ \\
\hline $\begin{array}{l}\text { Teoria da renovação } \\
\text { superficial ou da } \\
\text { renovação de } \\
\text { Dunckwerts }\end{array}$ & $\begin{array}{l}\qquad \frac{d C}{d t}=A(Y \cdot D) \frac{1}{2}(C s-C t) \\
\text { onde g é a tensão superficial }\end{array}$ & $\begin{array}{l}\text { É a proposta à contínua } \\
\text { renovação do meio de } \\
\text { dissolução na superfície } \\
\text { da partícula, não se } \\
\text { atingindo Cs na interface. }\end{array}$ \\
\hline
\end{tabular}

Modelos de liberação do fármaco A interpretação quantitativa dos valores obtidos nos ensaios de dissolução é facilitada pela utilização de uma equação genérica, que traduz matematicamente a curva de dissolução em função de alguns parâmetros relacionados com a forma farmacêutica. Em alguns casos, essa equação pode ser deduzida através de uma análise teórica do processo, como numa cinética de ordem zero. Na maioria dos casos, porém, não existe um fundamento teórico, sendo usada uma equação empírica mais adequada. O tipo de fármaco, a sua forma polimórfica, cristalinidade, tamanho de partícula, solubilidade e quantidade incorporada na forma farmacêutica podem influenciar a cinética de libe ração (COSTA; LOBO, 
2001B, EL ARINI; LEUENBERGER, 1995, SALOMON; DOELKER, 1980). Têm sido desenvolvidos muitos modelos matemáticos com o objetivo de descrever a liberação do fármaco a partir da forma farmacêutica que o contém (OFOEFULE et al., 2000). No entanto, os mais freqüentemente usados são os de Higuchi (1963) e Peppas (1985).

\subsection{Cinética de ordem zero}

A dissolução de fármacos a partir de formas farmacêuticas que não desagregam e que liberam o fármaco lentamente, desde que a sua área não se modifique e que não se atinjam condições de equilíbrio, pode ser representada pela seguinte equação:

$$
W_{0}-W t=K t
$$

sendo $\mathrm{W}_{0}$ a quantidade de fármaco inicialmente presente na forma farmacêutica, $\mathrm{W}_{\mathrm{t}}$, a quantidade de fármaco presente na forma farmacêutica após o tempo $t \mathrm{e} K$, a constante de proporcionalidade. Esta equação pode ser transformada na seguinte:

$$
f t=K o t
$$

sendo $f t=1-(W t / W 0)$ a fração de fármaco dissolvido no tempo $t$ e $K 0$ a constante aparente de dissolução ou a constante de liberação de ordem zero (COSTA, LOBO, 2001b). Deste modo, e desde que as condições já referidas se mantenham, um gráfico da fração de fármaco dissolvido versus tempo será linear (VARELAS et al., 1995). Esta relação pode ser aplicada a FFLM tais como comprimidos matriciais que contenham fármacos pouco solúveis. As formas farmacêuticas que seguem este perfil liberam a mesma quantidade de fármaco por unidade de tempo, o qual é o modelo ideal para as formas farmacêuticas de liberação prolongada. A expressão seguinte pode, de um modo simplificado, representar este modelo:

$$
Q t=Q o+K_{o} t
$$

onde $Q t$ é a quantidade de fármaco dissolvido ao tempo $t, Q 0$ é a quantidade inicial de fármaco dissolvido na solução (a maioria das vezes $Q 0=0$ ) e $K_{0}$ é a constante de liberação de ordem zero. 


\subsection{Cinética de primeira ordem}

A aplicação deste modelo aos estudos de dissolução foi proposta pela primeira vez por Gibaldi e Feldman (1967) e mais tarde por Wagner (1969). Hixson e Crowell adaptaram a equação de Noyes- Whitney $(d C / d t=K(C s-C t))$ da seguinte forma:

$$
\frac{d W}{d t}=K S\left(c_{s}-c\right)
$$

onde $W$ é a quantidade de soluto na solução ao tempo $t, d W / d t$ é a taxa de passagem do soluto para a solução ao tempo $t$ e $K$ é uma constante. Trabalhando a equação anterior, integrando-a e aplicando logaritmos decimais, obtém- se a seguinte equação:

$$
\log Q_{t}=\log Q_{o}+\frac{K 1^{t}}{2,303}
$$

onde $Q t$ é a quantidade de fármaco liberado no tempo $t, Q 0$ é a quantidade inicial de fármaco na solução e $K 1$ é a constante de liberação de primeira ordem. Desta forma, o gráfico do logaritmo decimal da quantidade liberada do fármaco versus tempo será linear. As formas farmacêuticas que seguem esteperfil de dissolução, tais como as que contêm fármacoshidrossolúveis em matrizes porosas, liberam o fármaco de forma proporcional à quantidade remanescente no seu interior de tal modo que a quantidade de fármaco liberada por unidade de tempo diminui (MULYE; TURCO, 1995).

\subsection{Modelo de Weibull}

Uma equação empírica genérica descrita por Weibull, em 1951, foi adaptada para os processos de dissolução/ liberação de fármacos por Langenbucher (1972). Esta equação pode ser aplicada com sucesso a quase todos os tipos de curvas de dissolução e é normalmente usada nestes estudos (Costa, Lobo, 2001b). Quando aplicada à liberação do fármaco a partir de formas farmacêuticas a equação de Weibull exprime a fração cumulativa do fármaco $(m)$ na solução ao tempo $t$ : 


$$
\begin{aligned}
& m=1-\exp \left[-\frac{(t-T i) b}{a}\right] \\
& \operatorname{ou} \\
& \log [-1 n(1-m)]=b \log (t-T i)-\log a
\end{aligned}
$$

onde $a$ define a escala temporal do processo, Ti representa o intervalo de tempo antes do início do processo de dissolução ou de liberação (na maioria das vezes é igual a zero), $b$ é o parâmetro de forma que caracteriza a curva como sendo exponencial ( $b=1$; Caso 1$)$, sigmóide (forma de $S$ ) ( $b>1$; Caso 2) ou parabólica ( $b<1$; Caso 3). A partir da segunda equação pode-se obter uma relação linear para a correspondência entre $\log$-log de $-\ln (1-m)$ versus tempo $(t)$. $\mathrm{O}$ parâmetro de forma (b) é obtido a partir do declive da recta e o parâmetro de escala (a) é estimado a partir do valor da ordenada ( $1 / a)$ ao tempo $t=1$. O parâmetro $a$ pode ser substituído pelo tempo de dissolução $(T d)$, que é definido por $a=(T d) b$ e é obtido a partir do gráfico como o tempo correspondente à ordenada $-\ln (1-m)=1$. Uma vez que $-\ln (1-m)=1$ é equivalente a $m=0,632, T d$ representa o intervalo de tempo necessário para dissolver ou liberar $63,2 \%$ do fármaco presente na forma farmacêutica. Para as formas farmacêuticas que seguem este modelo, o logaritmo da quantidade de fármaco dissolvido versus o logaritmo do tempo será linear

\subsection{Modelo de Higuchi}

Higuchi desenvolveu diversos modelos teóricos para estudar a liberação de fármacos solúveis e pouco solúveis incorporados em matrizes semi-sólidas e sólidas. O estudo de dissolução a partir de um sistema plano constituído por matriz homogênea pode ser exemplificado pela seguinte equação :

$$
\left(Q_{t}=K_{H v}{ }^{t}\right) \text {, }
$$

onde $Q$ é a quantidade de fármaco libertado no tempo $t$ por unidade de área, $C$ é a concentração inicial de fármaco, Cs é a solubilidade do fármaco no meio da matriz e $D$ é a difusibilidade do fármaco (constante de difusão) no seio da matriz (Higuchi, 1961, 1963). Esta 
equação é válida durante todo o tempo de dissolução exceto quando se atinge a total depleção do fármaco na forma farmacêutica. (Figura 6)

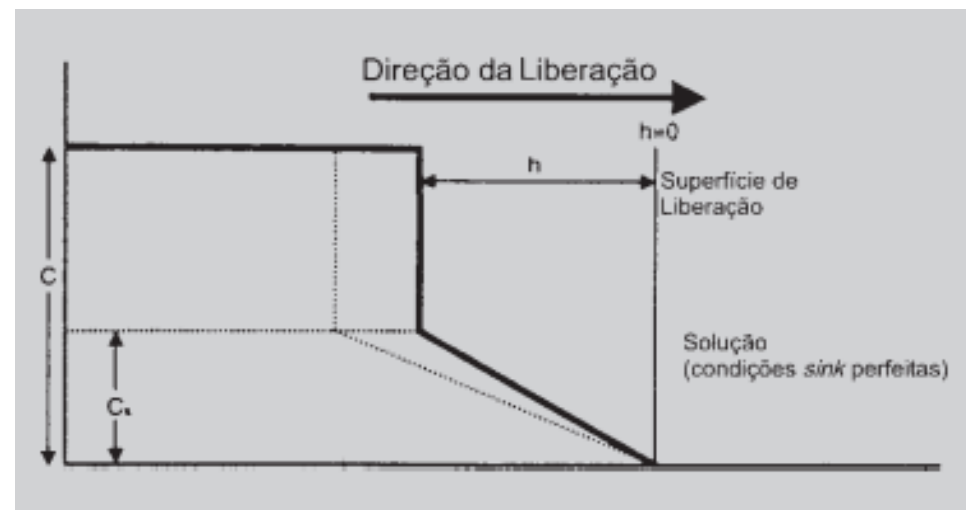

Figura 6 - Perfil teórico da concentração do fármaco num sistema matricial em contacto directo com um meio de liberação em condições "sink".(Manadas et all., 2002).

Higuchi desenvolveu, também, outros modelos para a liberação a partir de formas farmacêuticas constituídas por matrizes homogêneas esféricas e matrizes não homogêneas planas ou esféricas. Para o estudo de dissolução a partir de um sistema matricial plano heterogêneo, no qual a concentração do fármaco na matriz é inferior à sua solubilidade e a liberação ocorre por entre os poros da matriz, Higuchi sugeriu a seguinte equação:

$$
f t=Q=\frac{\sqrt{D \varepsilon}}{\tau}\left(2 C-\varepsilon C_{g}\right) C_{s}^{t}
$$

onde $Q$ é a quantidade de fármaco libertada no tempo $t$ por unidade de superfície, $C$ é a concentração inicial do fármaco, $e$ é a porosidade da matriz, $\tau$ é o fator de tortuosidade do sistema capilar, Cs é a solubilidade do fármaco na matriz/meio excipiente e $D$ é a constante de difusão do fármaco no meio. Estes modelos assumem que este tipo de sistemas nem são revestidos nem as matrizes pelas quais são constituídos sofrem alterações significativas na presença de água. Higuchi (1962) propôs um modelo para os casos em que o fármaco é dissolvido a partir de uma solução saturada (onde $C 0$ é a concentração da solução) dispersa em matriz porosa:

$$
f t=Q=\sqrt{2 C_{o}^{\tau}} \frac{D t}{\tau \pi}
$$

\subsection{Modelo de Hixson-Crowell}


Hixson e Crowell, reconhecendo que a área de uma partícula é proporcional à raiz cúbica do seu volume, derivaram uma equação que pode ser descrita da seguinte forma:

$$
W_{0}^{1 / 3}-W_{t}^{1 / 3}=K_{z}^{t}
$$

onde WO é a quantidade inicial de fármaco existente na forma farmacêutica, Wt é a quantidade restante de fármaco existente na forma farmacêutica ao tempo $t$ e $K S$ é a constante que incorpora a relação superfície/volume (COSTA, LOBO, 2001b). Esta expressão aplica-se a formas farmacêuticas, tais como os comprimidos, nos quais a dissolução ocorre em planos que são paralelos à superfície do fármaco se as dimensões do comprimido diminuirem proporcionalmente, de tal modo que a forma geométrica inicial se mantém constante durante todo o processo. A equação anterior pode ser trabalhada e simplificada:

$$
\left(1-f_{t}\right)^{\frac{1}{3}}=1-K_{\beta}^{t}
$$

onde $f t=1-(W t-W 0)$ e $f t$ representa a fracção de fármaco dissolvido ao tempo $t$ e $K \beta$ é uma constante de liberação. Portanto, um gráfico que relacione a raiz cúbica da fração não liberada do fármaco versus tempo será linear se as condições de equilíbrio não forem atingidas e se a forma geométrica da forma farmacêutica diminuir proporcionalmente ao longo do tempo. Quando se utiliza este modelo, assume-se que a taxa de liberação é limitada pela dissolução das partículas do fármaco e não pela difusão que possa ocorrer através da matriz polimérica (COSTA, LOBO,2001b).

\subsection{Modelo de Korsmeyer-Peppas}

Korsmeyer e colaboradores (1983) desenvolveram um modelo simples e semi-empírico que relaciona exponencialmente a liberação do fármaco com o tempo (KORSMEYER, et al., 1983):

$$
f_{t}=a t^{n}
$$


onde $a$ é uma constante que incorpora características estruturais e geométricas da forma farmacêutica, $n$ é o expoente de liberação, indicativo do mecanismo de liberação do fármaco, e a função de $t$ é $M t$ / $M 8$ (liberação fraccional do fármaco). Ou seja:

$$
\frac{M_{t}}{M \infty}=a t^{n}
$$

Para usar esta equação é necessário que a liberação ocorra de modo unidimensional e que o sistema possua uma relação largura/espessura ou comprimento/espessura de pelo menos 10 . Este modelo é genericamente utilizado para analisar a liberação de formas farmacêuticas poliméricas, quando o mecanismo de liberação não é bem conhecido ou quando possam estar envolvidos mais do que um tipo de mecanismos de liberação (PEPPAS, 1985). Foi desenvolvida uma forma modificada desta última equação (EL ARINI; LEUENBERGER, 1998, FORD et al., 1991, HARLAND et al., 1988, KIM; FASSIHI, 1997a, 1997b, PILLAY; FASSIHI, 1999) para considerar o tempo de espera $(l)$ no início da liberação do fármaco a partir da forma farmacêutica:

$$
\frac{M_{(t-\zeta)}}{M^{\infty}}=a(t-\zeta)^{n}
$$

Quando existe a possibilidade de um efeito de liberação abrupta inicial (b) esta equação transforma-se em:

$$
\frac{M_{(t-b)}}{M^{\infty}}=a t^{n}+b
$$

Este modelo matemático, também conhecido como "Power Law", tem sido usado com muita freqüência para descrever a liberação do fármaco a partir de diversos tipos de FFLM (KIM; FASSIHI, 1997a, 1997b, LIN; YANG, 1989, SANGALLI et al., 1994).

\subsection{Produção de nanoparticulas (NPs) e microparticulas (MPs)}

O tamanho das partículas, bem como sua distribuição de tamanhos, é o fator chave para o uso de diferentes materiais orgânicos e inorgânicos. Freqüentemente, tais propriedades têm que ser modificadas, para subseqüente uso destes materiais e, portanto, operações de cominuição e 
recristalização são realizadas em larga escala nas indústrias farmacêuticas, veterinárias, químicas e de polímeros entre outras (GALLAGHER et al., 1989).

A produção de partículas submicrométricas, seja nano partículas ou nano cápsulas, tem sido amplamente estudada por diversos autores, pois apresentam características interessantes para o uso em sistemas de liberação controlada de fármacos. Polímeros como o PHBV (poli(hidroxibutirato-co-hidroxivalerato)), PLA (poli(ácido lático) e PCL (policaprolactona) são de grande interesse na produção dessas nanopartículas devido as suas propriedades de biodegradabilidade e biocompatibilidade (BARAN et al., 2002a,b, BLOUZA et al., 2006, NECKEL, 2006, OURIQUE et al., 2008, POLETTO et al., 2008, REIS et al., 2006, WEISSANGELI et al., 2008).

Pela combinação de dois polímeros, novos materiais têm sido desenvolvidos com a vantagem de apresentarem propriedades não encontradas em materiais convencionais, sendo conhecidos pelo termo genérico de híbridos poliméricos. Tendo em vista os sistemas de liberação controlada, o desenvolvimento de nanopartículas híbridas polímero natural/polímero sintético desperta interesse, pois estas se apresentam como uma alternativa para a produção de novos materiais multifuncionais que incluem os sistemas de liberação controlada(WEISS-ANGELI et al., 2008).

Método de liberação sustentada de fármacos veterinários é uma área em que pequenas partículas com tamanho (TP) e distribuição de tamanho de partícula (DTP) controlado são requeridas para melhorar/modificar a ação terapêutica de várias drogas. Usando nano partículas, com tamanho controlado, é possível aumentar o período de biodisponibilidade do princípio ativo, tempo de metabolização, diminuir a dosagem terapêutica ou ainda modificar o sistema de distribuição de fármacos intra-corpóreo. Dentre outros, sistemas de liberação oral, implantes subcutâneos e injeções, sejam sub-cutâneas e/ou intra-musculares, são exemplos de aplicações de drogas, que sob a forma de micro e/ou nanopartículas, podem melhorar a eficiência da droga e eliminar efeitos colaterais indesejáveis (REVERCHON, 1999).

Segundo Spinosa, Górniak e Bernardi, a concentração ideal de uma droga deve obedecer uma faixa onde não ocorra uma sub dosagem e conseqüentemente uma super dosagem ou intoxicação. Em um sistema biológico, esta faixa é determinada por vários fatores, sendo em muitos casos, a aplicação de varias dosagens para que o fármaco se mantenha nesta faixa. Medicamentos com os mais variados veículos são produzidos para este fim. Como exemplo, 
medicamentos diluídos em solução aquosa devem ser solúveis em água e sua ação deve ser considerada imediata com variação da via de aplicação.

\subsection{Preparação de Nano partículas}

O processo de preparação de nanopartículas devera ser simples, continuo e eficiente; viável para larga escala; aceito por autoridades regulatórias; e permitir quantidades flexíveis de fármaco. Vários processos tal como moagem úmida, homogeneização sob alta-pressao, emulsificação, expansão rápida e congelamento por atomização podem ser usados para produzir NPs (KHARB et al., 2006), os quais serão descritos a seguir.

\subsection{Moagem úmida.}

O processo envolve atrito do fármaco com uma solução aquosa do fármaco contendo surfactante. $\mathrm{O}$ fármaco e disperso em uma solução aquosa contendo um surfactante e submetido à moagem úmida. $\mathrm{O}$ impacto do fármaco com o meio de moagem gera energia suficiente para converter os cristais do fármaco em NPs. O elemento de moagem geralmente e composto de vidro, oxido de zircônio estabilizado com silicato de zircônio, ou uma resina de poliestireno de alta densidade de forma esférica (0.4-3.0-mm diâmetro). A temperatura do processo e inferior a $40{ }^{\circ} \mathrm{C}$ e pressão aproximada dê20 psi. O tempo de moagem pode levar horas ou dias dependendo da dureza do fármaco. Entre as limitações deste processo estão à contaminação do produto pelo atrito com as esferas e o tamanho variável das partículas (KHARB et al., 2006). Nano cristais de naproxeno foram preparados por moagem úmida; sua biodisponibilidade foi comparada com o NaprosymR (naproxen suspension, Roche, Geneva Switzerland) e AnaproxR (naproxen tablet, Roche). O estudo revelou que o tempo requerido para alcançar a concentração terapêutica máxima reduziu em $50 \%$ para a dispersão dos nano cristais. Paralelamente a área sobre curva 
(ASC) aumentou de 2,5 a 4,5 vezes durante a primeira hora do estudo (LIVERSIDGE; CONZENTINO, 1995).

\subsection{Homogeneização por alta pressão.}

O processo de homogeneização sob alta-pressao e baseado no principio da cavitação, no qual bolhas ou cavidades de vapor são formadas dentro de um liquido, devido à aplicação de determinada pressão e, a implosão destas bolhas gera grande quantidade de energia. No processo de homogeneização, uma pre-suspensão do fármaco (na ordem micrométrica) e preparada por moagem na presença de uma solução de surfactante. A pre-suspensao e sujeita a homogeneização por alta pressão através de passagem através de um pequeno homogeneizador com aproximadamente $25 \mathrm{~mm}$. A forca de cavitação (energia gerada pela implosão das bolhas de vapor) e suficiente para desintegrar o fármaco da ordem de MPs para NPs. A pressão de homogeneização varia entre 100 a 1500 bar a homogeneidade do produto. A principal vantagem da homogeneização por alta pressão e que permite produção em pequena e larga escala, já que diversos modelos de homogeneizadores são disponíveis. Paralelamente, o nível de contaminação do fármaco neste processo e negligenciavel. Uma limitação do processo e que a elevada pressão empregada em muitos casos muda a estrutura cristalina do fármaco. Este efeito leva um aumento da fração amorfa do fármaco. A variação da cristalinidade pode resultar em instabilidade e problemas de controle de qualidade do fármaco. (KHARB et al., 2006). Scholer e colaboradores (2001) mostraram o aumento da biodisponibilidade do AtovaquoneR fármaco usado no tratamento da leishmaniose, por formulação como nanosuspensao. Em comparação com o fármaco micronizado, nano suspensões de Atovaquone em dose equivalente reduziram a inefetividade de 40 para $15 \%$ em uma concentração reduzida de $7,5 \mathrm{mg} / \mathrm{kg}$. A dosagem do fármaco diminuiu de 22,5 (fármaco micronizado) para $7,5 \mathrm{mg} / \mathrm{kg}$ (nano suspensão), mas a atividade aumentou em 2,5 vezes. 


\subsection{Tecnologia da Emulsificação ou nano precipitação.}

A Emulsificação pode ser usada para preparar suspensões de NPs. Neste método, o fármaco - disperso em um solvente orgânico - e disperso em uma fase aquosa contendo surfactante. Esta etapa e seguida de evaporação do solvente orgânico sobre pressão reduzida (rota evaporação), o qual resulta na precipitação de partículas do fármaco para formar uma suspensão de NPs, a qual e estabilizada pela adição de surfactante. A emulsificação não deve ser empregada para fármacos que apresentem baixa solubilidade em ambos os meios empregados (aquoso ou orgânico) (KHARB et al., 2006). A velocidade de dissolução do mitotano, uma agente antineoplasico, preparado em nano supensão por emulsificação aumentou cinco vezes comparada com o produto comercial (TROTTA, 2001). Métodos mais recentes envolvem a formação de NPs a partir de fluidos supercríticos, em emulsões do tipo $\mathrm{H} 2 \mathrm{O} / \mathrm{CO} 2$ supercrítico (neste caso, o surfactante devera ter boa solubilidade em $\mathrm{CO} 2$, com fracas forcas de dispersão das cadeias, como por exemplo, um perfluorpolieter).

\subsection{Congelamento por atomização em líquido (SFL).}

Neste processo, desenvolvido na Universidade do Texas (Austin, TX) e comercializado pela Dow Chemical Company (Midland, MI), uma solução cosolvente aquosa, orgânica ou aquosa-organica; uma emulsão aquosa-organica; ou suspensão do fármaco e atomizado junto a um liquido criogênico tal como nitrogênio liquido para produzir NPs congeladas, as quais são subseqüentemente liofilizadas para obter um pó congelado. $\mathrm{O}$ rápido resfriamento causado pelas baixas temperaturas no nitrogênio liquido e elevado grau de atomização resulta em NPs amorfas. Helio, propano, outros líquidos criogênicos como argônio e diidrofluoroeters ou dióxido de silício podem ser empregados para atomização. (KHARB et al., 2006). NPs de danazol foram produzidas pelo processo SFL. O pó obtido exibiu significativo aumento na velocidade de dissolução, comparado ao danazol micronizado: somente $30 \%$ do danazol micronizado foi dissolvido em 2 minutos, sendo que para as NPs obtidas por SFL foram dissolvidos 95\%. Estudos 
recentes empregaram NPs de danazol/PVP K-15 obtidas por SFL para avaliar a estabilidade em longo prazo e verificaram que elas permaneceram amorfas, mas apresentaram rápida velocidade de dissolução apos seis meses de armazenamento (HU et al., 2004).

\subsection{Precipitação pro evaporação em solução aquosa (EPAS).}

O processo EPAS também foi desenvolvido pela Universidade do Texas (Austin) e comercializado pela Dow Corning. Neste processo, o fármaco disperso em solvente orgânico e aquecido sob pressão em temperatura inferior a temperatura de ebulição do solvente orgânico e então atomizado junto a uma solução aquosa aquecida contendo um surfactante (estabilizante). $\mathrm{O}$ surfactante também pode ser adicionado juntamente com um solvente orgânico para inibir a cristalização e crescimento das partículas. Este processo permite a obtenção de NPs para incorporação em preparação parenteral, ou podem ser secos para produzir formas farmacêuticas solidas. O EPAS foi empregado para produzir NPs de ciclosporina A e danazol, os quais mostraram elevadas velocidades de dissolução. Em estudos recentes, NPs de danazol preparadas pelos processos SFL e EPAS produziram um pó amorfo; NPs obtidas pelo processo SFL apresentaram valores de dissolução superiores aquelas obtidas pelo processo EPAS, embora ambas as metodologias possam ser empregadas (CHEN et al., 2002; CHEN et al., 2004). Os materiais e sistemas nano estruturados formados exibem propriedades e fenômenos físicos, químicos e/ou biológicos significativamente novos e modificados devido a sua escala nanometrica. O objetivo e explorar estas propriedades por meio de controle de estruturas e dispositivos em níveis atômico, molecular e supramolecular e manter a estabilidade de interfaces e a integração dessas nanoestruturas (DURAN et al., 2006).

\subsection{Precipitação com fluido supercrítico (PCA).}


No processo PCA (RTP Pharmaceuticals and licensed to SkyePharma Plc [London, UK]), dióxido de carbono supercrítico e misturado com solvente orgânico contendo o fármaco. O solvente expande no dióxido de carbono supercrítico, aumentando assim a concentração do soluto em solução, resultando em uma solução supersaturada e causando a precipitação do soluto. MPs e NPs são formadas apos a precipitação do fármaco por transferência de massa devido à extração do solvente orgânico junto ao dióxido de carbono. Elevada transferência de massa e importante para minimizar a aglomeração das partículas e reduzir o tempo de secagem (KHARB et al., 2006).

\subsection{Expansão rápida sob uma interface líquido-gás (RESS).}

No processo RESS uma solução ou dispersão de fosfolipídios ou outro surfactante disponível em fluido supercrítico e formado. Assim, rápida nucleação do fármaco e induzida no fluido supercrítico contendo o surfactante (KHARB et al., 2006). Este processo foi usado por Young e colaboradores (2000) para preparar NPs de ciclosporinas na faixa de 500-700 nm. Solução de Tween 80R foi usada como surfactante para prevenir a floculação e aglomeração das NPs.

\subsection{Produção de partículas utilizando fluido super critico}

A aplicação da tecnologia supercrítica, usando o dióxido de carbono como anti solvente, é um processo que tem sido proposto como alternativa para produção de micro ou nanopartículas de fármacos, e produção de fármacos carregados em NPs (carregadores de drogas). Este processo tem se destacado, uma vez que confere qualidades ao produto, tais como: tamanho de partículas submicroscópico, com distribuição de tamanhos controlada, morfologia homogênea, alta 
eficiência de encapsulamento da droga na matriz polimérica e produtos isentos de traços de solventes, entre outros (THIES; MULLER, 1998; REVERCHON et al., 2000a,b).

A aplicação dos solventes, em condição supercrítica, é baseada na observação experimental da característica, que muitos gases apresentam, de melhorar significativamente o seu poder de solubilização, quando submetidos a altas pressões (McHUGH; KRUKONIS, 1994). A combinação das propriedades das fases líquida e vapor, característica do estado supercrítico, ocorre de uma forma extremamente vantajosa, para a utilização dos fluidos supercríticos como solventes. O FSC possui densidade próxima à do líquido (o que fortalece as suas propriedades de solvente). Por outro lado, a viscosidade, a difusividade e a tensão superficial apresentam valores próximos aos do estado gasoso, o que torna as propriedades de transporte bastante favoráveis.

Existem atualmente três rotas para a formação de partículas usando fluidos supercríticos que se diferem pelo modo como o $\mathrm{CO}_{2}$ é usado: como solvente, Rápida Expansão de Soluções Supercríticas (RESS - Rapid Expansion of Supercritical Solutions), como soluto, Partículas a partir de Soluções Saturadas de Gás (PGSS - Particle from gas saturated solution) e a precipitação utilizando o fluido pressurizado (GAS - Gas Anti-Solvent) ou fluido supercrítico (SAS - Supercritical Anti-Solvent) como antisolvente. Esta última podendo receber o nome de Precipitação com Anti-Solvente Comprimido (PCA - Precipitation with a Compressed AntiSolvent), Sistema de Extração de Solvente em Aerosol (ASES - Aerosol Solvent Extraction System) e Dispersão da Solução Aumentada por Fluidos Supercríticos (SEDS - Solution Enhanced Dispersion by Supercritical fluids). Porém, a principal diferença entre estes processos é a maneira como ocorre o contato entre a solução orgânica e o anti-solvente.

A vantagem do uso do $\mathrm{CO}_{2}$ como anti-solvente é a possibilidade de processar uma quantidade maior de soluto. O uso de um fluido anti-solvente compressível é vantajoso, quando comparado com a utilização de anti-solventes líquidos, por causa da facilidade da recuperação do solvente e anti-solvente, secagem ou purificação do precipitado e rápidas taxas de transferência de massa entre o solvente e o anti-solvente (DIXON, 1993). Apesar deste processo utilizar solventes orgânicos e, portanto, requerer a etapa de secagem do precipitado, a técnica de secagem, utilizando fluidos no estado supercrítico, é extremamente vantajosa. Como o solvente líquido é solúvel no fluido supercrítico, não existe a interface líquido vapor durante a retirada do solvente. Assim, as forças de capilaridade ou de superfície são bem menores, o que possibilita a 
remoção do solvente, preservando a estrutura do material precipitado (SRINIVASAN; ELLIOT, 1992).Na Tabela 3 são apresentados alguns polímeros precipitados pelos processos GAS e SAS. 
Tabela 3 - Polímeros precipitados pelos processos GAS e SAS.

\begin{tabular}{|c|c|c|c|}
\hline $\begin{array}{l}\text { SOLUTO } \\
\text { (SOLVENTE) }\end{array}$ & MÉTODO & RESULTADOS OBSERVADOS & REFERENCIA \\
\hline $\begin{array}{l}\text { Etil e Metil Celulose } \\
\text { (DCM e DMSO) }\end{array}$ & GAS & $\begin{array}{l}\text { Blendas dos dois polímeros foram precipitadas em } \\
\text { diferentes condições experimentais e foram obtidas } \\
\text { micro esferas com diâmetros variando entre } 5 \text { e } 30 \mu \mathrm{m} \text {. }\end{array}$ & Duarte et al. (2006) \\
\hline $\begin{array}{l}\text { Poli vinil álcool } \\
\text { (DMSO) }\end{array}$ & GAS e SAS & $\begin{array}{l}\text { As morfologias variaram entre esferas, balões e } \\
\text { filamentos dependendo da técnica. O tamanho médio das } \\
\text { partículas precipitadas variou entre } 50 \text { e } 250 \mathrm{~nm} \text { e entre } 1 \\
\text { e } 20 \mu \mathrm{m} \text { dependendo da técnica e das condições } \\
\text { experimentais. }\end{array}$ & Adami et al. (2007) \\
\hline $\begin{array}{l}\text { metallocene cyclic olefin } \\
\text { (Vários solventes) }\end{array}$ & SAS & $\begin{array}{l}\text { Partículas esféricas ou fibras foram obtidas dependendo } \\
\text { da concentração do polímero nos solventes. Dependendo } \\
\text { da região do diagrama de fases onde a precipitação } \\
\text { ocorreu, diferentes tamanhos de partículas foram obtidos. }\end{array}$ & Chang et al. (2007) \\
\hline $\begin{array}{l}\text { PHBV } \\
(\mathrm{DCM})\end{array}$ & SAS & $\begin{array}{l}\text { Nas diferentes condições investigadas, foram obtidas } \\
\text { partículas na forma esférica com tamanhos variando } \\
\text { entre } 3 \text { e } 9 \mu \mathrm{m} \text { com diferentes graus de aglomeração. }\end{array}$ & Costa et al. (2007) \\
\hline $\begin{array}{l}\text { Polivinilpirrolidona } \\
\text { (DCM e ACE) }\end{array}$ & SAS & $\begin{array}{l}\text { Partículas esféricas com diferentes graus de aglomeração } \\
\text { foram obtidas dependendo da concentração do polímero } \\
\text { no solvente orgânico. O diâmetro médio das partículas } \\
\text { variou entre } 34 \text { e } 678 \mathrm{~nm} \text { dependendo da condição } \\
\text { experimental. }\end{array}$ & Gokhale et al. (2007) \\
\hline $\begin{array}{l}\text { Ácido poli-L-láctico } \\
\text { (DCM) }\end{array}$ & SAS & $\begin{array}{l}\text { Foram obtidas partículas esféricas com diâmetro de } \\
\text { aproximadamente } 1 \mu \mathrm{m} \text { relativamente aglomeradas. }\end{array}$ & Obrzut et al. (2007) \\
\hline $\begin{array}{l}\text { Ácido poli-L-láctico, } \\
\text { poli metacrilato de } \\
\text { metila e poli } \\
\text { caprolactona } \\
\text { (DCM) }\end{array}$ & SAS & $\begin{array}{l}\text { Para todos os sistemas investigados, fibras constituídas } \\
\text { por micropartículas de polímero coalescidas foram } \\
\text { obtidas. As fibras obtidas apresentaram superfície } \\
\text { escamosa e área superficial extremamente alta. }\end{array}$ & González et al.(2008) \\
\hline
\end{tabular}


Na preparação de drogas para liberação controlada o solvente líquido intumesce a matriz polimérica e serve como meio de transporte para a droga. Uma alternativa é substituir o solvente orgânico líquido por um fluído supercrítico, com a vantagem que o produto final é completamente livre de qualquer contaminação por solvente residual. Uma outra vantagem é o efeito plastificante do $\mathrm{CO}_{2}$, que favorece o processo de impregnação devido à diminuição da temperatura de transição vítrea (KIKIC; VECCHIONE, 2003). Para sucesso no processo de impregnação é necessário que a droga (soluto) seja solúvel no $\mathrm{CO}_{2}$. Guney e Akgermn (2000) afirmam que drogas que têm solubilidades na ordem de $10^{-6}$ a $10^{-}$

${ }^{4}$ em fração mássica possuem solubilidade suficiente para fazer do processo de impregnação supercrítica uma alternativa viável aos processos que utilizam solventes orgânicos. A solubilidade da progesterona em $\mathrm{CO}_{2}$ (ALESSI et al., 1996, FAVARETO et al., 2008a) encontra-se exatamente nessa faixa de solubilidade. Portanto, a incorporação da progesterona em polímeros utilizando tecnologia supercrítica só será possível utilizando o processo de impregnação.

BAKER et al. (2005) utilizaram o método de emulsão assistida em $\mathrm{CO}_{2}$ para impregnar progesterona em micropartículas de tamanho de $4 \mu \mathrm{m}$ de poliestireno com a superfície grafitada com poli(N-vinilpirrolidona) a partir de suspensão aquosa do látex emulsificada por $\mathrm{CO}_{2}$ com SAM 185, um surfactante polimérico. Em condições de $25^{\circ} \mathrm{C}$, 310 bar e 24 horas obteve-se resultado de impregnação de $10 \%$ em massa.

\subsection{Equilíbrio de fases relacionado ao processo de precipitação e/ou encapsulamento de partículas em fluidos pressurizados}

A maior parte das publicações referentes à precipitação de sólidos usando técnicas anti-solvente a alta pressão foca os efeitos das condições operacionais tais como temperatura, pressão e taxa de adição de solução e anti-solvente sobre o tamanho e distribuição de tamanho das partículas, bem como na sua morfologia. Todavia, objetivando avaliar a viabilidade de tais processos e otimizar a escolha das variáveis operacionais, o comportamento de fases do sistema envolvido torna-se importante pois permite selecionar 
valores de variáveis como temperatura e pressão que permitem operar em diferentes condições do diagrama de fases do sistema envolvido.

Para qualquer processo de precipitação com fluidos pressurizados existe uma relação entre o mecanismo de cinética de nucleação e crescimento das partículas e o comportamento de fases (BRISTOW et al., 2001). Neste sentido, o comportamento de fases do sistema soluto + solvente + anti-solvente é fundamental visando entender o mecanismo de formação de partículas e para determinar as condições de operação mais satisfatórias durante a aspersão da solução dentro da câmara de precipitação. O conhecimento e o entendimento do comportamento de fases pode ser decisivo para o sucesso da operação uma vez que dependendo da região do diagrama de fases, definida pelas condições de processo, pode ou não haver a formação de partículas.

Abaixo do ponto crítico da mistura soluto+solvente orgânico+anti-solvente, há a coexistência de fases e uma descrição quantitativa requer a modelagem da distribuição da área interfacial, a distribuição de tamanho das micro gotas, a transferência de massa interfacial e a cinética de precipitação. Na vizinhança ou acima do ponto crítico da mistura, onde ocorre completa miscibilidade, a transferência de massa é governada por exemplo, por efeitos de micro misturas necessitando de um conhecimento da distribuição espacial da concentração local do soluto, solvente e anti-solvente (BRISTOW et al., 2001).

Reverchon et al. (2003) observaram que abaixo do ponto crítico de um sistema binário solvente/anti-solvente, uma fase líquida saturada é formada e que grandes cristais são gerados. Acima do ponto crítico da mistura uma fase é formada, sendo que nesta condição um alto nível de supersaturação ocorre formando, conseqüentemente, minúsculas partículas. Estes autores observaram através da análise dos trabalhos publicados que há uma carência de informações na correlação entre a morfologia das partículas e os principais fenômenos que governam o processo: particularmente a dispersão do jato, transferência de massa e equilíbrio de fases. Em alguns casos, o comportamento de fases de sistemas binários solvente/antisolvente pode ser bastante modificado quando o soluto é envolvido no sistema, principalmente em se tratando de polímeros. Neste caso, a relação entre o comportamento de fases e a morfologia do material precipitado muda drasticamente quando se leva em conta apenas o comportamento de fases do sistema binário e não o ternário. Porém, em outros casos a presença do soluto não altera significativamente tal 
comportamento, sendo possível relacionar as características do material precipitado ao comportamento de fases do sistema binário solvente+anti-solvente.

Reverchon e De Marco (2004) generalizaram os resultados obtidos em seu trabalho, assumindo que partículas nanométricas são produzidas quando a precipitação ocorre em uma fase supercrítica à direita e acima do ponto crítico de um sistema ternário. Quando o ponto de operação estiver localizado à direita, mas, abaixo do ponto crítico da mistura ternária, (uma fase subcrítica gasosa fora da curva de equilíbrio) grandes partículas seriam preferencialmente produzidas. Já, quando o ponto de operação estiver localizado abaixo da curva de equilíbrio, (uma fase rica em líquido) seriam produzidas partículas cristalinas. A abordagem baseada em diagramas pseudobinários negligencia o equilíbrio envolvendo o terceiro componente (soluto), assumindo que este precipita das fases fluidas em qualquer que seja sua composição. Em alguns casos, porém, onde o anti-solvente age como um co-solvente, parte do soluto pode manter-se dissolvida no solvente e pode ser perdida na saída do precipitador. Em particular, o chamado efeito de co-solvência pode ocorrer quando uma mistura de dois componentes, solvente + soluto, é mais solúvel em um solvente supercrítico do que cada um dos componentes puros apenas (REVERCHON; DE MARCO, 2004). De Gioannis et al. (2004) estudaram o efeito co-solvente e anti-solvente do $\mathrm{CO} 2$ na solubilidade de griseofulvina em misturas de $\mathrm{CO} 2+$ etanol e $\mathrm{CO} 2+$ acetona. No método utilizado por estes autores (estático sintético), $\mathrm{CO} 2$ é adicionado gradualmente a uma solução líquida (soluto dissolvido em solvente orgânico líquido) previamente introduzida em uma célula de safira de volume variável em diferentes temperaturas e pressões. A solubilidade da griseofulvina nas misturas $\mathrm{CO} 2+$ solventes orgânicos foi determinada pelo método do ponto de precipitação ou de dissolução dependendo se o CO2 diminui ou aumenta a solubilidade do composto no solvente líquido. Estes autores verificaram que a solubilidade deste composto na mistura $\mathrm{CO} 2+$ acetona diminui em todas as condições investigadas quando $\mathrm{CO} 2$ é adicionado. Conseqüentemente, neste caso o CO2 age como um anti-solvente. Entretanto, para a mistura $\mathrm{CO} 2+$ etanol a solubilidade da griseofulvina é maior do que em qualquer um dos solventes puros ( $\mathrm{CO} 2$ ou etanol) dentro de certa faixa de frações molares de $\mathrm{CO} 2$, agindo este como um co-solvente e promovendo a solubilidade do sólido. 
Shariati e Peters (2002), investigando o comportamento de fases do sistema ternário $\mathrm{CO} 2$ + 1-propanol + ácido salicílico, também empregando o método sintético, verificaram o mesmo efeito de co-solvente e anti-solvente do $\mathrm{CO} 2$ conforme citado acima. Estes autores observaram que em baixas concentrações de $\mathrm{CO} 2$, este age como um cosolvente. Conforme a concentração de CO2 no sistema é aumentada, este passa a agir como anti-solvente. Outro fenômeno apresentado neste trabalho é que o efeito de co-solvente exercido pelo $\mathrm{CO} 2$ diminui, à medida que a concentração do soluto sólido no sistema aumenta.

\subsection{PHB e PCL}

Há uma gama de biopolímeros naturais ou sintéticos que podem ser empregados como agentes encapsulantes de compostos bioativos, por apresentarem biocompatibilidade e biodegradabilidade. Dentre os principais destacam-se o ácido poliláctico, policaprolactona, polilactídeo, poli(lactídeo-co-glicolídeo), polietilenoglicol, polivinil álcool, poliidroxibutirato e o co-polímero poli(3-hidroxibutirato-co-hidroxivalerato) (YEO; KIRAN, 2005; COCERO et al.,2009). Os últimos dois polímeros citados acima são produzidos por síntese bacteriana chegando a até $80 \%$ do peso seco da massa bacteriana gerada. Além disso, estes polímeros tem atraído muito interesse devido ao seu alto grau de degradabilidade, chegando a uma degradação efetiva num período de aproximadamente 60 dias além de ser totalmente

biocompatível (BUCCI et al., 2007). A utilização do co-polímero poli(3hidroxibutirato-co-hidroxivalerato) ou simplesmente PHBV no campo da biomedicina vem ganhando muita importância nos últimos anos tanto na engenharia de tecidos como na preparação de sistemas de liberação controlada uma vez que á possível preparar um sistema de liberação de drogas através da degradação gradual da matriz polimérica no organismo e a conseqüente liberação do princípio ativo (SENDIL et al., 1999; BARAN et al., 2002a; CHEN; DAVIS, 2002; CHEN; WU, 2005). Além disto, o co-polímero PHBV foi proposto como matéria-prima na produção de embalagens para a indústria de alimentos. Estas 
embalagens podem conter um princípio ativo impregnado como um agente antioxidante, podendo aumentar a vida de prateleira de produtos alimentícios pela liberação gradual do princípio ativo (BUCCI et al., 2005).

\subsubsection{Polihidroxibutirato-co-hidroxivalerato (PHB-V)}

O estudo de materiais com propriedades de biodegradabilidade e biocompatibilidade aumenta continuamente por razões ecológicas, de reciclagem e também pelo interesse da aplicação destes materiais nas áreas médica e farmacêutica (PICH et al, 2006b). O poli(hidroxibutirato-co-hidroxivalerato) (PHB-V) (Figura XX) é um poliéster copolímero de hidroxi butirato e hidroxivalerato (3HV), pertencente ao grupo dos poli(hidroxi alcanoatos) (PHA) naturalmente sintetizados e acumulados por microorganismos na forma de grânulos intracelulares (GRAGE et al., 2009 ).

O PHBV foi sintetizado pela primeira vez pela ICI (Imperial Chemical Industries) em 1983 e pode ser produzido pela adição de ácido propiônico ao substrato de nutrientes fornecidos às bactérias ou pela modificação de fontes de carbono (VROMAN; TIGHZERT, 2009). A estrutura química do PHBV é apresentada na Figura 7.

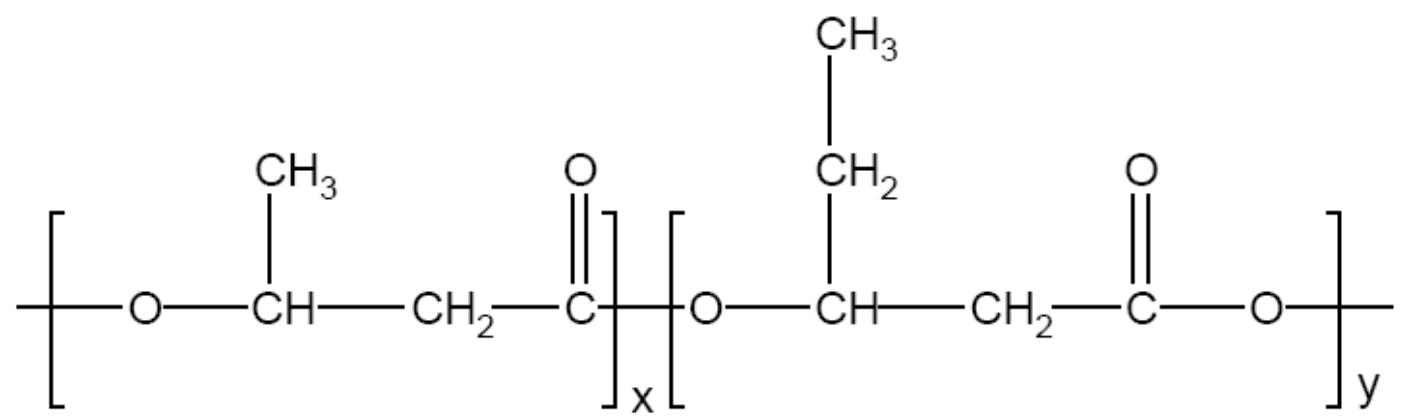

Figura 7 - Estrutura química do PHBV (Fonte: PICH et al., 2006b).

Atualmente, uma variedade de PHBVs com diferentes teores de $3 \mathrm{HV}$, produzidos pela bactéria Ralstonia eutropha, é fabricada com marca registrada BIOPOL $®$ (Monsanto). A empresa brasileira PHB Industrial tem produção de 4 a 5 toneladas mensais, com base na sacarose do açúcar, totalmente voltada para exportação. O desenvolvimento de PHB com 
base na cana-de-açúcar resultou da parceria do Centro de Tecnologia Canavieira (CTC), antigo centro de tecnologia da Copersucar, da Usina da Pedra, do Instituto de Pesquisas Tecnológicas do Estado de São Paulo (IPT) e da Universidade de São Paulo (USP) (CARMIGNAN, 2006; BASTOS, 2007).

Por apresentar biodegradabilidade e biocompatibilidade, o PHBV encontra numerosas aplicações na medicina como implantes, sistemas de liberação controlada de fármacos e engenharia de tecidos (PICH et al., 2006a; FRANCESCHI, et al., 2008; POLETTO et al., 2008; CARMIGNAN, 2006). Quando usado como material de embalagem, o PHBV é degradado num período de 5 a 6 semanas em ambientes microbiologicamente ativos, pela ação de enzimas e/ou deterioração química associada a organismos vivos (VROMAN; TIGHZERT, 2009; SIRACUSA et al., 2008).

\subsubsection{Poli-E-caprolactona (PCL)}

A poli(E-caprolactona) é amplamente empregado em suturas devido a sua biocompatibilidade, sendo um dos mais importantes polímeros biodegradáveis na medicina (LU; CHEN, 2004). Poliésteres como a poli( $\varepsilon$-caprolactona) apresentam propriedades bioadesivas. A bioadesividade confere um acréscimo na deposição das partículas em regiões do trato gastrintestinal, aumentando a absorção sistêmica de fármacos (LAMPRECHT et al., 2000a).

\subsubsection{Características físico-químicas}

A poli( $\varepsilon$-caprolactona) é um poliéster alifático (Figura 8), semi-cristalino, com temperatura de transição vítrea de $-60^{\circ} \mathrm{C}$ e ponto de fusão entre 59 e $64^{\circ} \mathrm{C}$, dependendo da sua natureza cristalina. O peso molecular pode variar entre 10.000 a $80.000 \mathrm{~g} / \mathrm{mol}$. A poli(e-caprolactona) é solúvel em clorofórmio, diclorometano, tetracloreto de carbono, 
benzeno, tolueno, ciclohexano e 2-nitropropano à temperatura ambiente. Apresenta baixa solubilidade em acetona, 2-butanona, acetato de etila, dimetilformamida e acetonitrila, e é insolúvel em álcool, éter de petróleo e éter dietílico. A poli(E-caprolactona) quando empregada em sistemas de liberação de fármacos apresenta como propriedade a alta permeabilidade a substâncias, principalmete, de baixo peso molecular (KIBE, 2001; GIBAUD et al., 2004; SINHA et al., 2004).

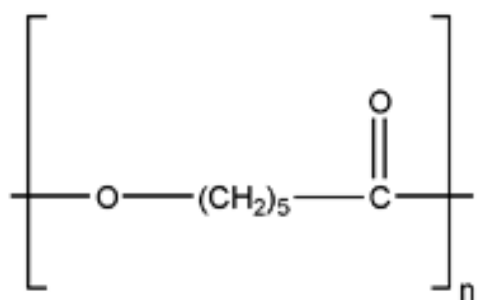

Figura 8 - Fórmula estrutural da poli(\&-caprolactona).

A degradação da poli( $\varepsilon$-caprolactona) em ambientes aquosos é favorecida pelo meio alcalino e pelas altas temperaturas. A degradação ocorre por hidrólise química e/ou enzimática, principalmente da ligação éster. Durante a degradação a diminuição da massa molar é acompanhada por uma ampla distribuição da massa molar e pelo desenvolvimento de picos de baixa massa molar (ELDSÄTER et al., 2000).

\subsubsection{Poli(E-caprolactona) em formas de liberação controlada}

Lamprecht e colaboradores (2000a) caracterizaram micropartículas de três diferentes poliésteres biodegradáveis, poli(ácido lático), poli(ácido lático-co-glicólico) e poli(e-caprolactona). Sulfassalazina e betametasona microencapsuladas foram preparadas por dois métodos de emulsificação/evaporação do solvente (A/O/A ou Sólido/O/A). Os resultados demonstraram que o polímero empregado não influenciou o perfil de liberação das micropartículas, enquanto o método de obtenção (Sólido/O/A) controlou a liberação, diferentemente do método A/O/A. No mesmo ano, Lamprecht e colaboradores (2000b) analisaram ainfluência dos parâmetros tempo de homogeneização e concentração de substância ativa, no tamanho de partícula e na polidispersão, para obtenção de 
nanopartículascontendo albumina sérica bovina através da técnica da emulsão dupla (A/O/A), empregando poli(ácido lático-co-glicólico) e poli(E-caprolactona) como polímeros. A eficiência da encapsulação da substância ativa hidrofílica e o perfil de liberação foram comparáveis para ambos os polímeros. JEONG e colaboradores (2003) avaliaram o efeito da microestrutura cristalina de microesferas de papaverina e poli( $\varepsilon$ caprolactona), preparadas através do método de emulsão dupla (A/O/A), na liberação da substância. A liberação da papaverina foi governada pela microestrutura das micropartículas de poli( $\varepsilon$-caprolactona), sugerindo que a difusão muda de acordo com as condições do processo, como a concentração de polímero, suas características térmicas e seu peso molecular. Quanto maior a concentração de poli(E-caprolactona) empregada, melhor o controle da liberação. O tamanho das micropartículas determinou a liberação, assim como a massa molar da poli(E-caprolactona) empregada, quanto maior, mais rapidamente ocorreu a liberação da papaverina. GIBAUD e colaboradores (2004) estudaram a influência dos polímeros poli(e-caprolactona), Eudragit ${ }^{\circledR}$ RS, Eudragit ${ }^{\circledR}$ L e misturas (blendas) em micropartículas de acetato de fluodrocortisona obtidas por dois métodos de evaporação de solvente, $\mathrm{O} / \mathrm{A}$ e Suspensão/O/A, avaliando os perfis de liberação (tampão fosfato $0,1 \mathrm{M}, \mathrm{pH} 7,4,37^{\circ} \mathrm{C}$ ) em condições sink.

\subsection{Caracterização das partículas}

Qualquer que seja o método empregado para produção de partículas e impregnação é fundamental o conhecimento do comportamento de fases do sistema de interesse para se determinarem as condições de operação mais adequadas. $\mathrm{O}$ desenvolvimento da nanotecnologia depende fundamentalmente do tipo de material, assim como da caracterização de suas propriedades (MANADAS et. al, 2002). Em função de sua natureza coloidal, dificuldades técnicas são encontradas na caracterização físico-química das nano partículas. A caracterização das suspensões engloba a avaliação morfológica, a distribuição de tamanho de partícula, a distribuição de massa molar do polímero, a determinação do potencial Zeta e do $\mathrm{pH}$, a determinação da quantidade de fármaco 
associado as nanoestruturas, a cinética de liberação do fármaco em função do tempo. $\mathrm{O}$ conjunto de informações obtidas pela caracterização destes sistemas pode conduzir a proposição de modelos que descrevam a organização das nano partículas em nível molecular, que será dependente da composição quali-quantitativa das formulações (SCHAFFAZICK et al., 2003).

\subsection{Microscopia de varredura}

As microscopias eletrônicas de varredura (MEV) (HORISAWA, et al.2002; WATNASIRICHAIKUL, et al. 2000) têm sido muito empregadas na obtenção de informações relativas à forma e ao tamanho das nano partículas. A MEV pode permitir também a diferenciação entre nano cápsulas e nano esferas, possibilitando, inclusive, a determinação da espessura da parede das nano cápsulas (ROLLOT et al. 1986; MOSQUEIRA et al., 2000).

Rollot e colaboradores (1986), demonstraram que nanoesferas apresentam forma esférica, com estrutura polimérica sólida, ao passo que, as nanocápsulas são formadas por um fino (cerca de $5 \mathrm{~nm}$ ) invólucro polimérico ao redor do núcleo oleoso.

Gouvender e colaboradores, através de MET, mostraram que a incorporação de quantidades baixas ou elevadas de fármaco não alterou a morfologia de nanopartículas formadas por PLA-bloco-poli(óxido de etileno). Santos-Magalhães e colaboradores33, através de MEV, verificaram a presença de uma segunda população de partículas, com cerca de $2 \mu \mathrm{m}$ de diâmetro, em uma suspensão de nanocápsulas de PLGA, após 3 meses da preparação, a qual apresentava diâmetro inicial de $180 \pm 52 \mathrm{~nm}$.

\subsection{Distribuição de tamanho de partícula}


De uma forma geral, as nanopartículas obtidas através de diferentes métodos, após a preparação, apresentam uma distribuição unimodal, com um baixo índice de polidispersão (CALVO et al., 1996, GOVENDER et al., 1999, AVGOUSTAKIS et al., 2002). Os métodos usuais para a determinação da distribuição de tamanho das nanopartículas consistem em espectroscopia de correlação de fótons e MEV ou MET (LEGRAND et al., 1999). Dependendo da formulação, podem ser verificadas diferenças de tamanho de partículas conforme o método empregado na sua determinação, uma vez que a microscopia eletrônica fornece uma imagem da partícula isolada do meio, enquanto a espectroscopia de correlação de fótons possibilita a determinação do raio hidrodinâmico das partículas em suspensão (HOFFMANN et al., 1997).

têm sido desenvolvidos para a avaliação dos principais fatores que afetam o diâmetro das PA rtículas de sistemas nanoestruturados. Geralmente, as nanopartículas, mesmo preparadas através de diferentes métodos, apresentam diâmetros médios entre $100 \mathrm{e}$ $300 \mathrm{~nm}$ (SCHAFFAZICK et al., 2002, MULLER et al., 2000, HOFFMANN et al., 1997, ARAUJO et al., 1999), no entanto, partículas com diâmetros em torno de 60 a $70 \mathrm{~nm}$ (GOVENDER et al., 2000) ou mesmo inferiores a $50 \mathrm{~nm}$ podem ser obtidas (SEIJO et al., 1990). A composição quali-quantitativa (QUINTANAR-GUERRERO et al., 1996) e o método de preparação das nanopartículas são fatores determinantes do diâmetro médio e da polidispersão das partículas. No caso das nanocápsulas, um fator importante, que influencia o diâmetro das partículas, é a natureza do óleo utilizado como núcleo. Os resultados são atribuídos às diferenças de viscosidade (YU, et al., 1993), hidrofobicidade (LOSA et al., 1993) ou tensão interfacial (MOSQUEIRA et al., 2000) das substâncias empregadas.

Outra observação relevante é que a adição de monômero à emulsão (ROLLOT et al., 1986) (método de polimerização interfacial) ou, ainda, a presença do polímero (LOSA et al., 1993) (método de deposição de polímero pré-formado) podem conduzir à diminuição de tamanho de partícula em relação à emulsão devido, provavelmente, à redução da energia livre interfacial do sistema, no primeiro caso, ou mediante um efeito estabilizador do polímero ao redor das gotículas, no segundo.

Empregando-se o método de polimerização in situ, a presença do fármaco no meio pode alterar (FRESTA et al., 1995) ou não (SEIJO et al., 1990) o diâmetro médio das partículas, uma vez que esse, assim como o tipo de tensoativo empregado, podem interferir 
ou não na síntese e deposição das cadeias oligoméricas formadas (ALONSO et al., 1991). A presença do fármaco no meio reacional influencia o processo de nucleação, conduzindo a partículas maiores com ampla distribuição de tamanho (FRESTA et al., 1995). Em alguns estudos (BRASSEUR et al., 1991, FRESTA et al., 1995, MARCHAL-HEUSSLER et al., 1990, ALONSO et al., 1991), quando o fármaco foi adicionado após o término da polimerização, o tamanho destas não foi alterado pela sua associação. Utilizando-se o método de precipitação de polímeros pré-formados, a presença do fármaco na fase orgânica, antes da precipitação do polímero em meio aquoso, também pode (GOVENDER et al., 1999) ou não (GUTERRES et al., 1995, SCHAFFAZICK et al., 2002) influenciar o diâmetro médio de partículas.

É importante mencionar que a tendência à agregação e sedimentação das nanopartículas dispersas, em função do tempo, pode ser monitorada pela determinação de mudanças na distribuição de tamanho de partículas (CALVO, et al., 1996, MOLPECERES et al., 1997, GUTERRES et al., 1995).

\subsection{Calorimetria exploratória diferencial, difração de raios $\mathrm{X}$ e espectroscopia no infravermelho}

Os métodos termo-analíticos, tais como calorimetria exploratória diferencial (DSC), são de grande utilidade para a análise de polímeros (GEDDE, 1990), e têm sido utilizados também para investigar interações entre os polímeros e os fármacos em diversas formulações de microesferas103 e nanopartículas (CALVO, et al., 1996, GAMISANS et al., 1999). Deste modo, informações úteis podem ser obtidas a respeito da morfologia do polímero cristalino e sobre o estado de dispersão sólida ou molecular do fármaco associado a estes sistemas poliméricos (MAGENHEIM; BENITA, 1991, BARKAI, et al., 1990). Análises através de DSC têm sido utilizadas também para estudar as interações intermoleculares entre fármacos e adjuvantes, sendo de grande utilidade em estudos de préformulação, na medida em que podem ser obtidas informações sobre potenciais incompatibilidades físicas ou químicas entre o fármaco e os adjuvantes (VENKATARAM 
et al., 1995). Também é possível investigar reações químicas, como polimerização, depolimerização e degradação (GEDDE, 1990). A caracterização do estado físico de indometacina associada a nanocápsulas e a nanoesferas de PCL, realizada por DSC e difração de raios $X$, indicou que o fármaco está disperso molecularmente na matriz polimérica (CALVO et al., 1996). Adicionalmente, através do uso de espectroscopia no infravermelho, foi verificada a ausência de reações químicas entre a indometacina e o polímero. Empregando-se DSC, raios X e espectroscopia no infravermelho também foi verificado que o diclofenaco sódico estaria disperso molecularmente em nanoestruturas preparadas com uréia-formaldeído105. Ainda, através de DSC e raios X (VERGER et al., 1998), foi verificado que um fármaco anti-hipertensivo diidropiridínico estaria molecularmente disperso na matriz de nanoesferas, preparadas com PCL, PLA ou PLGA. Além do emprego de DSC na elucidação da forma de associação dos fármacos às nanoestruturas, esta técnica também pode ser aplicada na obtenção de informações a respeito da organização de outros componentes das formulações nestes sistemas. Assim, análises por DSC (MULLER et al., 2001) permitiram propor que o monoestearato de sorbitano, um tensoativo, estaria dissolvido no núcleo oleoso (triglicerídeo dos ácidos cáprico e caprílico) das nanocápsulas de PCL. No caso das nanoesferas, foi proposto um sistema bifásico polímero-tensoativo, onde o monoestearato de sorbitano estaria disperso na matriz polimérica.

\subsection{Potencial Zeta}

O potencial Zeta reflete o potencial de superfície das partículas, o qual é influenciado pelas mudanças na interface com o meio dispersante, em razão da dissociação de grupos funcionais na superfície da partícula ou da adsorção de espécies iônicas presentes no meio aquoso de dispersão (MAGENHEIM; BENITA, 1991;MOSQUEIRA, et al. 2000). Este parâmetro é determinado utilizando-se técnicas de eletroforese (HOFFMANN, et al.1997, CALVO, et al. 1997)

Ele é calculado pela seguinte equação: 


$$
\zeta=f_{H} \eta \nu_{e} / \varepsilon_{r} \varepsilon_{0} E
$$

em que $\zeta$ : potencial zeta; $f_{\mathrm{H}}$ : constante de Henry; $\mu$ : viscosidade do eletrólito; $v_{e}$ : velocidade eletroforética $; \xi_{\mathrm{r}}$ : constante dielétrica; $\xi_{\mathrm{o}}$ : permitividade $E$ : campo elétrico $v_{\mathrm{e}} / E$ : mobilidade eletroforética.

Os fosfolipídeos (lecitinas), os poloxamers (copolímeros dos óxidos de etileno e de propileno) e os polímeros constituintes das nanopartículas são os principais componentes presentes nas formulações capazes de influenciar o potencial zeta. Especialmente os poliésteres, como o PLA, e as lecitinas fornecem um potencial negativo à interface, enquanto que, os poloxamers (tensoativos não-iônicos) tendem a reduzir o valor absoluto deste parâmetro (LEGRAND, et al. 1999).

Calvo e colaboradores prepararam nanoemulsões e nanocápsulas de PCL, nas quais quitosana (um polissacarídeo catiônico) foi incorporada às formulações para fornecer potencial de superfície positivo às partículas $(\mathrm{z}=+37 \mathrm{mV} \mathrm{a} \mathrm{z}=+61 \mathrm{mV})$, objetivando facilitar a interação destas com as membranas biológicas fosfolipídicas, além de prevenir a desestabilização das nanoestruturas de poliéster devido à adsorção de cátions e proteínas catiônicas presentes nos fluidos biológicos.

A determinação do potencial zeta também pode ser útil na elucidação do mecanismo de associação de fármacos às nanopartículas (CHASTEIGNER et. al., 1995, ALONSO et. al., 1991). Um exemplo desta abordagem é o trabalho de Alonso e colaboradores, em que o potencial zeta de nanoesferas de poli(cianoacrilato de butila) foi determinado para se determinar, o mecanismo pelo qual o fármaco, sulfato de amicacina, e este polímero interagem. Neste trabalho, foi verificado que, quando o fármaco foi adicionado às nanopartículas em quantidades crescentes, a redução, em módulo, do potencial Zeta foi concordante com o aumento da taxa de associação do fármaco, sugerindo os autores, que ocorreu uma interação eletrostática entre o fármaco e o polímero.

Estudos comparativos entre nanocápsulas, nanoesferas e nanoemulsão foram realizados para a proposição de modelos descritivos da organização destas nanopartículas. 
Calvo e colaboradores (1997) observaram os efeitos da composição das diferentes formulações sobre os valores do potencial zeta. Foi verificado que a presença da fase oleosa, nas nanocápsulas e nanoemulsões, conferiu a estas um potencial zeta mais negativo $(\mathrm{z}=-41,94 \mathrm{mV}$ e $\mathrm{z}=-42,32 \mathrm{mV}$, respectivamente) em relação às nanoesferas $(\mathrm{z}=-16,33$ $\mathrm{mV}$ ). Tendo em vista a semelhança dos resultados obtidos para nanocápsulas e nanoemulsões, os autores sugeriram que a camada polimérica ao redor das gotículas de óleo seria um delgado filme polimérico. Com o mesmo objetivo, Losa e colaboradores determinaram valores de potencial zeta similares para nanocápsulas e nanoemulsões, concluindo que a camada polimérica ao redor das gotículas de óleo poderia não ser contínua. Por outro lado, Mosqueira e colaboradores (2000) não observaram alteração do valor do potencial zeta em função da natureza do núcleo oleoso (triglicerídeo dos ácidos cáprico e caprílico, succinato de diglicerila dos ácidos cáprico e caprílico, dicaprilato/dicaprato de propilenoglicol, oleato de etila, óleo mineral, dodecano, óleo de soja) utilizado para a preparação de nanocápsulas de PLA, concluindo que o óleo deveria estar completamente encapsulado pelo polímero. Além disto, sugeriram, através de comparações dos valores de potencial zeta de diferentes formulações, que a lecitina, utilizada como tensoativo, poderia estar localizada na superfície externa do polímero ou misturada com o filme polimérico ao redor do núcleo oleoso.

\subsection{Liberação in vitro}

Segundo Soppimath et al., (2001), a liberação dos fármacos a partir de sistemas nano particulados poliméricos depende de diferentes fatores:

a) da difusão do fármaco na superfície das partículas;

b) da difusão do fármaco através da matriz das Nanoesferas;

c) da difusão através da parede polimérica das nanocapsulas;

d) da erosão da matriz polimérica ou

e) da combinação dos processos de difusão e erosão. 
Métodos como a difusão em sacos de diálise e a separação baseada na ultracentrifugação, na filtração à baixa pressão ou na ultra filtração - centrifugação, têm sido utilizados para este fim.

Bain; Munday e Smith (1999) Compararam dois métodos de liberação in vitro de microesferas de poly(d,l-lactide) (PDLLA) utilizando solução tampão em ph fisiológico (ph 7,4) contendo 0,1\% w / v de Tween80. Em um Método( A). $10 \pm 2.0 \mathrm{mg}$ de microesferas, foi adicionado $100 \mathrm{ml}$ solução pré-aquecid a $37 \pm 5{ }^{\circ} \mathrm{C}$, foram agitadas horizontalmente a 1,5 Hz em garrafas hermeticamente fechadas. Amostras foram retiradas e Um volume idêntico foi reposto por meio da seringa anexada. Droga liberada foi determinada por HPLC. (BAIN et al. 1998). Em outro método (B). $50 \pm 5.0 \mathrm{mg}$ de microesferas foram mergulhados em $500 \mathrm{ml}$ de solução agitados a $100 \mathrm{rpm}$ utilizando o aparelho USP tipo II (Sotax AT7, Basileia, Suiça) mantido a 33; 35; 37 e $39{ }^{\circ} \mathrm{C}$ e em 30, 50 e $75 \mathrm{rpm}$. As amostras foram dosadas por espectofotometria em 330nm. Concluíram que a a técnica utilizada para determinação da liberação in vitro, interfere na mesma. A utilização do sistema USP, liberou mais o fármaco. Outro dado interresante deste estudo, foi que a temperatura e a velocidade de rotações por minuto alteraram positivamente o padrão de liberação, corroborando com os dados encontrados por Perale et al. (2009) trabalhando com PCL. Ambos concluíram que o aumento da temperatura e RPM, aumenta a degradação das partículas, liberando mais rapidamente o farmaco encapsulado. Perale, et al. (2009) também identificaram que o peso molecular alterou o perfil de liberação do fármaco 
Capitulo 3 


\subsection{INTRODUÇÃ̃O}

Nesta seção são apresentadas as descrições dos materiais utilizados, do aparato experimental e do procedimento para a obtenção dos dados experimentais de equilíbrio de fases, de precipitação e de impregnação.

\subsection{OBJETIVOS}

Empregar o processo SAS (Fluídos Supercríticos como Anti-Solventes) para a produção de nanopartículas de poli hidroxibutirato com Valerato (PHB-V) + Progesterona $\left(\mathrm{P}_{4}\right)$ e Poli- $\in$-caprolactona (PCL)

\subsection{PRODUÇÃO DAS PARTÍCULAS}

\subsubsection{Materiais e Métodos}

Na Tabela 4 são apresentadas as procedências e as purezas dos componentes químicos utilizados neste trabalho:

Tabela 4 - Características das substâncias usadas.

\begin{tabular}{lll}
\hline Componente & Procedência & Pureza \\
\hline Dióxido de Carbono & White Martins & $99,9 \%$ \\
Clorofórmio & VETEC & $99,8 \%$ \\
Progesterona & Genix Indústria Farmacêutica Ltda & $99,9 \%$ \\
PHB & PHB Industrial S.A. & $99 \%$ \\
PCL & PHB Industrial S.A. & $99 \%$ \\
Hexano PA & f. Maia ind. e com. Ltda & $99,9 \%$ \\
\hline
\end{tabular}


Foi utilizadas duas partidas do polímero PHB-V (FE 110 e FE 113) (PHB INDUSTRIAL S.A. Serrana- SP Brasil) de massas molares de 379,160 g/mol e 214,589 g/mol, respectivamente. Os polímeros das micro-partículas (MPs), PHB-V2; PHB-V3; PHB-V1/PCL; PHB-V2/PCL e PHB-V3/PCL foram submetidos a um processo de purificação que consistiu em:. Quinze gramas do polímero dissolvidos em $300 \mathrm{~mL}$ de clorofórmio $\left(\right.$ VETEC $^{\circledR}$, P.A 99,8\%) sob agitação e temperatura de $60{ }^{\circ} \mathrm{C}$. Após a solução ser filtrada adicionou-se lentamente hexano até a precipitação do polímero. Como controle, utilizaram-se as micro-partículas PHB-V1, constituídas da própria amostra de PHB-V não precipitada, ou seja, o PHB-V em forma de pó como recebido da PHB Industrial S.A.

\subsubsection{Equilíbrio de fases}

As medidas experimentais de equilíbrio de fases a altas pressões, realizadas neste trabalho, foram conduzidas em uma célula de volume variável com visualização, baseada no método estático sintético, (SANTOS et al. 2006, FAVARETO et al. 2008a, FAVARETO et al. 2008b, TAKEUCHI et al. 2008, MOURA et al. 2009). A unidade experimental está esquematicamente representada na Figura 9, e consiste basicamente de uma célula de equilíbrio, com duas janelas de safira, uma para observação visual, com 2,5 centímetros de diâmetro e outra para entrada de luz, com 1,5 centímetros de diâmetro, um transdutor de pressão (Smar LD 301) para faixa de pressão de 0 a 400 bar e precisão de 0,1 bar, um programador portátil (Smar, HT 201), para a aquisição de dados de pressão e uma bomba tipo seringa (ISCO 260D), com volume de $260 \mathrm{~cm}^{3}$ e pressão de até 500 bar. 


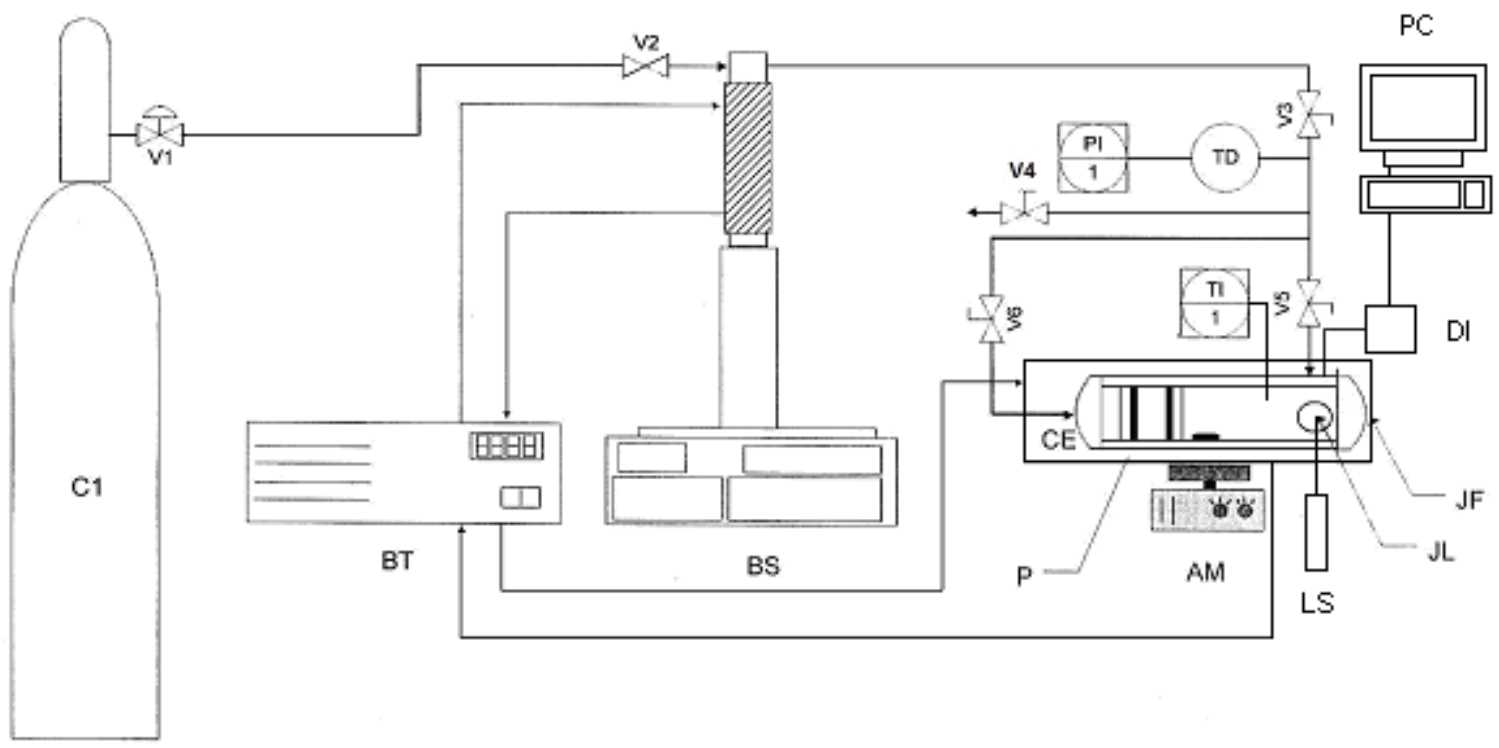

Figura 9 - Diagrama esquemático do aparato experimental de medidas de equilíbrio de fases.

A célula de equilíbrio tem um volume interno de $25 \mathrm{~cm}^{3}$ e contém um pistão móvel, que permite controlar a pressão no interior da célula. As transições de fases foram registradas como pontos de bolha ou pontos de orvalho variando a pressão por temperatura constante. A célula é conectada a um banho de água e um controlador PID (DIGI MEC marca, modelo SHM 112). O controlador foi conectado a um termopar (PT-100, com uma precisão de $0,1 \mathrm{~K}$ ), que está em contato direto com a mistura dentro da célula de equilíbrio. A temperatura controlada tem uma precisão de $1 \mathrm{~K}$.

Uma quantidade de solução estoque de clorofórmio com PHB-V ou PHBV/PCL foi pesada em uma balança de precisão (MARTE AM-220, com precisão 0,0001 g) e carregada no interior da célula. Antes da adição do $\mathrm{CO}_{2}\left(\right.$ White Martins $\left.{ }^{\circledR}\right)$ todas as linhas e a célula foram evacuadas com $\mathrm{CO}_{2}$, à baixa pressão para remover o ar residual. Em seguida, o $\mathrm{CO}_{2}$ foi bombeado para a célula, a fim de chegar à composição global desejada, monitorando o volume da bomba de alta pressão. Com base nas incertezas das massas introduzidas tem-se uma precisão de $1 \%$. Em seguida, a mistura no interior da célula foi mantida em contínua agitação com um agitador magnético (IKA RH basic 1) e uma barra de agitação revestidos de teflon. Após atingir a temperatura desejada, a pressão foi aumentada pela aplicação de pressão sobre a parte de trás do pistão, com a bomba de seringa, até observação de uma única fase. Neste ponto, o sistema foi deixado a estabilizar por 30 minutos. Mantendo-se a temperatura constante e a solução sob agitação, a pressão foi vagarosamente reduzida até que ocorra o turvamento ou 
formação de bolhas, sendo registradas transições de equilíbrio de fases do tipo líquidovapor (ELV) e do tipo sólido-líquido-vapor (ESLV).

Este procedimento foi repetido 3 vezes para avaliar a reprodutibilidade da metodologia experimental e obter um valor médio de temperatura e de pressão para as transições de fases observadas.

\subsubsection{Produção das microparticulas (MPs).}

Para a precipitação do PHBV foi utilizado o equipamento Super Particle SAS Model 200 da marca THAR. (Figura 3)

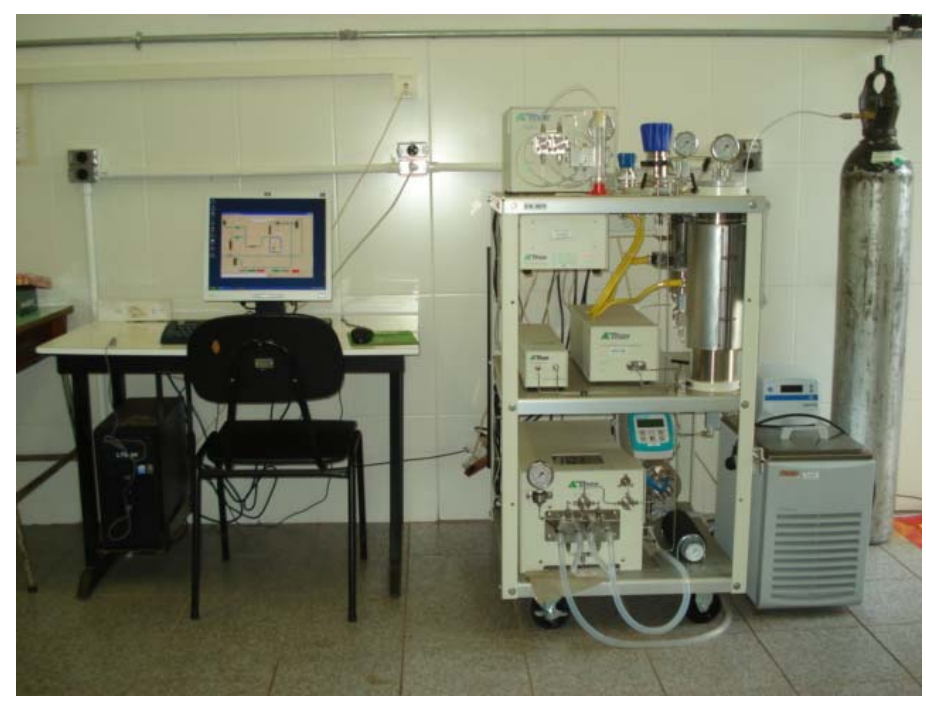

Figura 10 - Foto ilustrativa do equipamento SAS/SEDS.

O equipamento consiste de duas bombas de alta pressão (uma para alimentação do anti-solvente e outra para a solução contendo o soluto), uma câmara de expansão, duas válvulas reguladoras de pressão (uma para o anti-solvente e outra para a solução), para garantir o controle de pressão, um banho termo-estabilizado, para liquefazer antisolvente, antes de ser enviado à bomba, um medidor de fluxo, para monitorar a vazão mássica do anti-solvente e um software para o controle e monitoramento de temperatura, vazão e pressão.

O aparato experimental sofreu algumas modificações reversíveis, para aumentar a turbulência na câmara de expansão. Deste modo, o anti-solvente é alimentado perpendicularmente (método SAS) e/ou coaxialmente (método SEDS) em relação à solução contendo o soluto. $\mathrm{O}$ equipamento opera com alimentação de soluto e 
solvente em modo contínuo. A solução líquida contendo o soluto é introduzida na câmara por uma bomba de alta pressão (THAR P-50), com pressão controlada por meio de uma válvula reguladora de pressão (Swagelok modelo KPB1S0A415P20000). A solução é injetada na câmara via um tubo capilar de sílica fundida. O anti-solvente primeiramente passa por um trocador de calor acoplado a um banho termostatizado (THERMO, série NESLAB RTE), mantido à baixa temperatura, para liquefazer e ser bombeado para a bomba de alta pressão (THAR P-350), monitorado por um medidor de vazão mássica (SIMIENS, modelo MSS6000). Antes de entrar na câmara de expansão, o anti-solvente é aquecido até a temperatura desejada, em um trocador de calor elétrico, ligado a um controlador de temperatura.

A câmara de expansão é um recipiente cilíndrico de aço inoxidável com um volume interno de 2000 1. No fundo da câmara de expansão há um filtro de aço posicionado para recolher as partículas produzidas e permitir o fluxo do anti-solvente. A temperatura da câmara de expansão é controlada por uma jaqueta de aquecimento elétrica. A pressão na câmara é controlada por uma válvula automática reguladora de pressão e sua medida pode ser acompanhada por um manômetro analógico. A mistura de solventes orgânicos proveniente da solução e o anti-solvente é separada em uma segunda câmera de aço inox com $500 \mathrm{~mL}$, pressurizada à 10 bar. A pressão no separador é monitorada por um manômetro analógico e controlada por uma válvula reguladora de pressão (GO, modelo BP3-1A11B5I111). Após a produção das micro e nano partículas, utiliza-se o anti-solvente no processo de secagem, na mesma vazão estabelecida do processo de expansão, durante o período de 20 minutos.

As bombas de anti-solvente e solução, assim como o módulo controlador de temperatura e a válvula automática reguladora de pressão possuem portas RS232, sendo conectados a um computador e controlados via interface da própria THAR.

As condições operacionais para produção das MPs de PHB-V e PHB-V/PCL estão descritas nas tabelas 5 e 6.

Tabela 5 - Condições operacionais do processo para expansão dos polímeros PHBV.

\begin{tabular}{ll}
\hline Condições operacionais & Variáveis \\
\hline Pressão na câmara de expansão (bar) & $85-145$ \\
Concentração da solução (mg/mL) & $5-10$ \\
Vazão de solução (mL/min) & $5-10$ \\
Vazão de $\mathrm{CO}_{2}(\mathrm{~g} / \mathrm{min})$ & $80-160$ \\
Massa molar do PBHV $(1000 \mathrm{x} \mathrm{g/mol})$ & $214-379$ \\
\hline
\end{tabular}


Tabela 6 - Condições operacionais para expansão da blendas de PHBV/PCL.

\begin{tabular}{ll}
\hline Condições Operacionais & Variaveis \\
\hline Pressão na câmara de expansão (bar) & $85-145$ \\
Concentração da solução (mg/mL) & $5-10$ \\
Vazão de solução (mL/min) & $5-10$ \\
Vazão de $\mathrm{CO}_{2}(\mathrm{~g} / \mathrm{min})$ & $80-160$ \\
Percentagem mássica de PCL & $20-50$ \\
Massa molar do PBHV $(1000$ x g/mol) & $214-379$ \\
\hline
\end{tabular}

\subsubsection{Impregnação de Progesterona nas MPs}

Os experimentos de impregnação foram realizados no mesmo aparato experimental de medidas de equilíbrio de fases, conforme apresentado esquematicamente na Figura 2, com a diferença de não se utilizar o pistão, por se tratar de um experimento a pressão constante. A finalidade de se trabalhar sem o pistão é ter um maior volume, $35 \mathrm{~cm}^{3}$, da célula, sendo a pressão controlada diretamente pela bomba tipo seringa (ISCO 260D) conectada à célula.

Os experimentos foram conduzidos pesando-se 3,0 g de partículas em uma balança de precisão (MARTE AM-220, com precisão 0,0001 g) e carregando-as ao interior da célula. As partículas utilizadas como controle foram constituídas da própria amostra de PHBV não precipitada, ou seja, o PHBV em forma de pó como recebido da PHB Industrial S.A. sem nenhum tratamento. Esta amostra foi denominada PHB-V1. As demais amostras PHB-V2; PHB-V3; e as blendas de PHB-V e PCL, PHB-V1/PCL; PHB-V2/PCL; PHB-V3/PCL. Após carregarem-se as partículas, introduziu-se a progesterona, envolvida por algodão com o objetivo desta não entrar em contato direto com as partículas.

Conectou-se a célula ao banho de água e à bomba tipo seringa passando-se $\mathrm{CO}_{2}$ a baixa pressão pela linha para remover todo o ar residual. Após isto, o $\mathrm{CO}_{2}$ foi bombeado para a célula, monitorando-se a pressão pelo transdutor de pressão (Smar LD 301) e o programador portátil (Smar, HT 201) até que se atinja a pressão préestabelecida. Com o controlador PID (DIGI MEC marca, modelo SHM 112) conectado a um termopar (PT-100, com uma precisão de $0,1 \mathrm{~K}$ ) no interior da célula ajustou-se a temperatura.

Ao atingir a temperatura e a pressão pré-estabelecidas para o experimento iniciou-se a contagem do tempo até atingir o período desejado. Após este 
período, descarregou-se o $\mathrm{CO}_{2}$ da célula e coletaram-se as amostras das partículas do polímero impregnado com a progesterona.

\subsubsection{Determinação da quantidade de progesterona na amostra}

Para quantificar a progesterona impregnada no polímero, utilizou-se a espectrofotometria de UV. Na Figura 11, encontra-se o pico de absorção, em 240 nm, para a solução de progesterona em álcool etílico.

A progesterona impregnada nos polímeros foi extraída utilizando etanol à temperatura ambiente, sob agitação, durante 24 horas.

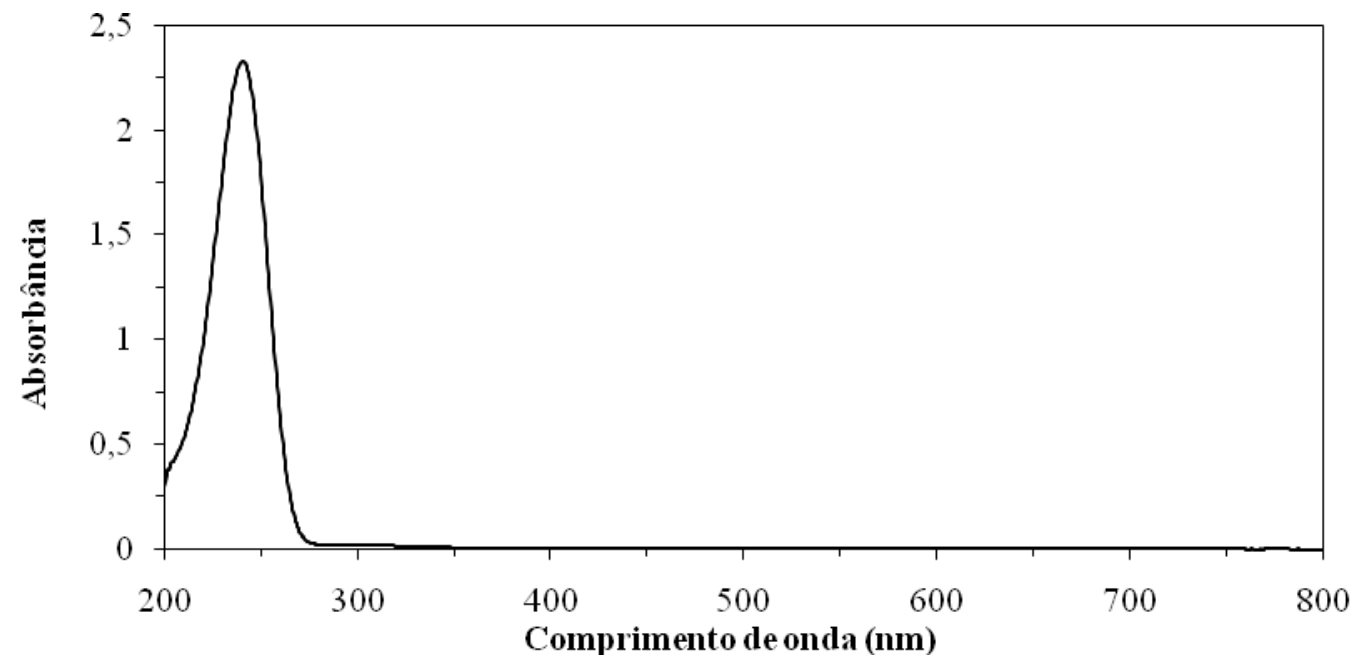

Figura 11 - Varredura de UV-Vis de progesterona em álcool etílico.

Na Figura 12, encontra-se a curva de calibração, com os valores de absorção e concentração de progesterona em álcool etílico. 


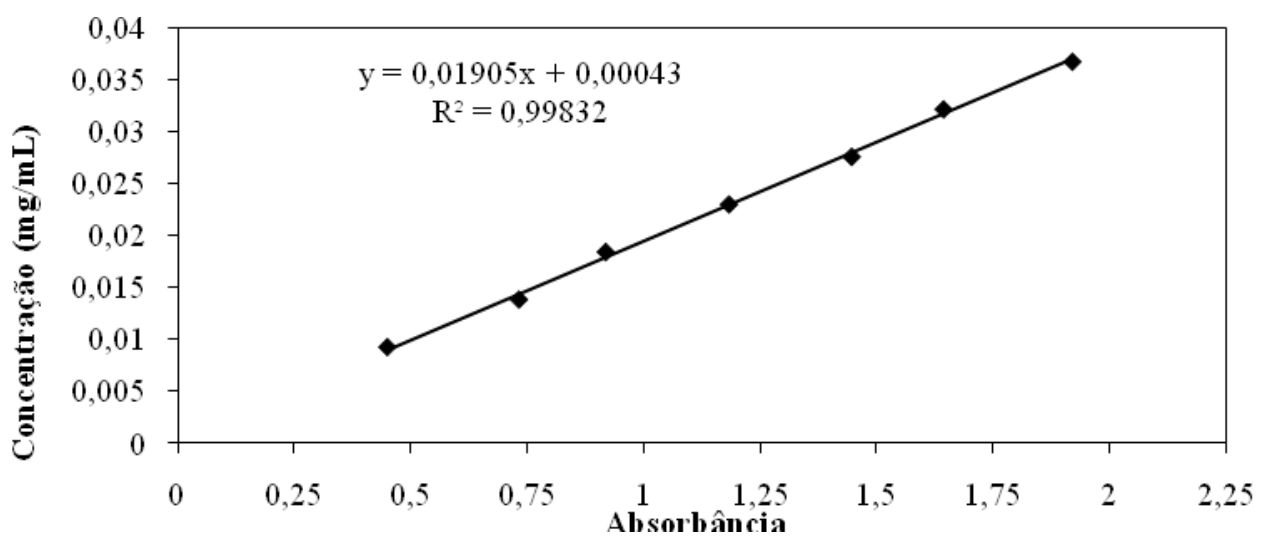

Figura 12 - Curva de calibração de progesterona em álcool etílico.

\subsection{RESULTADOS E DISCUSSÃO}

O conhecimento do comportamento de fases dos sistemas envolvidos nos processos de precipitação e de impregnação é de fundamental importância. Portanto, antes de realizar esses processos o comportamento de fases do sistemas $\mathrm{CO}_{2}+$ Progesterona e $\mathrm{CO}_{2}+$ Mitotano foi estudado.

Além do comportamento de fases dos sistemas publicados, foram realizadas medidas experimentais de equilíbrio de fases envolvendo $\mathrm{CO}_{2}$, clorofórmio e PHBV. A Figura 4 contem os resultados de transição de fases para os sistemas binários $\mathrm{CO}_{2}(1)+$ clorofórmio (2) e ternário $\mathrm{CO}_{2}(1)+$ clorofórmio (2) + PHBV (3) na faixa de temperatura de $30^{\circ} \mathrm{C}$ à $60^{\circ} \mathrm{C}$. 


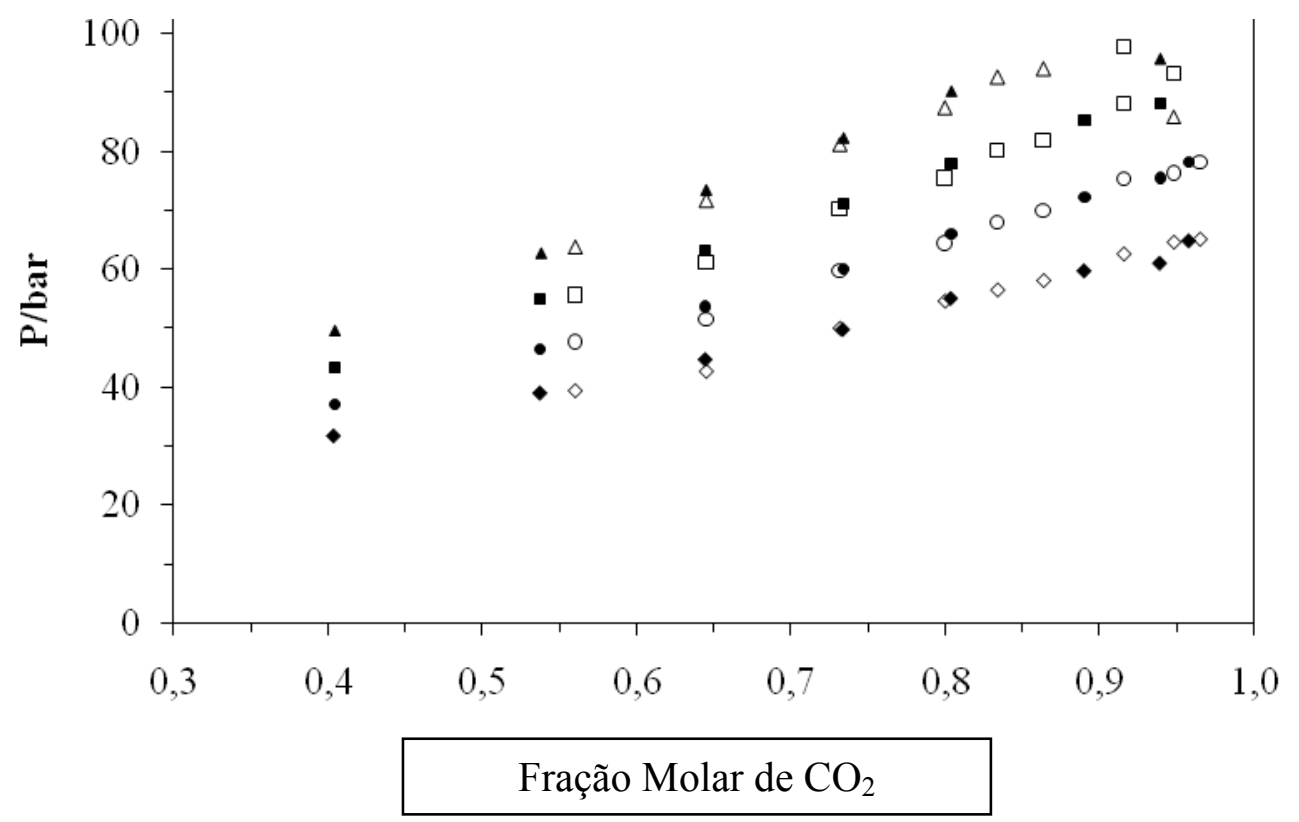

Figura 13 - Diagrama P,x,y para o sistema binário $\mathrm{CO} 2(1)+$ clorofórmio $(2) ; \diamond 30^{\circ} \mathrm{C}, \circ 40^{\circ} \mathrm{C} \mathrm{K}$, $50{ }^{\circ} \mathrm{C}, \triangle 60^{\circ} \mathrm{C}$ (FAVARETO et al., 2008b) e ternário CO2 (1) + clorofórmio (2) + PHBV (3) $\bullet, 30^{\circ} \mathrm{C}$, $\bullet, 40{ }^{\circ} \mathrm{C} \square, 50{ }^{\circ} \mathrm{C}, \triangle, 60{ }^{\circ} \mathrm{C}$ este trabalho.

A partir da Figura 13, observou-se que a presença de PHB-V não interfere nos valores de pressão de transição de fases no sistema binário $\mathrm{CO}_{2}(1)+$ clorofórmio (2), descrito por Favareto et al., 2008b, na faixa de temperatura de 30 à $60{ }^{\circ} \mathrm{C}$, quando comparados com os dados experimentais para o sistema ternário $\mathrm{CO}_{2}(1)+$ clorofórmio (2) + PHBV (3).

Os resultados de transição de fases da Figura 4 permitiram selecionar as condições de temperatura, de pressão e de concentração com segurança, para o processo de expansão do polímero. Já a seleção das condições de temperatura, de pressão e de concentração para o processo de impregnação da progesterona no polímero foram baseadas nas simulações das isotermas para o sistema CO2 (1) + progesterona (2), usando as equações de estado Peng-Robinson ((FAVARETO et al., 2008a), para a fase fluída e Rodrigues-Reartes (RODRIGUEZ-REARTES et al., 2007), para a fase sólida e os dados experimentais de transição de fases medidos. Na Figura 14 encontra-se o diagrama de solubilidade da progesterona em função da pressão. 


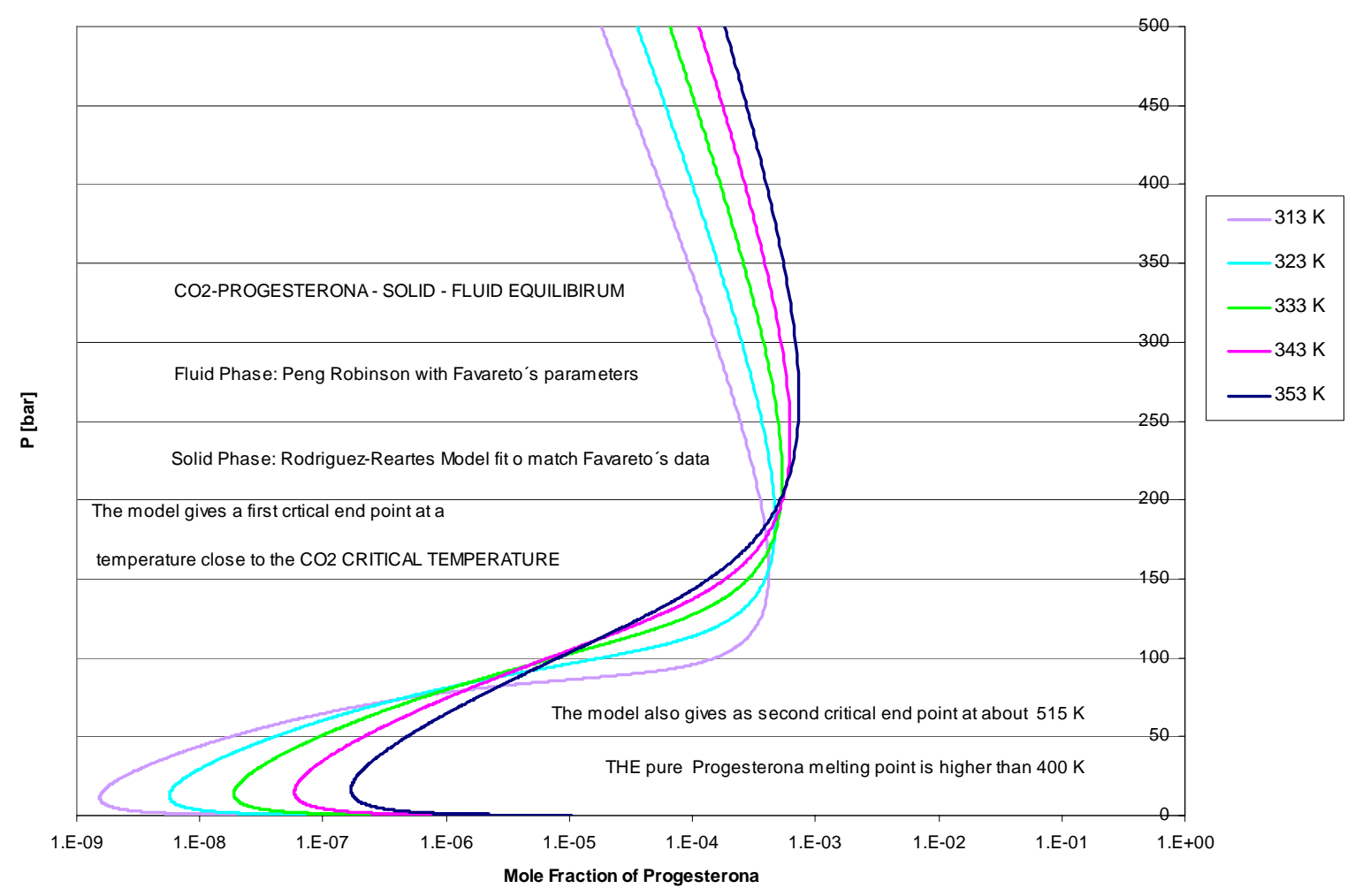

Figura 14 - Isotermas de solubilidade de progesterona em CO2.

Para medidas de equilíbrio de fases de progesterona em uma solução orgânica e $\mathrm{CO}_{2}$, mediu-se a solubilidade da progesterona em quatro diferentes solventes: Clorofórmio, álcool etílico, acetato de etila e dimetilformamida. Na Tabela 7 encontrase a média dos dados experimentais de solubilidade de progesterona, na temperatura de $25{ }^{\circ} \mathrm{C}$, para os solventes orgânicos testados.

Tabela 7 - Dados experimentais de solubilidade de progesterona em solventes orgânicos.

\begin{tabular}{lll}
\hline Solvente & Solubilidade (g/g solução) & Desvio \\
\hline Clorofórmio & 0,5155 & 0,0017 \\
Álcool etílico & 0,0826 & 0,0002 \\
Acetato de etila & 0,1055 & 0,0035 \\
Dimetilformamida & 0,1998 & 0,0029 \\
\hline
\end{tabular}

Os experimentos de expansão de PHBV de soluções em clorofórmio, utilizando $\mathrm{CO}_{2}$ supercrítico como anti-solvente, foram conduzidos de modo a se obterem as melhores condições de operações para obtenção de micro partículas de PHBV. Foram avaliadas as condições operacionais de volume da câmera de expansão, o diâmetro do capilar, a concentração da solução, a vazão da solução, a vazão de $\mathrm{CO}$, e o tempo de despressurizarão, para os polímeros de PHBV das partidas FE100 e FE113, usando alimentação do anti-solvente perpendicularmente (método SAS) e/ou 
coaxialmente (método SEDS), em relação à solução contendo o soluto. Objetivou-se avaliar a morfologia, a dimensão e distribuição granulométrica das partículas produzidas. Na Tabela 8, encontram-se os valores das condições operacionais de cada ensaio experimental de expansão realizado.

Tabela 8 - Experimentos de Precipitação.

\begin{tabular}{|c|c|c|c|c|c|c|c|c|c|}
\hline Exp. & Processo & Pol. & Sol. & VC & DC & CS & Qsol & $\mathrm{QCO}_{2}$ & TD \\
\hline 1 & SEDS & PHBV FE110 & $\mathrm{CHCl}_{3}$ & 2 & 184 & 40 & 6 & 160 & 30 \\
\hline 2 & SAS & PHBV FE110 & $\mathrm{CHCl}_{3}$ & 2 & 184 & 40 & 6 & 160 & 30 \\
\hline 3 & SAS & PHBV FE110 & $\mathrm{CHCl}_{3}$ & 2 & 184 & 10 & 6 & 160 & 30 \\
\hline 4 & SAS & PHBV FE110 & $\mathrm{CHCl}_{3}$ & 2 & 184 & 10 & 2 & 160 & 30 \\
\hline 5 & SEDS & PHBV FE110 & $\mathrm{CHCl}_{3}$ & 2 & 184 & 10 & 6 & 160 & 30 \\
\hline 6 & SEDS & PHBV FE110 & $\mathrm{CHCl}_{3}$ & 2 & 184 & 10 & 2 & 160 & 30 \\
\hline 7 & SAS & PHBV FE110 & $\mathrm{CHCl}_{3}$ & 2 & 184 & 10 & 10 & 160 & 30 \\
\hline 8 & SAS & PHBV FE110 & $\mathrm{CHCl}_{3}$ & 0,9 & 184 & 10 & 2 & 160 & 30 \\
\hline 9 & SAS & PHBV FE110 & $\mathrm{CH}_{2} \mathrm{Cl}_{2}$ & 2 & 184 & 10 & 10 & 160 & 30 \\
\hline 10 & SAS & PHBV FE110 & $\mathrm{CHCl}_{3}$ & 2 & 100 & 10 & 6 & 160 & 30 \\
\hline 11 & SAS & PHBV FE110 & $\mathrm{CHCl}_{3}$ & 2 & 100 & 10 & 1 & 160 & 30 \\
\hline 12 & SAS & PHBV FE110 & $\mathrm{CHCl}_{3}$ & 2 & 184 & 10 & 6 & 160 & 180 \\
\hline 13 & SAS & PHBV FE110 & $\mathrm{CHCl}_{3}$ & 2 & 184 & 10 & 6 & 160 & 5 \\
\hline 14 & SAS & PHBV FE110 & $\mathrm{CHCl}_{3}$ & 2 & 184 & 20 & 10 & 160 & 30 \\
\hline 15 & $\begin{array}{l}\text { SAS } \\
\text { SEDS }\end{array}$ & PHBV FE110 & $\mathrm{CHCl}_{3}$ & 2 & 184 & 10 & 6 & 160 & 30 \\
\hline 16 & SAS & $\begin{array}{l}\text { PHBV } \\
\text { FE110+PCL }\end{array}$ & $\mathrm{CHCl}_{3}$ & 2 & 184 & $10+10$ & 6 & 160 & 30 \\
\hline 17 & SAS & PHBV FE113 & $\mathrm{CHCl}_{3}$ & 2 & 184 & 10 & 10 & 160 & 30 \\
\hline 18 & SAS & PHBV FE113 & $\mathrm{CHCl}_{3}$ & 2 & 184 & 10 & 10 & 80 & 30 \\
\hline
\end{tabular}

Pol. = Polímero, VC = Volume da Câmera de Precipitação (L), DC = Diâmetro do Capilar $(\mu \mathrm{m}), \mathrm{CS}+$ Concentração da Solução $(\mathrm{mg} / \mathrm{mL})$, Qsol = vazão da solução $(\mathrm{mL} / \mathrm{min})$, Qco 2 = vazão de $\mathrm{CO}_{2}$ (g/min), TD = Tempo de Des pressurização $(\mathrm{min})$.

Nas Figuras 15, 16 e 17 encontram-se as micrografias referentes aos experimentos mostrados na Tabela 8. 


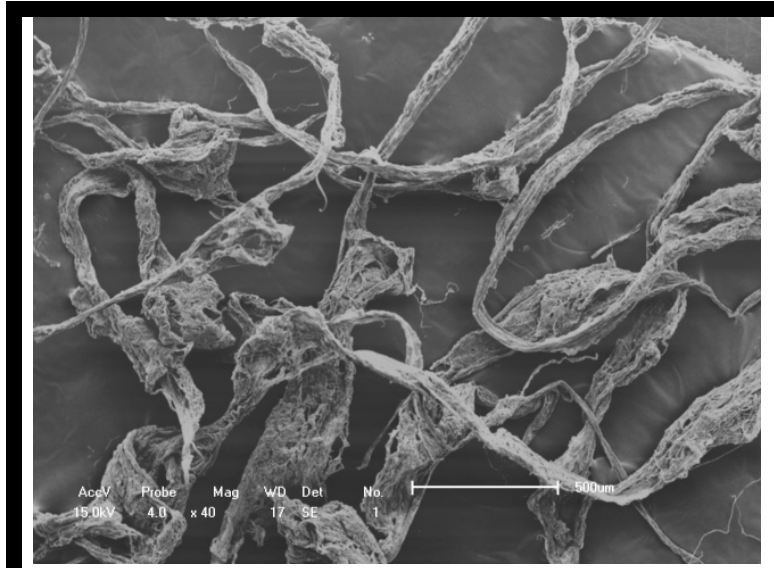

Exp. 1 PHBV FE110 aumento 40x

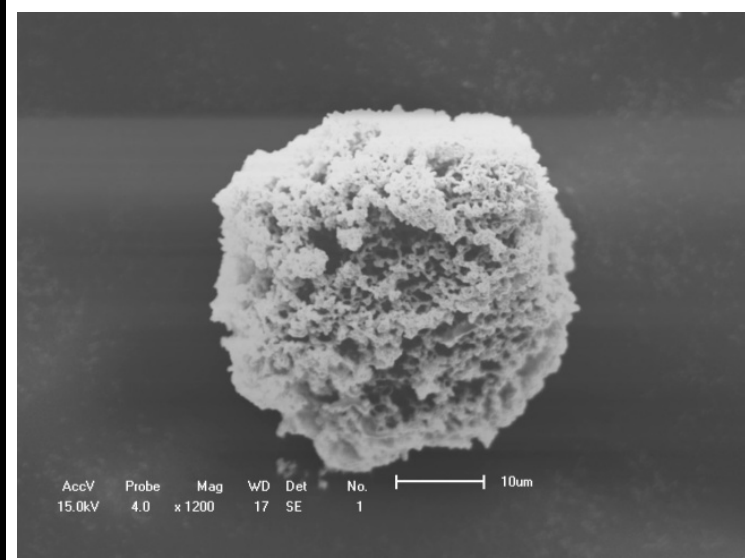

Exp. 3 PHBV FE110 aumento 1200x

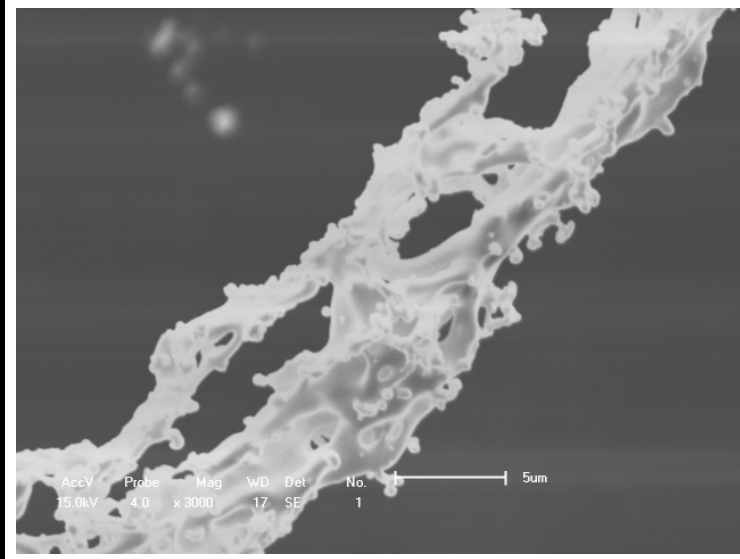

Exp. 5 PHBV FE110 aumento 2000x

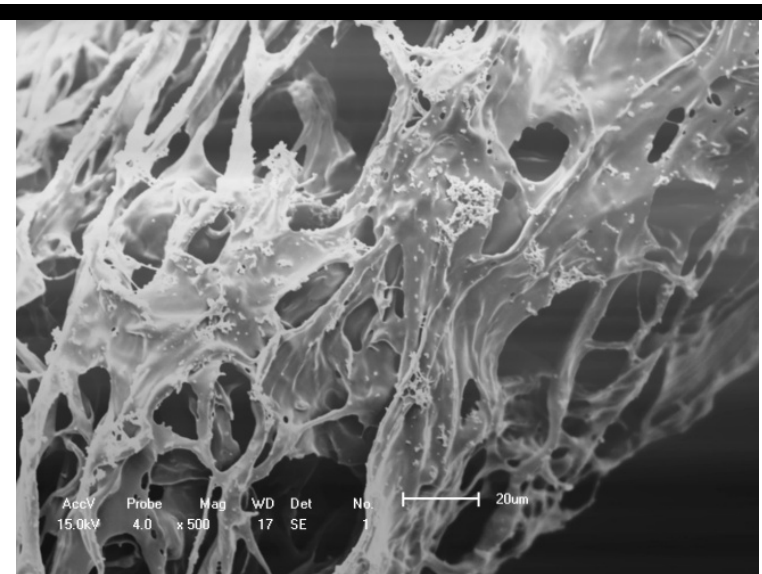

Exp. 2 PHBV FE110 aumento 500x

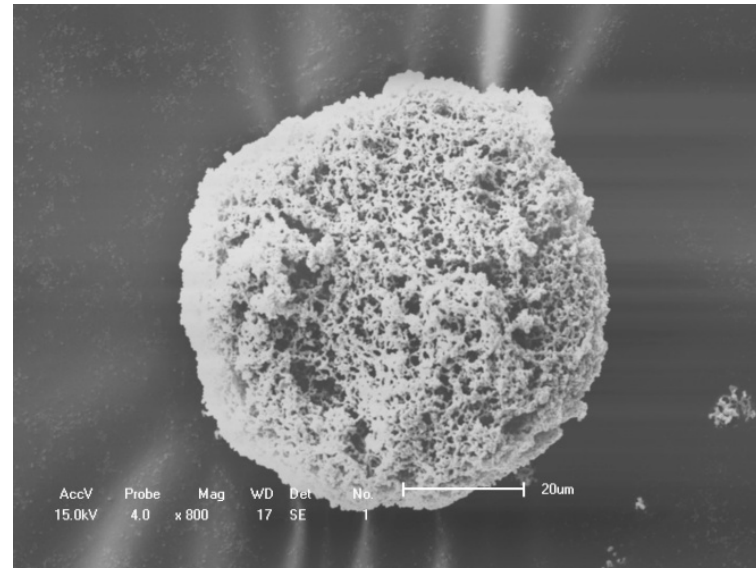

Exp. 4 PHBV FE110 aumento 1000x

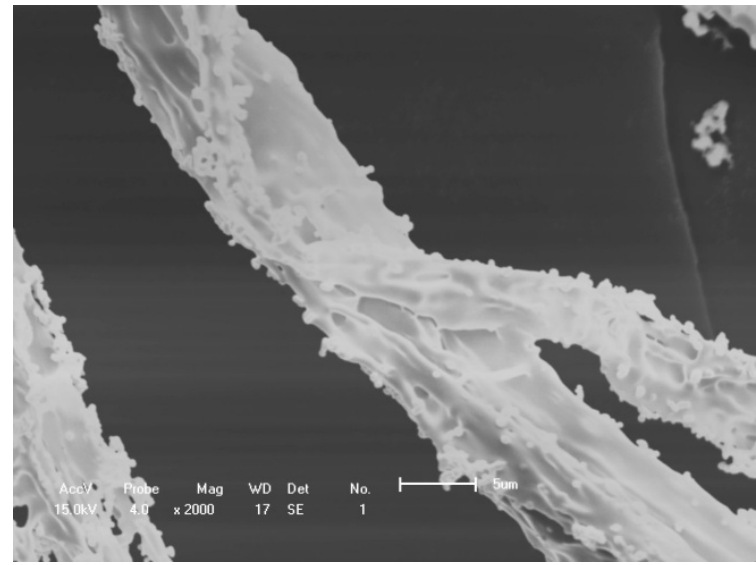

Exp. 6 PHBV FE110 aumento 2000x

Figura 15 - Microscopia eletrônica de varredura das partículas provenientes dos experimentos 1,2 $3,4,5$ e 6 . 

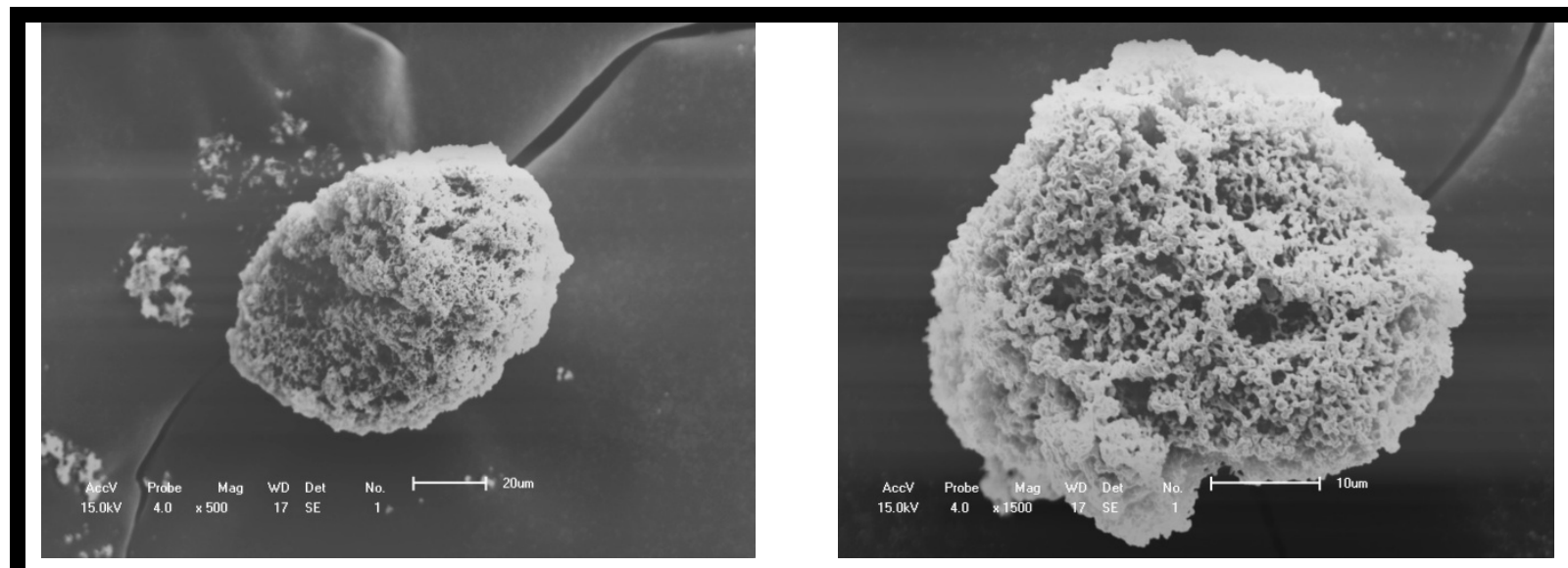

Exp. 7 PHBV FE110 aumento 500x

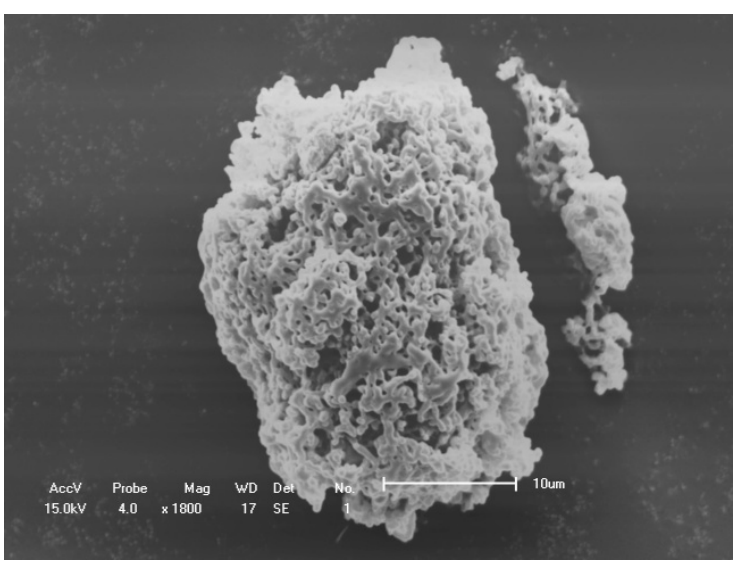

Exp. 9 PHBV FE110 aumento 1000x

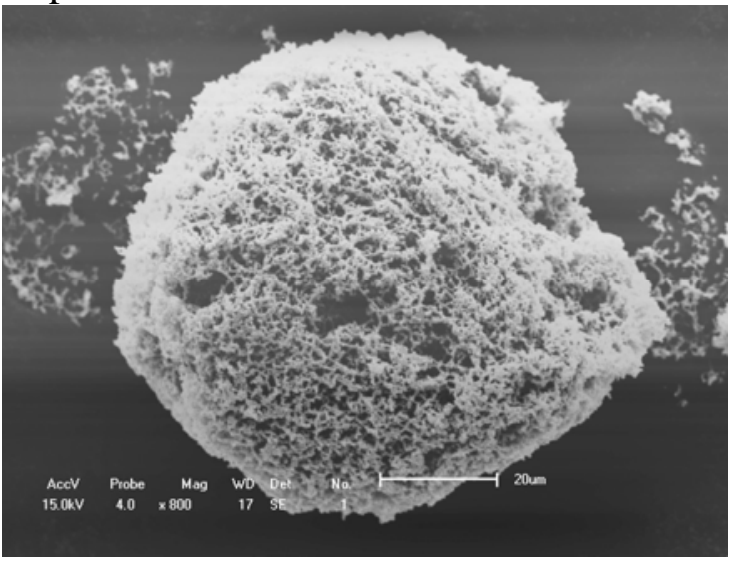

Exp. 11 PHBV FE110 aumento 800x
Exp. 8 PHBV FE110 aumento 1500x

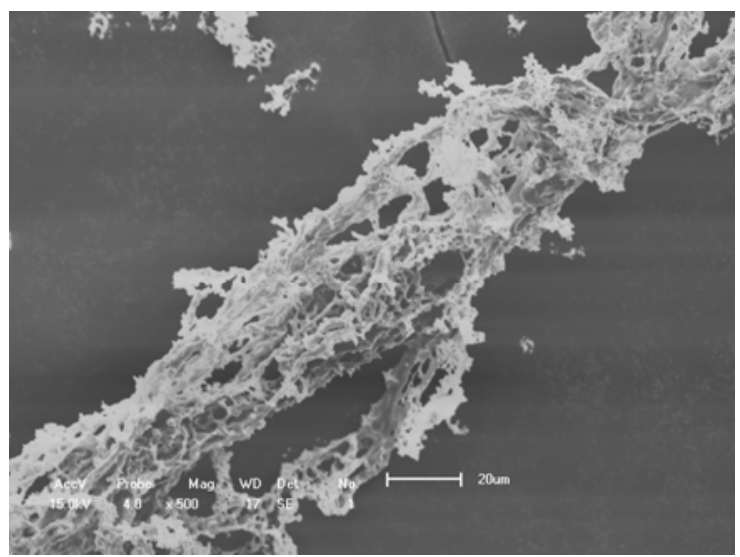

Exp. 10 PHBV FE110 aumento 500x

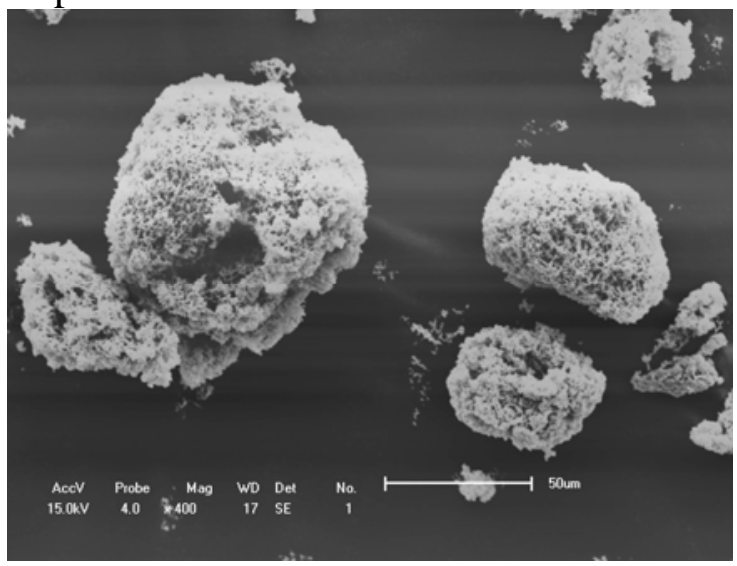

Exp. 12 PHBV FE110 aumento 400x

Figura 16 - Microscopia eletrônica de varredura das partículas provenientes dos experimentos 7,8,9,10,11 e 12 . 


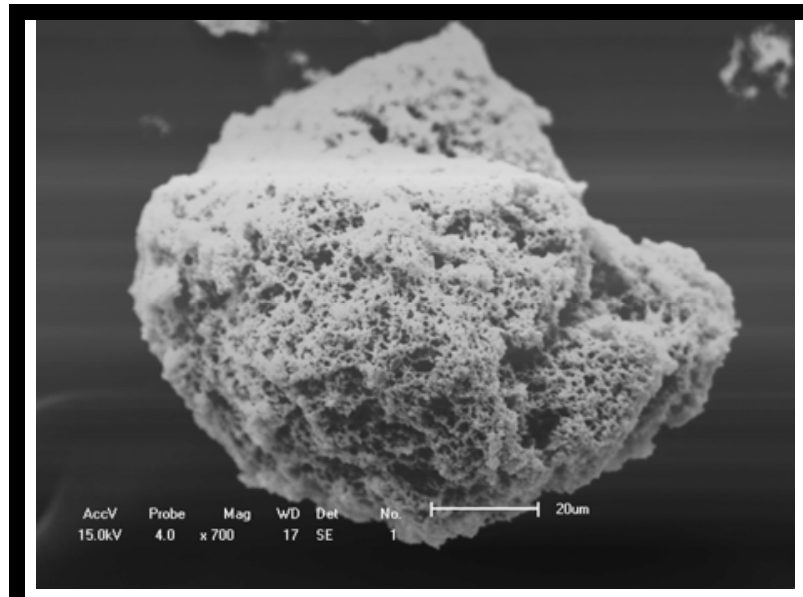

Exp.13 PHBV FE110 aumento 700x

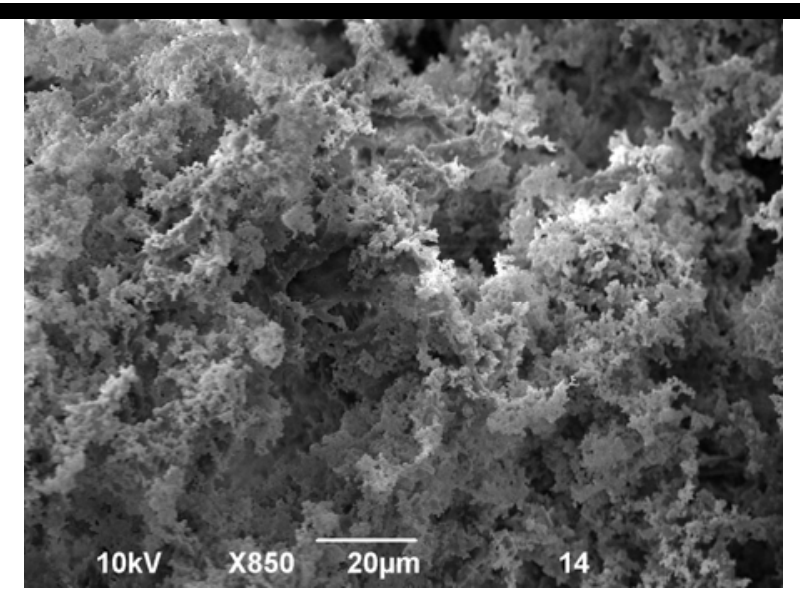

Exp. 14 PHBV FE110 aumento 850x

Figura 17 - Microscopia eletrônica de varredura das partículas provenientes dos experimentos 13, 14.

A partir das micrografias obtidas dos experimentos de precipitação foi possível observar que se formaram fibras nos experimentos 1, 2, 5, 6, 10 e 14. Para os experimentos 1, 2 e 14 deve-se ao fato da alta concentração, $40 \mathrm{mg} / \mathrm{mLe} 20 \mathrm{mg} / \mathrm{mL}$, do PHBV FE110 na solução de clorofórmio. Estes resultados estão de acordo com os obtidos por COSTA et al. (2007), que estudaram a precipitação de PHBV pela técnica SAS e afirmam que a formação de fibras é característica de soluções poliméricas concentradas devido à alta viscosidade destas soluções. Os experimentos realizados com o processos SEDS, 5 e 6, também formaram fibras, o que pode ter ocorrido pelo fato do $\mathrm{CO}_{2}$ e a solução entrarem coaxialmente no interior da câmera de precipitação e, por ser uma câmera de grande tamanho,( 2 Litros), não se teve uma turbulência necessária para a formação de partículas.

Nos experimentos 3, 4, 7, 8, 9, 11, 12 e 13, realizados pelo processo SAS, obteveram-se partículas muito porosas, irregulares e com uma larga distribuição de tamanhos, como pode ser observado na Figura 18. 


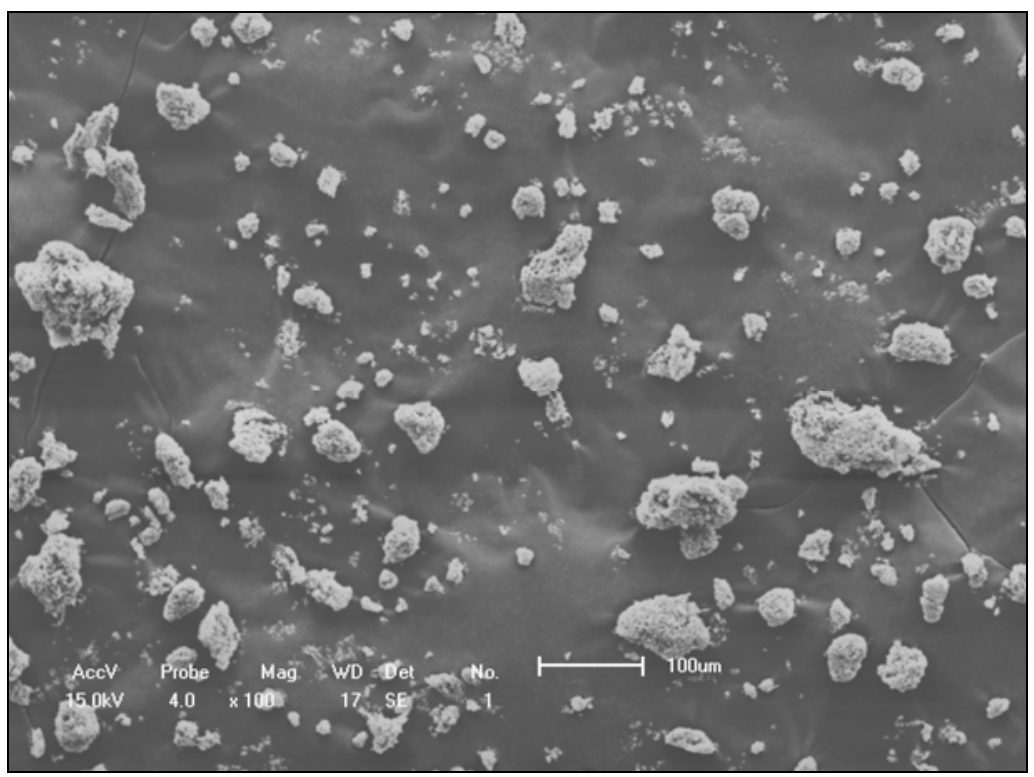

Figura 18 - Micrografia das partículas precipitadas no experimento 3. Aumento 1000x.

No experimento 15, conduzido com a mistura dos processos SAS e SEDS, em que $\mathrm{o} \quad \mathrm{CO}_{2}$ é alimentado tanto perpendicularmente como coaxial mente, respectivamente, obteve-se o melhor resultado: partículas esféricas na faixa de 0,5 a 1,5 $\mu \mathrm{m}$ e superfície lisa, como pode ser observado na Figura 19.

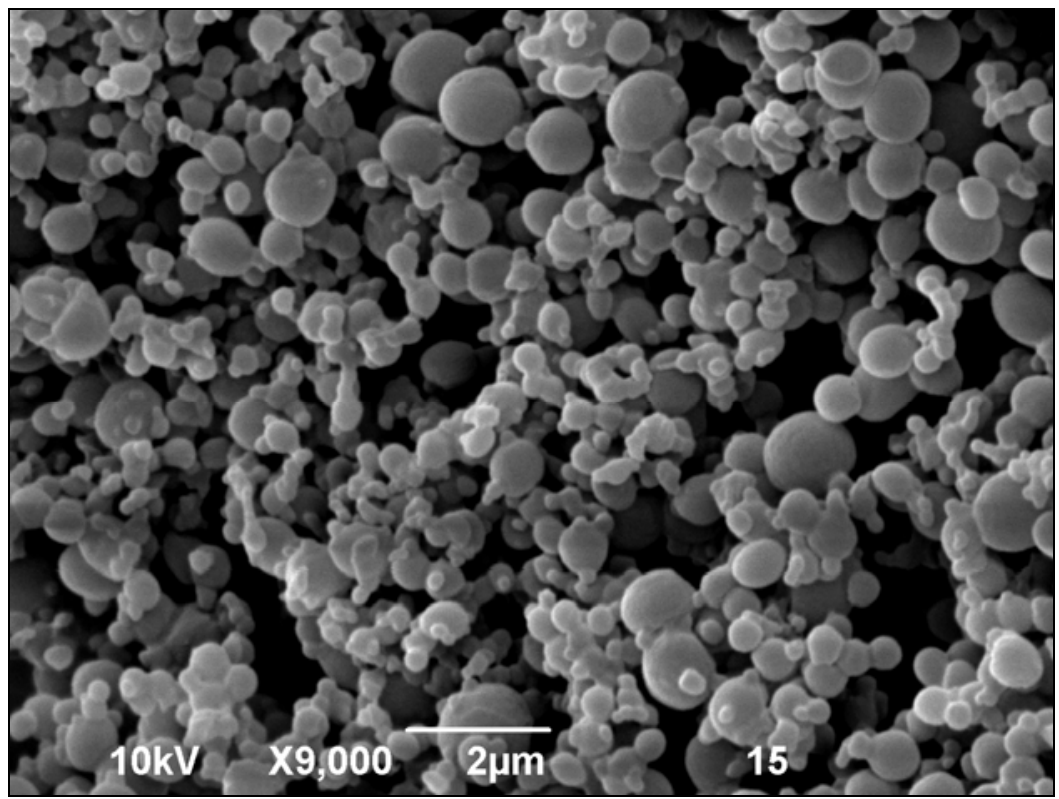

Figura 19 - Micrografia das partículas precipitadas no experimento 15. Aumento 9000x.

Para os experimentos de impregnação, foram selecionadas 3 amostras de PHBV; experimentos 17 e 18 e PHBV FE 113, utilizado sem nenhum tratamento. Os 
experimentos foram conduzidos à temperatura de $50{ }^{\circ} \mathrm{C}$, pressão de 250 bar e duração de 8 horas.

Na Tabela 9, encontram-se os valores encontrados da fração mássica de progesterona impregnada na amostra.

Tabela 9 - Fração mássica de progesterona impregnada na amostra.

\begin{tabular}{ll}
\hline Amostra & \% de P4 na amostra \\
\hline Não processada (PHB-V1) & $1,64 \%$ \\
$17(\mathrm{PHB}-\mathrm{V} 2)$ & $5,2 \%$ \\
$18(\mathrm{PHB}-\mathrm{V3})$ & $5,55 \%$ \\
\hline
\end{tabular}

Na Figura 20, encontram-se micrografias das amostras impregnadas, para o polímero não processado e processados pelas condições operacionais, referentes aos experimentos 17 e 18.

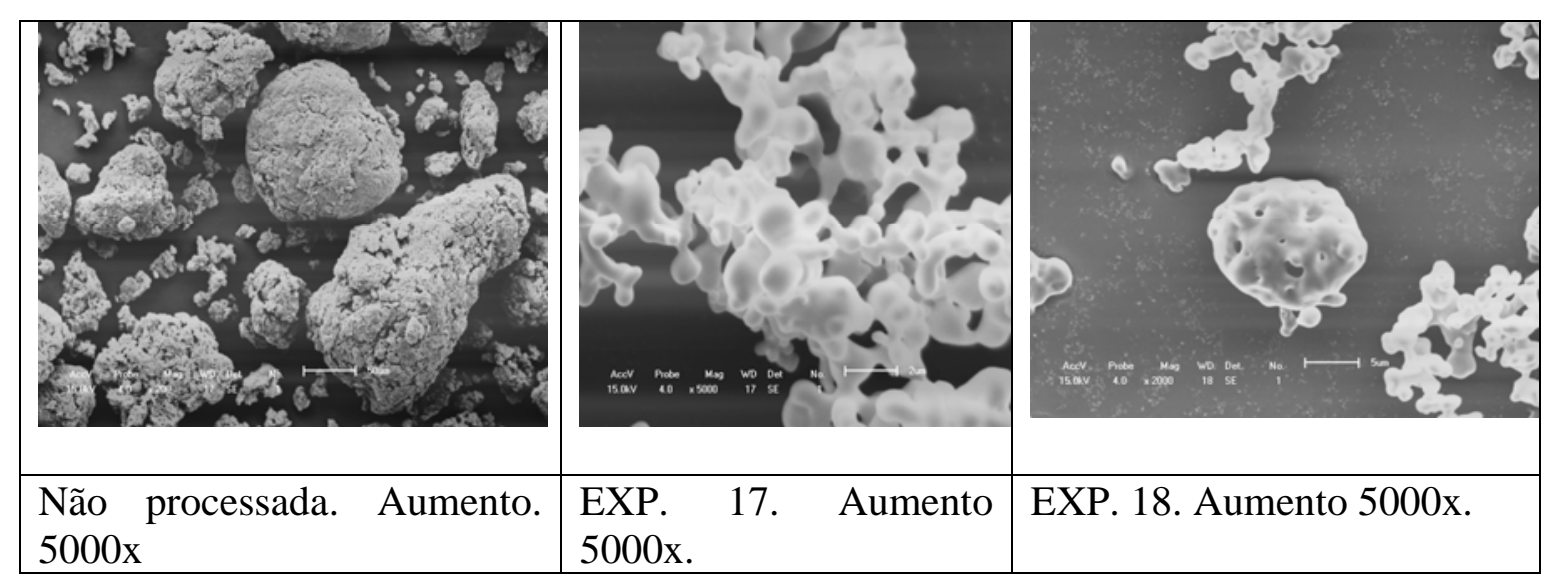

Figura 20 - Micrografias das amostras impregnadas.

\subsubsection{EQUILÍBRIO DE FASE}

Foram medidos dados experimentais de equilíbrio de fases a alta pressão usando o método estático sintético para os sistemas ternários $\mathrm{CO}_{2}+$ Clorofórmio + PHB FE113, para avaliar o efeito da massa molar do PHBV no comportamento de fases. Na Tabela 6, encontram-se os dados experimentais de ELV e ESLV, para o sistema $\mathrm{CO}_{2}$ (1) + clorofórmio (2) + PHB FE113 (MW = 214.589 g/mol), com concentração da solução de $10 \mathrm{mg} / \mathrm{mL}$. Na Figura 14, encontram-se os resultados contidos na Tabela 10. O comportamento de fase do sistema $\mathrm{CO}_{2}(1)$ + clorofórmio (2) não foi significativamente 
alterado pela adição de PHBV ao sistema. Os resultados dos dados experimentais de transição de fases para os sistemas $\mathrm{CO}_{2}(1)+$ clorofórmio (2) + PHBV de MW = $379.160 \mathrm{~g} / \mathrm{mol}$ e $\mathrm{CO}_{2}(1)$ + clorofórmio (2) + PHBV de $\mathrm{MW}=214.589 \mathrm{~g} / \mathrm{mol}$. são inéditos e de grande importância na produção de micro e nano partículas usando a tecnologia supercrítica.

Tabela 10 - Dados experimentais de ELV e ESLV para o sistema CO2 (1) + clorofórmio (2) + PHB FE113, com concentração da solução de $10 \mathrm{mg} / \mathrm{mL}$.

\begin{tabular}{|c|c|c|c|c|c|}
\hline $\mathrm{X}_{1}$ & $\mathrm{P} / \mathrm{bar}$ & $\begin{array}{l}\text { Tipo } \\
\text { Transição }\end{array}$ & $\mathrm{x}_{1}$ & $\mathrm{P} / \mathrm{bar}$ & $\begin{array}{l}\text { Tipo } \\
\text { Transição }\end{array}$ \\
\hline \multicolumn{6}{|c|}{$\mathrm{T}=30^{\circ} \mathrm{C}$} \\
\hline 0,4746 & 35,7 & ELV-PB & 0,8797 & 58,8 & ESLV-PB \\
\hline 0,5940 & 41,3 & ELV-PB & 0,9253 & 62,3 & ESLV-PB \\
\hline 0,6896 & 46,7 & ESLV-PB & 0,9499 & 65,6 & ESLV-PB \\
\hline 0,7928 & 52,4 & ESLV-PB & & & \\
\hline \multicolumn{6}{|c|}{$\mathrm{T}=40^{\circ} \mathrm{C} \mathrm{K}$} \\
\hline 0,4746 & 41,7 & ELV-PB & 0,8797 & 71,0 & ESLV-PB \\
\hline 0,5940 & 49,8 & ELV-PB & 0,9253 & 75,4 & ESLV-PB \\
\hline 0,6896 & 56,6 & ESLV-PB & 0,9499 & 79,3 & ESLV-PB \\
\hline 0,7928 & 63,6 & ESLV-PB & & & \\
\hline \multicolumn{6}{|c|}{$\mathrm{T}=50^{\circ} \mathrm{C}$} \\
\hline 0,4746 & 48,9 & ELV-PB & 0,8797 & 84,3 & ESLV-PB \\
\hline 0,5940 & 58,4 & ELV-PB & 0,9253 & 88,1 & ESLV-PB \\
\hline 0,6896 & 66,9 & ESLV-PB & 0,9499 & 89,6 & ESLV-PO \\
\hline 0,7928 & 75,1 & ESLV-PB & & & \\
\hline \multicolumn{6}{|c|}{$\mathrm{T}=60^{\circ} \mathrm{C}$} \\
\hline 0,4746 & 55,9 & ELV-PB & 0,8797 & 96,4 & ESLV-PB \\
\hline 0,5940 & 67,3 & ELV-PB & 0,9253 & 97,8 & ESLV-PB \\
\hline 0,6896 & 77,4 & ESLV-PB & 0,9499 & 95,3 & ESLV-PO \\
\hline 0,7928 & 86,6 & ESLV-PB & & & \\
\hline
\end{tabular}

\subsubsection{Precipitação de PHBV e blendas PHBV-PCL}

A partir dos testes preliminares de precipitação de PHBV verificou-se que a união das metodologias SAS e SEDS promove melhores resultados de formação de micro e nanopartículas de polímeros. Foi executado um planejamento experimental, para investigação dos efeitos das variáveis de processo na expansão do polímero PHBV e blendas de PHBV/PCL. 
Tabela 11 - Condições operacionais do processo para expansão dos polímeros PHBV.

\begin{tabular}{ll}
\hline Condições operacionais & Variáveis \\
\hline Pressão na câmara de expansão (bar) & $85-145$ \\
Concentração da solução (mg/mL) & $5-10$ \\
Vazão de solução (mL/min) & $5-10$ \\
Vazão de $\mathrm{CO}_{2}$ (g/min) & $80-160$ \\
Massa molar do PBHV (1000 x g/mol) & $214-379$ \\
\hline
\end{tabular}

Na Tabela 12, encontram-se os resultados do processo de precipitação de acordo com a Tabela 11. Os resultados avaliados foram o tamanho médio de partículas (TMP) e o desvio padrão amostral. Uma das formas mais aceitas para avaliar o tamanho das micro e nano partículas, no processo de precipitação, é a supersaturação. A variação de massa molar de PHBV promoveu um inversão dos valores de vazão da solução e de vazão de $\mathrm{CO}_{2}$. Para o um PHBV de massa molar maior, é necessária uma maior vazão da solução e menor vazão de $\mathrm{CO}_{2}$, para a obtenção de tamanho de micropartículas menor, à luz dos dados de supersaturação. Nos experimentos de precipitação realizados, não foi possível produzir nano partículas, variando-se as condições operacionais prédefinidas na Tabela 7. No entanto, os resultados obtidos estão de acordo com os valores encontrados na literatura (Costa, et al.,2007). 
Tabela 12 -Planejamento experimental de precipitação de PHB-V.

\begin{tabular}{llllllll}
\hline Exp. & $\begin{array}{l}\text { MM } \\
\text { (g/mol) }\end{array}$ & $\begin{array}{l}\text { Pressão } \\
\text { (bar) }\end{array}$ & $\begin{array}{l}\text { Solução } \\
\text { (mg/mL) }\end{array}$ & $\begin{array}{l}\mathbf{Q}_{\text {sol. }} \\
(\mathbf{m L} / \mathbf{m i n})\end{array}$ & $\begin{array}{l}\mathbf{Q}_{\mathbf{c o 2}} \\
(\mathbf{g} / \mathbf{m i n})\end{array}$ & $\begin{array}{l}\text { TMP } \\
(\boldsymbol{\mu m})\end{array}$ & $\begin{array}{l}\text { Desvio } \\
(\boldsymbol{\mu m})\end{array}$ \\
\hline P1 & 214.589 & 85 & 10 & 5 & 80 & 1,25 & 0,3 \\
P2 & 214.589 & 85 & 10 & 5 & 160 & 1,02 & 0,3 \\
\hline P3 & 214.589 & 85 & 10 & 10 & 160 & 1,26 & 0,4 \\
P4 & 214.589 & 85 & 10 & 10 & 80 & 1,22 & 0,4 \\
P5 & 214.589 & 85 & 20 & 5 & 80 & 1,31 & 0,4 \\
P6 & 214.589 & 85 & 20 & 5 & 160 & 1,40 & 0,4 \\
P7 & 214.589 & 85 & 20 & 10 & 80 & 1,77 & 0,8 \\
P8 & 214.589 & 85 & 20 & 10 & 160 & 1,31 & 1,0 \\
P9 & 214.589 & 145 & 10 & 5 & 80 & 1,02 & 0,3 \\
P10 & 214.589 & 145 & 10 & 5 & 160 & 0,74 & 0,2 \\
P11 & 214.589 & 145 & 10 & 10 & 80 & 1,04 & 0,3 \\
P12 & 214.589 & 145 & 10 & 10 & 160 & 1,18 & 0,4 \\
P13 & 214.589 & 145 & 20 & 5 & 80 & 1,21 & 0,3 \\
P14 & 214.589 & 145 & 20 & 5 & 160 & 1,01 & 0,3 \\
P15 & 214.589 & 145 & 20 & 10 & 80 & 0,93 & 0,3 \\
P16 & 214.589 & 145 & 20 & 10 & 160 & 0,88 & 0,3 \\
P17 & 379.160 & 85 & 10 & 5 & 80 & 0,80 & 0,2 \\
P18 & 379.160 & 85 & 10 & 5 & 160 & 0,79 & 0,2 \\
P19 & 379.160 & 85 & 10 & 10 & 160 & 0,78 & 0,2 \\
P20 & 379.160 & 85 & 10 & 10 & 80 & 0,83 & 0,2 \\
P21 & 379.160 & 85 & 20 & 5 & 80 & Fibra & \\
P22 & 379.160 & 85 & 20 & 5 & 160 & Fibra & \\
P23 & 379.160 & 85 & 20 & 10 & 80 & Fibra & \\
P24 & 379.160 & 85 & 20 & 10 & 160 & Fibra & \\
P25 & 379.160 & 145 & 10 & 5 & 80 & 0,77 & 0,2 \\
P26 & 379.160 & 145 & 10 & 5 & 160 & 0,79 & 0,2 \\
P27 & 379.160 & 145 & 10 & 10 & 80 & 0,75 & 0,2 \\
P28 & 379.160 & 145 & 10 & 10 & 160 & 0,76 & 0,2 \\
\hline P29 & 379.160 & 145 & 20 & 5 & 80 & Fibra & \\
P30 & 379.160 & 145 & 20 & 5 & 160 & Fibra & \\
P31 & 379.160 & 145 & 20 & 10 & 80 & Fibra & \\
P32 & 379.160 & 145 & 20 & 10 & 160 & Fibra & \\
\hline & & & & & & & \\
\hline
\end{tabular}

Na Tabela 14, encontram-se os resultados do processo de precipitação de acordo com as condições operacionais descritas na Tabela 13. Os resultados avaliados foram o tamanho médio de partículas (TMP) e o desvio padrão amostral.

Observa-se que a maior porcentagem mássica de PCL (50\%) produz maiores tamanhos de micropartículas. 
Tabela 13 - Condições operacionais para expansão da blendas de PHBV/PCL.

\begin{tabular}{ll}
\hline Condições Operacionais & Variaveis \\
\hline Pressão na câmara de expansão (bar) & $85-145$ \\
Concentração da solução (mg/mL) & $5-10$ \\
Vazão de solução (mL/min) & $5-10$ \\
Vazão de $\mathrm{CO}_{2}(\mathrm{~g} / \mathrm{min})$ & $80-160$ \\
Percentagem mássica de PCL & $20-50$ \\
Massa molar do PBHV (1000 x g/mol) & $214-379$ \\
\hline
\end{tabular}

Tabela 14 - Tamanho médio de partículas e respectivo desvio-padrão do tamanho de partículas experimentais obtidas por precipitação de blendas de PHBV/PCL, segundo condições operacionais descritas na tabela 13.

\begin{tabular}{lllllllll}
\hline Exp. & W & $\begin{array}{c}\text { MM } \\
(\mathbf{g} / \mathbf{m o l})\end{array}$ & $\begin{array}{c}\text { Pressão } \\
(\mathbf{b a r})\end{array}$ & $\begin{array}{c}\text { Solução } \\
(\mathbf{m g} / \mathbf{m L})\end{array}$ & $\begin{array}{c}\mathbf{Q}_{\text {sol. }} \\
(\mathbf{m L} / \mathbf{m i n})\end{array}$ & $\begin{array}{c}\mathbf{Q}_{\mathbf{c o} 2} \\
(\mathbf{g} / \mathbf{m i n})\end{array}$ & $\begin{array}{c}\text { TMP } \\
(\boldsymbol{\mu m})\end{array}$ & $\begin{array}{c}\text { Desvio } \\
(\boldsymbol{\mu m})\end{array}$ \\
\hline B1 & 20 & 214.589 & 85 & 10 & 5 & 80 & 1,41 & 0,5 \\
B2 & 20 & 214.589 & 85 & 20 & 5 & 160 & 1,21 & 0,5 \\
B3 & 20 & 214.589 & 145 & 10 & 10 & 160 & 1,25 & 0,3 \\
B4 & 20 & 214.589 & 145 & 20 & 10 & 80 & 1,48 & 0,5 \\
B5 & 20 & 379.160 & 85 & 10 & 10 & 160 & 0,98 & 0,2 \\
B6 & 20 & 379.160 & 85 & 20 & 10 & 80 & Fibr & \\
B7 & 20 & 379.160 & 145 & 10 & 5 & 80 & 1,02 & 0,2 \\
B8 & 20 & 379.160 & 145 & 20 & 5 & 160 & 1,03 & 0,3 \\
B9 & 50 & 214.589 & 85 & 10 & 10 & 80 & 1,99 & 0,7 \\
B10 & 50 & 214.589 & 85 & 20 & 10 & 160 & 2,02 & 0,7 \\
B11 & 50 & 214.589 & 145 & 10 & 5 & 160 & 1,55 & 0,4 \\
B12 & 50 & 214.589 & 145 & 20 & 5 & 80 & 1,69 & 0,5 \\
B13 & 50 & 379.160 & 85 & 10 & 5 & 160 & 1,33 & 0,3 \\
B14 & 50 & 379.160 & 85 & 20 & 5 & 80 & 1,69 & 0,6 \\
B15 & 50 & 379.160 & 145 & 10 & 10 & 80 & & \\
B16 & 50 & 379.160 & 145 & 20 & 10 & 160 & nd & nd \\
\hline
\end{tabular}

nd: experimento não realizado devido a quebra da bomba de alta pressão P350 do módulo SAS 200.

\subsubsection{Impregnação de progesterona em partículas de PHBV e blendas PHBV/PCL}

Tabela 15 - Condições operacionais do processo de impregnação de progesterona no polímero PHBV e blendas de PHBV/PCL.

\begin{tabular}{ll}
\hline Condições operacionais & Variáveis \\
\hline Pressão (bar) & $150-250$ \\
Temperatura $\left({ }^{\circ} \mathrm{C}\right)$ & $50-70$ \\
Tempo $(\mathrm{h})$ & $4-8$ \\
\hline
\end{tabular}

Devido à quebra da bomba P350, a mesma foi substituída por uma bomba tipo seringa, de menor capacidade de vazão de $\mathrm{CO} 2$. O nível para maior vazão de $\mathrm{CO}_{2}$ não é atingido com esse tipo de bomba, impossibilitando seguir o planejamento proposto. Assim, decidiu-se pela produção de micropartículas de PHBV e blendas, usando apenas as condições operacionais de pressão de 85 bar e vazão de 80 gramas/min de $\mathrm{CO}_{2}$. Essas 
condições operacionais da bomba seringa foram definidas porque o tamanho da câmara de expansão do SAS 200 não é compatível com a câmara de armazenagem da bomba tipo seringa. Assim, foram produzidas micropartículas de PHBV e blendas de PHBV/PCL usando esses dados, para posterior impregnação com progesterona.

O processo de impregnação foi realizado nas condições de $250 \mathrm{bar}$, de $50{ }^{\circ} \mathrm{C}$ e $8 \mathrm{~h}$ para as micro-partículas de PHBV. Para a blenda de PHBV/PCL as condições empregadas foram 200 bar, $35{ }^{\circ} \mathrm{C}$ e $18 \mathrm{~h}$ (Tabela 15). Essas condições de temperatura e pressão foram estabelecidas a partir dos dados de comportamento de fases do sistema progesterona $+\mathrm{CO}_{2}$.

Na Figura 21, encontram-se micrografias das amostras impregnadas, para o polímero não processado e processados pelas condições operacionais, referentes aos experimentos 17 e 18.

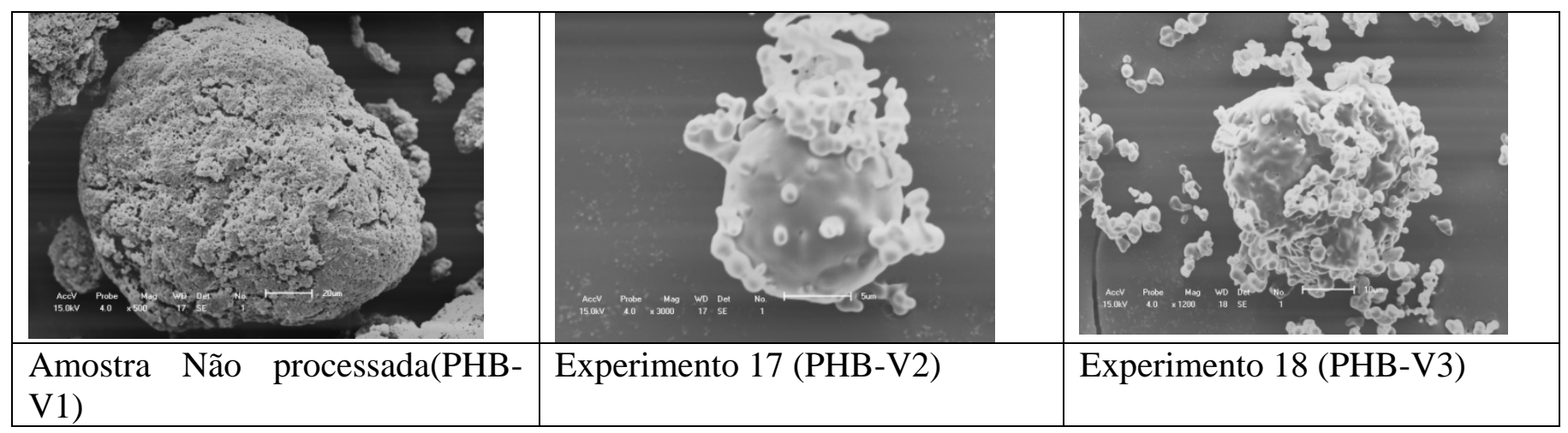

Figura 21 - Micrografias das amostras impregnadas. 
Capitulo 4 


\section{CARACTERIZAÇÃO DAS AMOSTRAS E EXPERIMENTOS DE LIBERAÇÃO IN VITRO}

\subsection{Introdução}

Nesta seção, serão apresentados os resultados referentes aos testes de liberação in vitro das partículas impregnadas com progesterona, conforme proposto no projeto. São também apresentados, os testes realizados para caracterização das diferentes amostras e a determinação da quantidade total de $\mathrm{P}_{4}$ nas amostras.

\subsection{MATERIAIS E MÉTODOS}

\subsubsection{Localização}

Todos os ensaios de liberação e dosagens por HPLC, foram realizados no Laboratório de Farmacologia e Endocrinologia da Reprodução (LFER), localizado no Centro de Biotecnologia da Reprodução (CBRA) do departamento de Reprodução Animal (VRA) da Faculdade de Medicina Veterinária e Zootecnia da Universidade de São Paulo (FMVZ-USP), Campus de Pirassununga-SP; as dosagens por espectrometria de massa no laboratório de espectrometria de massa Thomson na Universidade de Campinas UNICAMP Campinas-SP; a microscopia de varredura eletrônica (MEV) foi realizada na Universidade de Maringá, Maringá-PR; para a determinação do potencial zeta, contamos com a colaboração do laboratório Embrapa Instrumentação Agropecuária- CNPDIA, em São Carlos SP. 


\subsubsection{DOSAGEM DA PROGESTERONA}

\subsubsection{CROMATOGRAFIA LIQUIDA DE ALTO DESEMPENHO (HPLC)}

As análises por cromatografia líquida de alto desempenho (HPLC), foram realizadas como se segue:

Para fase estacionária, foi utilizada uma coluna C18 ODS (Shin Pack CLC ODS, $0,15 \mathrm{~mm}$ x $6.0 \mathrm{~mm} \varnothing) \mathrm{v}$. Para a fase móvel foi utilizada acetonitrila/água na proporção 60:40, em um fluxo de $2 \mathrm{~mL} / \mathrm{min}$. A detecção foi realizada em comprimento de onda de $244 \mathrm{~nm}$. As amostras (20 microlitros) foram injetadas automaticamente em dose única (ISS-200,Perkin Elmer). O tempo esperado de retenção da progesterona é de 1.6 - 4.4 min aproximadamente.A curva de calibração foi preparada com base na mensuração do pek base (Figura 22).O intervalo de linearidade está entre 0,01 e 54,5 micrograma/mL (R2 =0,999971)

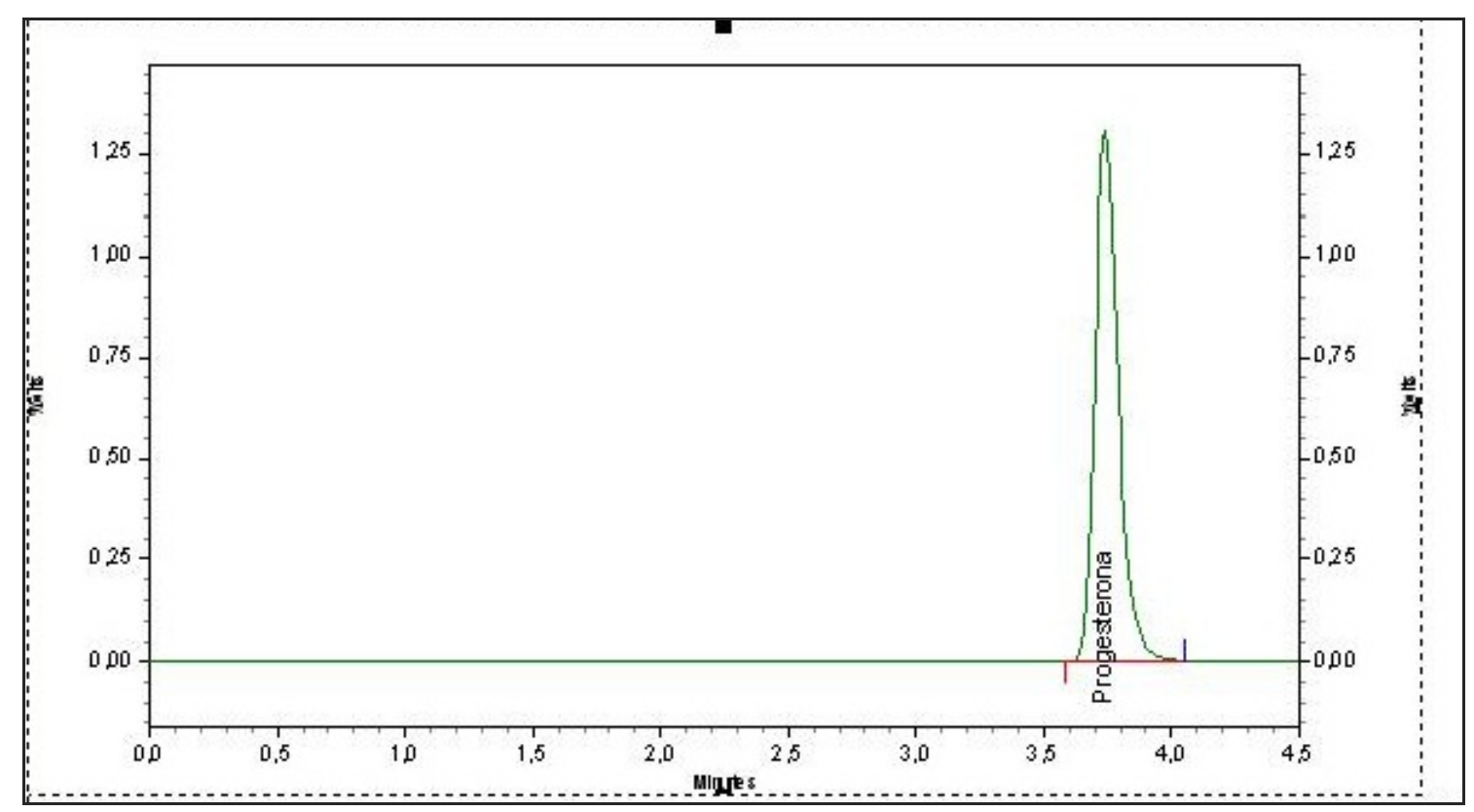

Figura 22 - Cromatograma do padrão de progesterona HPLC.

\subsubsection{ANÁLISE POR LC-MS/MS PARA QUANTIFICAÇÃO DE $P_{4}$}


As amostras foram diluídas para 200 vezes, ou seja, 5 uL foram diluídos para 995 uL de metanol:H2O (1:1). Dessa diluição foi feita uma nova diluição também para 200 vezes na mesma condição e esse volume foi analisado na concentração de ng/mL.Foi utilizado um espectrômetro de massas triplo-quadrupolo API-4000 Q TRAP (Applied Biosystems) equipado com fonte e ESI Turbo-V (Figura 11). As análises foram realizadas em modo MRM em modo positivo visando monitorar as transições 315.5>109.1 e 315.5>297.2. Utilizou-se um HPLC Agilent series 1100 para eluição isocrática do analito em metanol/água 50\%, em tempo total de corrida de 2,5 min. A curva de calibração foi construída com triplicatas de 1, 5, 10, 25 e 50 ng/mL de $\mathrm{P}_{4}$.

\subsubsection{EQUIPAMENTOS}

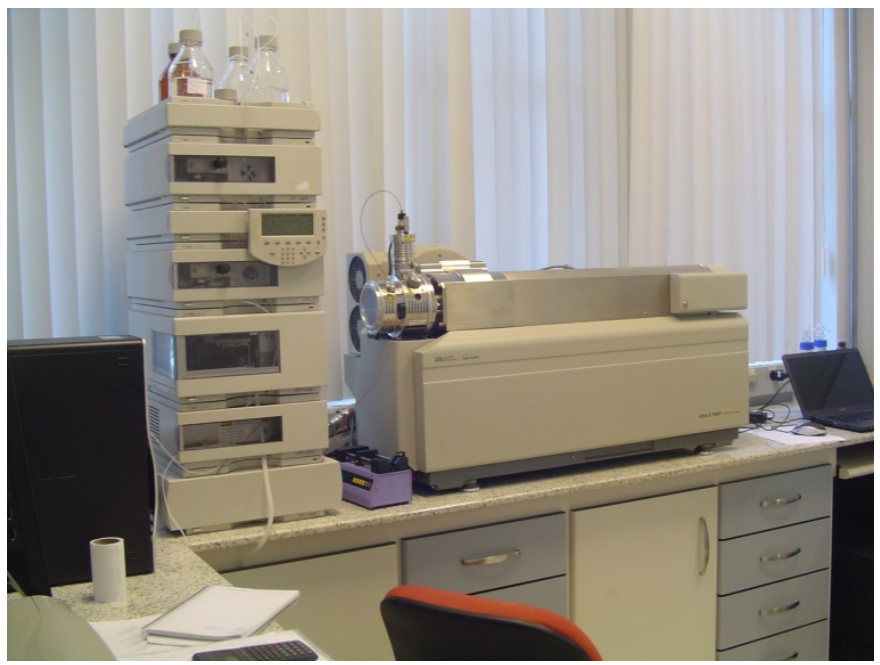

Figura 23 - Equipamento 4000 Qtrap LC/MS/MS - Applied Biosystems ${ }^{\circledR}$; Cromatografo Agilent 1100 Fonte turbo Spray.

\subsubsection{CONDIÇÕES CROMATOGRÁFICAS}

Foi Utilizada uma coluna Phenomenex Aqua C18, 125A (50 x $2.0 \mathrm{~mm})$ de 5 micras, com fase Móvel A (água + 0.1\% de ácido fórmico) 25\% e fase móvel B (metanol grau HPLC) 75\% com fluxo de $600 \mathrm{uL} / \mathrm{min}$., temperatura do forno de $20^{\circ} \mathrm{C}$ 
tempo de lavagem do injetor de 30 segundos; tempo de retenção de $1.03 \pm 0.2$ minutos; tempo de corrida de 2.5 minutos e volume de injeção de 20 microlitros.

\subsubsection{CONDIÇÕES DO ESPECTRÔMETRO DE MASSAS}

Tipo de ionização de ESI;Modo Positivo m/z: 315.25; Íon de quantificação de 315.25 > 109.11; Íon de confirmação $315.25>297.24$; Temperatura da fonte $=750^{\circ} \mathrm{C}$; CUR:20

CAD Hight; IS 5500; TEM 750; GS1 45; GS2 20; DP 76; EP 10; Dwell (msec) 350; CE (109) 39; CE (297) 25; CXP (109) 8; CXP (297) 18

Curva de calibração: (Figura 24, 25 e 26)

Para curva de liberação foi utilizado um padrão sigma diluído em água: metanol (1:1) nas seguintes concentrações:0 ng/mL; 1 ng/mL; 5 ng/mL; 10 ng/mL; 15 $\mathrm{ng} / \mathrm{mL} ; 25 \mathrm{ng} / \mathrm{mL} ; 50 \mathrm{ng} / \mathrm{mL}$

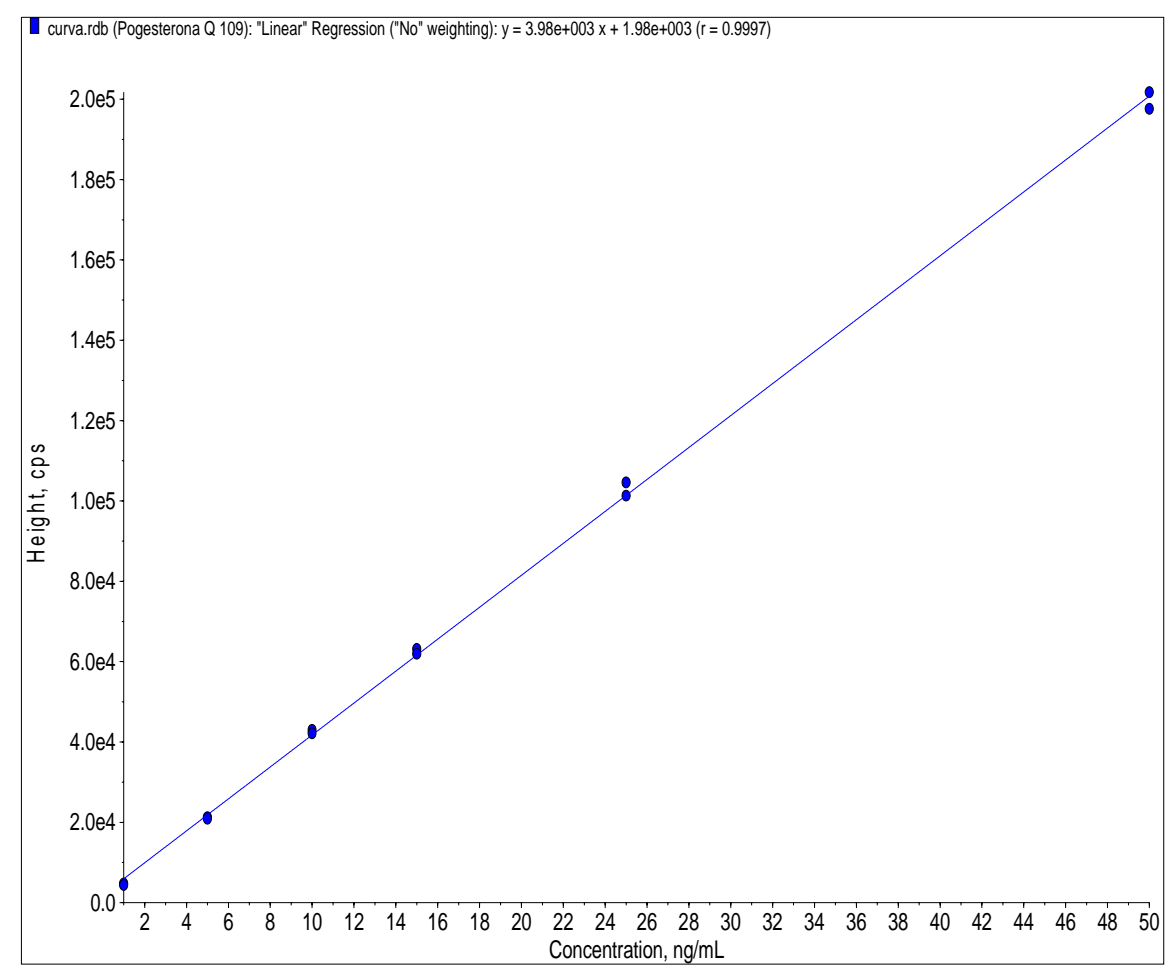

Figura 24 - Curva de calibração do íon de quantificação m/z 109. 
XIC of +MRM (2 pairs): 315.3/109.1 Da from Sample 21 (0) of Data07_12_09.wiff (Turbo Spray)

Max. $174.3 \mathrm{cps}$.

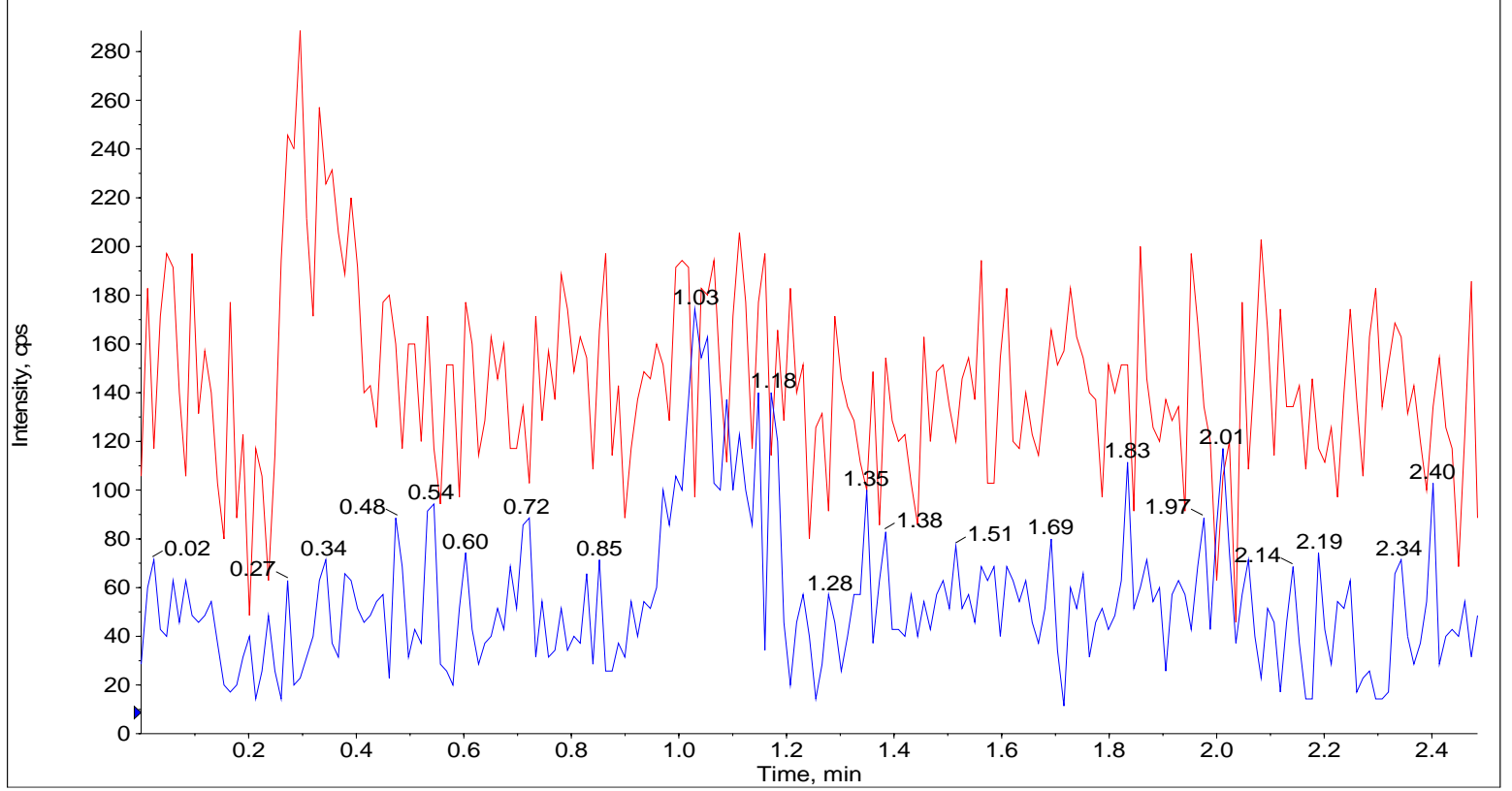

Figura 25 - Espectro de íons totais (TIC) do branco.

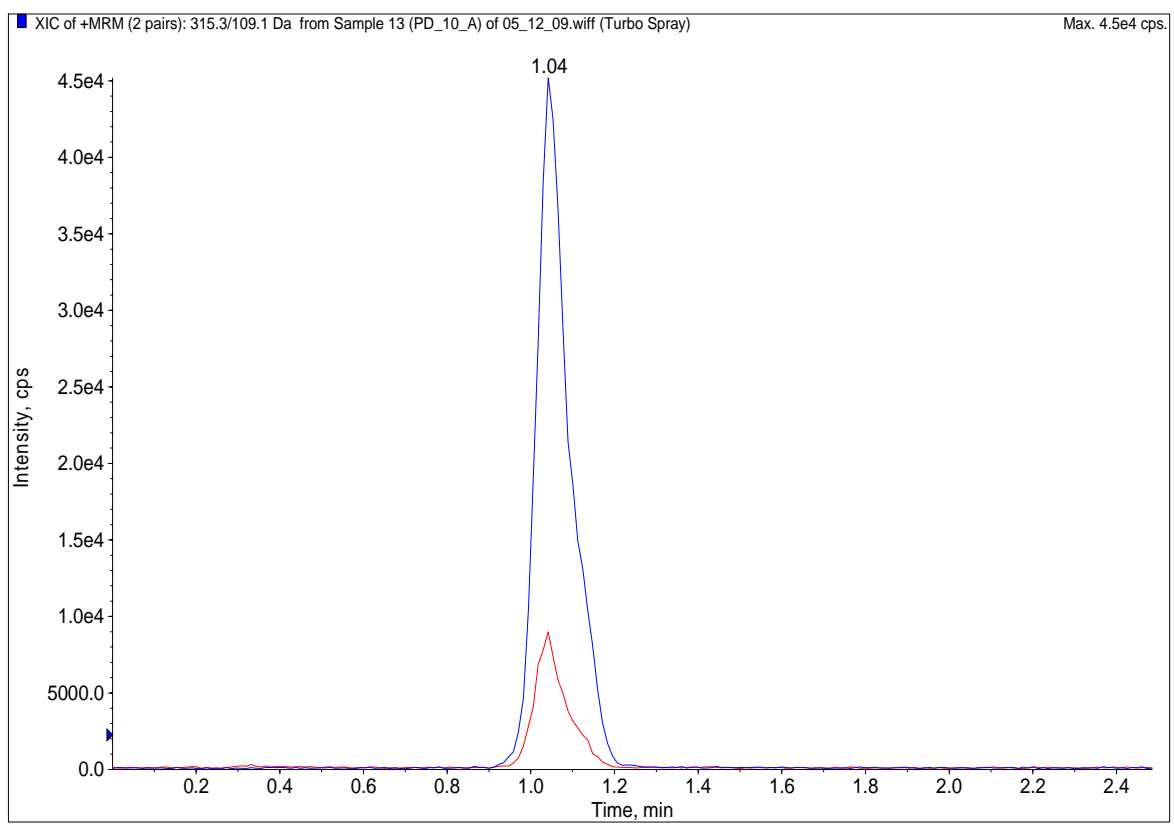

Figura 26 - Espectro de íons totais (TIC) de solução padrão de P4.

\subsubsection{DETERMINAÇÃO DA QUANTIDADE TOTAL DE PROGESTERONA NA} PARTÍCULA. 
Partículas de Poli-hidroxi-butirato e valerato (PHB-V), de três diferentes tamanhos (grupos PHB-V1, PHB-V2 e PHB-V3) e suas combinações com poli-ecaprolactano (PCL; grupos PHB-V1/PCL, PHB-V2/PCL e PHB-V3/PCL) impregnadas com $\mathrm{P}_{4}$, foram pesadas em balança de precisão (MARTE, modelo AM-220), para determinar sua massa total. Foram acondicionadas em frascos de $12 \mathrm{ml}$ e suspendidas em 10 ml de solução de etanol (Sigma ${ }^{\circledR}$ PA pureza mínima de 99,99\%). Todos os frascos foram acondicionados em banho maria com agitação horizontal (Precision-

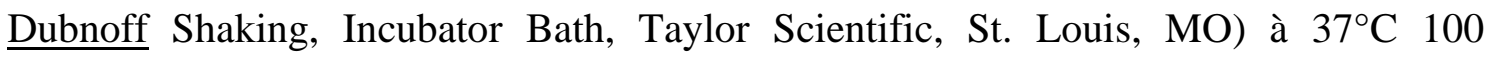
mov/min. A cada duas horas, os frascos foram submetidos à agitação mecânica (vórtex) e retornaram ao banho-maria com agitação. Após 48 horas, os frascos foram centrifugados à $2.000 \mathrm{~g}$, por 10 minutos, com tempo de parada de 5 minutos. Coletouse $1 \mathrm{ml}$ da solução sobrenadante, com pipeta automática e despejou-se em uma seringa de $3 \mathrm{ml}$, com um filtro de 0.45 micra acoplado na ponta e o conteúdo foi transferido para frascos de cor âmbar ("vial”), fechados e guardados em geladeira $\left(5^{\circ} \mathrm{C}\right)$, até o momento de leitura por LC/MS/MS.

\subsubsection{CALORIMETRIA DIFERENCIAL DE VARREDURA (DSC)}

A quantificação da fração de cada polímero precipitado foi feita por integração das áreas das análises de calorimetria diferencial de varredura (DSC) utilizando-se aparelho SHIMADZU modelo TGA-50. (Figura 27). 


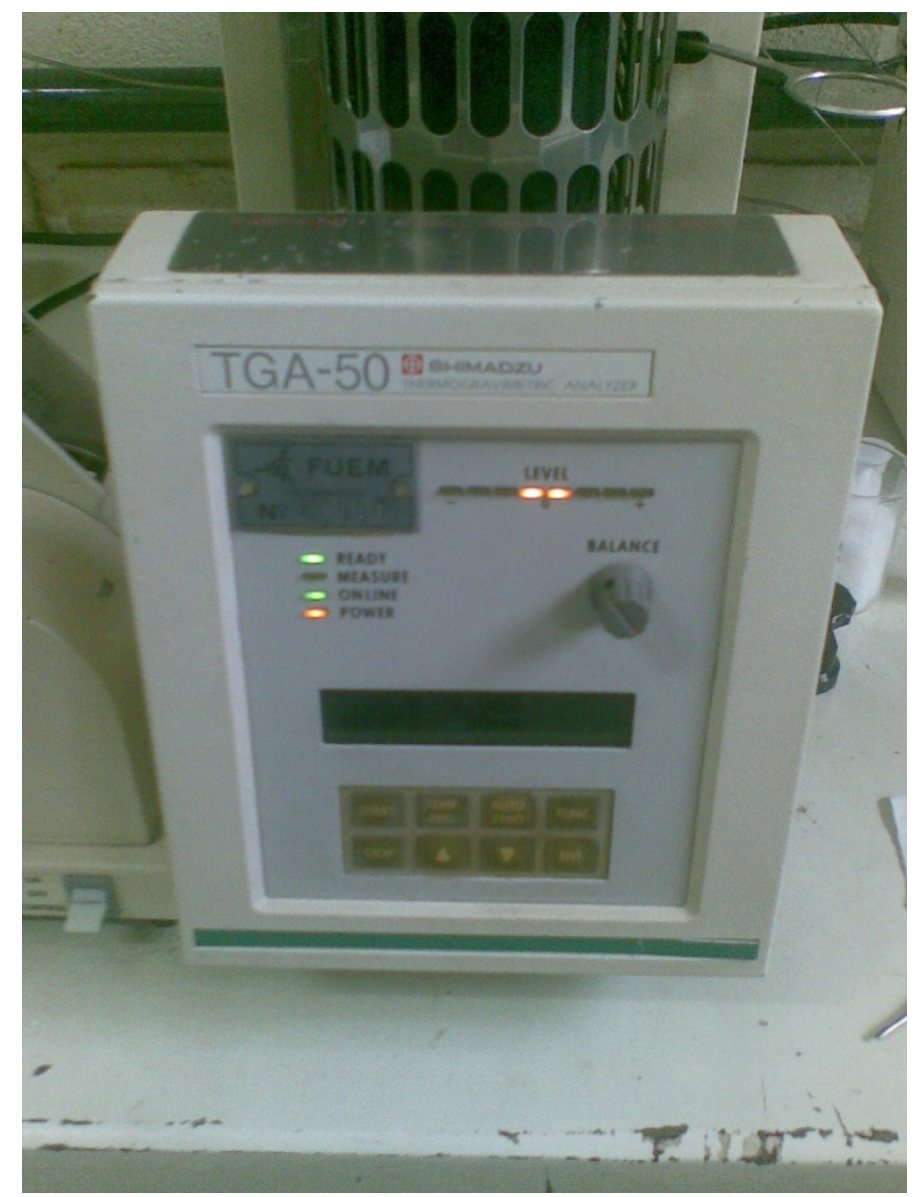

Figura 27 - Calorímetro diferencial SHIMADZU modelo TGA-50.,

Para quantificação da progesterona impregnada pesaram-se 0,0500 g de amostra em balança analítica de precisão (MARTE, modelo AM-220) e adicionou-se em 25mL de álcool etílico (F. MAIA, pureza mínima de 99,3 \%) sob agitação, durante 24 horas, para extração da progesterona. Em seguida, centrifugou-se a suspensão à 8.000 rpm, durante 30 minutos em uma centrifuga JOUN, modelo GR2022. Filtrou-se o sobrenadante em filtro de nylon de $0,45 \mu \mathrm{m}$.

\subsubsection{MICROSCOPIA ELETRÔNICA DE VARREDURA}

A distribuição de tamanhos das partículas foi determinada usando a técnica de microscopia eletrônica de varredura, utilizando o equipamento SHIMADZU, modelo SS-550 Superscan. (Figura 28) As micrografias foram analisadas com o programa Size Meter 1.1.(Figura 29) 


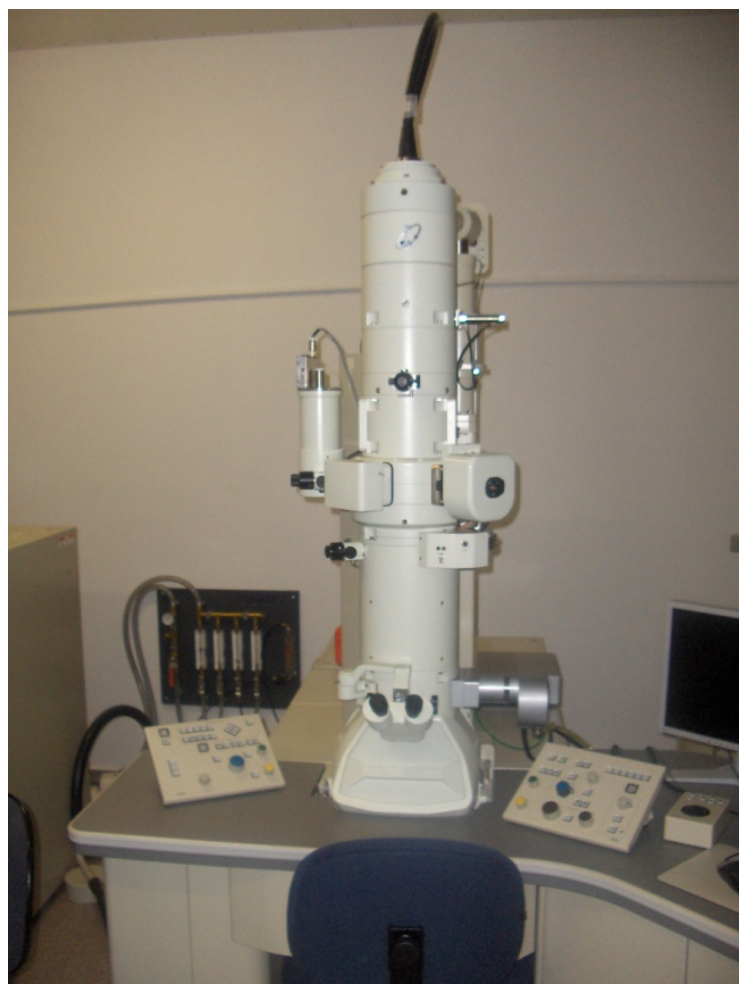

Figura 28 - Microscópio eletronico SHIMADZU, modelo SS-550 Superscan. Maringá- PR.

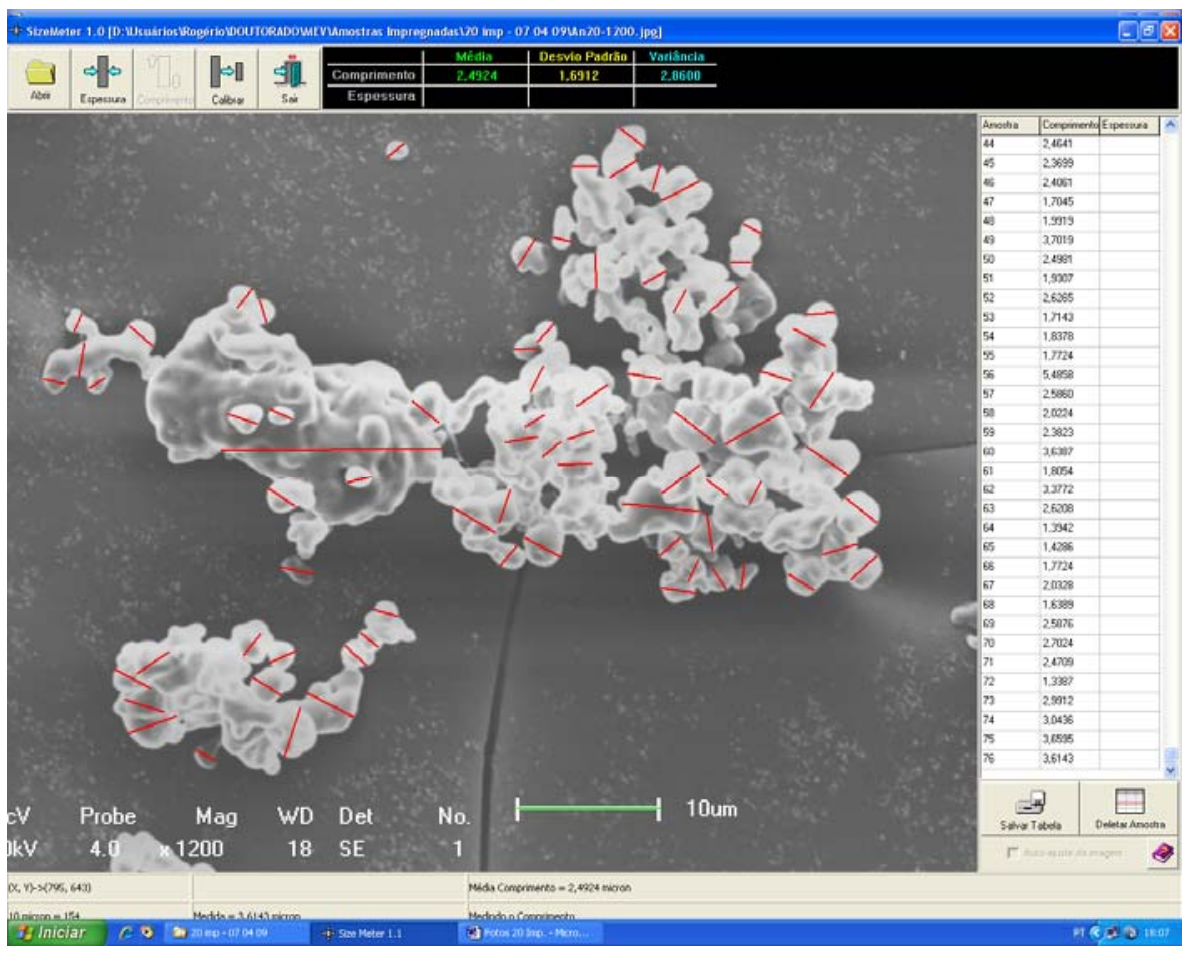

Figura 29 - Programa Size Meter 1.1. 


\subsubsection{POTENCIAL ZETA}

Foi utilizado como solvente, etanol e água na proporção 60:40 w/w. As amostras foram solubilizadas em banho ultra-sônico (Unique ${ }^{\circledR}$ 25KHZ - 3.8lt com aquecimento). As amostras foram submetidas à análise utilizando equipamento Malvern zetasizer nano-zs para determinação do potencial zeta e viscosidade das amostras.

\subsection{Resultados e discussão}

\subsubsection{Caracterização das partículas de PHB-V}

Na Tabela 16, encontram-se os valores de tamanho médio de partícula, desvio padrão experimental e fração mássica de progesterona impregnada nas amostras PHBV1; PHB-V2 e PHB-V3.

Nestas partículas, não houve a mistura de poli- -capolactano (PCL), e a amostra PHB-V1, não foi submetida ao processo supercrítico, sendo utilizada como controle. Esta partícula,foi submetida somente ao processo de impregnação com progesterona. As partículas PHB-V1 E PHB-V2, são amostras oriundas dos experimentos 17 e 18 respectivamente. O tamanho médio das partículas, bem como a porcentagem de progesterona impregnada, encontra-se na tabela 16. As fotografias da MEV encontram-se nas figuras 30, 31 e 32, e a distribuição do tamanho destas partículas, dentro de cada experimento, nas figuras 17,19 e 21. Observou-se que a amostra não processada apresentou partículas com tamanho médio de 39,5 $\mu \mathrm{m}$ de comprimento por 25,5 $\mu \mathrm{m}$ de largura, com grande distribuição de tamanhos e formatos irregulares. A impregnação foi de $1,79 \%$ de progesterona em relação à massa de partículas. As partículas PHBV1, PHBV2 E PHBV3, carregaram 894,56; 3091,24 e 3714,49 $\mu \mathrm{g}$ de progesterona para cada $50 \mathrm{mg}$ de partícula, respectivamente. As partículas PHB-V2 e PHB-V3 apresentaram menores tamanhos, 1,6 $\mu \mathrm{m}$ e 2,4 $\mu \mathrm{m}$, e maior rendimento no processo de impregnação: 6,06 e 7,43 \% respectivamente. 
Tabela 16 - Tamanho médio de partícula PHB-V e porcentagem de progesterona impregnada, em relação à massa de NPs na amostra.

\begin{tabular}{llll}
\hline Amostra & TMP $(\mu \mathrm{m})$ & Desvio $(\mu \mathrm{m})$ & $\%$ \\
\hline PHB-V1 & $39,6 \times 25,5$ & $29,2 \times 20,8$ & 1,79 \\
PHB-V2 $(19)$ & 1,6 & 0,4 & 6,06 \\
PHB-V3 (20) & 2,4 & 1,9 & 7,43 \\
\hline
\end{tabular}

\subsubsection{Características das MPs PHB-V1}

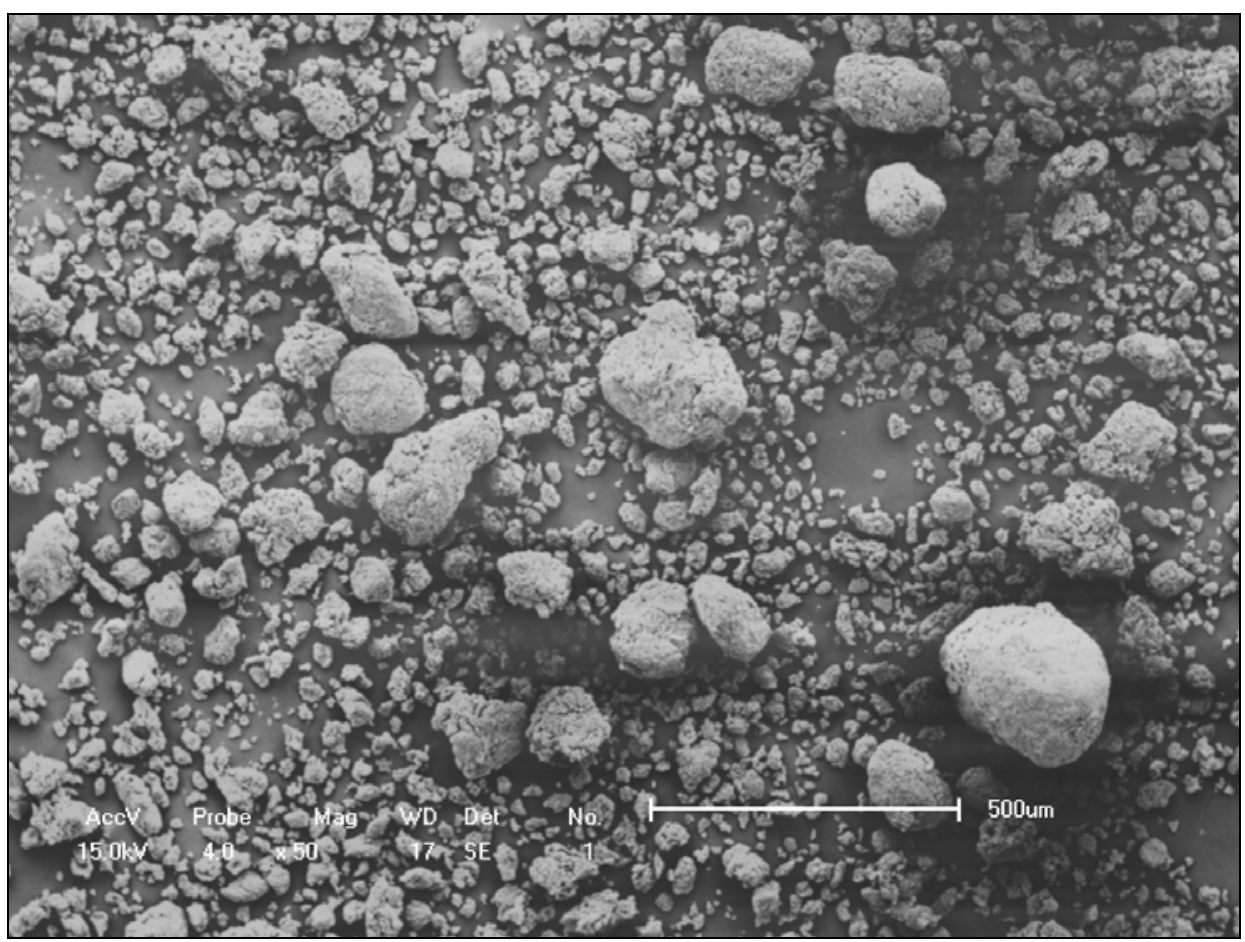

Figura 30 - PHBV-1 aumento40X (500 $\mu \mathrm{M})$. 


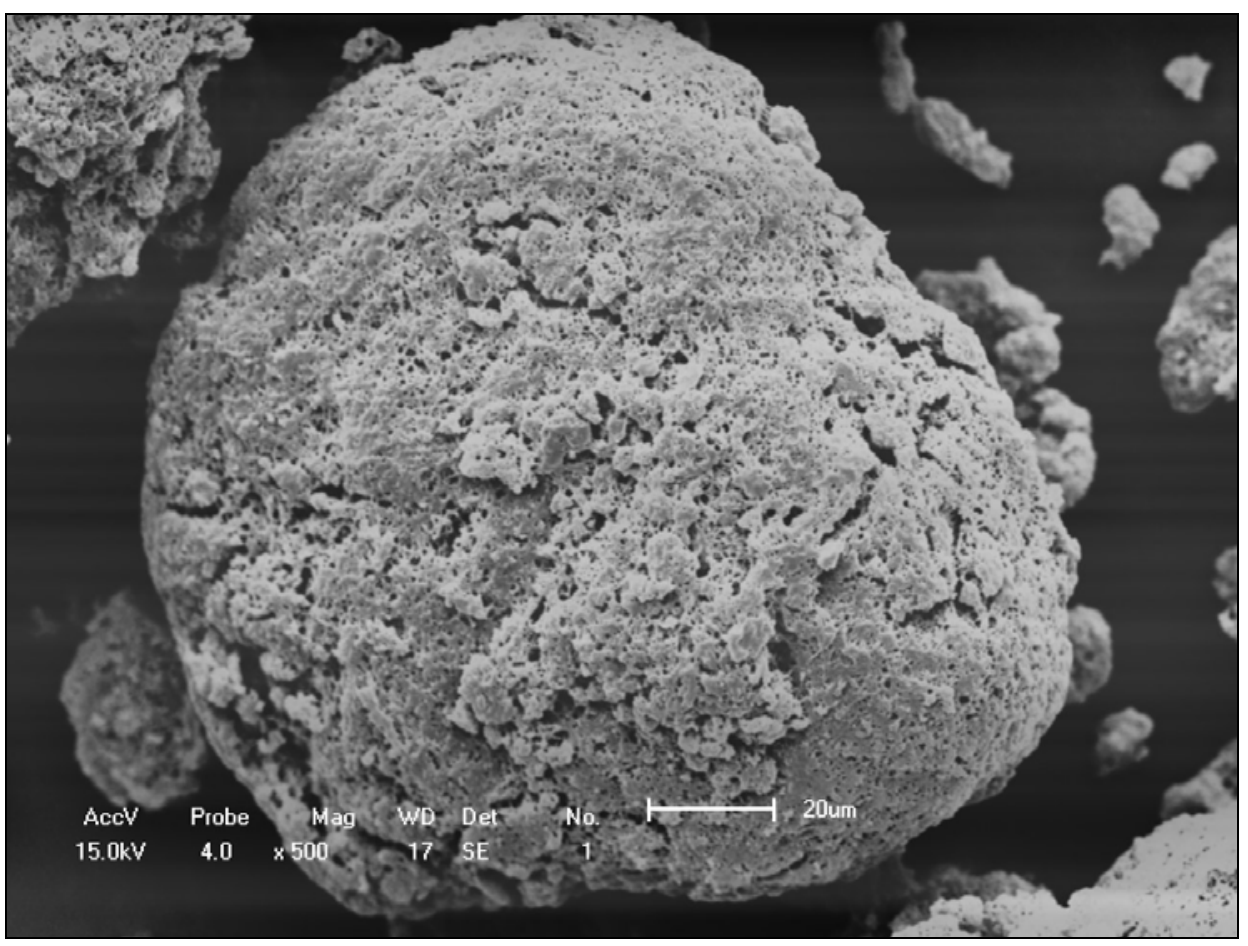

Figura 31 - PHB-V1 aumento 500x (20 $\mu \mathrm{m})$.

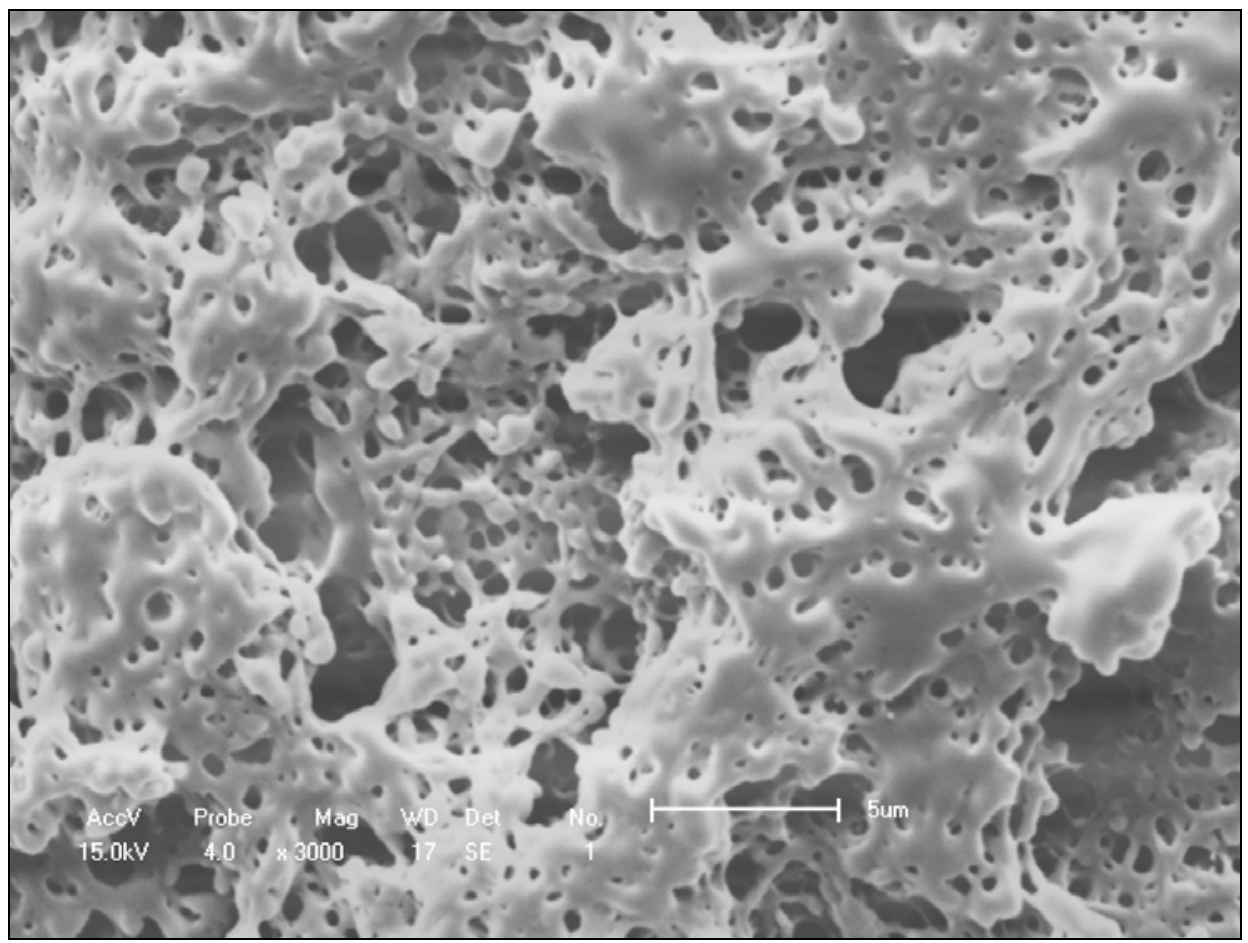

Figura 32 - PHB-V1 aumento 300x (5 $\mu \mathrm{m})$. 


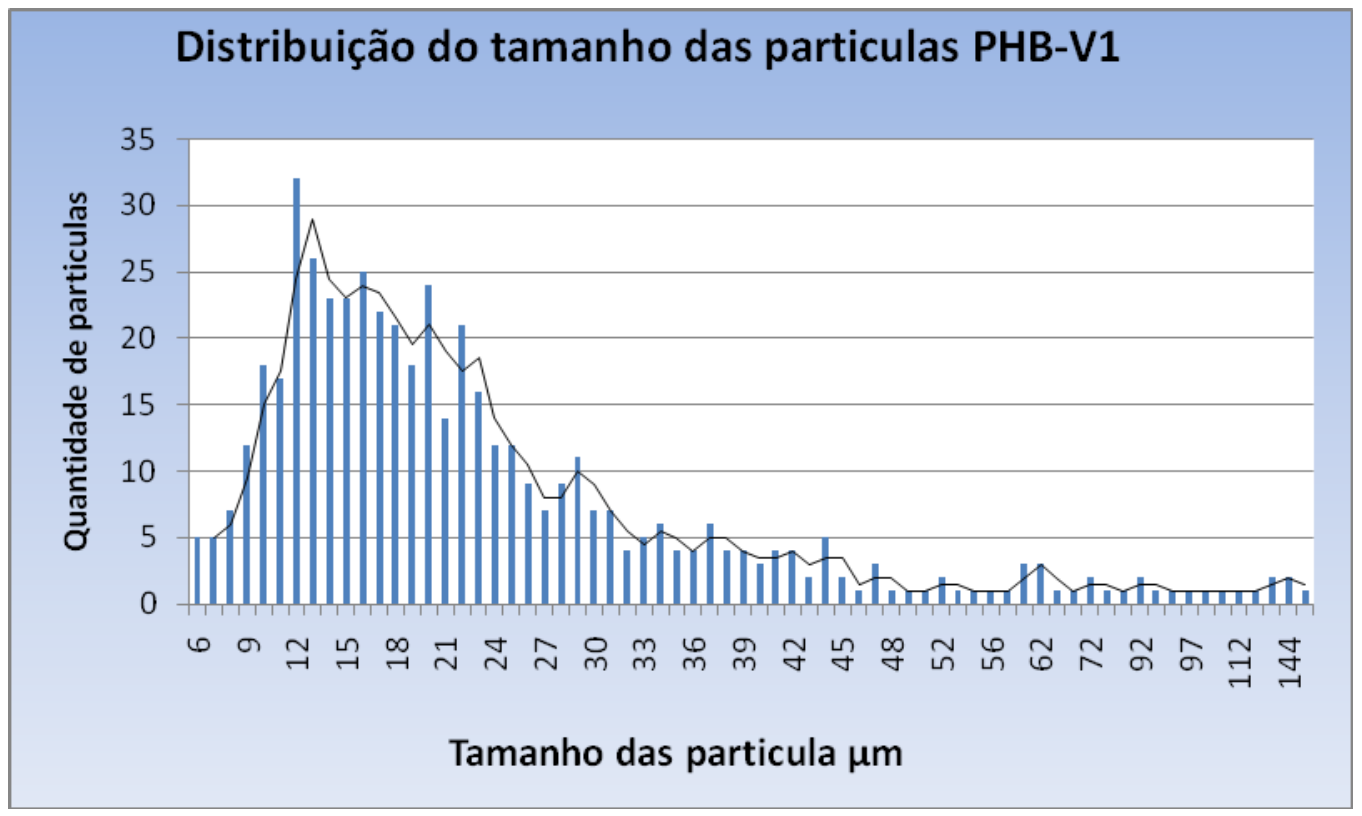

Figura 33 - Distribuição do tamanho das partículas de PHB-V1 amostra não processada.

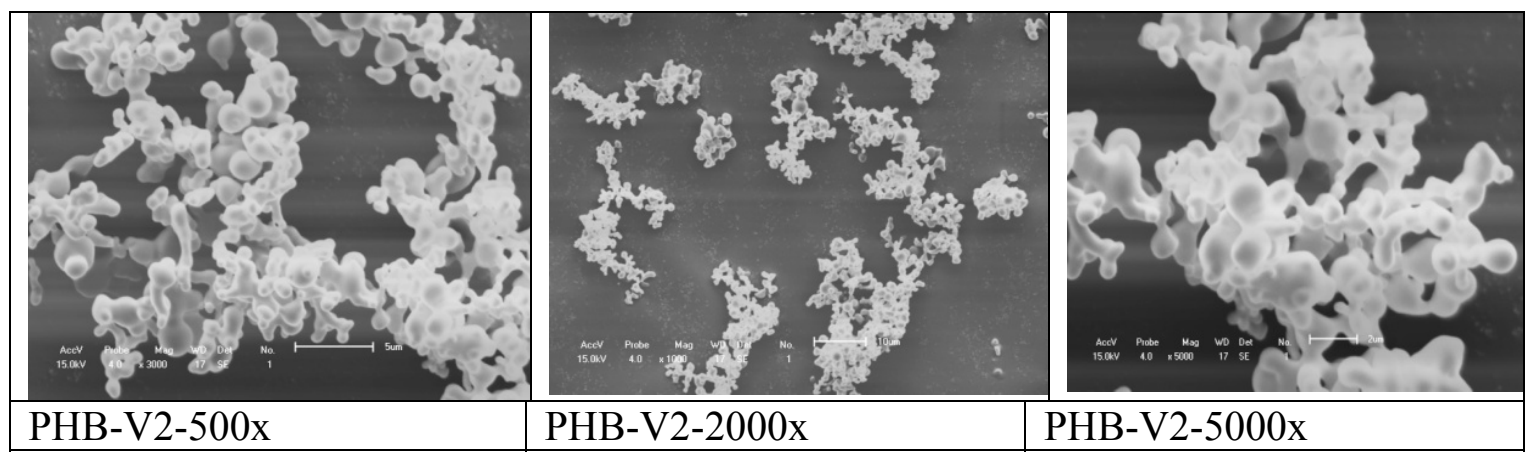

Figura 34 - Microscopias eletrônicas de varredura PHB-V2.

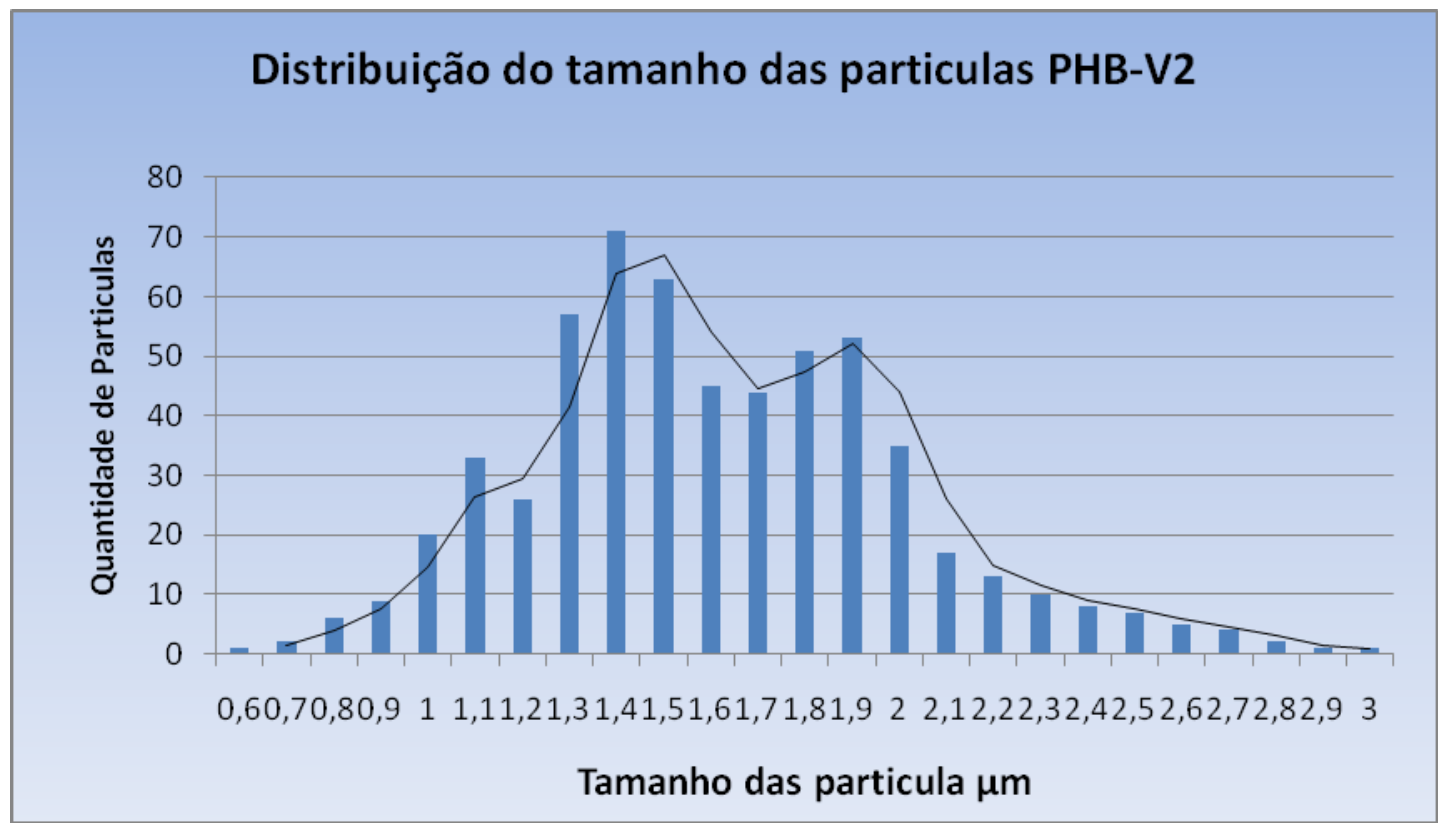

Figura 35 - Distribuição do tamanho das partículas da amostra de PHB-V2 obtida por processo supercrítico. 


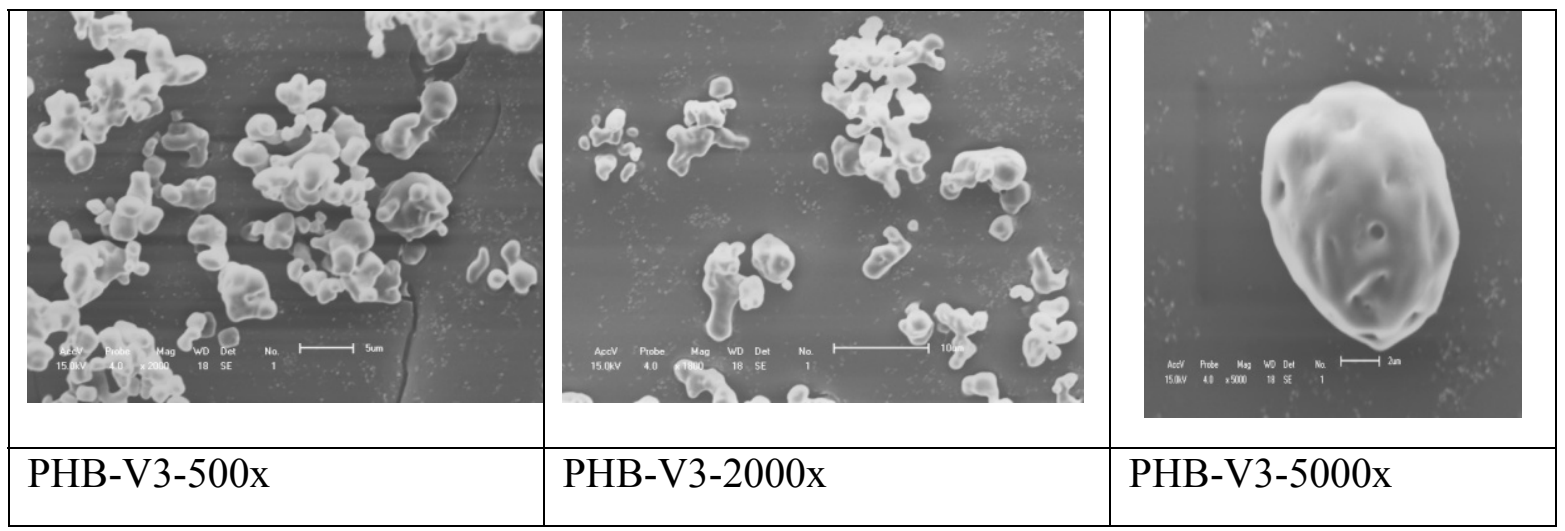

Figura 36 - Microscopias eletrônicas de varredura PHB-V3.

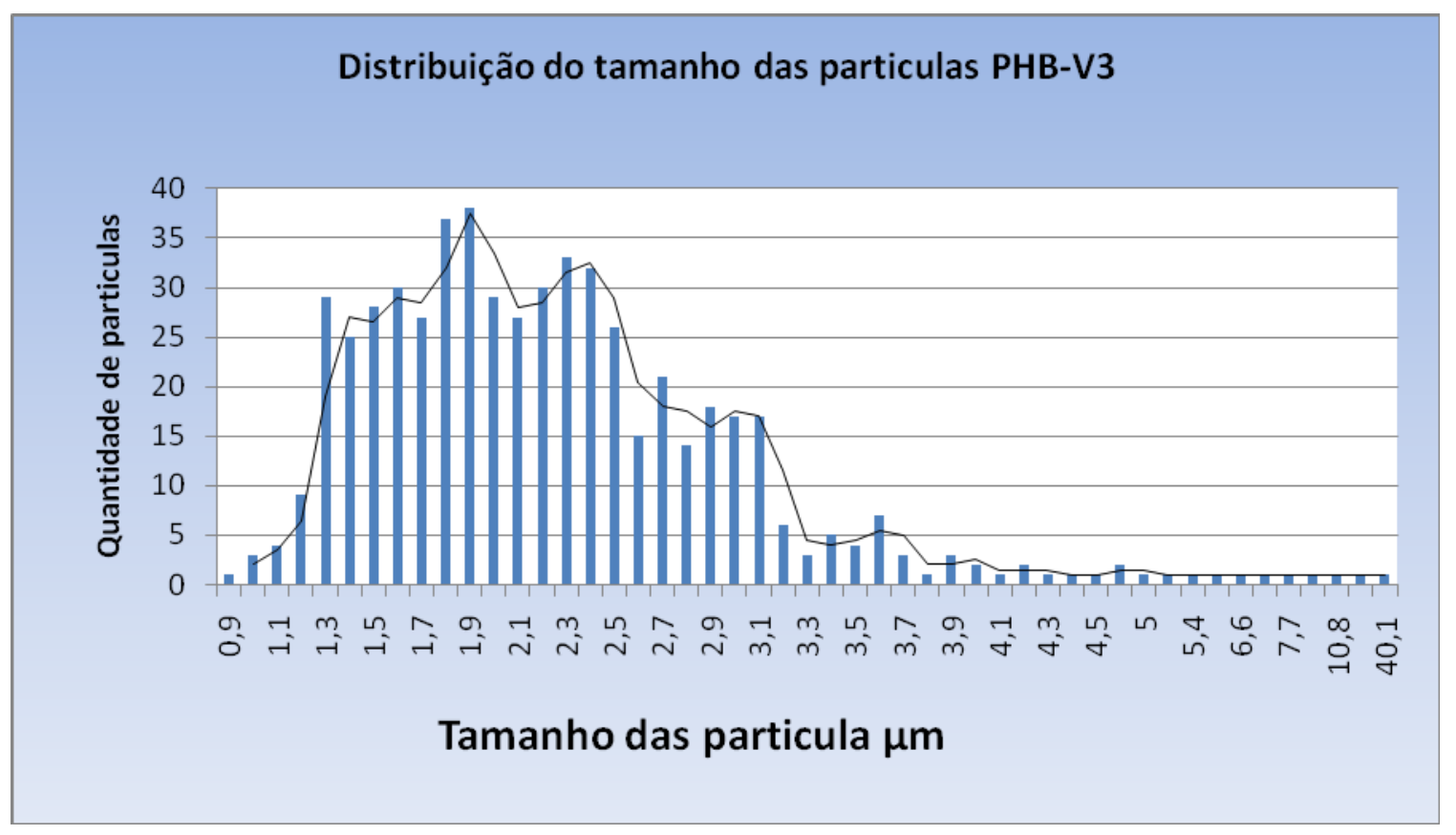

Figura 37 - Distribuição do tamanho das partículas da amostra de PHB-V3 obtida por processo supercrítico.

\subsubsection{Conclusões}

Foi observado através da análise por MEV, que as amostras PHB-V2 e PHBV3 apresentam partículas esféricas, irregulares, com baixa distribuição de tamanho comparadas com as partículas da amostra PHB-V1. A carga máxima de progesterona carregada nesta partícula também foi menor que as partículas processadas em meio supercrítico. 
A distribuição do tamanho das partículas das amostras PHB-V2 e PHB-V3 foi menor que PHB-V1. O tamanho médio das partículas foi de 39,6; 1,6 e 2,4 $\mu \mathrm{m}$ de diâmetro para as partículas PHB-V1; PHB-V2; PHB-V3 respectivamente. O desvio padra do tamanho das amostras foi alto para as partículas PHB-V1 $(29,2 \mu \mathrm{m})$. o mesmo não ocorreu para as partículas que passaram pelo processo supercrítico. Nesta partículas, o desvio foi de 0,4 e 1,9 $\mu \mathrm{m}$ para as amostras PHB-V2 e PHB-V3 respectivamente.

\subsection{Caracterização das partículas de PHB-V/PCL}

As partículas PHB-V1/PCL, PHB-V2/PCL e PHB-V3/PCL, foram confeccionadas com a proporção de 50\% PHB-V e 50\% PCL.

O tamanho médio das partículas e respectivas porcentagens de progesteronadas blendas de PHB-V/PCL encontram-se na Tabela 13. Nas figuras 22, 24 e 26 estão ilustradas as MEVs das partículas PHB-V1/PCL, PHB-V2/PCL e PHB-V3/PCL, com tamanhos de 1,97; 1,14 e 1,99 $\mu \mathrm{m}$, respectivamente. Nas figuras 23, 25 e 27 está ilustrada a distribuição do tamanho das partículas das misturas PHB-V1/PCL, PHBV2/PCL e PHB-V3/PCL, obtidas por processo supercrítico. As NPs de PHBV3/PCL carregaram a maior porcentagem de progesterona: 11,04\%, em relação à massa de partículas.

Figura 38 - Tamanho médio de partícula PHB-V/PCL e porcentagem de progesterona impregnada, em relação à massa de NPs na amostra.

\begin{tabular}{llll}
\hline Mistura Polimérica & TMP e desvio padrão $(\mu \mathrm{m})$ & Variância & $\%$ \\
\hline PHB-V1/ PCL & $1,97 \pm 0,62$ & 0,39006 & 5,86 \\
PHB-V2/ PCL & $1,14 \pm 0,32$ & 0,1008 & 3,86 \\
PHB-V3/ PCL & $1,99 \pm 0,52$ & 0,2742 & 11,04 \\
\hline
\end{tabular}




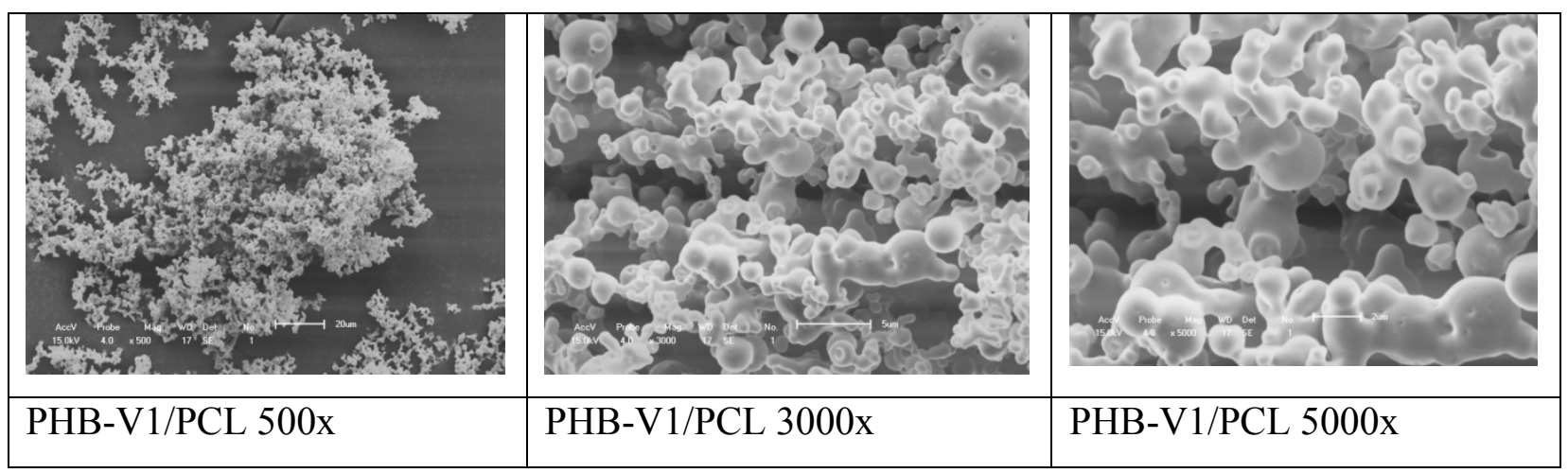

Figura 39 - Microscopias eletrônicas de varredura PHB-V1/PCL.

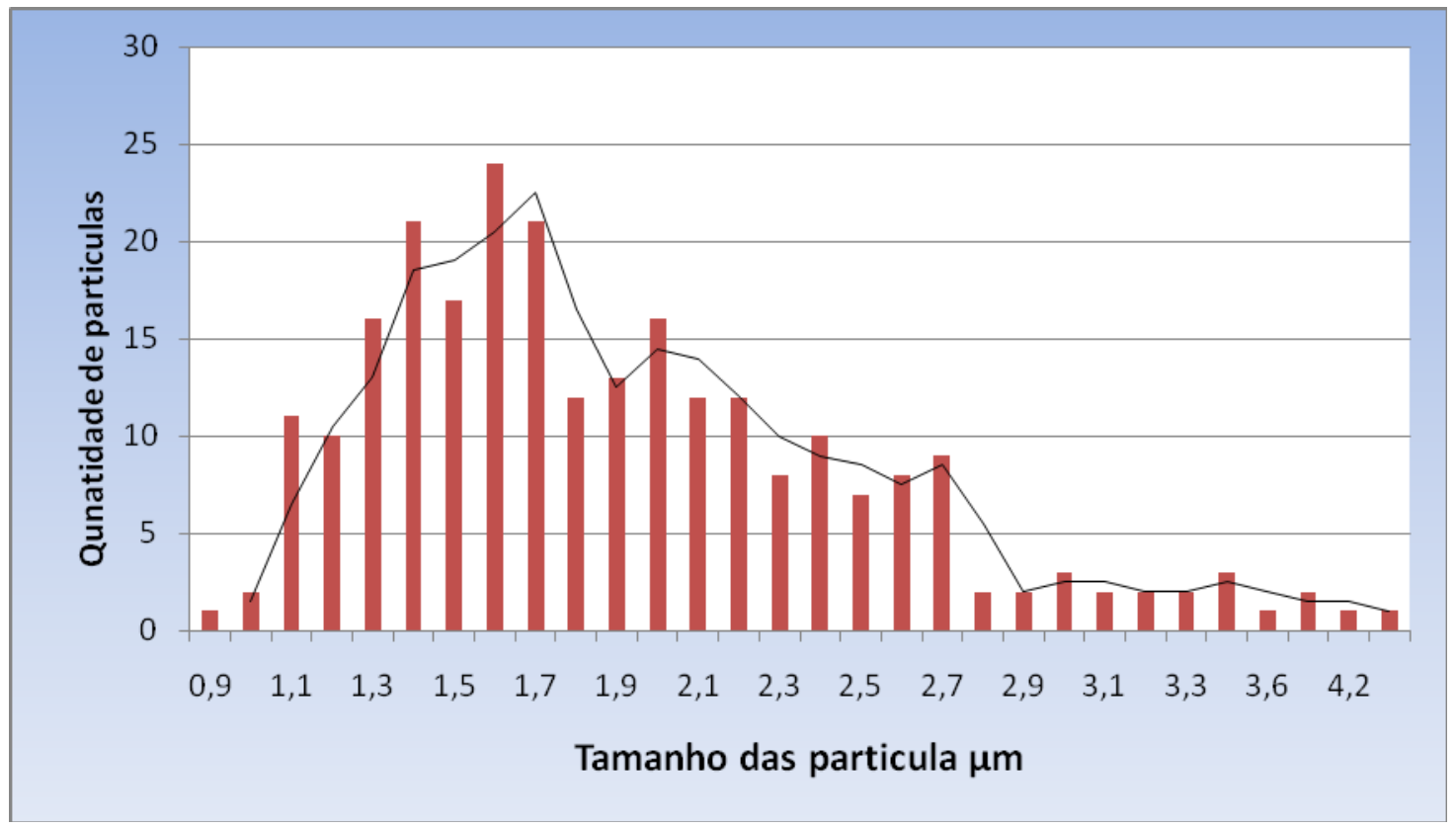

Figura 40 - Distribuição do tamanho das partículas de PHB-V1/PCL obtidas por processo supercrítico.

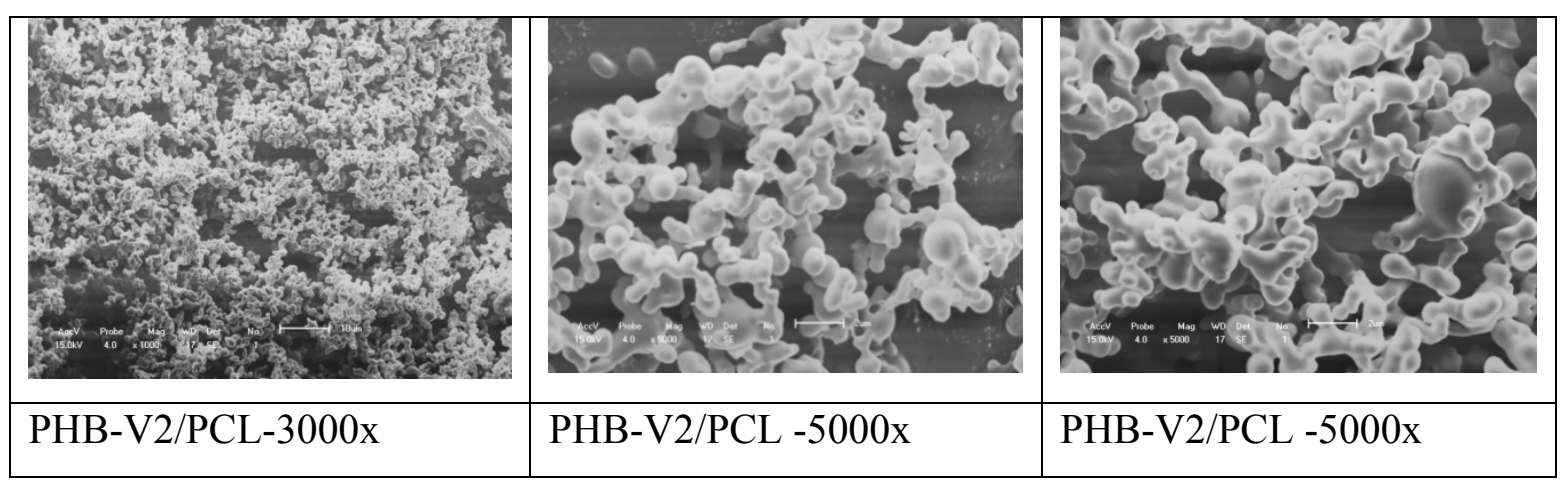

Figura 41 - Microscopias eletrônicas de varredura PHB-V2/PCL. 


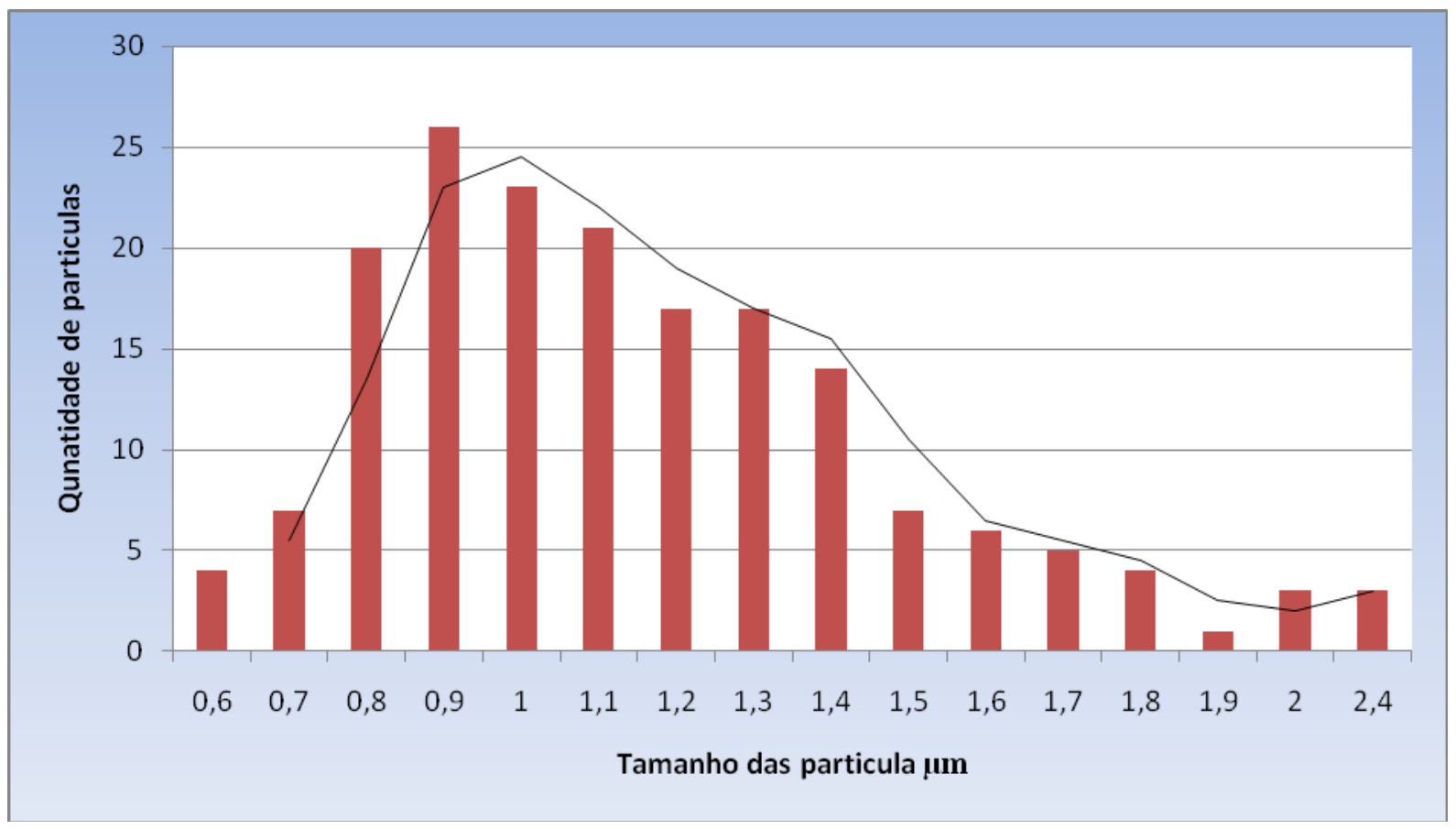

Figura 42 - Distribuição do tamanho das partículas de PHB-V2/PCL obtidas por processo supercrítico.

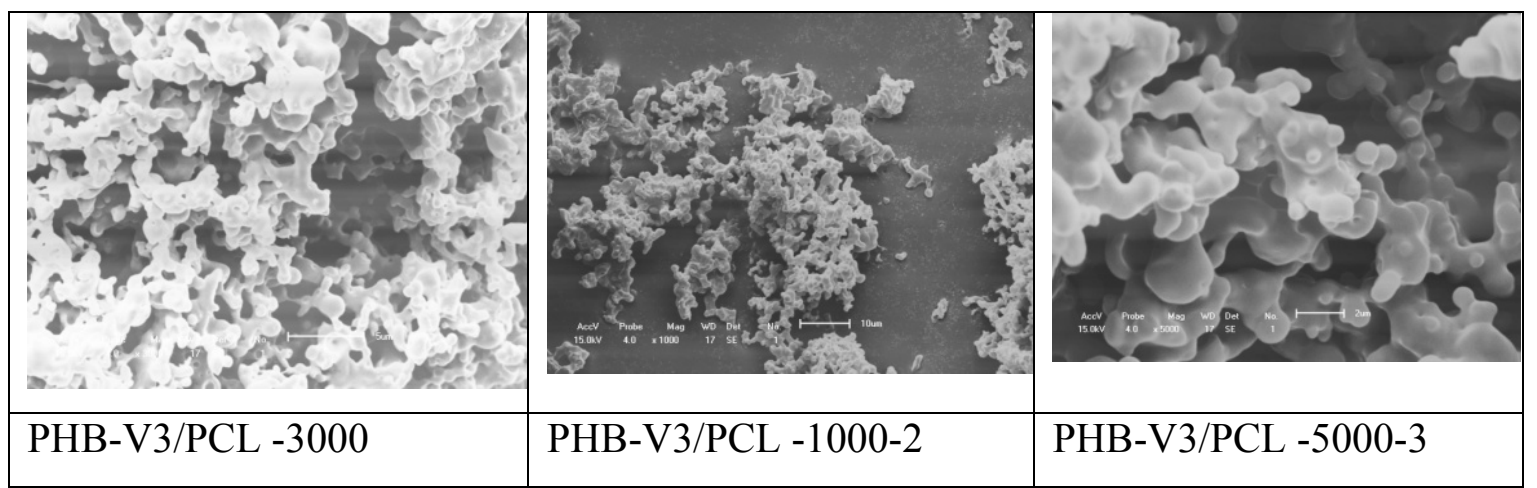

Figura 43 - Microscopias eletrônicas de varredura PHB-V3/PCL.

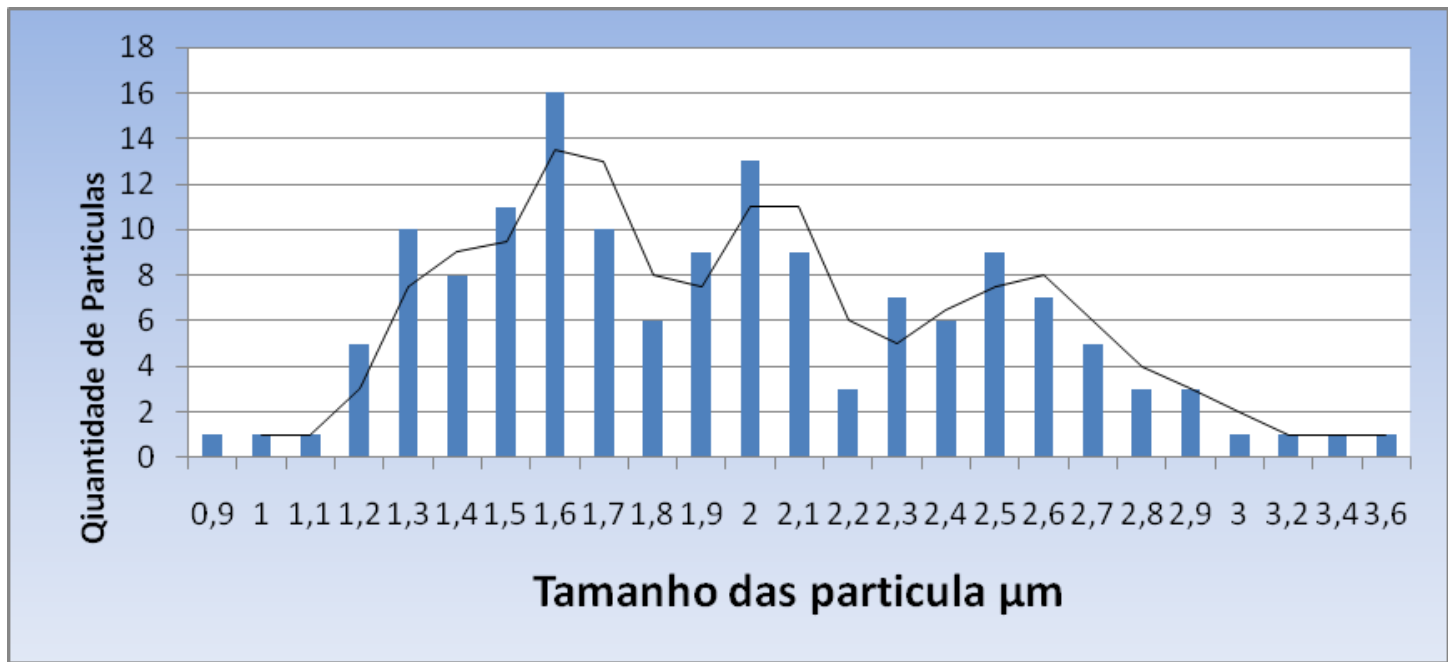

Figura 44 - Distribuição do tamanho das partículas de PHB-V3/PCL obtidas por processo supercrítico. 


\subsection{POTENCIAL ZETA}

O potencial zeta é por definição o potencial elétrico no plano de deslizamento $\left(x_{\mathrm{S}}\right)$, que pode ser calculado a partir de uma propriedade eletrocinética. Ele reflete o potencial de superfície das partículas, o qual é influenciado pelas mudanças na interface com o meio dispersante, em razão da dissociação de grupos funcionais na superfície da partícula ou da adsorção de espécies iônicas presentes no meio aquoso de dispersão (MAGENHEIM, et al.,1991;MOSQUEIRA et. Al.,2000). Este parâmetro é determinado utilizando- se técnicas de eletroforese (HOFFMANN, et al., 1997; ALONSO, et al., 1991; CALVO et. Al., 1997). Os fosfolipídeos (lecitinas), os poloxamers (copolímeros dos óxidos de etileno e de propileno) e os polímeros constituintes das nanopartículas são os principais componentes presentes nas formulações capazes de influenciar o potencial zeta. A sua determinação é importante para se produzir uma suspensão de partículas para os experimentos de liberação in vivo e entender os mecanismos relacionados à cinética de liberação in vitro. Quando se administram em um modelo animal, NPs ou MPs convencionais, estas são rapidamente removidas da circulação sanguínea pela ação de células do sistema fagocitário, dificultando a chegada do fármaco ao sítio de ação(CALVO, et al, 2001). Diferentes estratégias têm sido propostas para modificar a distribuição in vivo das nanopartículas, baseadas principalmente na redução da hidrofobicidade da superfície das partículas pela adsorção física de um polímero hidrofílico [poli(etilenoglicol)] (Soppimath, et al, 2001; Calvo, et al, 2001; De Jaeghere, et al. 1999)

Via de regra, um valor de potencial zeta relativamente alto é importante para uma boa estabilidade físico-química da suspensão coloidal, pois grandes forças repulsivas tendem a evitar a agregação em função das colisões ocasionais de nanopartículas adjacentes. As características de superfície das partículas, também podem alterar a resposta biológica do fármaco associado. No atual estudo, o potencial zeta encontrado, sempre apresentou um valor negativo (tabela $\mathrm{xx}$ ). Na pratica, as partículas com potencial negativo elevado após a suspensão na solução álcool/água, 
permaneciam no fundo do tudo. Quanto o potencial zeta se aproxima do zero, as partículas tendem a se manter em suspensão (figura 45).

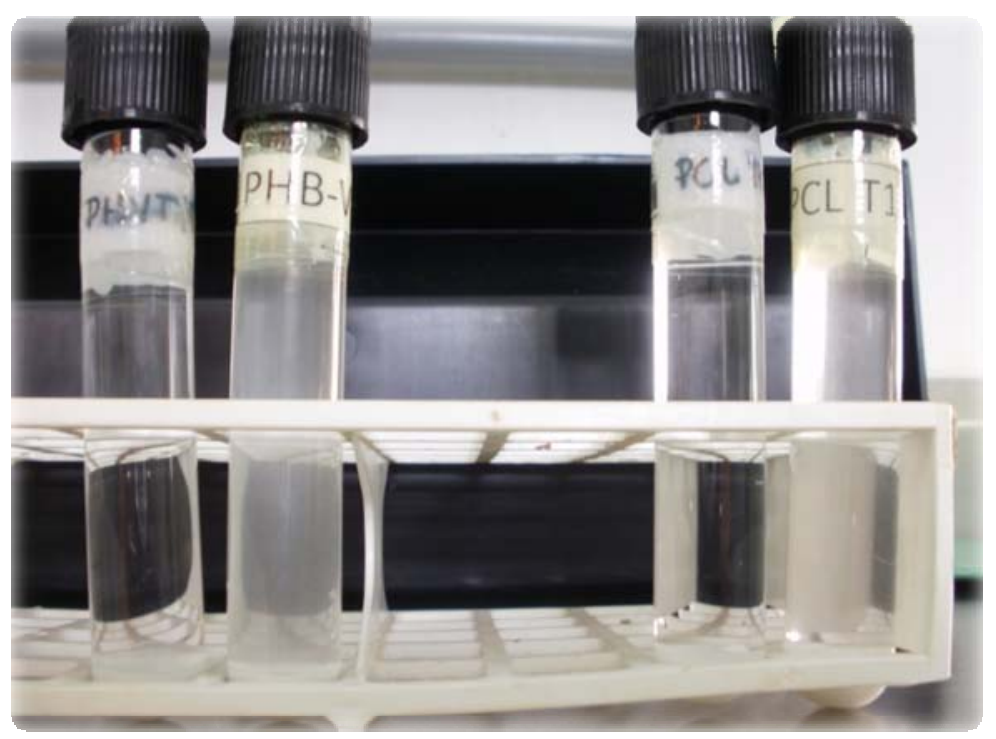

Figura 45 - Exemplo de partículas em suspensão em solução álcool/água. Pirassununga 2010.

No experimento 2, o potencial zeta das partículas não diferiram entre si. Com exceção da partícula PHB-V3, todas apresentaram um valor negativo em pH entre $7.0 \mathrm{e}$ 7.6. e a viscosidade não se alterou entre as partículas. Estes dados, corroboram com os encontrados na literatura (Müller, et al., 2001; Guterres, et al., 2008). As formulações preparadas com a poli( $\varepsilon$-caprolactona) apresentaram potencial zeta negativo $(-23,3 \pm 0,3$ $\mathrm{mV}$ ) decorrente da presença dos grupamentos éster do polímero. Segundo Legrand e colaboradores (1999), os poliésteres, como o PLA, e as lecitinas fornecem um potencial negativo à interface, enquanto que, os poloxamers (tensoativos não-iônicos) tendem a reduzir o valor absoluto desta variavel. Em resumo, um valor de potencial zeta relativamente alto é importante para uma boa estabilidade físico-química da suspensão coloidal, pois grandes forças repulsivas tendem a evitar a agregação em função das colisões ocasionais de nanopartículas adjacente(LEGRAND, et al.,1999). Os valores do potencial zeta das partículas estão demonstrados na tabela 17 e nas figuras 46,47 e 48 . A variação do potencial em relação ao ph esta demonstrada nas figuras 49, 50 e 51 . 
Tabela 17 - Potencial zeta das partículas.

\begin{tabular}{lrr}
\hline Particula & \multicolumn{2}{c}{$\begin{array}{c}\text { Potencial } \\
\text { Zeta }\end{array}$} \\
\hline PHB-V1/PCL & -43 & pH \\
PHB-V2/PCL & $-48,4$ & 7,08 \\
PHB-V3/PCL & $-52,6$ & 7,56 \\
PHB-V1 & $-43,8$ & 7,31 \\
PHB-V2 & $-51,6$ & 7,6 \\
PHB-V3 & $-72,6$ & 7,6 \\
\hline
\end{tabular}

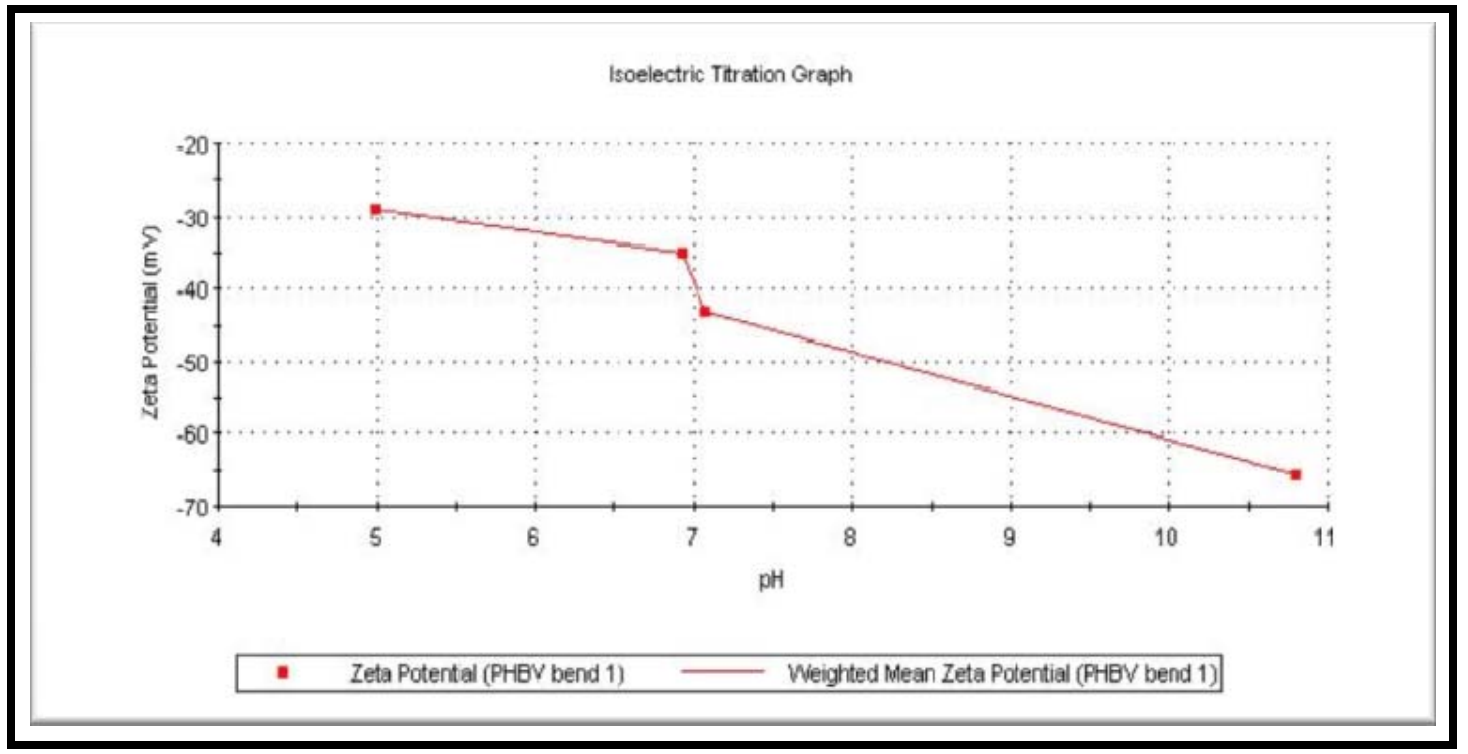

Figura 46 - Potencial Zeta Blenda PHB-V1/PCL.

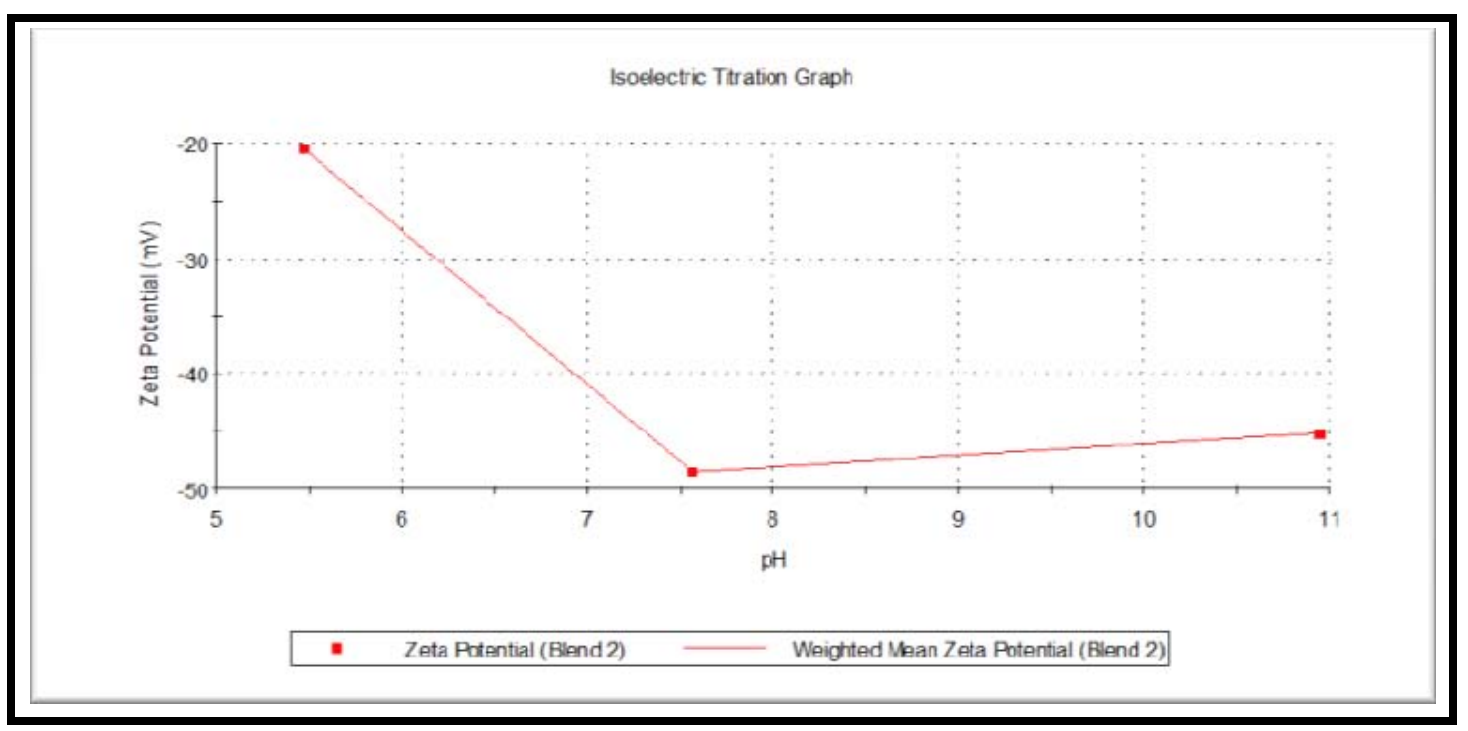

Figura 47 - Potencial Zeta Blenda Potencial Zeta Blenda PHB-V2/PCL. 


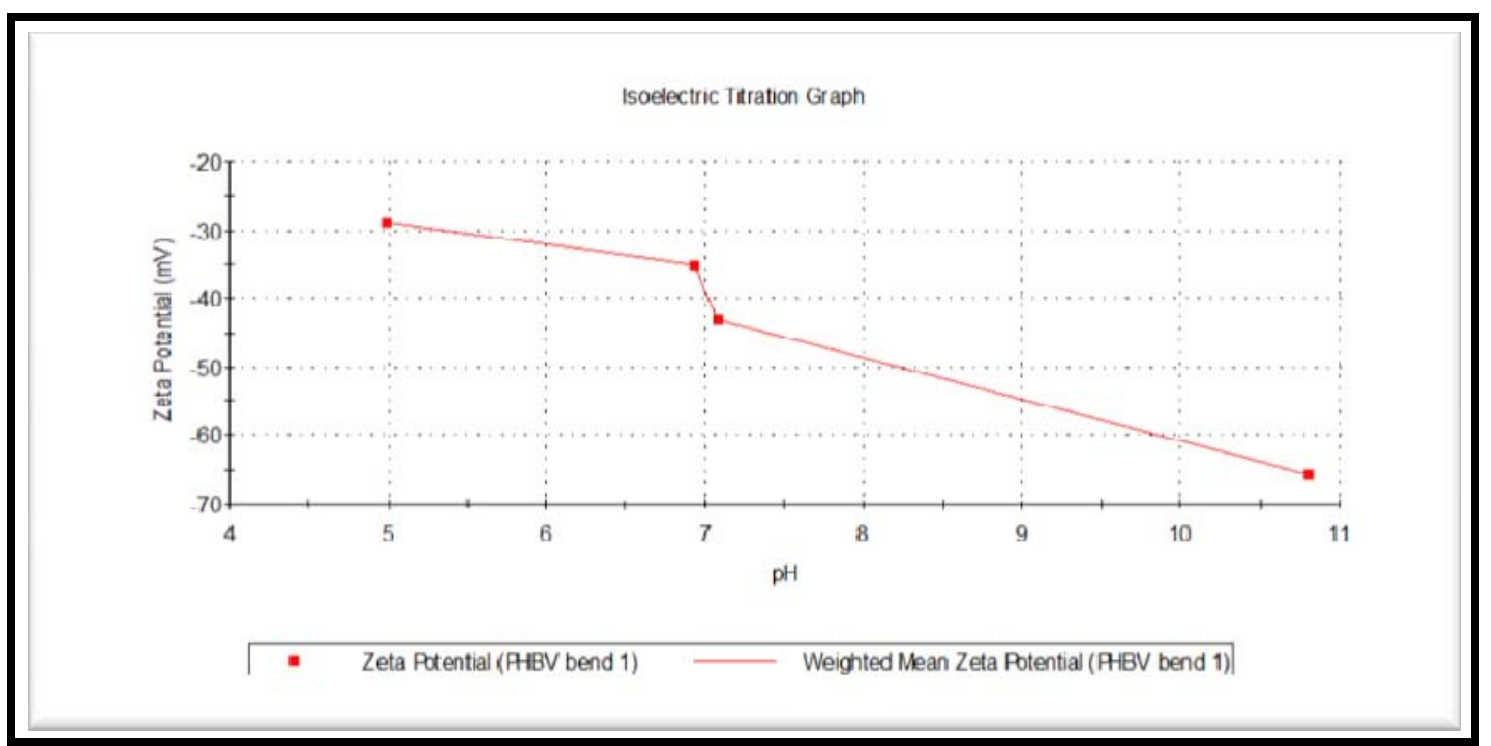

Figura 48 - Potencial Zeta Blenda Potencial Zeta Blenda PHB-V3/PCL.

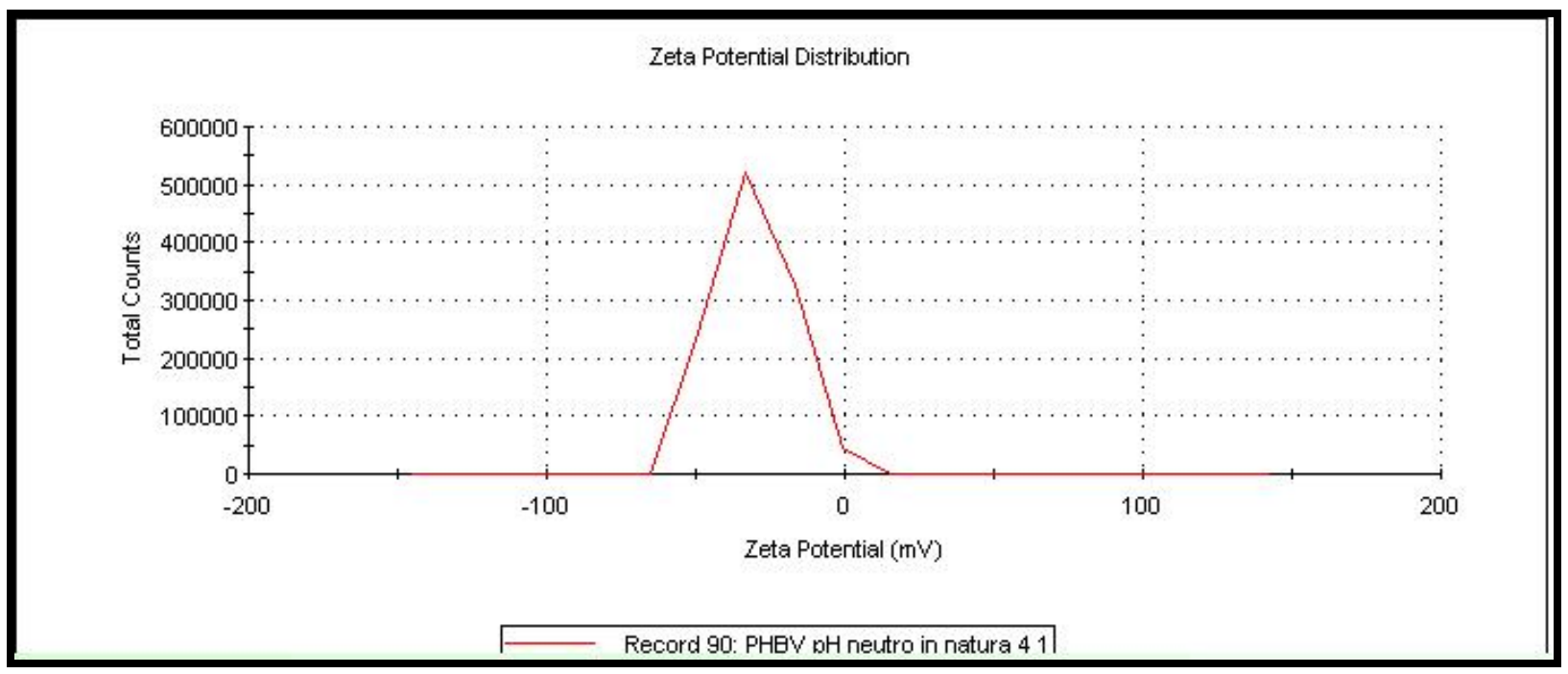

Figura 49 - Potencial Zeta Blenda PHB-V1, Ph 7,0, viscosidade 1.1900, potencial Zeta -30,6 mV variação $12,7 \mathrm{mV}$.

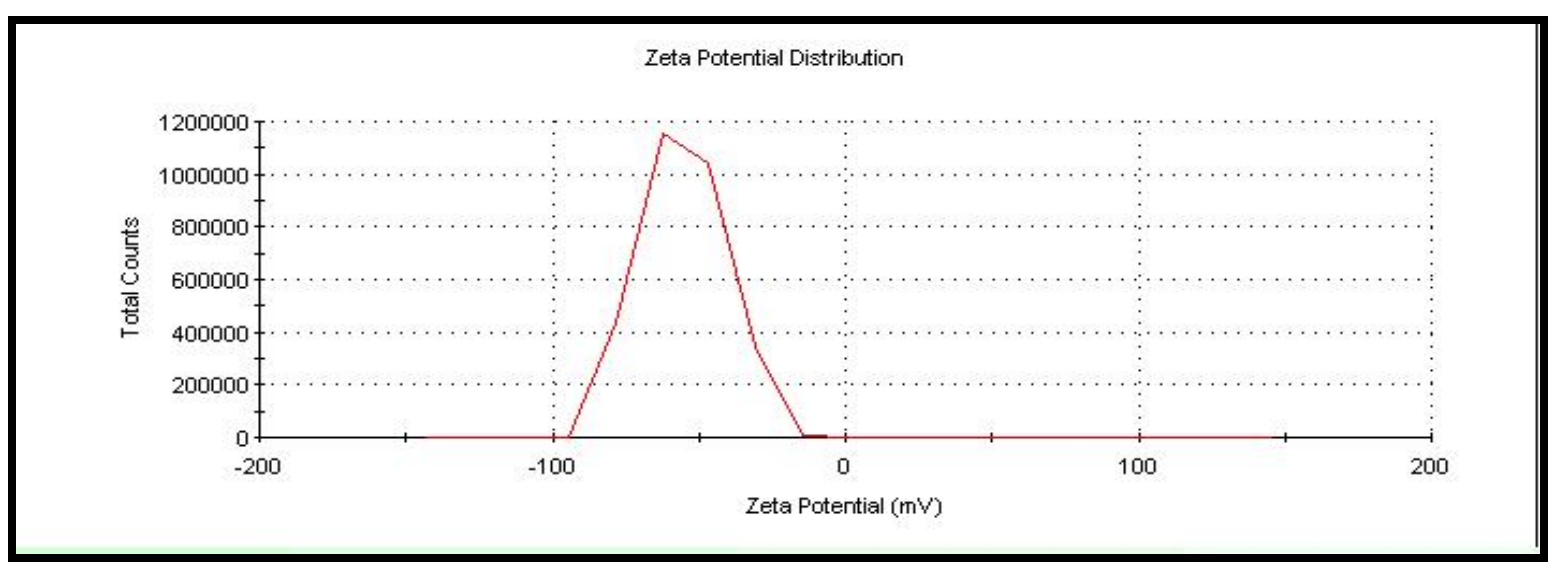

Figura 50 - Potencial Zeta Blenda PHB-V2, Ph 7,6, viscosidade 1.1900, potencial Zeta -51,6 mV variação $18,5 \mathrm{mV}$. 


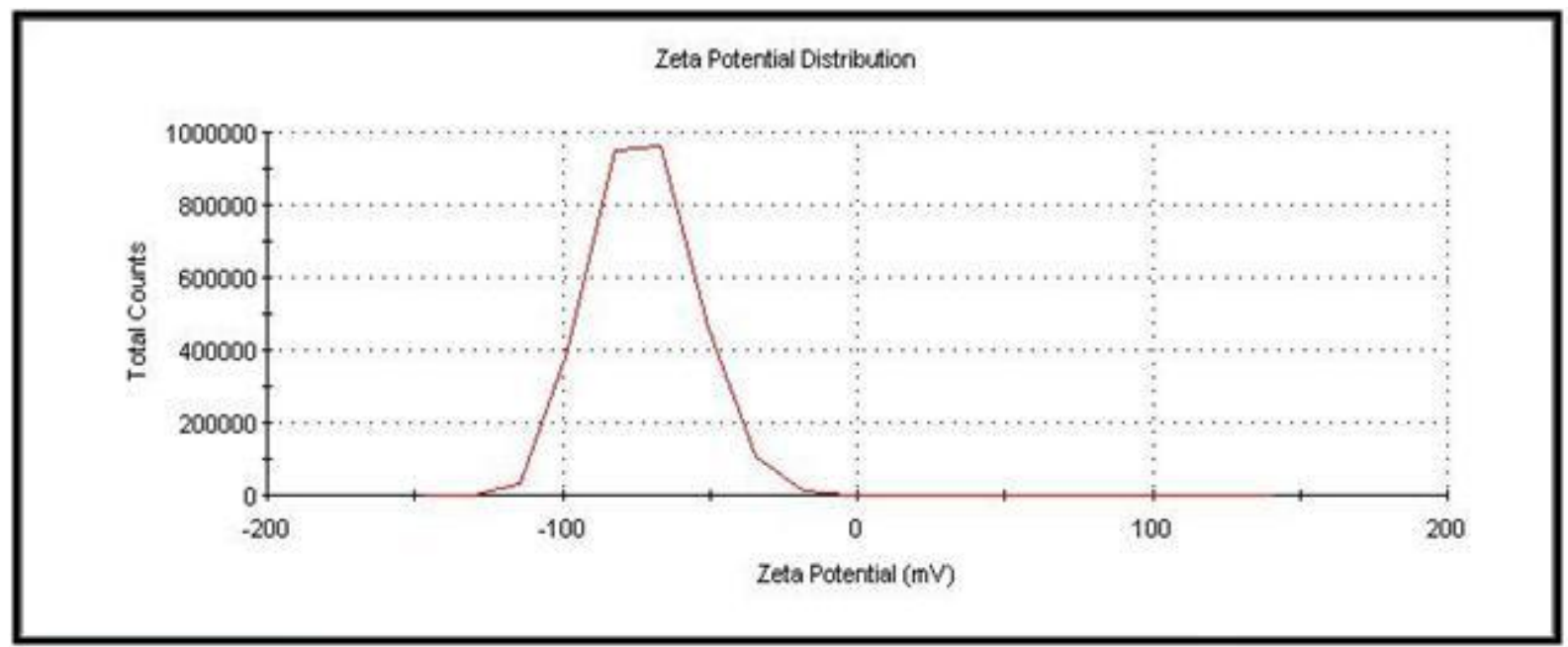

Figura 51 - Potencial Zeta Blenda PHB-V3, Ph 7,6, viscosidade 1.1900, potencial Zeta -72,6 mV variação $17,3 \mathrm{mV}$.

\subsection{Calorimetria exploratória diferencial (DSC)}

Para determinação da presença ou não do PCL nas blendas e o ponto de fusão dos vários compostos das blendas poliméricas, foi realizado DSC. Na figura 52 estão ilustrados os pontos para cada composto da blenda.

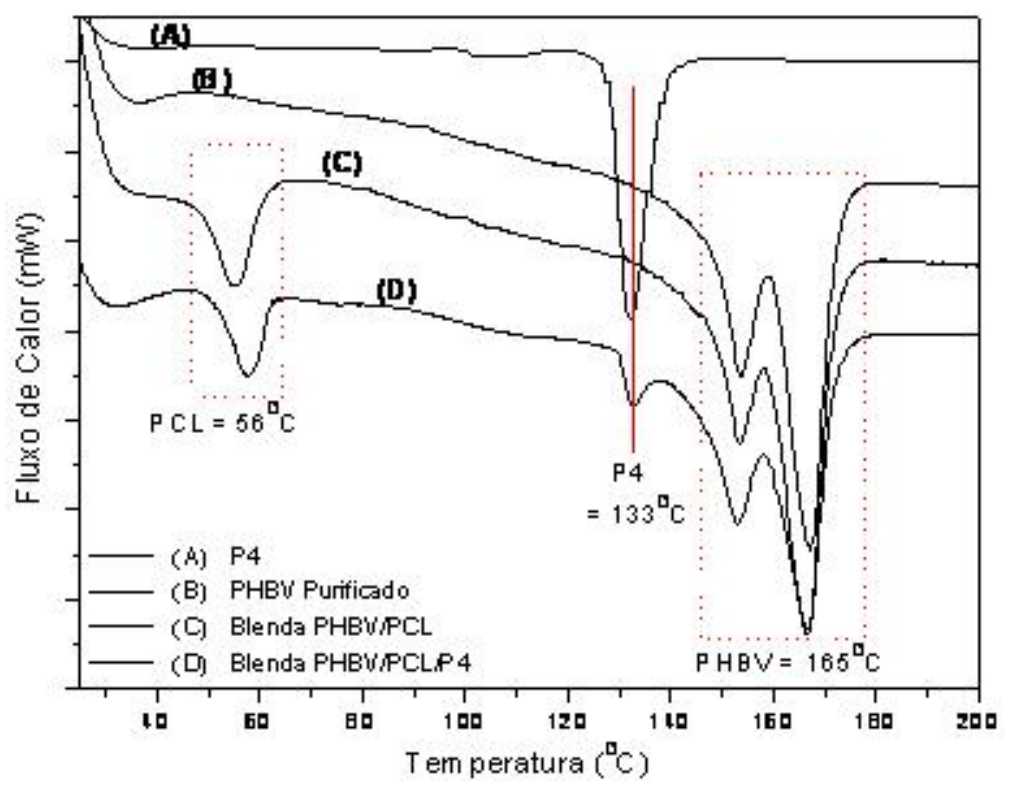

Figura 52 - Determinação do ponto de fusão dos variados compostos das blendas poliméricas. 
Nas figuras 53, 54 e 55, estão ilustradas as análises para as partículas PHBV/PCL, onde a linha vermelha identifica o ponto de fusão do poli- - -capolactana (PCL).

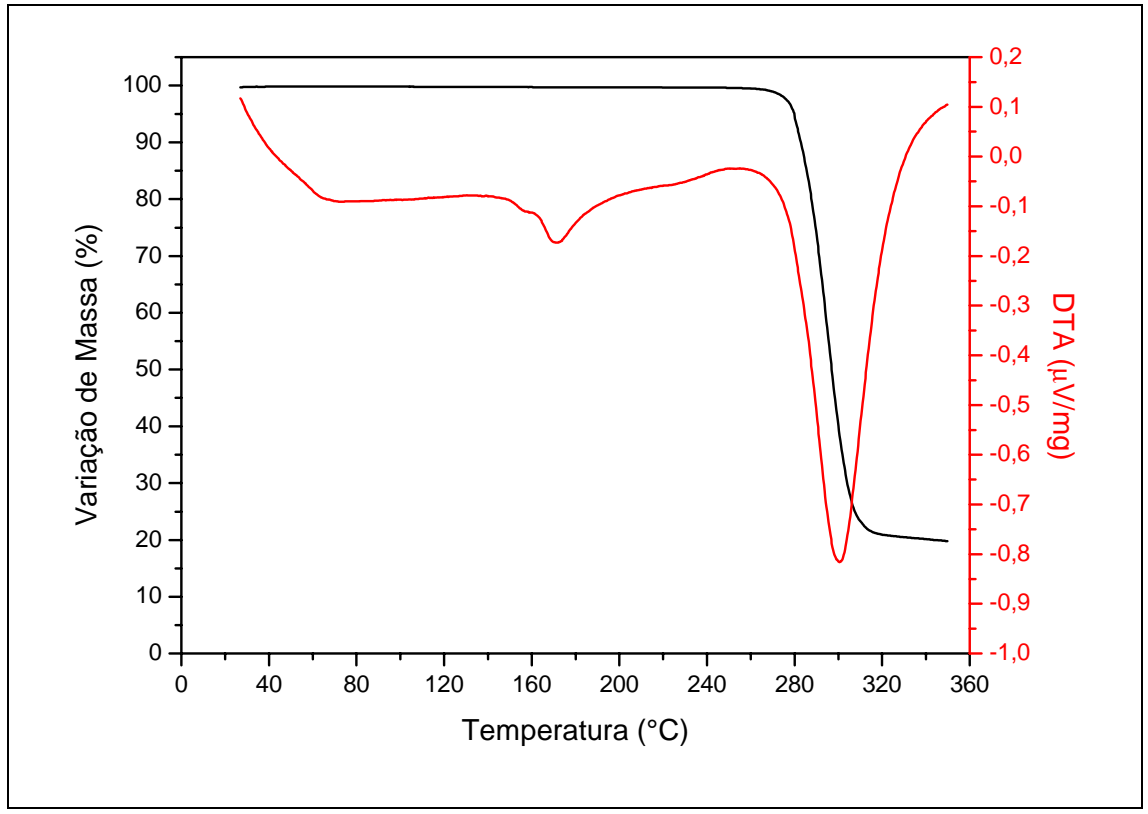

Figura 53 - Termogravimetria diferencial (DSC) PHB-V1/PCL.

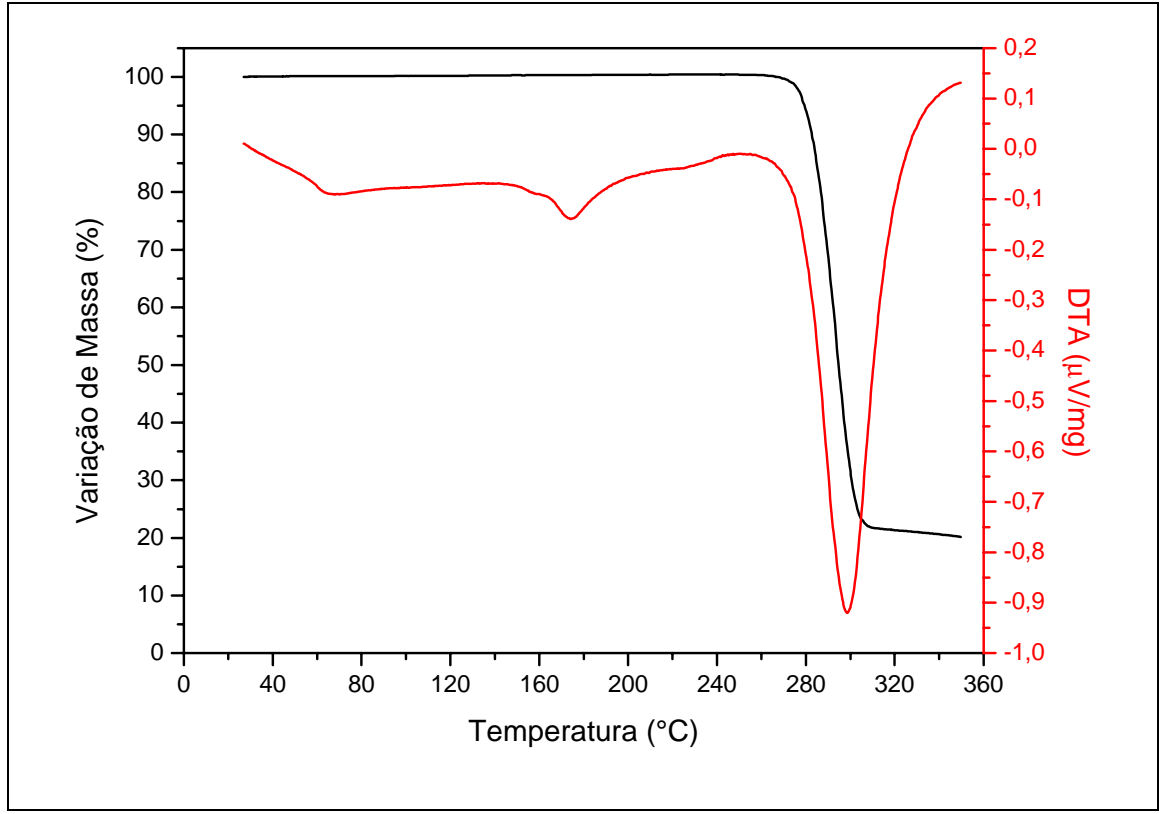

Figura 54 - Termogravimetria diferencial (DSC) PHB-V2/PCL. 


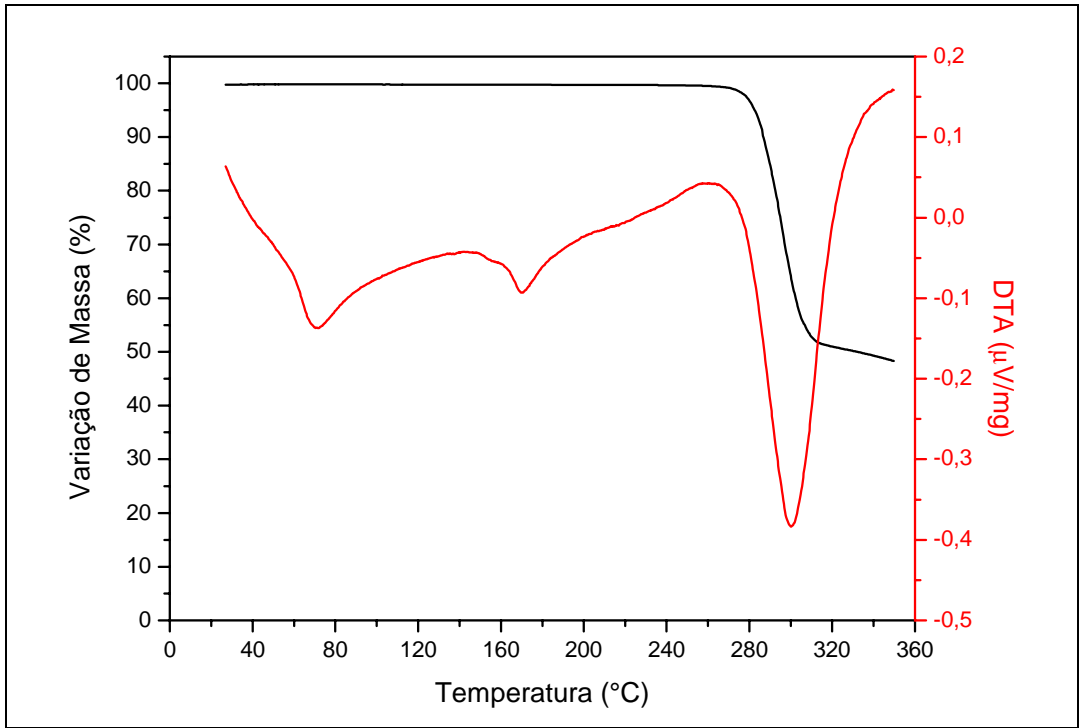

Figura 55 - Termogravimetria diferencial (DSC) PHB-V3/PCL.

Como demonstrado nas figuras 53, 54 e 55, todas as amostras apresentaram PCL na matriz polimérica. A amostra PHB-V3, apresentou uma quantidade maior que as demais. Esta esta partícula apresentou um TMP de 1,99 $\pm 0,52 \mu \mathrm{m}$ e a maior carga de $\mathrm{P} 4,13,49 \%$ de $\mathrm{P} 4$. Porém, esta se encontrava na superfície da partícula, como evidenciado no estudo da cinética de liberação in vitro (figura 60).

Em 2001, MÜLLER e colaboradores caracterizaram produtos secos de nanocápsulas e nanoesferas de poli( $\varepsilon$-caprolactona) contendo diclofenaco através de análise térmica (DSC) e MEV. Observaram que a poli- $\varepsilon$-caprolactona (PM $80.000 \mathrm{~g} / \mathrm{mol}$ ) em formulações de nanocápsulas e nanoesferas apresenta um menor grau de cristalinidade que na matéria-prima pura.

No atual estudo, o PCL utilizado foi o mesmo para todas as amostras, sendo, portanto esta diferença na carga de P4 devido ao modelo de produção. O PCL por ter um ponto de fusão inferior ao PHB, quando no momento do esvaziamento da câmara, pode ocorrer ou não a formação de "crateras" na superfície da partícula. Esta alteração na morfologia é evidenciada pela MEV. 
Capitulo 5 


\section{LIBERAÇÃO IN VITRO}

\subsection{Experimento 1 (Piloto)}

Com intenção de comparar a solução fosfato tamponado (DPBS),com a solução de álcool/água, como meio de liberação e tubo tipo Falcon de plástico ou tubo de vidro, utilizou-se técnica descrita por Baker et al (2005) adaptada.

Alíquotas de MPs foram pesadas para determinar sua massa total e acondicionadas em frascos tipo Falcon plástico de $15 \mathrm{ml}$ e vidro, também de $15 \mathrm{ml}$. As amostras foram então suspendidas com 10 mL de álcool/água 60/40 ou solução tampão fosfato (DPBS), conforme demonstrados na Tabela 18.

Tabela 18 - Divisão das amostras no experimento 1.

\begin{tabular}{lllll}
\hline Amostra & Tipo de NPs & Massa/ mg & Tipo frasco & Solução \\
\hline A1 & PHB-V + P4 & 6,48 & Falcom & $\begin{array}{l}\text { Álcool/água } \\
(60: 40)\end{array}$ \\
A2 & PHB-V + P4 & 7,86 & Falcom & $\begin{array}{l}\text { Álcool/água } \\
(60: 40)\end{array}$ \\
A3 & PHB-V + P4 & 5,88 & Falcom & $\begin{array}{l}\text { DPBS } \\
\text { DPBS }\end{array}$ \\
A5 & PHB-V + P4 & 6,33 & Falcom & $\begin{array}{l}\text { Álcool/água } \\
(60: 40)\end{array}$ \\
A6 & PHB-V + P4 & 5,37 & Vidro & $\begin{array}{l}\text { Álcool/água } \\
(60: 40)\end{array}$ \\
A7 & PHB-V + P4 & 5,61 & Vidro & $\begin{array}{l}\text { Álcool/água } \\
(60: 40)\end{array}$ \\
A8 & PCL + P4 & 8,43 & Vidro & $\begin{array}{l}\text { Álcool/água } \\
(60: 40)\end{array}$ \\
A9 & PCL + P4 & 7,24 & Vidro & DPBS \\
A10 & PCL + P4 & 10,89 & Vidro & DPBS \\
\hline
\end{tabular}

\subsubsection{Características das amostras}




\title{
5.1.1.1 PHB- $V+P_{4}$
}

Poli-hidroxi-butirato e valerato

Impregnada, $50^{\circ} \mathrm{C}, 150$ bar, 8 horas

\subsubsection{PCL $+P_{4}$}

\author{
Poli- -capolactona \\ Expandida, $3.200 \mathrm{psi}, 65^{\circ} \mathrm{C}, 4$ horas
}

\subsubsection{Metodologia empregada}

Após a suspensão com a solução específica, foram centrifugadas à $2.000 \mathrm{~g}$ por 10 minutos, com tempo de parada de 5 minutos. Coletou-se a primeira amostra (tempo zero) e em seguida, todas as amostras foram colocadas em banho maria, com agitação, (Dubnoff), à $37^{\circ} \mathrm{C}, 100 \mathrm{mov} / \mathrm{min}$. Amostras de $1 \mathrm{ml}$ foram coletadas no sobrenadante do frasco nos tempos $0,2,4,6,8,10,12$ horas. Após a coleta foi reposto no frasco $1 \mathrm{ml} \mathrm{de}$ solução. Este procedimento acompanhou todas as colheitas. Após a centrifugação, coletou-se $1 \mathrm{ml}$, e despejou-se em uma seringa de $3 \mathrm{ml}$ com um filtro de 0.22 micra acoplado na ponta. $\mathrm{O}$ conteúdo foi acondicionado em frascos de cor âmbar, fechados e guardados em geladeira $\left(5^{\circ} \mathrm{C}\right)$ até a hora da leitura em HPLC.

Para o cálculo de liberação foram utilizadas as seguintes equações:

Qe x 10

Onde Qe corresponde a quantidade de P4 encontrada na leitura do HPLC em $\mu \mathrm{g} / \mathrm{mL}$

Massa descartada nas coletas ( Md )

Md x Qe

Massa acumulada de P4 no meio ( Mac ) 
$\mathrm{a}+\mathrm{Md}$

Fator de correção para $50 \mathrm{mg}$ de amostra $\mathrm{Fc}$

$50 / \mathrm{Qi}=\mathrm{Fc}$

Onde Qi é a quantidade inicial de NPs no frasco

Quantidade de P4 liberada no meio para cada $50 \mathrm{mg}$ de NPs (QP4)

$\operatorname{Mac} \times \mathrm{Fc}=\mathrm{QP} 4$

\subsubsection{Resultados e discussão}

Os resultados estão ilustrados nos figuras 56,57 e demonstrados nas tabelas 19 e 20.

Não estão apresentados os dados das amostras utilizando o DPBS, pois as NPs não foram ao fundo do frasco nem mesmo após a centrifugação Com isto, no momento da colheita, poderiam ser retiradas partículas no sobrenadante da solução. Isto ocorreu talvez devido a grande quantidade de poros das partículas combinado com a progesterona que não é solúvel em água. Com isto as partículas permaneceram na superfície do frasco. O mesmo não ocorreu quando utilizou-se a solução de álcool/água (60:40) como solvente. Não foi determinado o Ph da solução nem o potencial zeta das partículas, por se tratar de um ensaio piloto. A utilização do tampão fosfato, como solução no ensaio de liberação in vitro, foi em função de se assemelhar ao modelo biológico, porém sem resultado.

Tabela 19 - Quantidade (mg) de Progesterona liberada por $50 \mathrm{mg}$ de NPs.

\begin{tabular}{lllll}
\hline Amostra & A1 & A2 & A5 & A6 \\
\hline TEMPO & PHB & PHB & PHB & PHB VIDRO \\
horas & FALCON & FALCON 2 & VIDRO & 2 \\
0h & 0 & 0 & 0 & 0 \\
$\mathbf{0 , 3 h}$ & 0,50 & 0,18 & O,15 & 0,097 \\
$\mathbf{2 h}$ & 0,48 & 0,30 & 0,39 & 0,36 \\
$\mathbf{4 h}$ & 0,47 & 0,34 & 0,51 & 0,48 \\
$\mathbf{6 h}$ & 0,48 & 0,36 & 0,57 & 0,50 \\
$\mathbf{8 h}$ & 0,47 & 0,37 & 0,61 & 0,59 \\
$\mathbf{1 0 h}$ & 0,48 & 0,38 & 0,66 & 0,60 \\
$\mathbf{1 2 h}$ & 0,49 & 0,39 & 0,65 & 0,60 \\
\hline
\end{tabular}




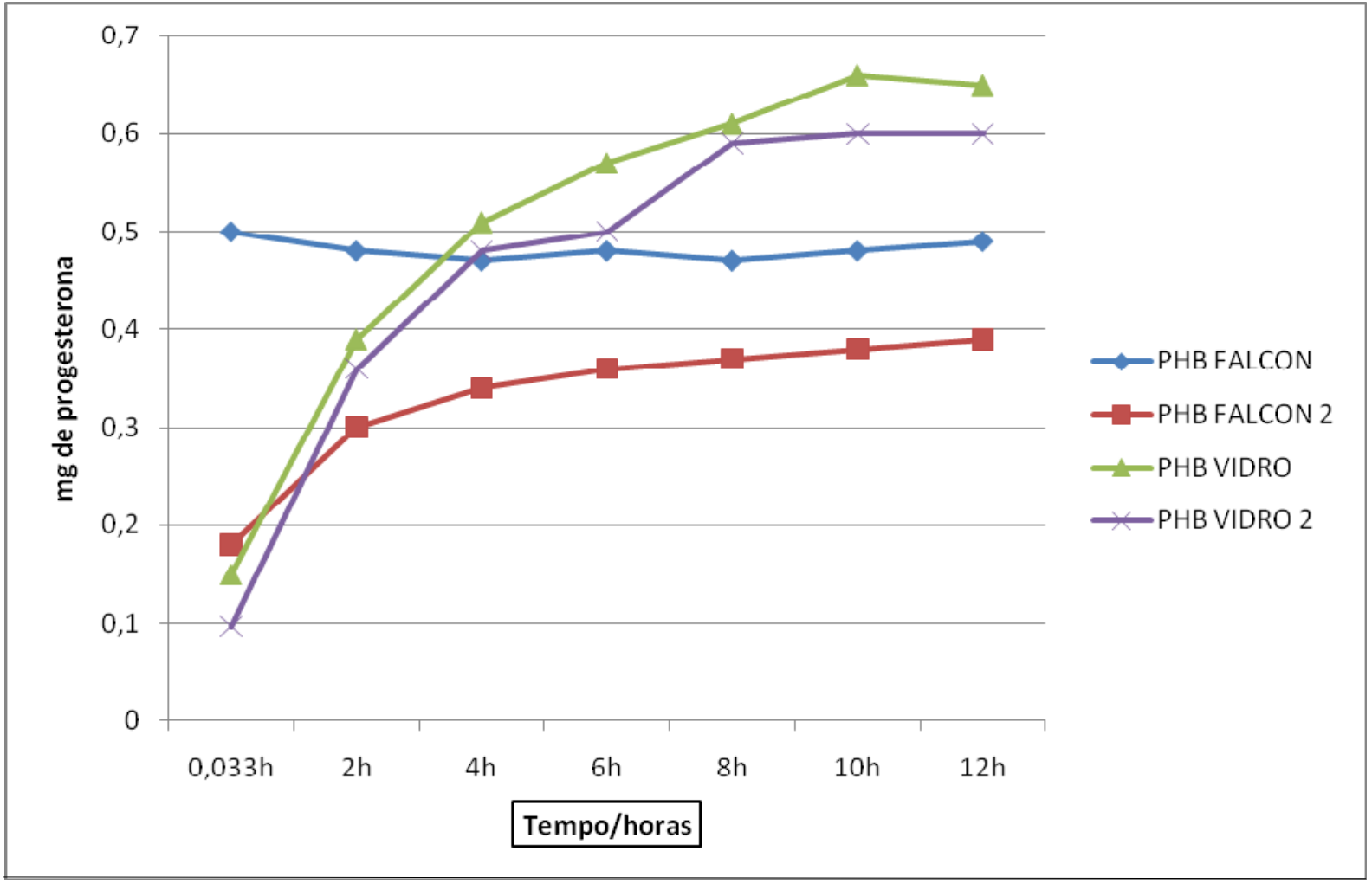

Figura 56Quantidade de Progesterona (mg) liberada por 50 mg de NPs de PHB-V em função do tempo.

Tabela 20 - Quantidade de Progesterona (mg) liberada pelas amostras de PCL por 50 mg de NPs.

\begin{tabular}{lll}
\hline Amostra & A7 & A8 \\
\hline TEMPO horas & PCL VIDRO & PCL VIDRO2 \\
0h & 0 & 0 \\
2h & 3699,2823 & 3939,2169 \\
$\mathbf{4 h}$ & 4338,7815 & 4509,9235 \\
$\mathbf{6 h}$ & 4719,0407 & 5022,3189 \\
$\mathbf{8 h}$ & 5074,9753 & 5598,7794 \\
$\mathbf{1 0 h}$ & 5252,2172 & 5500,1522 \\
$\mathbf{1 2 h}$ & 5267,4923 & 5497,9386 \\
\hline
\end{tabular}




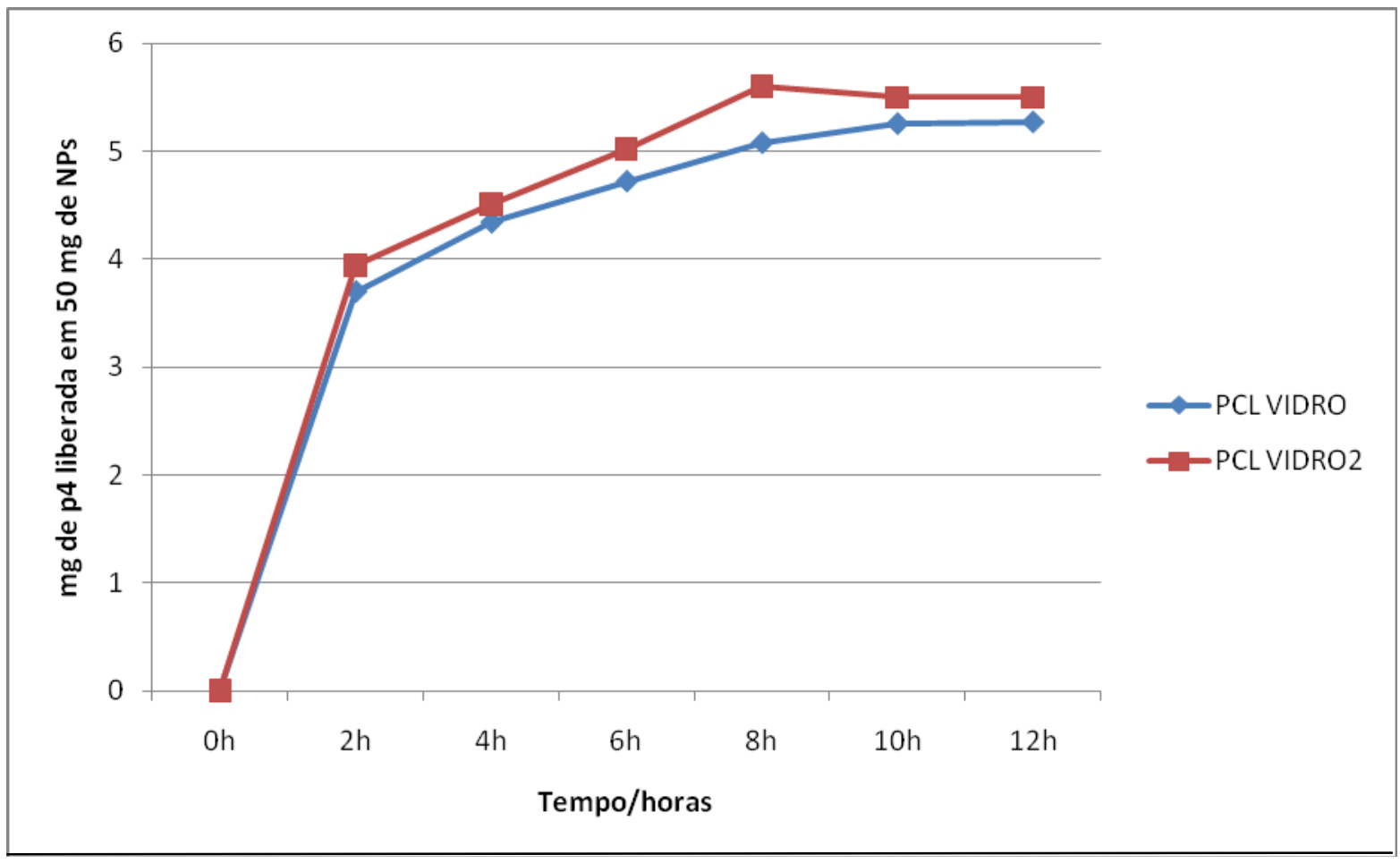

Figura 57Quantidade de Progesterona (mg) liberada em função do tempo em 50 mg de NPs.

\subsubsection{Conclusão}

Os testes de liberação in vitro, devem ser conduzidos em frascos de vidro, utilizando-se como meio de liberação a mistura 60:40 de álcool e água.

\subsection{Experimento 1}

\subsubsection{MATERIAIS E MÉTODOS}

Para determinação do perfil de liberação in vitro das partículas, foi utilizado o método de centrifugação descrito por Baker et al (2005), levando-se em consideração as condições do experimento anterior. 
Partículas de Poli-hidroxi-butirato e valerato (PHB-V) de três diferentes tamanhos (grupos PHB-V1, PHB-V2 e PHB-V3) e suas combinações com poli-ecaprolactano (PCL; grupos PHB-V1/PCL, PHB-V2/PCL e PHB-V3/PCL) impregnadas com $\mathrm{P}_{4}$, segundo técnica já descrita.

Alíquotas de nano partículas (NPs) foram pesadas em balança de precisão para determinar sua massa total. Foram acondicionadas em frascos de $12 \mathrm{ml}$ e suspendidas em $10 \mathrm{ml}$ de solução álcool e água (60:40w/w) de acordo com metodologia descrita na United States Pharmacopeia (USP XXIV), sendo um frasco para cada tempo. Todos os frascos foram colocados em banho-maria com agitação horizontal (Precision-Dubnoff Shaking, Incubator Bath, Taylor Scientific, St. Louis, MO) à $37^{\circ} \mathrm{C} 100 \mathrm{mov} / \mathrm{min}$. Os frascos referentes a cada tempo, foram centrifugados à $2.000 \mathrm{~g}$ por 10 minutos, com tempo de parada de 5 minutos, e coletado $1 \mathrm{ml}$ da solução sobrenadante com pipeta automática. Despejou-se a amostra em uma seringa de $3 \mathrm{ml}$ com um filtro de 0.45 micra acoplado na ponta, e transferiu-se para frascos de cor âmbar ("vial"), que permaneceram acondicionados em geladeira $\left(5^{\circ} \mathrm{C}\right)$ até o momento da dosagem por LC/MS.

Os tempos de colheita foram 0 (logo após a suspensão) 2,4,8,12, 24, 48 horas.

\subsubsection{ANÁLISE ESTATÍSTICA}

Os dados obtidos foram analisados utilizando-se o programa estatístico Statistical Analysis System (SAS, 1985), com prévia verificação da normalidade dos resíduos pelo teste de Shapiro-Wilk (PROC UNIVARIATE). A variável dependente massa de P4 liberada em $50 \mathrm{mg}$ de NPs em função do tempo foi submetida à ANOVA, utilizando-se o comando REPEATED gerado pelo procedimento GLM (PROC GLM do SAS). Quando houve interação entre tempo e tratamento, as médias dentro tempo foram analisadas pelo teste de Tukey. Em todas as análises estatísticas, o nível de significância considerado foi de 5\%. Para análise dos contrastes entre os coeficientes angulares das curvas de liberação foi utilizado PROC GLM DO SAS. 


\subsubsection{RESULTADOS E DISCUSSÃO}

Observou-se que a associação do PHB-V/PCL aumentou a quantidade de

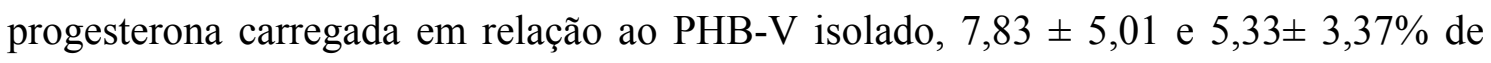
progesterona em relação à massa total de partículas para PHB-V/PCL e PHB-V, respectivamente (tabelas 13 e 12). A cinética de liberação diferiu entre os grupos nos diferentes tempos avaliados. (Tabela 22 e figuras 58 e 59).

O fármaco em nano e micro partículas é liberado por três mecanismos diferentes. No primeiro momento, a progesterona que está na superfície é liberada; em seguida, o fármaco que se encontra na marginal da partícula e, finalmente, a que se encontra dentro da partícula. (Figura 40). Na primeira fase de liberação, a progesterona que se encontra na superfície será liberada imediatamente em contato com o meio. $\mathrm{Na}$ amostra PHB-V1, o polímero não passou pelo processo supercrítico. Como esperado, a amostra PHB-V1, continha quantidades menores de progesterona $(1,77 \%)$. Nesta amostra, a $\mathrm{P}_{4}$ ficou somente na superfície, sendo liberada quase na sua totalidade no tempo 0. Estas partículas, como observado na figura 31, não apresentaram uma superfície regular e seu tamanho médio foi de $39,6 \pm 25,5 \mu \mathrm{m}$, enquanto o tamanho médio das partículas que foram submetidas ao processo supercrítico, foi de 1,82 $\pm 0,75$ $\mu \mathrm{m}$. A quantidade de progesterona carregada pelas partículas ficou em média 7,57\% da sua massa em progesterona com extremos de 3,94 \% (PHB-V2/PCL) e 13,49\% (PHBV3/PCL).

Com relação à porcentagem inicial de progesterona pode-se verificar que as partículas com PCL não liberaram toda sua progesterona durante o ensaio (Tabela 21), podendo indicar que estas partículas devem liberar progesterona por mais tempo, em um ensaio acima de 48 horas.

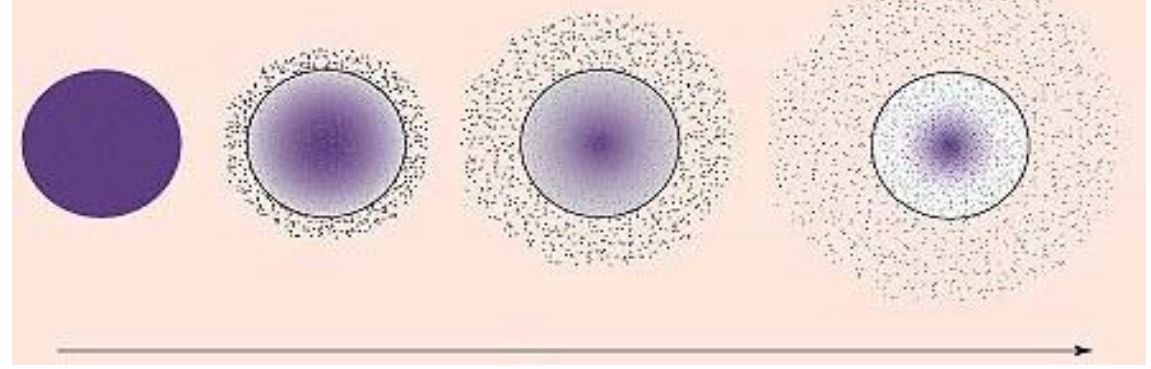

Figura 58 - Modelo do mecanismo de liberação de fármacos em nano ou micro partículas poliméricas. 
Tabela 21 - Quantidade de P4 inicial e final (mg/50mg de NPs) e porcentagem liberada durante o ensaio.

\begin{tabular}{lllllll}
\hline & PHB-V1 & PHB-V2 & PHB-V3 & $\begin{array}{l}\text { PHB- } \\
\text { V1/PCL }\end{array}$ & $\begin{array}{l}\text { PHB- } \\
\text { V2/PCL }\end{array}$ & $\begin{array}{l}\text { PHB- } \\
\text { V3/PCL }\end{array}$ \\
\hline P $_{4}$ inicial & 0,89 & 3,03 & 3,71 & 2,93 & 1,93 & 5,52 \\
$\mathbf{P}_{4}$ final & 0,80 & 2,88 & 3,21 & 2,04 & 1,21 & 4,23 \\
\% de $\mathbf{P}_{4}$ liberada & 89,88 & 95,05 & 86,52 & 69,62 & 62,69 & 76,63 \\
\hline
\end{tabular}


Tabela 22 - Massa de Progesterona liberada (mg) por 50 mg das amostras de MPs PHB-V1, PHB-V2, PHB-V3, PHB-V1PCL, PHB-V2PCL, PHB-V3PCL, em função do tempo.

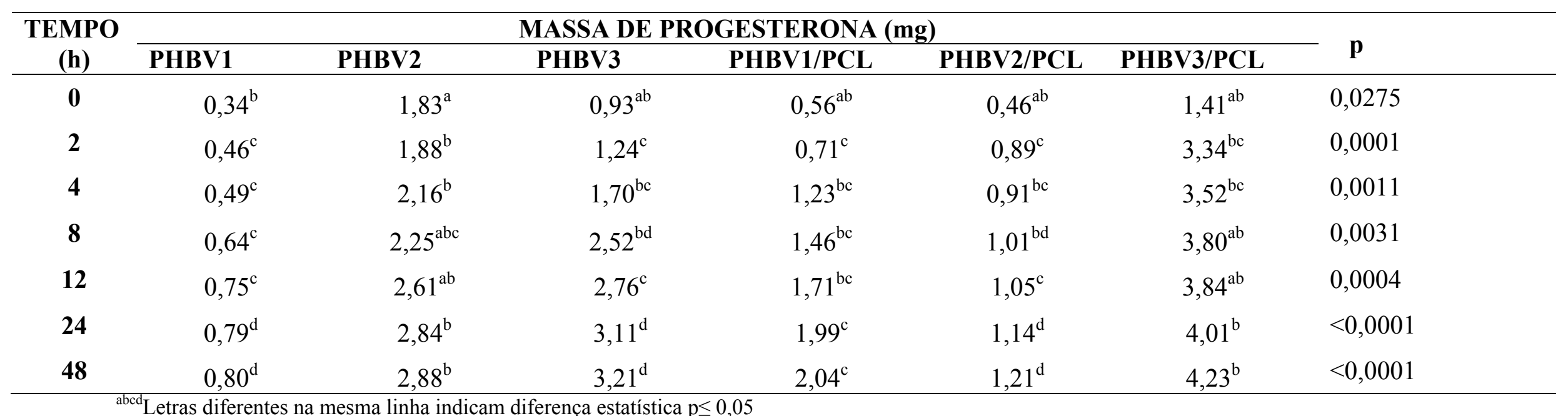




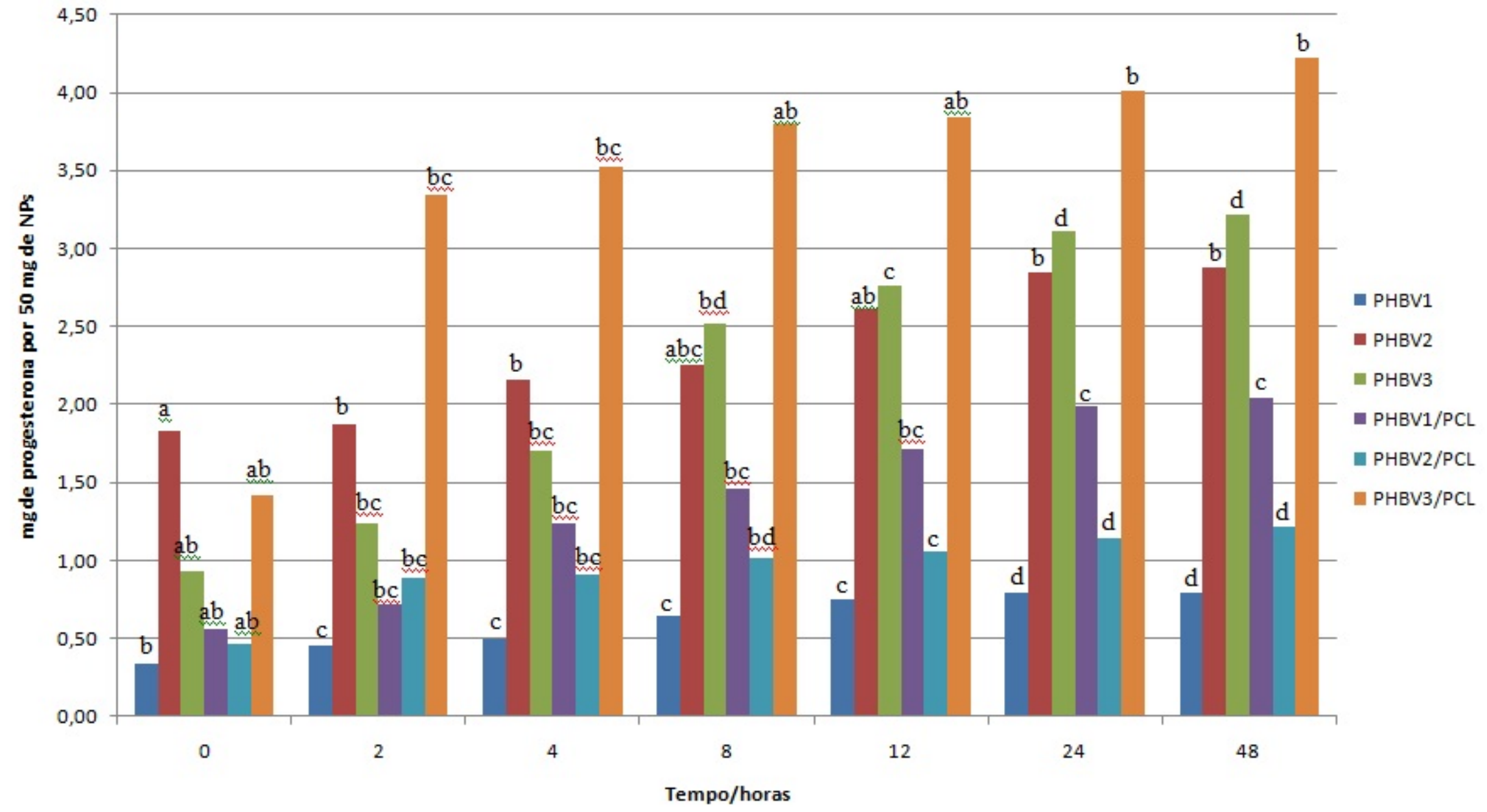

Figura 59 - Quantidade de progesterona liberada ( $\mathrm{mg}$ por $50 \mathrm{mg}$ de NPs) in vitro conforme tempo.( abcdLetras diferentes indicam diferença estatística p $\leq 0,05)$. 


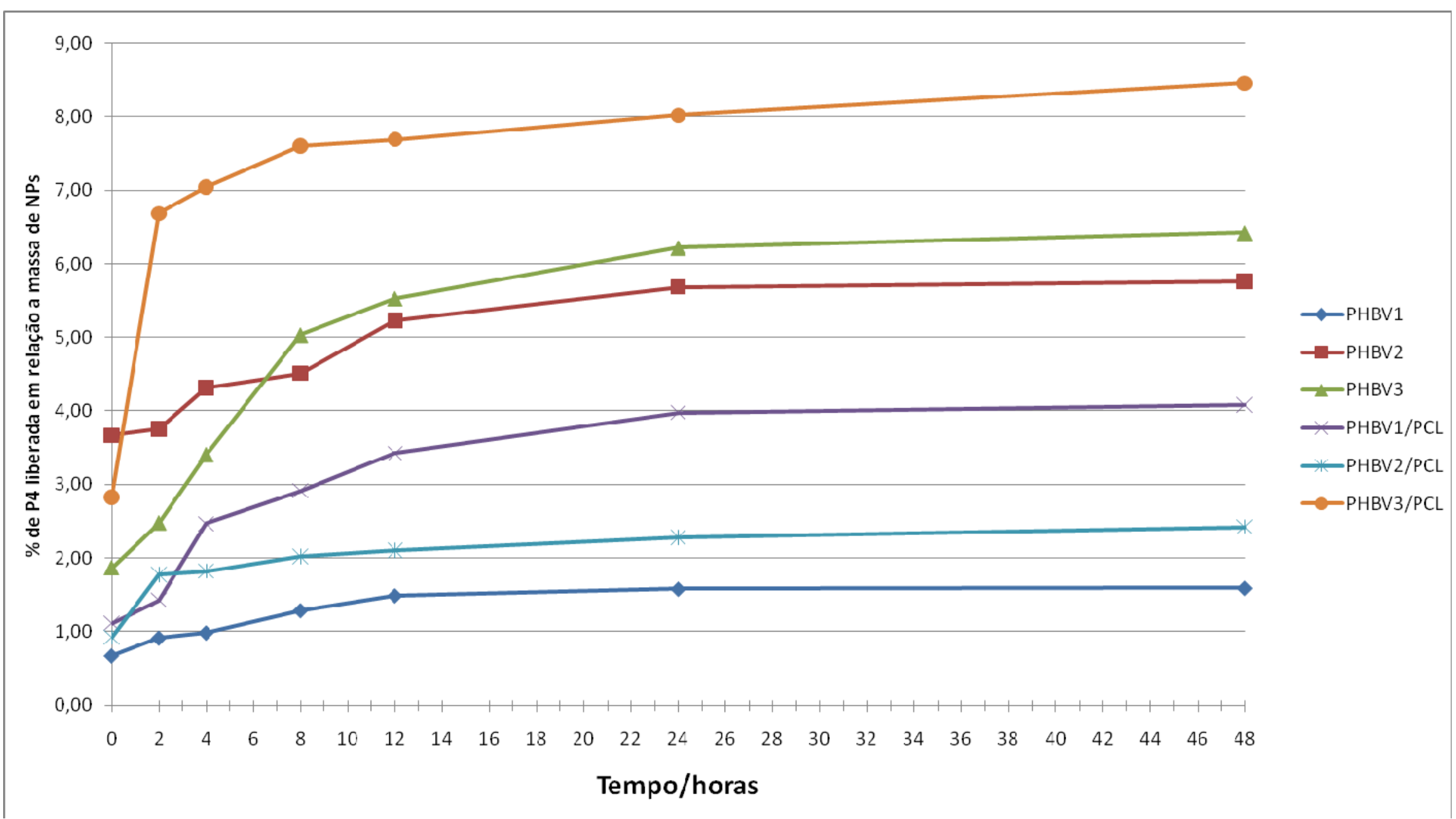

Figura 60 - Representação gráfica das curvas de liberação das diferentes amostras. 
Capitulo 6 


\section{CONCLUSÕES}

Diferenças de tamanho de partículas de PHB-V e suas associações ao PCL podem afetar a quantidade de progesterona carregada por impregnação, bem como a cinética da liberação de progesterona..

O processo supercrítico alterou a morfologia da partícula de PHB-V e sua blenda PHB-V/PCL. Esta alteração modificou o perfil liberatório, seu tamanho médio, carga de progesterona e a cinética de liberação. 


\section{REFERÊNCIAS BIBLIOGRÁFICAS}

ALESSI, P.; CORTESI, A.; KIKIC, I.; FOSTER, N.R.; MACNAUGHTON, S.J.; COLOMBO, I. "Particle Production of Steroid Drugs Using Supercritical Fluid Processing”, Ind. Eng. Chem. Res., 35, 4718-4726, 1996.

ALONSO, M. J.; LOSA, C.; CALVO, P.; VILA-JATO, J. L.; Int. J. Pharm., v. 68, p. 69. 1991.

ARAUJO, L.; SHEPPARD, M.; LÖBENBERG, R.; KREUTER, J.; Int J. Pharm., v.176, p. 209. 1999.

AVGOUSTAKIS, K., BELETSI, A., PANAGI, Z.; KLEPETSANIS, P., KARYDAS, A. G., ITHAKISSIOS, D. S.; Journal Controlled. Release, v. 79, p. 123. 2002.

BAIN,D.F., MUNDAY, D.L., COX, P.J. Evaluation of biodegradable rifampicin-bearing microsphere formulations using a stability-indicating high-performance liquid chromatographic assay European J. Pharmaceutical Sciences, v. 7, p. 57-65. 1998.

BAIN, D. F.; D. L. MUNDAY; and A. SMITH. modulation of rifam picin release from spray-driedmicrospheres using combinations of poly-(dl-lactide). J. Microencapsulation, vol. 16 , no. $3,369 \pm 385,1999$.

BAKER, G.A.; CAMPBELL, M.L.; YATES, M.Z.; MCCLESKEY, T.M., Carbon Dioxide Emulsion Assisted Loading of Polymer Microspheres toward Sustained Release Materials, Langmuir, 21, 3730-3732, 2005.

BANAKAR, U. V. Pharmaceutical Dissolution Testing. DEKKER, M., ed., New York: Marcel Dekker, pp.55-100. 1992.

BARAN, E. T; ÖZER, N; HASIRCI, V. Poly(hydroxybutyrate-co-hydroxyvalerate) nanocapsules as enzyme carriers for cancer therapy: an in vitro study. Journal of Microencapsulation, v. 19, n. 3, p. 363-376, 2002a.

BARAN, E. T; ÖZER, N; HASIRCI, V. In vivo half life of nanoencapsulated Lasparaginase. Journal of Materials Science: Materials in Medicine, v. 13, p 1113-1121, $2002 b$.

BARKaI, A.; PATHAK, Y. V.; BENITA, S.; Drug Dev. Ind. Pharm., v. 16, p. 2057. 1990.

BARUSELLI, P. S. ; REIS, EVERTON LUIS ; MARQUES, MÁRCIO DE OLIVEIRA ; NASSER, LUIZ FERNANDO TONISSI ; BÓ, GABRIEL A . The use of hormonal treatments to improve reproductive performance of anestrous beef cattle in tropical climates. Animal Reproduction Science, v. 82-83, p. 479-486, 2004. 
BASTOS, V. D. Biopolímeros epolímeros de matérias-primas renováveis alternativos aos petroquímicos. Revista do BNDES, v. 14, n. 28, p. 201-284, 2007.

BLOUZA, I. L; CHARCOSSET, C; SFAR, S; FESSI, H. Preparation and characterization of spironolactone-loaded nanocapsules for paediatric use. International Journal of Pharmaceutics, v. 325, p. 124-131, 2006.

BRASSEUR, N.; BRAUlt, D.; COUVREUR, P.; Int. J. Pharm., v. 70, p. 129. 1991.

BRAZEL, C. S., PEPPAS, N. A. Modeling of drug release from swellable polymers. Eur. J. Pharm. Biopharm., Amsterdam, v. 49, n. 1, p. 47-58, 2000.

BRISTOW, S.; SHEKUNOV, T.; SHEKUNOV, B.Y.; YORK, P., Analysis of the super saturation and precipitation process with supercritical CO2. Journal of Supercritical Fluids, v. 21, p. $257-271,2001$.

BUCCI, D. Z.; TAVARES, L. B. B.; SELL, I., Biodegradation and physical evaluation of PHB packaging. Polymer Testing, v. 26, p. 908 - 915, 2007.

CALVO, P.; VILA-JATO, J. L.; ALONSO, M. J. J. Pharm. Sci., v.85, p.530, 1996. Apud: DOUROUMIS, D.; FAHR, A. Nano- and micro-particulate formulate of poorly watersoluble drugs by using a novel optimized technique. Eur. J. Pharm. Biopharm., v.63, p. 173-175, 1996.

CARMIGNAN, F. Desenvolvimento de microesferas de ibuprofeno a partir dos biopolímeros polihidroxialcanoatos. estudo da influência das características físicoquímicas das microesferas sobre o perfil de liberação do fármaco e degradação das partículas. 151f. Dissertação (Mestrado) - Universidade Federal de Santa Catarina, Florianópolis, 2006.

CHASTEIGNER, S.; FESSI, H.; CAVÉ, G.; DEVISSAGUET, J-Ph.; PUISIEUX. Gastrointestinal tolerance study of a freeze-dried oral dosage form of indomethacinloaded nanocapsules. STP Pharma Sciences, v. 5, n. 3, p. 242-246, 1995.

CHEN, J.; DAVIS, S. S., The release of diazepam from poly(hydroxybutiratehydroxyvalerate) microspheres. Journal of Microencapsulation, v. 19, p. $191-201,2002$.

CHEN, G. Q.; WU, Q., The application of polyhydroxyalcanoates as tissue engineering materials. Biomaterials, v. 26, p. $6565-6578,2005$.

CHEN, X.; YOUNG, TJ; SARKARI, M.; WILlIAMS, R.O.; JOHNSTON, K. P. Preparation of Cyclosporine A Nanoparticles by Evaporative Precipitation into Aqueous Solution. Int. J. Pharm., v.242, n.1-2, p.3-14, 2002. 
CHEN, X.; WILLIAMS; R.O.; JOHNSTON, K.P. Rapid Dissolution of High Potency Danazol Powders Produced by Evaporative Precipitation into Aqueous Solution. J. Pharm. Sci., v.93, n.7, p.1867-1878, 2004.

CHONG, G.H.; YUNUS, R.; ABDULLAH, N.; CHOONG, T.S.Y.; SPOTAR, S. Coating and Encapsulation of Nanoparticles using Supercritical Antisolvent. American Journal of Applied Sciences. v. 7, 1352-1358, 2009.

COCERO, M. J.; MARTIN, A.; MATTEA, F.; VARONA, S., Encapsulation and coprecipitation processes with supercritical fluids: fundamentals and applications. Journal of Supercritical Fluids, v. 47, p. 546 - 555, 2009.

COlOMBO, P., BETTINI, R., MASSIMO, G., CATELlANI, P. L., PEPPAS, N. A. Drug diffusion front movement is important in drug release control from swellable matrix tablets. J. Pharm. Sci., New York, v. 84, n. Aug, p. 991-997, 1995.

COSTA, P., LOBO, J. M. S. Formas farmacêuticas de liberação modificada. Rev. Port. Farm., Lisboa, v. 59, n. 4, p. 181-190, 1999.

COSTA, P., LOBO, J. M. S. Influence of dissolution medium agitation on release profiles of sustained-release tablets. Drug Dev. Ind. Pharm., New York, v. 27, n. 8, p. 811-817, $2001 \mathrm{a}$.

COSTA, P., LOBO, J. M. S. Modeling and comparison of dissolution profiles. Eur. J. Pharm. Sci., Amsterdam, v.13, n. 2, p. 123-133, 2001 b.

DE GIOANNIS, B.; JESTIN, P.; SUBRA, P., Morphology and growth control of griseofulvin recrystallized by compressed carbon dioxide as antisolvent. Journal of Crystal Growth, v. 262, p. $519-526,2004$.

DIGHE, S. V. Development of dissolution tests for immediate release and modified release oral dosage forms. Stuttgart: Medpharm Scientific Publishers, p.15-28. 1993.

DIXON, D. J., PhD thesis, Polymeric Materials processed with Compresses Fluids Anti-solvent, 1993.

DURAN, N.; MATTOSO, L. H. C.; MORAIS, P. C. Nanotecnologia: Introdução, preparação, caracterização de nanomateriais e exemplos de aplicação. Sao Paulo: Artliber Editora, 2006.

EL ARINI, S. K., LEUENBERGER, H. Modeling of drug release from polymer matrices: effect of drug loading. Int. J. Pharm., Amsterdam, v. 121, n.25, p. 141-148, 1995.

ELDSÄTER, C.; ERLANDSSON, B.; RENSTAD, R.; ALBERTSSON, A.-C.; KARLSSON, S. The biodegradation of amorphous and crystalline regions in filmblown poly(E-caprolactone). Polymer, v. 41, p. 1297-1304, 2000. 
EMBLETON, J. K.; TIGUE, B. J. Polymers for biodegradable medical devices XI. Microencapsulation studies: characterization of hydrocortisone-loaded polyhydroxybutyratehydroxyvalerate microspheres. Journal of Microencapsulation. v. 19, n. 6, 737-752, 2002.

FARINHA, A., PAIS, J. P., BICA, A. O ensaio de dissolução in vitro na avaliação da qualidade biofarmacêutica. LEF - Boletim, Lisboa, v. 4, n. 15, p. 1-7, 1997.

FARINHA, A., BICA, A., TOSCANO, C., CAMPOS, R. C. Os ensaios de liberação in vitro na avaliação da qualidade biofarmacêutica de formas sólidas e semi-sólidas. LEF Boletim, Lisboa, v. 7, n. 26, p. 1-8, 2000.

FAVARETO, R.; CABRAL, V.F.; CORAZZA, M.L.; CARDOZO-FILHO, L., Vaporliquid and solid-fluid equilibrium for progesterone $+\mathrm{CO} 2$, progesterone + propane, and progesterone + n-butane systems at elevated pressures, J. of Supercritical Fluids 45, 161170,2008 .

FAVARETO, R.; FREGADOLLI, P.H.; CABRAL, V.F.; ANTUNES, O.A.C.; CARDOZO-FILHO, L., Phase Equilibria of Acrylonitrile and p-Bromobenzaldehyde in Carbon Dioxide, J. Chem. Eng. Data 53, 1080-1084, 2008 b.

FORD, J. L., Mitchell, K., ROWE, P., ARMSTRONG, D. J., ELliOTT, P. N. C., ROSTRON, C., HOGAN, J. E. Mathematical modeling of drug release from hydroxypropylmethylcellulose matrices: effect of temperature. Int. J. Pharm., Amsterdam, v. 71, p. 95-104, 1991.

FRANCESCHI, E.; KUNITA, M. H.; TRES, M. V.; RUBIRA, A. F.; MUNIZ, E. C.; CORAZZA, M. L.; DARIVA, C.; FERREIRA, S. R. S.; OLIVEIRA, J. V., Phase behavior and process parameters effects on the characteristics of precipitated theophylline using carbon dioxide as antisolvent. Journal of Supercritical Fluids, v. 44, p. 8- 20, 2008.

FRESTA, M.; PUGliSI, G.; GIAMMONA, G.; CAVALlARO, G.; MICALI, N.; FURNERI, P. M.; J. Pharm. Sci., v. 84, p. 895. 1995.

FREITAS, S.; MERKLE, H. P.; GANDER, B. Microencapsulation by solvent extraction/evaporation: reviewing the state of the art of microsphere preparation process technology. Journal of Controlled Release, v.102, p.313-332, 2005.

GALlAGHER, P.M.; COFFEY, M.P.; KRUKONIS, V.J.; KLASUTIS, N. "Gas Antisolvent Recrystallization: New Process to Recrystallize Compounds Insoluble in Supercritical Fluids, American Chemical Society Symposium, v. 44, pp. 334-354, 1989.

GAMISANS, F.; LACOULONCHE, F.; CHAUVET, A.; ESPINA, M.; GARCIA, M. L.; EGEA, M. A.; Int. J. Pharm., v. 179, p. 37. 1999.

GEDDE, U. W.; Drug Dev. Ind. Pharm., v. 16, p. 2465. 1990. 
GIBAUD, S.; AL AWWADI, N. J.; DUCKI, C.; ASTIER, A. Poly( $\varepsilon$-caprolactone and Eudragit microparticles cantainig fludrocortisone acetate. International Journal of Pharmaceutics, v. 269, p. 491-508, 2004.

GONZALES-PADILHA, E. RUIZ,R.; LEFEVER, D.; DENHAM, A.; WILTBANK, J.N. "Puberty in Beef Heifers. III. Induction of Fertile Estrus", Journal Animal ScienceI, v. 40, pp. 1110-1118, 1975.

GOVENDER, T.; STOLNIK, S.; GARNET, M. C.; ILlUM, L.; DAVIS, S. S.; J.Controlled Release, v. 57, p. 171. 1999.

GRAGE, K; JAHNS, A. C; PARLANE, N; PALANISAMY, R; RASIAH, I. A; ATWOOD, J. A; REHM, B. H. A. Bacterial Polyhydroxyalkanoate Granules: Biogenesis, Structure, and Potential Use as Nano-/Micro-Beads in Biotechnological and Biomedical Applications. Biomacromolecules, v. 10, p. 660-669, 2009.

GURSEL I., YAGMURLU, F., KORKUSUZ, F.; HASIRCI, V. In vitro antibiotic release from poly(3-hydroxybutyrate-co-3- hydroxyvalerate) rods. Journal of microencapsulation. V. 19, n. 2, 153-164, 2002.

GUTERRES, S. S.; FESSI, H.; BARRATT, G.; DEVISSAGUET, J-PH.; PUISIEUX, F.; Int. J. Pharm., v. 113, p. 57. 1995.

HANSON-RESEARCH-CORPORATION. Dissolution: Past, Present \& Future. 2. ed. Chatsworth: Hanson Research, p.2-12. 1996.

HARLAND, R. S., GAZZANIGA, A., SANGALli, M. E., COLOMBO, P., PEPPAS, N. A. Drug/polymer matrix swelling and dissolution. Pharm. Res., New York, v. 5, n. Aug, p. 488-494, 1988.

HIGUCHI, T. Rate of release of medicaments from ointment bases containing drugs in suspension. J. Pharm. Sci., New York, v. 50, p. 874-875, 1961.

HIGUCHI, T. Mechanism of sustained-action medication. Theoretical analysis of rate of release of solid drugs dispersed in solid matrices. J. Pharm. Sci., New York, v. 52, p. 1145-1149, 1963.

HOFFMANN, F.; CINATL JR., J.; KABICKOVÁ, H.; CINATL, J.; KREUTER, J.; STIENEKER, F.; Int. J. Pharm., v 157, p. 189. 1997

HORISAWA, E.; KUBOTA, K.; TUBOI, I.; SATO, K.; YAMANOTO, H.; TAKEUCHI, H.;KAWASHIMA, Y. Size-Dependency of DL-Lactide/ Glycolide Copolymer articulates for Intra-Articular Delivery System on Phagocytosis in Rat Synovium Pharm. Res., 19, 132. 2002 
HU, J.; JOHNSTON, K.P.; WILLIAMS, R.O. Stable Amorphous Danazol Nanostructured Powders with Rapid Dissolution Rates Produced by Spray Freezing into Liquid," Drug Dev. Ind. Pharm., v.30, n.7, p.695-704, 2004.

INFARMED. Farmacopeia Portuguesa VI, Lisboa, p. 116-121. 1997.

JENKINS, M.J.; CAO, Y.; HOWELL, L.; LEEKE, G.A., Miscibility in blends of poly(3hydroxybutyrate-co-3-hydroxyvalerate) and poly( $\varepsilon$-caprolactone) induced by melt blending in the presence of supercritical $\mathrm{CO}_{2}$, Polymer, 48, 6304-6310, 2007.

JEONG, J-C; LEE, J.; CHO, K Effects of crystalline microstruture on drug release behavior of poly( $\varepsilon$-caprolactone) microspheres. Journal of Controlled Release, v. 92, p. 249-258, 2003.

KANG, Y.; YIN, G.; OUYANG, P.; HUANG, Z.; YAO, Y.; LIAO, X.; CHEN, A.; PU, X., Preparation of PLLA/PLGA microparticles using solution enhanced dispersion by supercritical fluids (SEDS). Journal of Colloid and Interface Science, v. 322, p. 87 - 94, 2008.

KATZHENDLER, I., HOFFMAN, A., GOLDBERGER, A., FRIEDMAN, M. Modeling of drug release from erodible tablets. J. Pharm. Sci., New York, v. 86, n. 1, p. 110-115, 1997.

KHARB, V.; BHATIA, M.; DUREJA, H.; KAUSHIK, D. Nanoparticle Technology for the Delivery of Poorly Water-Soluble Drugs. Pharmaceutical technology, v.2, 2006.

KIBE, Pharmaceutical excipients 2001 - single user windows version 2.0 American Pharmaceutical Association, ROWE, R; SHESKEY, P. J.; WELLER, P; J. Washington, DC, USA e Pharmaceutical Press, London, UK, 2001.

KIKIC, I., VECCHIONE F., Supercritical impregnation of polymers, Current Opinion in Solid State and Materials Science . 7, p. 399-405, 2003.

KIM, H., FASSIHI, R. Application of a binary polymer system in drug release rate modulation. Part 1. Characterization of release mechanism. J. Pharm. Sci., New York, v. 86, p. 316-322, 1997a.

KIM, H., FASSIHI, R. Application of binary polymer system in drug release rate modulation. 2. Influence of formulation variables and hydrodynamic conditions on release kinetics. J. Pharm. Sci., New York, v. 86, n. 3, p. 323-328, 1997 b.

KREUTER, J., "Nanoparticles - A Historical Perspective. A Review", International Journal of Pharmaceutics, v. 331, pp. 1-10, 2007.

KORSMEYER, R. W., GURNY, R., DOELKER, E., BURI, P., PEPPAS, N. A. Mechanisms of solute release from porous hydrophilic polymers. Int. J. Pharm., Amsterdam, v. 15, p. 25-35, 1983. 
LAMPRECHT, A.; TORRES, H. R.; SCHÄFER, U. F.; LEHR, C.-M. Biodegradable microparticles as a two-drug controlled release formulation: a potential treatment of inflammatory bowel disease. Journal of Controlled Release, v. 69, p. 445-454, 2000a.

LAMPRECHT, A.; UBRICH, N.; PÉREZ, M. H.; LEHR, C.-M.; HOFFMAN, M.; MAINCENT, P. Influences of process parameters on nanoparticle preparation performed by a double emulsion pressure homogenization technique. International Journal of Pharmaceutics, v. 196, p. 177-182, 2000b.

LEGRAND, P.; BARRATT, G.; MOSQUEIRA, V.; FESSI, H.; DEVISSAGUET, J-Ph.; S.T.P. Pharma Sci. v. 9, p. 411. 1999.

LEIMANN, F. V.; GONÇALVES, O. H.; MACHADO, R. A. F.; BOLZAN, A.; Antimicrobial activity of microencapsulated lemongrass essential oil and the effect of experimental parameters on microcapsules size and morphology. Materials Science and Engineering. v. 29, 430-436, 2009.

LIN, S. Y., YANG, J. C. In-vitro dissolution behavior of some sustained-release theophylline dosage forms. Pharm. Acta Helv., Amsterdam, v. 64, n. 8, p. 236-240, 1989.

LIN, S. Y.; CHEN, K. S.; TENG, H. H.; LI, M. J. In vitro degradation and dissolution behaviours of microspheres prepared by three low molecular weight polyesters. Journal of microencapsulation. v. 17, n. 5, 577-586, 2000.

LIONZO, M. I. Z., RÉ, M. I., GUTERRES, S. S.; POHLMANN, A. R., Microparticles prepared with poly(hydroxybutyrateco- hydroxyvalerate) and poly(e- aprolactone) blends to control the release of a drug model. Journal of microencapsulation. v. 24, n. 2, 175-186, 2007.

LIVERSIDGE, G.G.; CUNDY, K. C. Particle size reduction for improvement of oral bioavailability of hydrophobic drugs: I. Absolute oral bioavailability of nanocrystalline danazol in beagle dogs. Int. J. Pharm., v.125, p. 91-97, 1995.

LOSA, C.; MARCHAL-HEUSSLER, L.; ORALLO, F.; VILA JATO, J. L.; ALONSO, M. J. Pharm. Res. v. 10, p. 80. 1993.

LU, Y.; CHEN, S. C. Micro and nano-fabrication of biodegradable polymers for drug delivery. Advanced Drug Delivery Reviews, v.56, p. 1621-1633, 2004.

MACMILLAN, K. L. ; TAUFA, V. K.; BARNES, D. R.; DAY, M. "Plasma Progesterone Concentrations in Heifers and Cows Treated with a New Intravaginal Device", Animal Reproduction Science, v. 26, pp. 25-40, 1991.

MAGENHEIM, B.; BENITA, S., Nanoparticle characterization: a comprehensive physicochemical approach. S.T.P. Pharma Sciences, v. 1, p. 221-241, 1991. 
MARCHAL-HEUSSLER, L.; MAICENT, P.; HOFFMAN, M.; SPITTLER, J.; COUVREUR, P.; Int. J. Pharm., v. 58, p. 115. 1990.

McHUGH, M.A. \& KRUKONIS, V.J. Supercritical Fluid Extraction: Principles and Practice. Butterworth-Heinemann, 2th Edition, 1994.

MOLPECERES, J.; ABERTURAS, M. R.; CHACON, M.; BERGES, L.; GUZMAN, M.; J. Microencapsulation, v. 14, p. 777. 1997.

MOSQUEIRA, V. C. F.; LEGRAND, P.; PINTO-ALPHANDARY, H.; PUISIEUX, F.; BARRATT, G.; Poly(D,L-Lactide) Nanocapsules Prepared by a Solvent Displacement Process: Influence of the Composition on Physicochemical and Structural Properties $\mathbf{J}$. Pharm. Sci., 89, 614. 2000.

MOURA, L.S.; FAVARETO, R.; LEAL, P.F.; CORAZZA, M.L.; CARDOZO-FILHO, L.; MEIRELES, M.A.A., Phase equilibrium measurements for $\mathrm{CO} 2+$ priprioca extract at high pressures, J. of Supercritical Fluids 48, 126-130, 2009.

MUllER, C. R.; BASSANI, V. L.; POHLMANN, A. R.; MICHALOWSKI, C. B.; PETROVICK, P. R.; GUTERRES, S. S.; Drug Dev. Ind. Pharm., v. 26, p. 343. 2000.

MULLER, C. R.; SCHAFFAZICK, S. R.; POHLMANN, A. R.; LUCCA FREITAS, L.; PESCE DA SILVEIRA, N.; DALLA COSTA, T.; GUTERRES, S. S.; Pharmazie, v.56, p.864. 2001.

MULYE, N. V., TURCO, S. J. A simple model based on first order kinetics to explain release of highly water soluble drugs from porous dicalcium phosphate dehydrate matrices. Drug Dev. Ind. Pharm., New York, v. 21, n. 8, p. 943-953, 1995.

NECKEL, G. L. Avaliação do potencial de utilização de nanocápsulas poliméricas na melhoria da resposta antimetastática de um alcalóide citotóxico, a camptotecina. 115 f. Dissertação (Mestrado) - Universidade Federal de Santa Catarina, Florianópolis, 2006.

ODDE,K.G. "A Review of Synchronization of Estrus in Postpartum Cattle", Journal Animal Science, v. 30, pp. 68-817, 1990.

OFOEFULE, S. I., OKOLI, S. E., CHUKWU, A. Mechanisms behind sustained release matrix tablets prepared with poly(acrylic) acid polymers. Acta Pharm., v. 50, n. 3, p. 229$238,2000$.

OURIQUE, A. F; POHLMANN, A. R; GUTERRES, S. S; BECK, R. C. R. Tretinoinloaded nanocapsules: Preparation, physicochemical characterization, and photostability study. International Journal of Pharmaceutics, v. 352, p. 1-4, 2008.

PEPPAS, N. A. Relation between the structure of polymers and the controlled release of active ingredients. Pharm. Acta Helv., Amsterdam, v. 58, p. 2-8, 1983. 
PEPPAS, N. A. Analysis of fickian and non-fickian drug release from polymers. Pharm. Acta Helv., Amsterdam, v. 60, n. 110-1, p. 1985.

PERALE, G.A., AROSIO P.A., MOSCATELLI D.A., BARRI V.B., MÜLLER M.B., MACCAGNAN S.C., MASI, M., A new model of resorbable device degradation and drug release: Transient 1-dimension diffusional model. Journal of Controlled Release, v. 136, p.196-205. 2009.

PICH, A; SCHIEMENZ, N; BOYKO, V; ADLER, H-J. P. Thermoreversible gelation of biodegradable polyester (PHBV) in toluene. Polymer, v. 47, p. 553-560, 2006 a.

PICH, A; SCHIEMENZ, N; CORTEN, C; ADLER, H-J. P. Preparation of poly(3hydroxybutyrate-co-3-hydroxyvalerate) (PHBV) particles in $\mathrm{O} / \mathrm{W}$ emulsion. Polymer, v. 47, p. 1912-1920, 2006b.

PILLAY, V., FASSIHI, R. In vitro release modulation from cross-linked pellets for sitespecific drug delivery to the gastrointestinal tract. Part 1. Comparison of pHresponsive drug release and associated kinetics. J. Controlled Release, Amsterdam, v. 59, 20, p. 229-242, 1999.

PIMENTEL, J. R. V. "Emprego de matriz polimérica biodegradável em dispositivos vaginais para liberação sustentada de progesterona em fêmeas bovinas: Testes in vitro e in vivo", Dissertação (mestrado), 97fls - Universidade de São Paulo. Faculdade de Medicina Veterinária e Zootecnia. Departamento de Reprodução Animal, 2006.

POLETTO, F. S; FIEL, L. A; DONIDA, B; RE, M. I; GUTERRES, S. S; POHLMANN, A. R. Controlling the size of poly(hydroxybutyrate-co-hydroxyvalerate) nanoparticles prepared by emulsification-diffusion technique using ethanol as surface agent. Colloids and Surfaces A: Physicochem. Eng. Aspects, v. 324, p. 105-112, 2008.

PREECHAGOON, D., UDOMPRATEEP, A., MANWIWATTANAGUL, G. Improved dissolution rate of poorly soluble drug by incorporation of buffers. Drug Dev. Ind. Pharm., New York, v. 26, n. 8, p. 891-894, 2000.

PRISTA, L. N., ALVES, A. C., MORGADO, R. Tecnologia farmacêutica. Lisboa: Fundação Calouste Gulbenkian, p. 2171-2191. 1996.

QUINTANAR-GUERRERO, D.; FESSI, H.; ALLÉMANN E.; DOELKER, E.; Int. J. Pharm., v. 143, p. 133. 1996.

REIS, C. P; NEUFELD, R. J; RIBEIRO, A. J; VEIGA, F. Nanoencapsulation I. Methods for preparation of drug-loaded polymeric nanoparticles. Nanomedicine: Nanotechnology, Biology, and Medicine, v. 2, p. 8-21, 2006.

REVERCHON, E. "Supercritical anti-solvent precipitation of micro- and nanoparticles", $\mathbf{J}$. Supercrit. Fluids, v. 15, pp. 1-21, 1999. 
REVERCHON, E., DELlA PORTA, G., FALIVENE, M.G. "Process Parameters and Morphology in Amoxicillin Micro and Submicro Particles Generation by Supercritical Antisolvent Precipitacion", Journal of Supercritical Fluids, v. 17, pp. 239-248, 2000a.

REVERCHON, E., DELLA PORTA, G., DE ROSA, I., SUBRA, P., LETOURNEUR, D. "Supercritical Antisolvent Micronization of Some Biopolymers". Journal of Supercritical Fluids, v. 18, pp. 239-245, 2000 b.

REVERCHON, E.; CAPUTO, G.; DE MARCO, I., Role of phase behavior and atomization in the supercritical antisolvent precipitation. Industrial \& Engineering Chemistry Research, v. 42, p. $6406-6414,2003$.

REVERCHON, E.; DE MARCO, I., Supercritical antisolvent micronization of Cefonicid: thermodynamic interpretation of results. Journal of Supercritical Fluids, v. 31, p. 207 215, 2004.

ROLlOT, J. M.; COUVREUR, P.; ROBLOT-TREUPEL, L.; PUISIEUX, F. Physicochemical and morphological characterization of polyisobutyl cyanoacrylate nanocapsules; J. Pharm. Sci. 75, 361. 1986.

ROY, D., DUCHER, F., LAUMAIN, A., LEGENDRE, J. Y. Determination of the aqueous solubility of drugs using a convenient 96 well plate based assay. Drug Dev. Ind. Pharm., New York, v. 27, n. 1, p. 107-109, 2001.

SALOMON, J. L., DOELKER, E. Formulation of prolonged release tablets. Part 1. Inert matrices. Pharm. Acta Helv., Amsterdam, v. 55, n. 6, p. 174-182, 1980.

SANGALLI, M. E., GIUNCHEDI, P., MAGGI, L., CONTE, U., GAZZANIGA, A. Inert monolithic device with a central hole for constant drug release. Eur. J. Pharm. Biopharm., Amsterdam, v. 40, p. 370-373, 1994.

SCHAFFAZICK, S. R.; POHLMANN, A. R.; DE LUCCA FREITAS, L; GUTERRES, S. S.; Acta Farm. Bonaerense, v. 21, p. 99. 2002.

SCHAFFAZICK, S. R.; GUTERREZ, S.S. Caracterizacao e estabilidade fisico-quimica de sistemas polimericos nanoparticulados para administracao de farmacos. Química Nova, v.26, n.5, p.726-737, 2003.

SCHOLER, N. Atovaquone Nanosuspensions Show Excellent Therapeutic Effect in a New Murine Model of Reactivated Toxoplasmosis. Antimicrob. Agents. Chemother. v. 45, n.6, p.1771-1779, 2001.

SANTOS, W.L.F.; FAVARETO, R.; CABRAL, V.F.; MUNIZ, E.C.; CARDOZO-FILHO, L.; RUBIRA, A.F., Phase equilibrium behavior of a system with N,N-Dimethylacrylamide, CO2 and disperse dye, J. of Supercritical Fluids 38, 319-325, 2006. 
SEIJO, B.; FATTAL, E.; TREUPEL, L. R.; COUVREUR, P.; Int. J. Pharm., v. 1, p. 62, 1990.

SENDIL, D; GÜRSEL, I; WISE, D. L; HASIRCI, V. Antibiotic release from biodegradable PHBV microparticles. Journal of Controlled Release, v. 59, p. 207-217, 1999.

SHARIATI, A.; PETERS, C.J., Measurements and modeling of the phase behavior of ternary systems of interest for the GAS process: I. The system carbon dioxide +1 - propanol + salicylic. Journal of Supercritical Fluids, v. 23, p. 195 - 208, 2002.

SINHA, V.R.; BANSAL, K.; KAUSHIK, R., KUMRIA, R.; TREHAN, A., Review: Poly$\varepsilon$-caprolactone microspheres and nanospheres: an overview, International Journal of Pharmaceutics, 278, 1-23, 2004.

SIRACUSA, V; ROCCULI, P; ROMANI, S; ROSA, M. D. Biodegradable polymers for food packaging: a review. Trends in Food Science \& Technology, v. 19, p. 634-643, 2008.

SOOTTITANTAWAT, A.; TAKAYAMA, K.; OKAMURA, K.; MURANAKA, D.; YOSHII, H.; FURUTA, T.; OHKAWARA, M.; LINKO, P. Microencapsulation of 1menthol by spray drying and its release characteristics. Innovative Food Science and Emerging Technologies. v. 6; 163-170, 2005.

SOPPIMATH, K.S.; AMINABHAVI, T.M.; KULKARNI, A.R.; RUDZINSKI, W.E. Biodegradable polymeric nanoparticles as drug delivery devices. J. Controlled Release,v.70, n.1-2, p.1-20, 2001.

SRINIVASAN, G. E ELLIOT, J.R., "Microcellular Materials via Polymerization in Supercritical Fluids", Ind. Eng. Chem. Res., 31, 1414-1417, 1992.

TAKEUCHI, T.M.; LEAL, P.F.; FAVARETO, R.; CARDOZO-FILHO, L.; CORAZZA, M.L.; ROSA, P.T.V.; MEIRELES, M.A.A., Study of the phase equilibrium formed inside the flash tank used at the separation step of a supercritical fluid extraction unit, J. of Supercritical Fluids 43, 447-459, 2008.

THIES, J. E MULLER, W., "Size Controlled Production of Biodegradable Microparticles with Supercritical Gases", European Journal of Pharmaceutics and Biopharmaceutics, v. 45, pp. 67-74, 1998.

TONGWEN, X., BINGLIN, H. Mechanism of drug release into a perfect sink from a coated planar matrix with a super saturation loading in the core. Int. J. Pharm., Amsterdam, v. 197, n. p. 23-34, 2000.

TROTTA, M. Emulsions Containing Partially Water-Miscible Solvents for the Preparation of Drug Nanosuspensions,. J. Controlled Release, v.76, n.1-2, p.119-128, 2001. 
VARELAS, C. G., DIXON, D. G., STEINER, C. A. Zeroorder release from biphasic polymer hydrogels. J. Controlled Release, Amsterdam, v. 34, p. 185-192, 1995.

Venkataram, S.; KhOHLOKWAne, M.; WAllis, S. H.; Drug Dev. Ind. Pharm., v.21, p. 847. 1995.

VERGER, M. L. L.; FLUCKIGER, L.; KIM, Y-I.; HOFFMAN, M.; MAINCENT, P.; Eur. J. Pharm. Biopharm., v. 46, p. 137. 1998.

VOLOVA, T.; SHISHATSKAYA, E.; SEVASTIANOV, V.; EFREMOV, S.; MOGILNAYA, O., Results of biomedical investigations of PHB and PHB/PHV fibers, Biochemical Engineering Journal, 16, 125-133, 2003.

VROMAN, I; TIGHZERT, L. Biodegradable Polymers. Materials, v. 2, p. 307-344, 2009.

WATNASIRICHAIKUL, S.; DAVIES, N. M.; RADES, T.; TUCKER, I. G. Preparation of Biodegradable Insulin Nanocapsules from Biocompatible Microemulsions; Pharm. Res. 17, 684. 2000

WEISS-ANGELI, V; POLETTO, F. S; ZANCAN, L. R; BALDASSO, F; POHLMANN, A. R; GUTERRES, S. S. Nanocapsules of Octyl Methoxycinnamate Containing Quercetin Delayed the Photodegradation of Both Components Under Ultraviolet A Radiation. Journal of Biomedical Nanotechnology, v.4, p. 80-89, 2008.

WHISNANT, C.S.; BURNS, P.J. "Evaluation of Steroid Microspheres for Control of Estrus in Cows and Induction of Puberty in Heifers", Theriogenology, v. 58, pp. 12291235, 2002.

YANG, X., ROBINSON, J.R., Bioadhesion in mucosal drug delivery, in: T. Okano (Ed.),

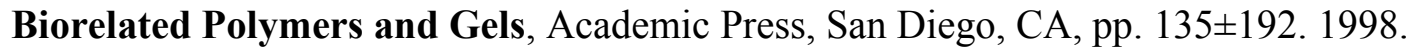

YEO, S.-D.; KIRAN, E., Formation of polymer particles with supercritical fluids: A review. Journal of Supercritical Fluids, v. 34, p. 287 - 308, 2005.

YOUNG, T.J. Rapid Expansion from Supercritical to Aqueous Solution to Produce Submicron Suspensions of Water-Insoluble Drugs. Biotechnol. Prog., v. 16, n.3, p.402407, 2000.

YU, W.; TABOSA DO EGITO, E. S.; BARRATT, G.; FESSI, H.; DEVISSAGUET, J-Ph.; Puisieux, F.; Int. J. Pharm., v. 89, p. 139. 1993.

ZIMBELMAN, R.G.;CHRISTIAN, R.E.; CASIDA, L.E. "Ovarian Response in Heifers to Progesterone Injections”, Journal Animal Science, v. 10, pp. 752-761, 1951.

ZULEGER, S., LIPPOLD, B. C. Polymer particle erosion controlling drug release. I. Factors influencing drug release and characterization of the release mechanism. Int. J. Pharm., Amsterdam, v. 217, n. 1-2, p. 139-152, 2001. 